\title{
Dinâmica da recomposição natural em bosques de mangue impactados: Ilha Barnabé (Baixada Santista), SP, Brasil
}

Tese apresentada ao Instituto Oceanográfico da Universidade de São Paulo, como parte dos requisitos para a obtenção do título de Doutor em Ciências, área de Oceanografia Biológica.

Orientadora: Prof ${ }^{\mathrm{a}}$. Dr ${ }^{\mathrm{a}}$. Yara Schaeffer-Novelli 


\title{
Universidade de São Paulo \\ Instituto Oceanográfico
}

\section{Ecologia de Manguezais: Dinâmica da recomposição natural em bosques de mangue impactados: Ilha Barnabé (Baixada Santista), SP, Brasil}

\author{
Ricardo Palamar Menghini
}

Tese apresentada ao Instituto Oceanográfico da Universidade de São Paulo, como parte dos requisitos para obtenção do título de Doutor em Ciências, área de Oceanografia Biológica.

Aprovado em

Banca Examinadora:

Profa Dra Yara Schaeffer-Novelli (Orientadora)

Conceito

Professora Doutora no Departamento de

Oceanografia Biológica do Instituto

Oceanográfico da Universidade de São Paulo.

Prof(a) Dr(a)

Conceito

$\operatorname{Prof}(a) \operatorname{Dr}(a)$

Conceito

Prof(a) $\operatorname{Dr}(a)$

Conceito

$\operatorname{Prof}(a) \operatorname{Dr}(a)$

Conceito 


\section{ÍNDICE}

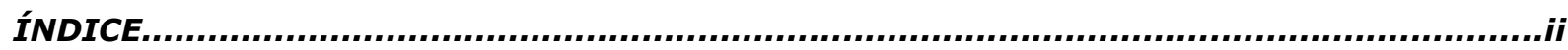

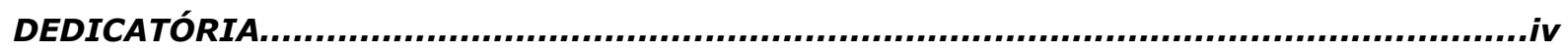

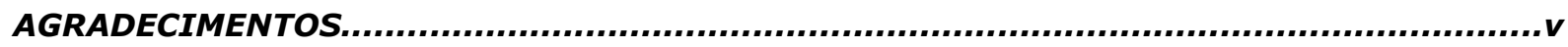

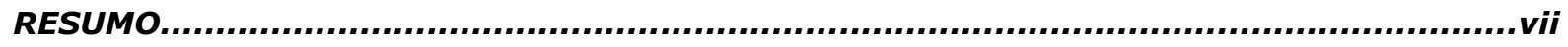

ABSTRACT

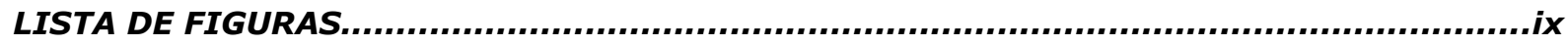

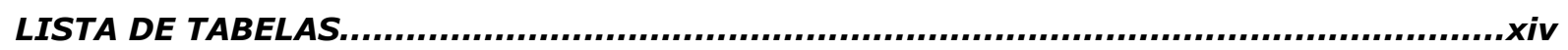

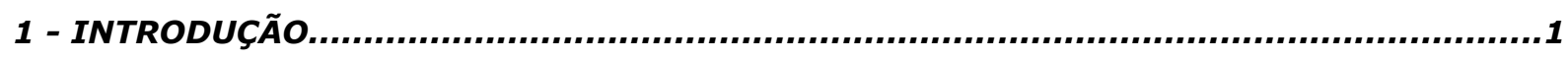

1.1 - Ecossistema manguezal: considerações gerais...........................................1

1.2 - Desenvolvimento do ecossistema manguezal..............................................2

1.3 - Ecossistema manguezal: ação de tensores.................................................

1.4 - Recomposição natural do ecossistema manguezal.....................................10

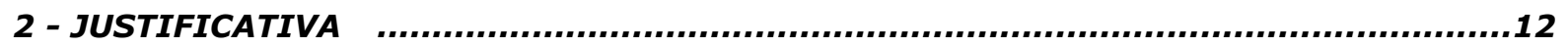

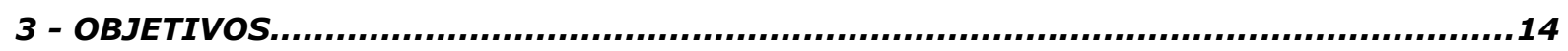

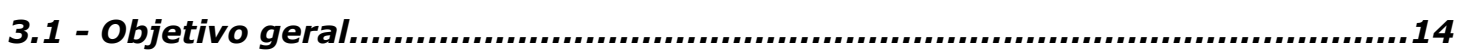

3.2 - Objetivos específicos...............................................................................14

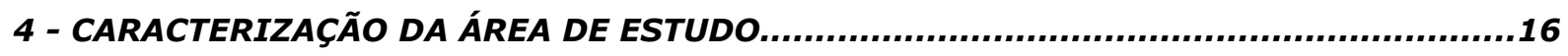

4.1 - Características geomorfológicas............................................................17

4.2 - Características climáticas.....................................................................18

4.3 - Características hidrológicas...............................................................19

4.4 - Qualidade ambiental............................................................................21

4.5 - Manguezais da Baixada Santista.........................................................27

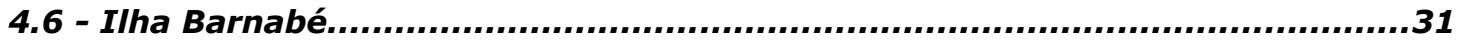

4.7 - Perspectivas para a Ilha Barnabé..........................................................35

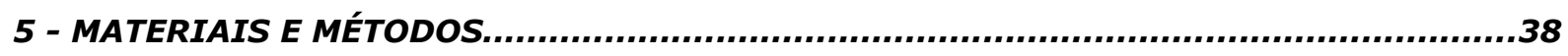

5.1 - Monitoramento da área impactada pelo evento ocorrido em 1998...............39

5.1.1 - Recomposição natural da cobertura vegetal..........................................39

5.1.2 - Produção de serapilheira...................................................................39

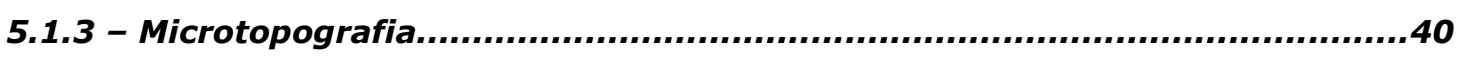

5.2 - Bosques de mangue da Ilha Barnabé....................................................43 
5.2.1 - Análise multitemporal de fotografias aéreas.......................................43

5.2.2 - Caracterização dos bosque em diferentes estágios sucessionais...............46

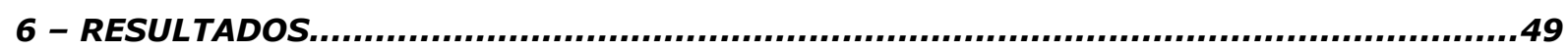

6.1 - Monitoramento da área impactada pelo evento ocorrido em 1998.............49

6.11 - Recomposição natural da cobertura vegetal..........................................49

6.1.2 - Produção de serapilheira....................................................................57

6.1.2.1 - Variação interanual........................................................................62

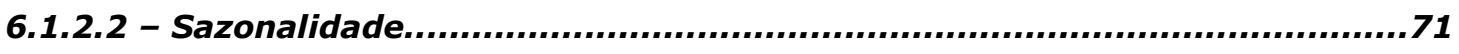

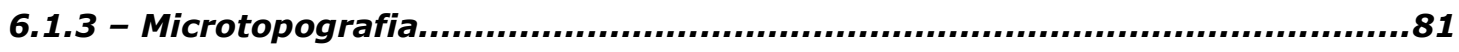

6.2 - Estudo dos manguezais da Ilha Barnabé...............................................91

6.2.1 - Análise multitemporal de fotografias aéreas....................................91

6.2.2 - Caracterização dos bosque em diferentes estágios sucessionais............107

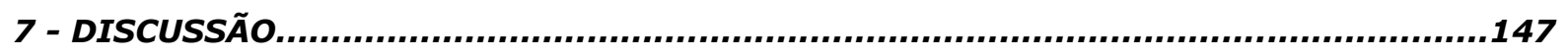

7.1 - Monitoramento da área impactada pelo evento ocorrido em 1998.............147

7.11 - Recomposição natural da cobertura vegetal......................................147

7.1.2 - Produção de serapilheira..........................................................153

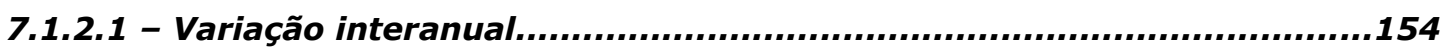

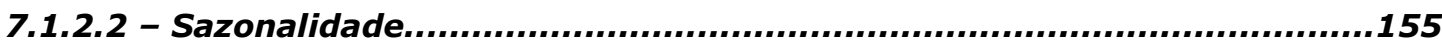

7.1.2.3 - Serapilheira: ferramenta de análise de manguezais impactados em processo de recomposição natural.................................................157

7.1.3 - Microtopografia...........................................................................163

7.2 - Estudo dos manguezais da Ilha Barnabé.............................................169

7.2.1 - Análise multitemporal de fotografias aéreas........................................169

7.2.2 - Caracterização dos bosque em diferentes estágios sucessionais............173

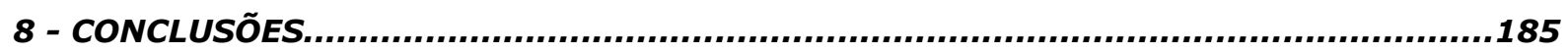

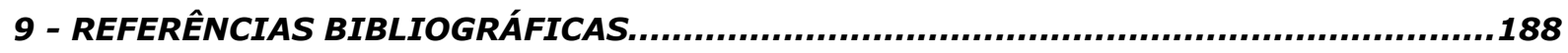




\section{DEDICATÓRIA}

Dedico este trabalho a Marília Gabriela Moriya Batista (Gabí) e a toda minha Família, em especial (meus pais, Lupércio e Mahilde, aos meus avós, Vó Maria, Vô Güido "Dom Masca", Vó Emília, Vô Dionísio e aos meus irmãos, Emerson e Daniel), amo muito todos vocês, Obrigado!!! 


\section{AGRADECIMENTOS}

Agradeço do fundo do coração à Professora Doutora Yara SchaefferNovelli, por ter aberto as portas da pós-graduação na Universidade de São Paulo/IOUSP e pela valiosa orientação. Porém, o que mais me admira é a sua ética profissional e extrema cidadania. Espero poder continuar trabalhando ao seu lado e aprendendo cada dia mais. Vida longa ao Instituto BiomaBrasil!!!!!

Ao Prof. Dr. Clemente Coelho-Júnior, ao imenso companheirismo e ensinamentos que vem me fornecendo desde a época da minha graduação. Todo meu aprendizado nos manguezais da Ilha Barnabé eu devo a você.

Aos Biólogos-Ambientalistas-Fotógrafos-Bodyboarders e companheiros de trabalhos de campo Renato Kiko Tamasato e Liminha. Sem a ajuda de vocês as coletas de campo seriam muito mais desgastantes e sem graça.

Ao Prof. Dr. Renato de Almeida, sem seus conhecimentos que me foram passados em magníficas coletas de campo em Cananéia meu aprendizado não teria sido o mesmo.

Profa. Dra. Marília Cunha-Lignon, agradeço profundamente pelos seus ensinamentos na área de geoprocessamento e por poder ter participado e estar participando tão de perto dos seus trabalhos em Cananéia.

André Scarlate Rovai, não tenho palavras para comentar sua amizade. Espero poder voltar a trabalhar ao seu lado, você é muito especial e um verdadeiro irmão para mim.

Ao mestre Gilberto Cintrón, sua sabedoria é impressionante.

À todos os professores das disciplinas cursadas na pós-graduação, em especial à Profa. Dra. Berta Lange de Morretes. 
À todos os funcionários da empresa Granel Química que sempre nos apoiaram quando precisamos.

À todos os funcionários do Instituto Oceanográfico e todas outras pessoas que de alguma forma contribuíram para a realização deste trabalho.

À CNPq pela concessão da bolsa de doutorado.

Agradeço profundamente à Marília Gabriela Moriya Batista pela paciência nos momentos difíceis e nas ajudas no campo e laboratório, the ofereço meu eterno amor.

À todos meus familiares e amigos que de certa forma me forneceram energia para a continuidade dos trabalhos.

À Vovó-do-mangue, Nanã e Iemanjá que estão sempre olhando pelos manguezais e me protegeram nas difíceis coletas de campo.

E a Deus, por me dar saúde para poder continuar estudando este maravilhoso ecossistema que se chama MANGUEZAL. 


\section{RESUMO}

A Baixada Santista encontra-se na região central do litoral de São Paulo ( $\left.23^{\circ} 55^{\prime} \mathrm{S}\right)$. É um típico ambiente costeiro tropical dominado por extensos manguezais. Entretanto, vem sofrendo intenso processo de alteração ambiental devido a atividades industriais e portuárias, além da ausência de planejamento urbano. A fim de avaliar a capacidade de recomposição natural dos manguezais na Ilha Barnabé foram realizados estudos em bosque impactado por derramamento e combustão de produto químico (DCPD) em 1998, monitorando a recomposição natural da vegetação (2002-2007); a produção de serapilheira (2002-2007) e a microtopografia (2004 e 2008). Também foram analisadas fotografias aéreas em escala multitemporal (1962, 1972, 1994 e 2003) e a caracterização estrutural de bosques em diferentes estágios sucessionais. No bosque impactado por produto químico, a recomposição natural se mostrou eficaz, porém lenta; a produção de serapilheira apresentou valores crescentes ao longo dos anos com grande contribuição de propágulos deformados ou abortados e a microtopografia mostrou intensa dinâmica sedimentar. A análise das fotografias aéreas mostrou os diversos impactos ocorridos na região com formação de clareiras na vegetação e recomposição natural parcial. A caracterização estrutural dos bosques em diferentes estágios sucessionais mostrou que a recomposição natural dos manguezais da Ilha Barnabé apresenta um mosaico de características estruturais refletindo as diferentes intensidades e tipos de tensores que atuam na região. A metodologia utilizada mostrou-se adequada para avaliação da capacidade de recomposição natural de bosques de mangue.

Palavras-chave: manguezal, Baixada Santista, impactos antrópicos, recomposição natural. 


\section{ABSTRACT}

"Dynamics of the natural recovery in mangroves stands at Barnabé Island (Baixada Santista), SP, Brazil."

The Baixada Santista and Santos Estuary are located in the central portion of the São Paulo State coastline (23055'S). It is a typical tropical coastal environment dominated by extensive mangroves areas despite the intensive harbor and heavy industrial activities, and their location within a continually evolving human landscape. The present study was developed in a mangrove area at Barnabé Island. In order to assess the natural recovery of the mangroves, a site impacted in 1998 by a DCPD (dicyclopentadiene) spill that was followed by a fire, natural recovery, litter fall and microtopography was monitored (2002-2008). Also was an analysed aerial photograph at Barnabé Island in multitemporal scale (1962, 1972, 1994 and 2003) and realized structural characterization in different successional stages mangroves stands. In a site impacted by a DCPD the recovery was successful but very low; in litter fall the values increasing in period and was observed propagule deformities and a intense sedimentary dynamics. The aerial photographs showed different impacts with gap creation and partial recovery process in some areas. Structural characterization in different successional stages mangroves stands showed zonation that reflects a gradient of stress. The methodology used appears adequate to describe and assess the capacity of natural recovery mangrove stands.

Key words: mangroves, Baixada Santista, man-induced impacts, natural recovery. 


\section{LISTA DE FIGURAS}

Figura 1 - Figura (modificada) propondo um padrão de desenvolvimento de bosques de mangue, segundo Jimenez et al. (1985), corroborado por dados de Fromard et al., (1998) e modificada por Alongi (2002) 4

Figura 2 - Modelo esquemático proposto por (Duke 2001) mostrando as seis fases (a-f) observadas na recomposição de clareiras no dossel de bosques de mangue.

Figura 3 - Modelo (modificado) proposto por Duke (2001), incorporando a dinâmica de clareiras (gaps) ao modelo de desenvolvimento dos bosques de mangue de Jimenez et al. (1985)........................................

Figura 4 - Diagrama proposto por Lugo (1978) e modificado por Lugo et al. (1981), ilustrando os diferentes pontos de atuação dos tensores no

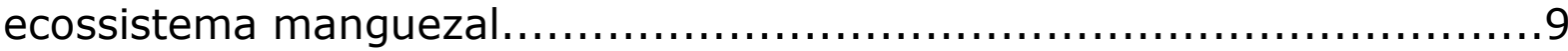

Figura 5 - Localização da área de estudo (Baixada Santista)................16

Figura 6 - Mapa de relevo da região da Baixada Santista, mostrando a escarpa da Serra do Mar e a planície litorânea. Extraído de Miranda (2005)

Figura 7 - Médias mensais de precipitação (barras) e temperatura (linha) para o município de Santos no período de 1941 a 1970 (Fonte:

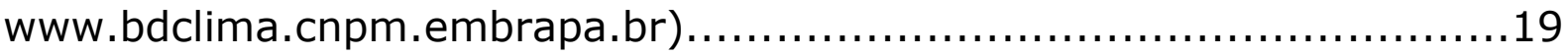

Figura 8 - Localização da Ilha Barnabé na Baixada Santista.................31

Figura 9 - Visão do evento ocorrido na área de estudo, 3 de setembro de 1998, com derramamento e combustão de produto químico (DCPD -

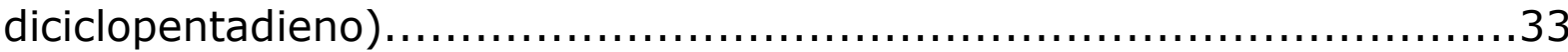

Figura 10 - Localização dos empreendimentos Embraport (azul) já em construção, Barnabé-Bagres (amarelo) e da Ilha Barnabé. Extraído de

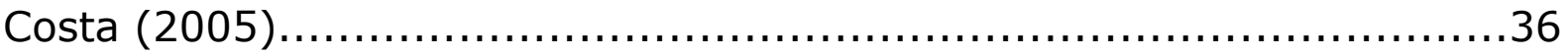

Figura 11 - Localização do bosque de mangue impactado pelo evento de 1998 (derramamento e combustão de DCPD) e dos experimentos realizados para o monitoramento da área: parcelas R2 e R3; cestas coletoras de serapilheira (círculo amarelos) e grade regular utilizada no levantamento microtopográfico.............................................42

Figura 12 - Taxa de sobrevivência por espécie e total dos indivíduos da

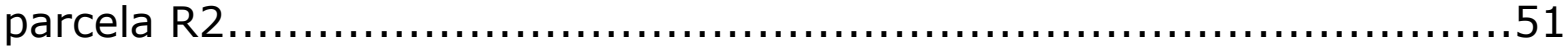

Figura 13 - Taxa de sobrevivência por espécie e total dos indivíduos da

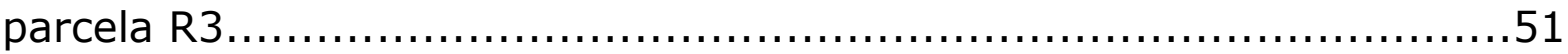

Figura 14 - Incremento na altura média dos indivíduos e dos indivíduos emergentes da parcela R2 
Figura 15 - Incremento na altura média dos indivíduos e dos indivíduos emergentes da parcela R3.....

Figura 16- Correlação entre incremento na altura média e a densidade de

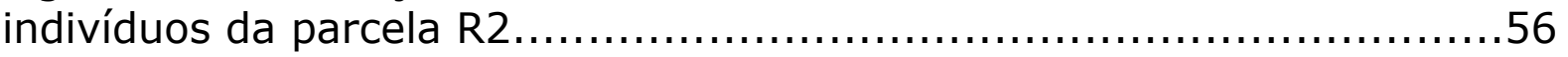

Figura 17 - Correlação entre incremento na altura média e a densidade de indivíduos da parcela R3 57

Figura 18 - Porcentagem (\%) correspondente cada fração da serapilheira do bosque de mangue da Ilha Barnabé nos diferentes anos estudados. .65

Figura 19 - Porcentagem (\%) correspondente a cada espécie na fração folhas da serapilheira do bosque de mangue da Ilha Barnabé nos diferentes anos estudados $(\mathrm{Lr}=L$. racemosa; $\mathrm{Rm}=R$. mangle; $\mathrm{As}=A$. schaueriana).... .67

Figura 20 - Porcentagem (\%) correspondente a cada espécie na fração propágulos/frutos da serapilheira do bosque de mangue da Ilha Barnabé nos diferentes anos estudados $(\mathrm{Lr}=L$. racemosa; $\mathrm{Rm}=R$. mangle; $\mathrm{As}=A$. schaueriana)....

Figura 21 - Porcentagem (\%) correspondente a cada espécie na fração flores da serapilheira do bosque de mangue da Ilha Barnabé nos diferentes anos estudados ( $\mathrm{Lr}=L$. racemosa; $\mathrm{Rm}=R$. mangle; $\mathrm{As}=A$.

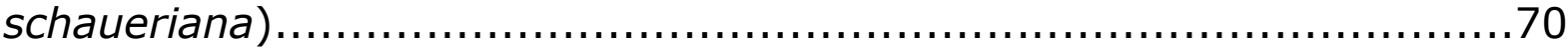

Figura 22 - Produção mensal $\left(\mathrm{g} \cdot \mathrm{m}^{-2} \cdot \mathrm{dia}^{-1}\right)$ de serapilheira total do bosque de mangue da Ilha Barnabé (as diferenças de cores representam cada ano de estudo) 72

Figura 23 - Produção mensal $\left(\mathrm{g} \cdot \mathrm{m}^{-2} \cdot \mathrm{dia}^{-1}\right.$ ) das frações da serapilheira do bosque de mangue da Ilha Barnabé... 73

Figura 24 - Produção mensal $\left(\mathrm{g} \cdot \mathrm{m}^{-2} \cdot \mathrm{dia}^{-1}\right)$ de folhas por espécies da serapilheira do bosque de mangue da Ilha Barnabé.......................74

Figura 25 - Produção mensal $\left(\mathrm{g} \cdot \mathrm{m}^{-2} \cdot \mathrm{dia}^{-1}\right)$ de propágulos/frutos por espécie da serapilheira do bosque de mangue da Ilha Barnabé.............76

Figura 26 - Produção mensal $\left(\mathrm{g} \cdot \mathrm{m}^{-2} \cdot \mathrm{dia}^{-1}\right)$ de flores por espécie da serapilheira do bosque de mangue da Ilha Barnabé.......................77

Figura 27 - Produção mensal $\left(\mathrm{g} \cdot \mathrm{m}^{-2} \cdot \mathrm{dia}^{-1}\right)$ de estípulas da serapilheira do bosque de mangue da Ilha Barnabé........................................78

Figura 28 - Produção mensal $\left(\mathrm{g} \cdot \mathrm{m}^{-2} \cdot \mathrm{dia}^{-1}\right)$ de detritos da serapilheira do bosque de mangue da Ilha Barnabé......................................79

Figura 29 - Produção mensal $\left(\mathrm{g} \cdot \mathrm{m}^{-2} \cdot \mathrm{dia}^{-1}\right)$ de madeira da serapilheira do bosque de mangue da Ilha Barnabé.......................................80

Figura 30 - Mapa de contorno topográfico com curvas de nível referente ao ano de 2004. 
Figura 31 - Mapa de contorno topográfico com curvas de nível referente ao ano de 2008.

Figura 32 - Mapa de contorno topográfico com curvas de nível e localização do bosque de mangue (polígono verde) referente ao ano de 2004. 83

Figura 33 - Mapa de contorno topográfico com curvas de nível e localização do bosque de mangue (polígono verde) e áreas com mortalidade de indivíduos (polígonos vermelhos) referente ao ano de 2008. 83

Figura 34 - Modelo de superfície 3D (wireframe) referente ao ano de 2004. 84

Figura 35 - Modelo de superfície 3D (wireframe) referente ao ano de 2008. .84

Figura 36 - Composição de mapa de contorno topográfico com curvas de nível (acima) e modelo de superfície 3D (wireframe) referente ao ano de 2004. .85

Figura 37 - Composição do mapa de contorno topográfico com curvas de nível e modelo de superfície 3D (wireframe) referente ao ano de 2008...86 Figura 38 - Sobreposição do modelo de superfície 3D (wireframe) com malha vetorial representando o sentido da drenagem terrestre no terreno, referente a 2004

Figura 39 - Sobreposição do modelo de superfície 3D (wireframe) com malha vetorial representando o sentido da drenagem terrestre no terreno, referente a 2008.

Figura 40 - Modelo gerado a partir do cálculo da dinâmica sedimentar ocorrida entre os anos de 2004 e 2008. Os valores (em centímetros) positivos (gradiente cinza) são referentes ao aumento na cota do terreno gerado por processo de sedimentação/colonização de vegetação e os valores (em centímetros) negativos (gradiente vermelho) referentes ao rebaixamento na cota do terreno por erosão/morte de

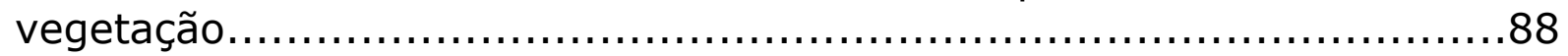

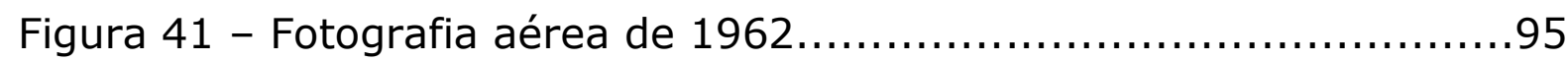

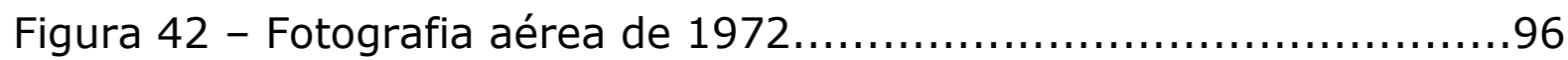

Figura 43 - Composição colorida das fotografias aéreas de 1962 e

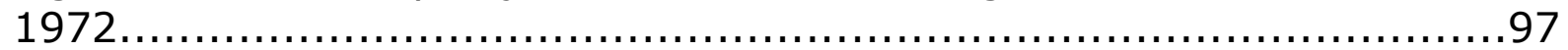

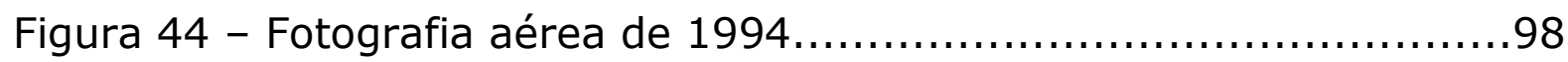

Figura 45 - Composição colorida das fotografias aéreas de 1972 e

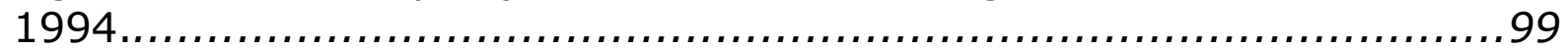

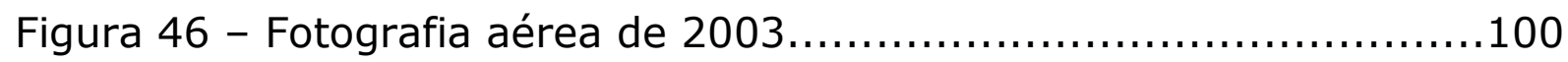

Figura 47 - Composição colorida das fotografias aéreas de 1994 e

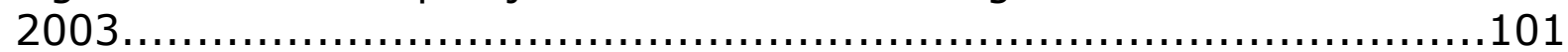


Figura 48 - Classificação das feições observadas na fotografia aérea de

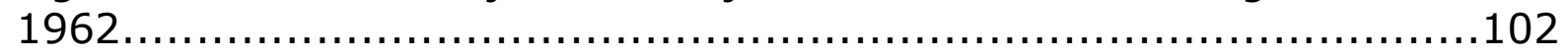

Figura 49 - Classificação das feições observadas na fotografia aérea de

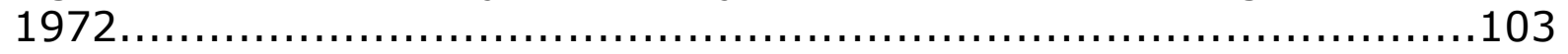

Figura 50 - Classificação das feições observadas na fotografia aérea de

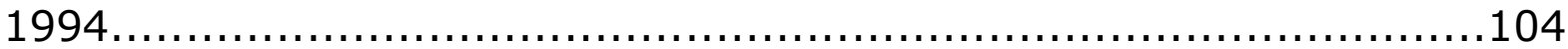

Figura 51 - Classificação das feições observadas na fotografia aérea de 2003. 105

Figura 52 - Localização das parcelas onde foram realizadas a caracterização estrutural dos bosques de mangue em diferentes estágios sucessionais.... 106

Figura 53 - Relação entre a idade do bosque e a altura média dos indivíduos na parcela R2 e projeção da idade que os indivíduos terão quando alcançarem o dossel (caso ocorra)................................152

Figura 54 - Relação entre a idade do bosque e a altura média dos indivíduos na parcela R3 e projeção da idade que os indivíduos terão quando alcançarem o dossel (caso ocorra) .152

Figura 55 - Relação da temperatura média mensal com os valores de produção de serapilheira do bosque de mangue da Ilha Barnabé................................................................... 156

Figura 56 - Propágulo de Rhizophora mangle abortado no início do seu desenvolvimento, coletado em cesta de serapilheira no bosque de mangue da Ilha Barnabé.

161

Figura 57 - Propágulos de Rhizophora mangle coletados em cesta de serapilheira no bosque de mangue da Ilha Barnabé apresentando deformações diversas (quantidade total coletada em uma cesta coletora) 161

Figura 58 - Detalhe do sistema radicial exposto de alguns indivíduos presentes na franja do bosque............................................. 165

Figura 59 - Mortalidade de indivíduos localizados na franja do

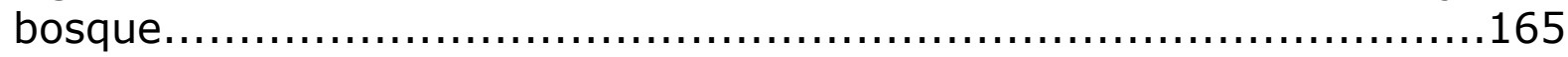

Figura 60 - Relação entre o dap médio e a idade dos bosques de mangue estudados na Ilha Barnabé.... 176

Figura 61 - Relação entre a densidade de indivíduos por hectare a idade dos bosques de mangue estudados na Ilha Barnabé. 177

Figura 62 - Indivíduos de L. racemosa colonizando uma clareira de grandes proporções localizada na Ilha Barnabé (Fotografia tirada em 18.07.2008). 180

Figura 63 - Detalhe dos indivíduos de L. racemosa colonizando clareira na Ilha Barnabé (Fotografia tirada em 18.07.2008). 181 
Figura 64 - Modelo proposto para o padrão de sucessão secundária encontrado nos manguezais estudados da Ilha Barnabé (para maiores

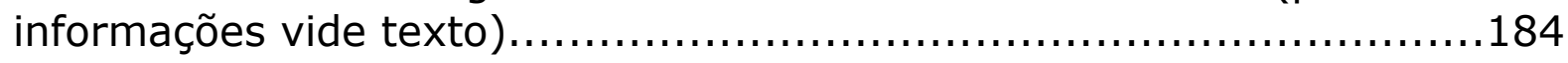




\section{LISTA DE TABELAS}

Tabela I - Principais fontes de poluição industrial na Baixada Santista

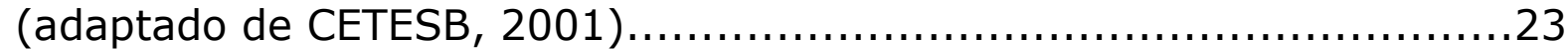

Tabela II - Principais fontes de poluição nos terminais portuários da Baixada Santista (adaptado de CETESB, 2001) ..........................24

Tabela III - Principais fontes de poluição relacionadas às áreas contaminadas da Baixada Santista (adaptado de CETESB, 2001)..........25

Tabela IV - Dados populacionais dos municípios da Baixada Santista para

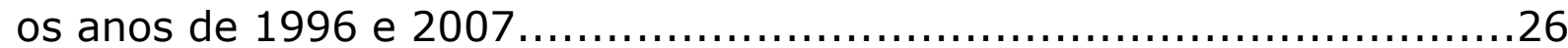

Tabela V - Movimentação anual de cargas do Porto de Santos (em

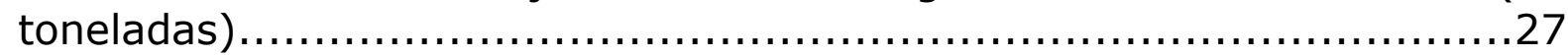

Tabela VI - Características das fotografias aéreas utilizadas.

Tabela VII - Número de indivíduos vivos e taxa de sobrevivência (\%) por espécie e total dos indivíduos da parcela R2 49

Tabela VIII - Número de indivíduos vivos e taxa de sobrevivência (\%) por espécie e total dos indivíduos da parcela R3 ................................50

Tabela IX - Altura média dos indivíduos e dos indivíduos emergentes, taxa de crescimento e densidade de indivíduos da parcelas $R 2 \ldots \ldots \ldots \ldots \ldots \ldots . \ldots 53$

Tabela X - Altura média dos indivíduos e dos indivíduos emergentes, taxa de crescimento e densidade de indivíduos da parcelas R3 ...................54

Tabelas XI - Estimativas das taxas mensais (fração total) de serapilheira do manguezal da Ilha Barnabé (médias e desvios

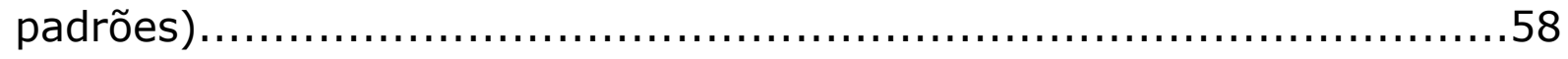

Tabelas XII - Estimativas das taxas mensais (fração folhas) de serapilheira do manguezal da Ilha Barnabé (médias e desvios

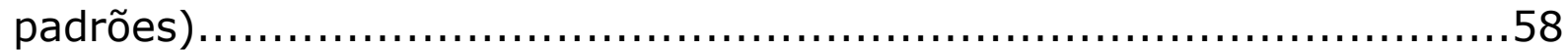

Tabelas XIII - Estimativas das taxas mensais (fração flores) de serapilheira do manguezal da Ilha Barnabé (médias e desvios

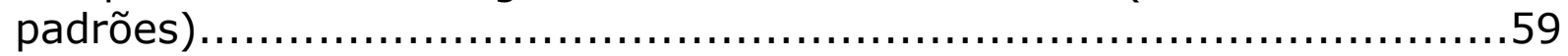

Tabelas XIV - Estimativas das taxas mensais (fração propágulos/frutos) de serapilheira do manguezal da Ilha Barnabé (médias e desvios padrões)

Tabelas XV - Estimativas das taxas mensais (fração madeiras) de serapilheira do manguezal da Ilha Barnabé (médias e desvios

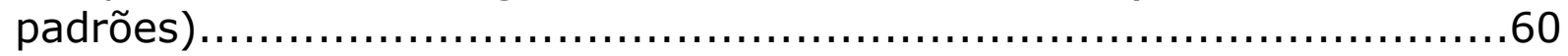

Tabelas XVI - Estimativas das taxas mensais (fração estípulas) de serapilheira do manguezal da Ilha Barnabé (médias e desvios padrões) .60 
Tabela XVII - Estimativas das taxas mensais (fração detritos) de serapilheira do manguezal da Ilha Barnabé (médias e desvios padrões) .61

Tabela XVIII - Taxas anuais $\left(\mathrm{g} \cdot \mathrm{m}^{-2} \cdot \mathrm{dia}^{-1}\right.$ ) de cada fração e taxa anual total (ton.ha ${ }^{-1} \cdot$ ano $^{-1}$ ) da serapilheira do bosque de mangue da Ilha Barnabé..... .62

Tabela XIX - Porcentagem (\%) das frações ao longo dos cinco anos de monitoramento da serapilheira do bosque de mangue da Ilha Barnabé .69

Tabela XX - Volume estimado de sedimentos na área de estudo em 2004 e 2008. 90

Tabela XXI - Dados do registro das fotografias aéreas.....................91

Tabela XXII - Área estimada da cobertura vegetal do ecossistema manguezal ao longo dos anos de estudo e de seus respectivos impactos antrópicos.

Tabela XXIII - Coordenadas geográficas das parcelas e idade estimada dos respectivos bosques de mangue.... 107

Tabela XXIV - Número de indivíduos e de troncos amostrados, altura média e dap médio dos bosques de mangue da Ilha Barnabé..............108 Tabela XXV - Densidade relativa (\%) de troncos vivos e mortos, por espécie e por classe de dap dos bosques de mangue da Ilha Barnabé............................................................... 109

Tabela XXVI - Área basal ( $\mathrm{m}^{2} / \mathrm{ha}$ ) viva e morta, por classe de dap dos bosques de mangue da Ilha Barnabé .....................................110

Tabela XXVII - Dominância em área basal (\%) viva e morta por espécieetotal dos bosques de mangue da Ilha Barnabé.....................111 


\section{1 - INTRODUÇÃO}

\section{1 - ECOSSISTEMA MANGUEZAL: CONSIDERAÇÕES GERAIS}

As regiões costeiras do planeta abrigam a maioria dos ecossistemas considerados altamente produtivos. Ecossistemas costeiros considerados "chaves", tais como recifes de corais e manguezais são sistemas singulares e extremamente produtivos de recursos naturais renováveis (fonte protéica, área para turismo, produtos diversos oriundos dos manguezais e outros bens e serviços). Estas regiões necessitam serem conservadas e o seu uso sustentável é a única alternativa para que possam continuar a prestar valiosos serviços à humanidade (Clark, 1996).

Os manguezais são ecossistemas costeiros tropicais cuja cobertura vegetal coloniza depósitos sedimentares formados por vasas lamosas, argilosas ou arenosas, ocupando a faixa do entremarés até o limite superior das preamares equinociais. A esse ambiente halófilo associa-se cobertura vegetal típica, caracterizada por espécies arbóreas típicas que Ihe conferem fisionomia peculiar. Essas formações encontram-se associadas a costas de baixa energia ou a ambientes estuarinos, lagunares, baías e enseadas, sendo consideradas zonas úmidas costeiras tropicais singulares, onde as marés permitem constante intercâmbio de água, nutrientes, sedimentos e organismos com as regiões costeiras adjacentes. Representam grande valor ecológico para as áreas que extrapolam a do próprio ecossistema, provendo diversos bens e serviços que atendem direta $\mathrm{e}$ indiretamente seres humanos e organismos costeiros (Lugo \& Snedaker, 1974; Schaeffer-Novelli, 1989; Twilley et al., 1996; Schaeffer-Novelli, 2002).

O conceito da "assinatura energética", introduzido por Odum (1967), descreve os compartimentos de energia que operam sobre os ecossistemas, influenciando suas funções, sendo o ecossistema manguezal altamente subsidiado por energias externas, podendo ser destacadas a disponibilidade de correntes de água fluvial ou marinha e os aportes de 
nutrientes trazidos pelos rios, marés, drenagem superficial e características do substrato. O aproveitamento máximo dessas fontes energéticas pelo ecossistema permite alto grau de desenvolvimento estrutural e elevada produtividade, porém tensores naturais ou induzidos pelo homem podem drenar energia, removendo estrutura e/ou limitando o desenvolvimento (Cintrón \& Schaeffer-Novelli, 1985; Schaeffer-Novelli et al., 1990).

\section{2 - DESENVOLVIMENTO DO ECOSSISTEMA MANGUEZAL}

O desenvolvimento dos bosques de mangue foi descrito inicialmente por Jimenez et al., (1985). Segundo estes autores o processo de desenvolvimento dos bosques de mangue possui quatro fases:

- Colonização: Quando os propágulos se enraízam numa área não ocupada previamente ou numa área onde ocorreu mortalidade massiva de indivíduos. A taxa de colonização depende da proximidade de uma fonte de propágulos, da energia do local (que pode inviabilizar o enraizamento) e a taxa de mortalidade das plântulas. O recrutamento e o subseqüente crescimento ocorrem rapidamente. Nesta fase o desbaste natural é mínimo (caso ocorra) e o crescimento em altura dos indivíduos é vigoroso e contínuo. A densidade aumenta nesta fase e só termina quando o dossel é fechado;

- Desenvolvimento inicial: Este estágio segue a colonização e é caracterizado por uma forte competição por espaço. Ocorre o fechamento do dossel devido ao rápido e contínuo crescimento das plântulas. O desbaste natural é muito intenso, acarretando um declínio na densidade de indivíduos. A taxa de mortalidade depende da velocidade em que o bosque se desenvolve. Novas colonizações podem formar um "banco de mudas" abaixo do 
dossel. Ao final desta fase o crescimento em altura é lento e o dossel alcança a altura máxima.

- Maturidade: Esta fase se inicia quando a máxima altura do dossel é atingida e a taxa de crescimento diminui. O crescimento ocorre pelo incremento de biomassa dos indivíduos, com um pequeno desbaste natural e diminuição da densidade. Nesta fase o bosque alcança o máximo desenvolvimento permitido pela "assinatura energética" local.

- Senescência: É a fase quando indivíduos começam a morrer ainda em pé devido a idade avançada. $O$ bosque é dominado por poucos, porém bem desenvolvidos indivíduos. A densidade do bosque é pequena e geralmente é grande a quantidade de necromassa no substrato (troncos e galhos caídos).

O processo de transição entre estas fases segundo o modelo proposto pelos pesquisadores era considerado como sendo progressivo e ininterrupto, portanto a idade da árvore refletiria a idade do bosque como um todo.

Estudando os manguezais da Guiana Francesa, Fromard et al., (1998) utilizando a este modelo e identificaram que todo o processo de desenvolvimento dos bosques de mangue na Guiana Francesa dura cerca de 80 anos até alcançar o estágio de senescência (Figura 1). 


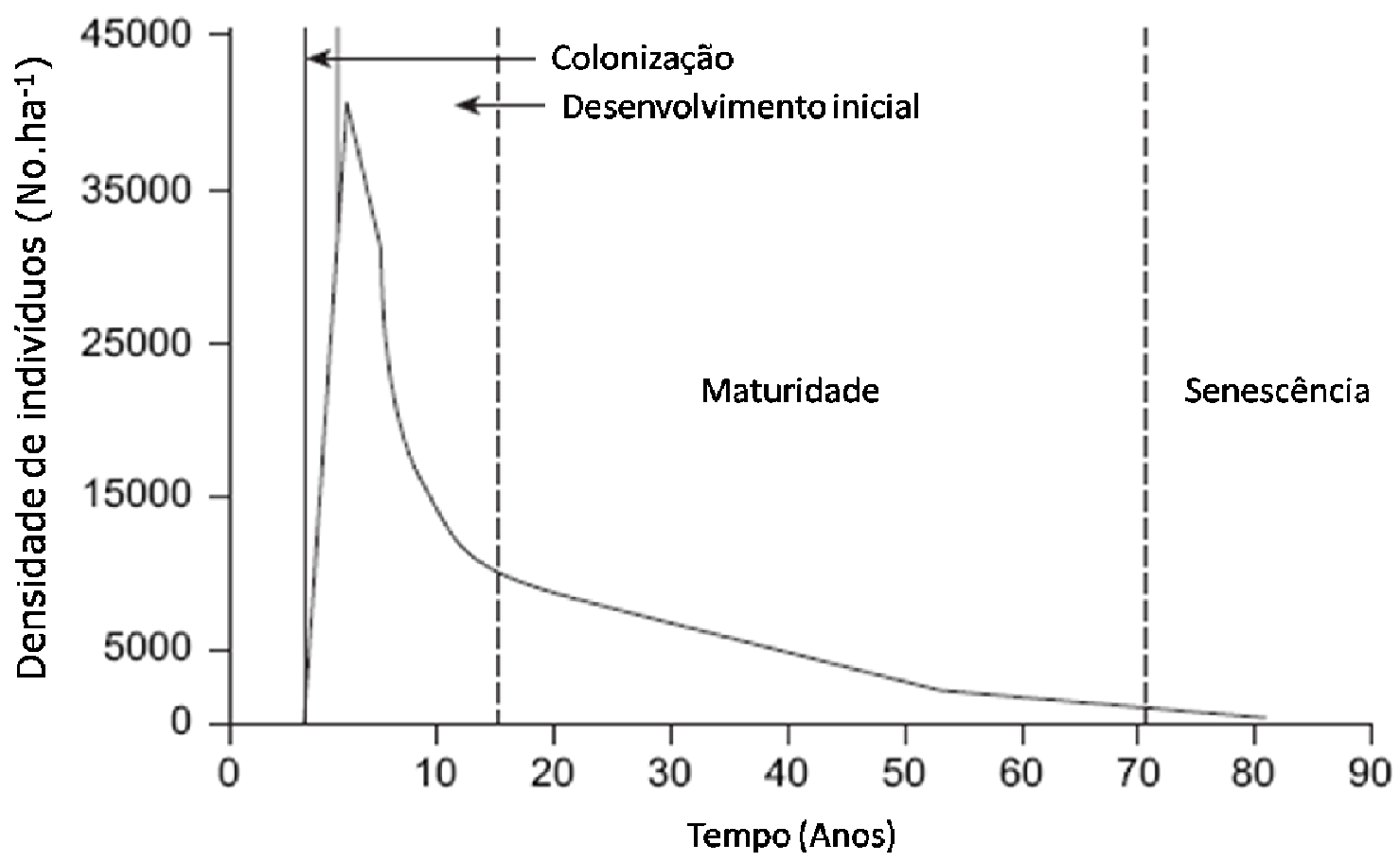

Figura 1 - Figura (modificada) propondo um padrão de desenvolvimento de bosques de mangue, segundo Jimenez et al. (1985), corroborado por dados de Fromard et al., (1998) e modificada por Alongi (2002).

Duke (2001), afirmou que a utilização apenas do modelo proposto por Jimenez et al., (1985) seria insuficiente para descrever todo o processo desenvolvimento dos manguezais, argumentando que:

- A idade das árvores nem sempre indica a idade do bosque.

- As árvores presentes em qualquer uma das fases do desenvolvimento não são necessariamente as mesmas que colonizaram inicialmente a área.

- A morte de árvores não é dependente apenas da sua idade.

O autor também comenta que embora alguns trabalhos tenham observado bosques de mangue em estágio avançado de senescência (Fromard, et al., 1998; Ewel et al., 1998), todo o processo de 
"colonização-desenvolvimento inicial-maturidade-senesncência-colapso" com a posterior recolonização do ambiente é muito raro de acorrer.

O maior argumento contra a idéia do modelo de desenvolvimento contínuo proposto por Jimenez et al. (1985), é a presença freqüente de pequenas clareiras (gaps) no dossel dos bosques de mangue (Duke, 2001).

Estas clareiras podem ser formadas por agentes naturais, tais como raios ou ventos fortes (Smith, 1992; Smith et al., 1994; Clarke \& Kerrigan, 2000; Sherman et al., 2000); temperaturas baixas (Lugo \& Patterson-Zucca, 1977); pela ação de insetos (Feller \& Mathis, 1997; Feller \& McKee, 1999) ou por tensores induzidos pelo homem (Menghini, 2004).

Duke (op cit.) propôs que a recomposição das clareiras formadas no dossel dos bosques de mangue é caracterizada por seis fases que vão desde a abertura da clareira no dossel, passando pelas fases de recomposição da vegetação, até alcançar novamente um estado "inalterado" (Figura 2). 


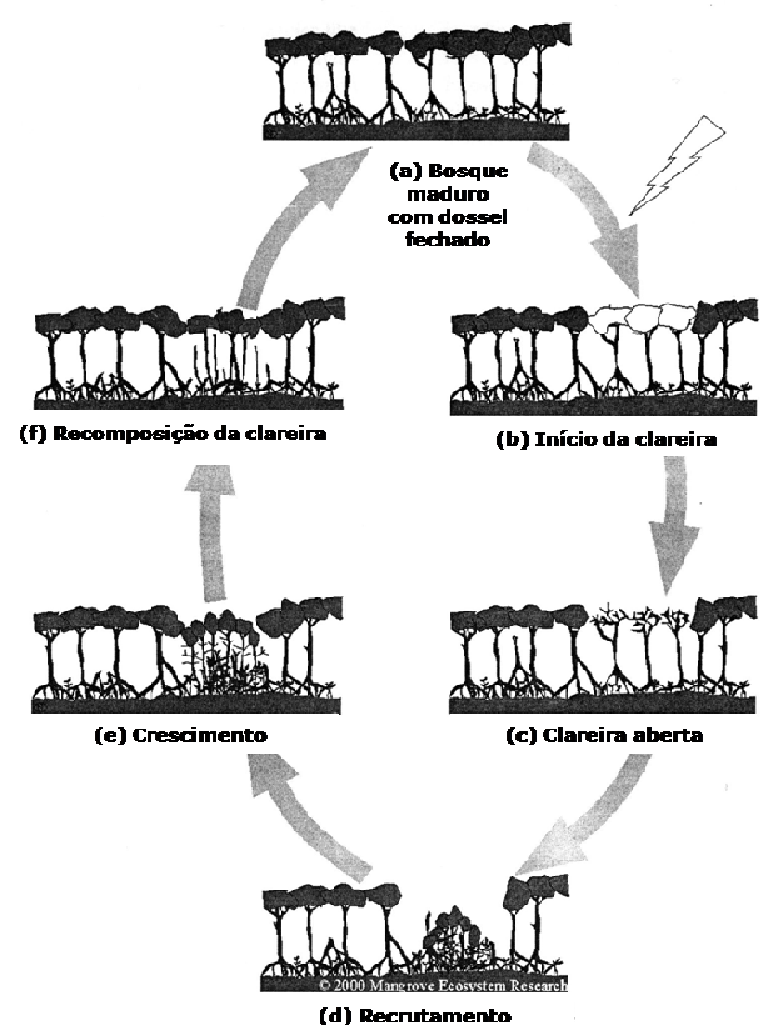

Figura 2 - Modelo esquemático proposto por (Duke 2001) mostrando as seis fases (a-f) observadas na recomposição de clareiras no dossel de bosques de mangue.

Duke (2001) sugere, portanto, um novo modelo para explicar todo o processo de desenvolvimento dos bosques de mangue, baseando-se no proposto por Jimenez et al. (1985), porém incorporando todo o processo de dinâmica de clareiras (Figura 3).

Segundo o autor, a formação de clareiras pode afetar apenas uma pequena porção do bosque por vez, mas ao longo do tempo é esperado que o efeito no bosque como um todo seja uniforme. Assumindo que ocorra uma reposição aleatoriamente e sistematicamente das árvores do bosque, o resultado esperado é que o desenvolvimento do bosque como um todo ocorra lentamente. 


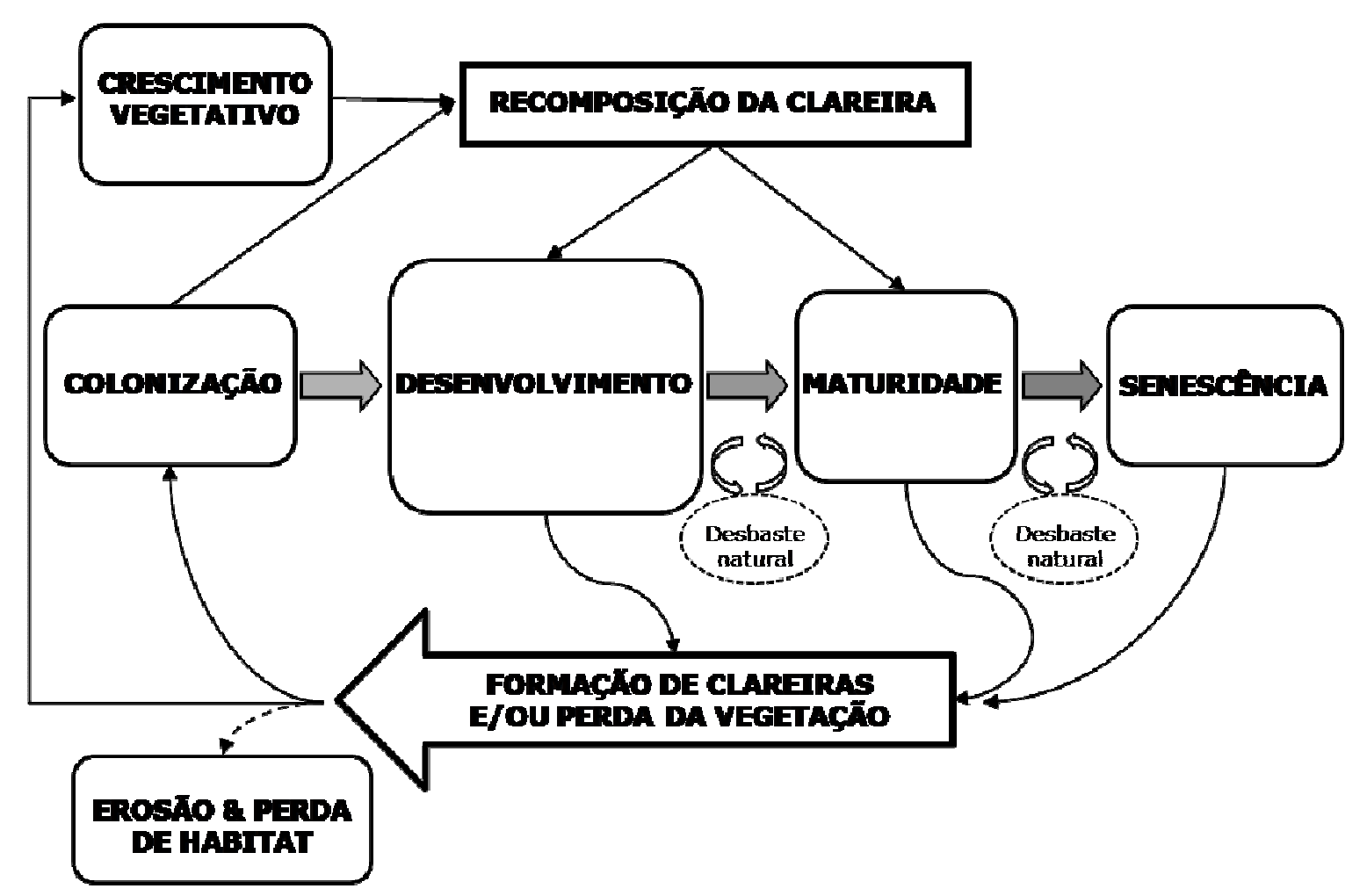

Figura 3 - Modelo (modificado) proposto por Duke (2001), incorporando a dinâmica de clareiras (gaps) ao modelo de desenvolvimento dos bosques de mangue de Jimenez et al. (1985).

\section{3 - ECOSSISTEMA MANGUEZAL: AÇÃO DE TENSORES}

Um tensor pode ser considerado como qualquer condição que cause uma mobilização de recursos ao sistema, aumentando desta forma o seu gasto energético e estresse é a resposta do sistema à ação do tensor (Lugo, 1978).

Manguezais podem ser considerados ecossistemas naturalmente estressados, devido às condições ambientais em que se desenvolvem, tais como: a salinidade do sedimento que dificulta obtenção de água doce; os fluxos das marés que removem energia potencial armazenada na forma de detritos orgânicos; os processos geomorfológicos costeiros que podem causar erosão e/ou deposição de sedimentos; e as tempestades, furacões ou tsunamis que podem causar perdas de componentes estruturais do sistema (Lugo, 1980). 
Segundo Lugo (1978), o custo energético de um tensor a um sistema depende da intensidade do tensor, ou seja, quanto de energia é drenado por unidade de área e de tempo; efeito multiplicativo ou aditivo do dreno de energia em todas as funções e na homeostase do sistema; freqüência de ocorrência do tensor; compartimentos do ecossistema atingido; condição do sistema na hora do impacto; intensidade de outros tensores na hora do impacto; efeito residual de outros tensores sobre o sistema e freqüência de retorno deste tensor em particular.

O custo energético ainda pode variar de intensidade, de acordo com os pontos de ataque dos tensores no ecossistema, sendo que Lugo (op. cit.) classificou em cinco tipos os tensores que podem atuar nos ecossistemas (Figura 4):

(1) Alterando a natureza da principal fonte de energia;

(2) Desviando uma porção da principal fonte de energia, porém após a mesma haver sido incorporada ao sistema;

(3) Removendo energia potencial antes desta ser estocada, mas depois de haver sido transformada pelo processo fotossintético;

(4) Removendo estoques de fatores limitantes à fotossíntese ou removendo porções da estrutura do sistema;

(5) Aumentando a taxa de respiração. 


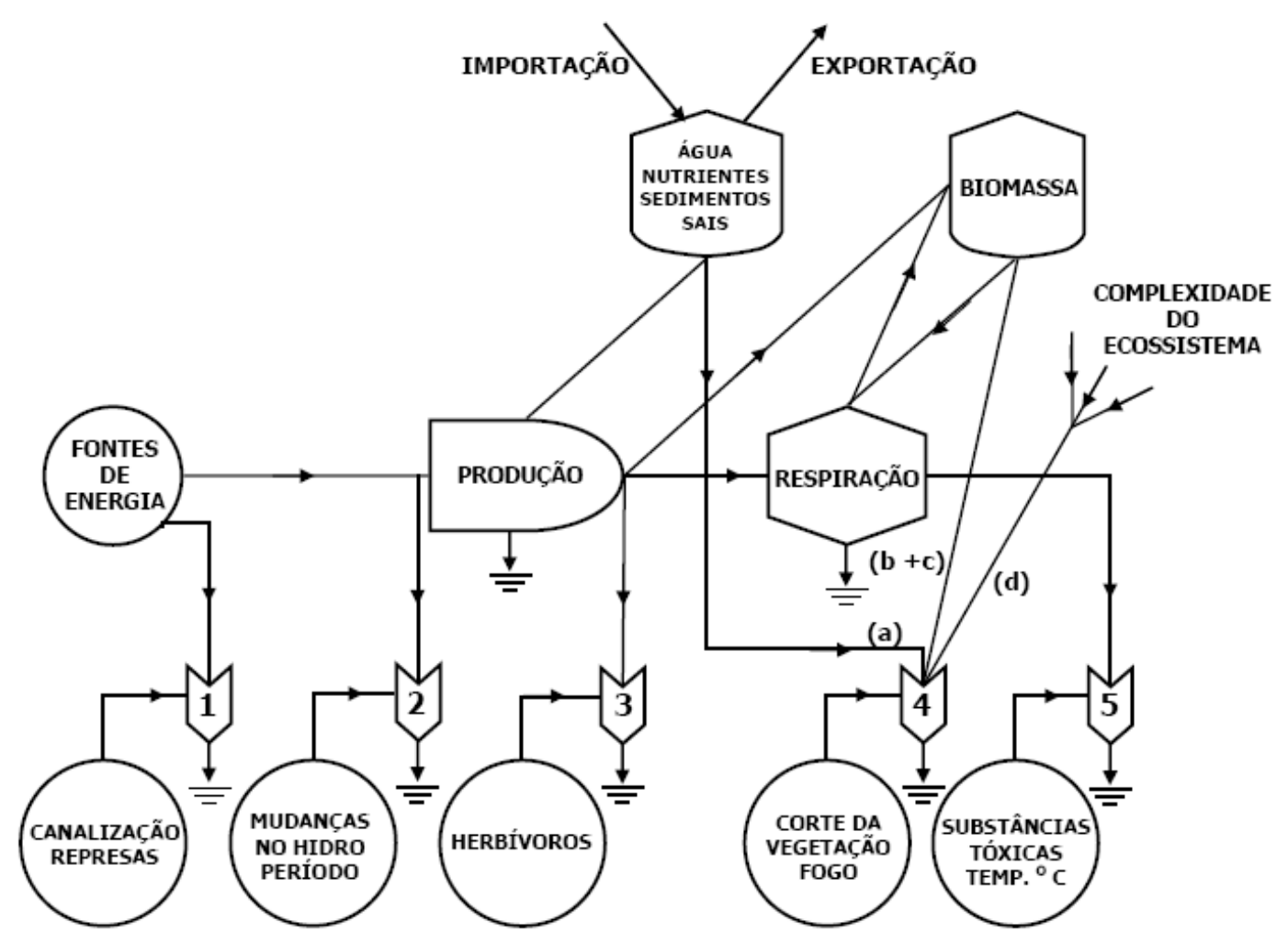

Figura 4 - Diagrama proposto por Lugo (1978) e modificado por Lugo et al. (1981), ilustrando os diferentes pontos de atuação dos tensores no ecossistema manguezal.

O mesmo autor cita algumas propriedades que podem ser observadas em ecossistemas estressados:

- Sucessão da vegetação interrompida ou retornando periodicamente a estágios iniciais.

- Poucos estágios entre o pioneiro e o clímax.

- Vegetação demonstrando estado de estresse, como deformações em resposta aos tensores.

- Variações na intensidade do tensor podem mudar a composição das espécies (geralmente quando se aumenta a intensidade ocorre decréscimo na diversidade). 
- Velocidade da sucessão ocorrendo em função do ambiente físico e dependendo do compartimento do sistema onde a desordem energética atua.

- Espécies apresentando zonação que reflete gradiente de estresse (não podendo ser confundidas com estágios sucessionais).

\section{4 - RECOMPOSIÇÃO NATURAL DO ECOSSISTEMA MANGUEZAL}

Entende-se por recomposição a restauração natural do ambiente, sem interferência do homem e regeneração a renovação ou restauração de estruturas ou tecidos, principalmente após perda ou mutilação (ACIESP, 1997). Portanto como o presente estudo focalizou o ecossistema manguezal como um todo, utilizaremos o termo recomposição natural, para se referir ao processo natural do ecossistema se restabelecer.

Segundo Odum (1981), os ecossistemas naturais possuem estratégias de crescimento e adaptações que os fazem aptos a se recomporem após perturbações (atuações de tensores) naturais periódicas (resiliência). Se o tensor não deixar efeito residual, o ecossistema pode voltar a um estado muito similar às condições anteriores ao distúrbio. Porém, sofrendo a influência de tensores residuais e/ou eventos agudos, o sistema poderá reestruturar-se, alcançando, porém níveis mais simples de organização.

Ewel (1971), descrevendo o padrão de resposta de um ecossistema a um tensor intermitente, demonstrou que se a condição de estresse é repetida antes da completa recomposição, o sistema gradualmente perde sua capacidade de recomposição e pode se manter num estado de menor desenvolvimento.

Há um limiar em que o ecossistema pode adaptar-se naturalmente sobre a ação de tensores naturais, entretanto, tensores induzidos pelo 
homem tendem a ser não seletivos, aleatórios e de grande intensidade, com periodicidade de ocorrência diferente daquela dos eventos naturais. A capacidade de um sistema se recompor depende da disponibilidade de energia suficiente para reorganizar a estrutura e ainda, das condições ambientais em que o sistema encontra-se inserido (Lugo \& Snedaker, 1974; Lugo, 1978). 


\section{2 - JUSTIFICATIVA}

Estudo recente avaliando os serviços prestados globalmente pelos ecossistemas estimou que cerca de $70 \%$ destes serviços são gerados pelos ecossistemas localizados nas regiões costeiras. Porém, estas mesmas regiões abrigam $41 \%$ da população global e 21 das 33 megacidades globais, acarretando desta forma diversos conflitos (Martinez et al., 2007).

As regiões costeiras desempenham, portanto um papel fundamental na sustentabilidade humana no planeta, porém a obsessão dos seres humanos com o rápido crescimento econômico está causando uma ruptura nos serviços prestados pelos ecossistemas costeiros, que em parte são os grandes responsáveis pelo crescimento econômico da humanidade (Costanza \& Farley, 2007).

Dentre todos os ecossistemas costeiros, os manguezais e os recifes de corais merecem destaque quanto a geração de bens e serviços. Manguezais são ecossistemas que apresentam condições propícias para alimentação, proteção e reprodução de muitas espécies animais, sendo considerado importante transformador de nutrientes em matéria orgânica, assim como gerador de bens e de serviços. Entretanto, pelo fato de não serem adequadamente quantificados, acabam tendo pouco peso nas decisões políticas. Esta negligência tem comprometido seriamente a sustentabilidade humana na biosfera (Schaeffer-Novelli, 1991; Costanza et al., 1997).

Recente trabalho realizado por renomados pesquisadores de todo 0 mundo, aponta como preocupante as atuais taxas de perda de áreas de manguezais ao redor do planeta, principalmente devido a aqüicultura, urbanização, aterros e poluição (Duke et al., 2007). A estimativa de Valiela et al. (2001) é que $35 \%$ dos manguezais do planeta foram destruídos por atividades humanas nas duas últimas décadas. 
Lugo (1999), revisando os estudos realizados globalmente no ecossistema manguezal, identificou áreas que merecem uma maior atenção por parte dos pesquisadores, destacando as respostas do ecossistema a ação de tensores e estudos sobre a capacidade de recomposição natural do ecossistema. Os resultados gerados por estas pesquisas são imprescindíveis à formulação e implantação de projetos de recuperação de manguezais.

Porém, Lugo (1978), adverte que apenas uma complexa análise a longo prazo consegue detectar eventos cíclicos que observados prematuramente podem parecer aleatórios e imprevisíveis. Portanto, o monitoramento (2002-2008) realizado no presente trabalho visa esta compreensão.

O presente trabalho tem como relevância, o estudo da capacidade de recomposição natural de manguezais localizados em áreas com recorrentes impactos antrópicos, incluindo impacto por derramamento de produto químico seguido de incêndio. Tais informações geradas serão imprescindíveis ao entendimento e gerenciamento da região costeira da Baixada Santista, onde está localizado o maior Porto da América Latina (Porto de Santos), um grande adensamento populacional (Região Metropolitana da Baixada Santista), um enorme complexo industrial (Cubatão), juntamente com ecossistemas costeiros de extrema importância ecológica, econômica e social. 


\section{3 - OBJETIVOS}

\section{1 - OBJETIVO GERAL}

Avaliar a dinâmica da recomposição natural em bosques de mangue localizados na Ilha Barnabé, dando seqüência ao trabalho de Menghini (2004), contemplando desta forma, estudo em média escala temporal, subsidiando a compreensão da ação de tensores nos manguezais da Baixada Santista e sua capacidade de recomposição natural.

\section{2 - OBJETIVOS ESPECÍFICOS}

- Monitoramento do processo de recomposição natural em bosque de mangue impactado por produto químico e incêndio, durante estágio inicial de recomposição natural (2002-2007).

- Monitoramento da produção de serapilheira em bosque de mangue impactado por produto químico e incêndio, durante estágio inicial de recomposição natural (2002-2007).

- Avaliação da dinâmica sedimentar em bosque de mangue impactado por produto químico e incêndio, através de estudos microtopográficos realizados nos anos de 2004 e 2008.

- Realização de estudo em escala multi-temporal nos manguezais da Ilha Barnabé utilizando fotografias aéreas verticais de diferentes datas (1962, 1972, 1994 e 2003) a fim de avaliar os diversos impactos ocorridos nos manguezais ao longo de cinco décadas, assim como sua capacidade de recomposição natural.

- Realizar caracterização estrutural nos bosques de mangue em diferentes estágios sucessionais observados no estudo em escala multi-temporal com fotografias aéreas. 
- Estruturar os diversos estudos realizados em escalas temporais e espaciais distintos, utilizando uma visão ecossistêmica para avaliar a dinâmica da recomposição natural de bosques de mangue localizados em área com decorrentes impactos antrópicos. 


\section{4 - CARACTERIZAÇÃO DA ÁREA DE ESTUDO}

A Baixada Santista encontra-se localizada no litoral do Estado de São Paulo (24050'S, 46045'W e 23045'S, 45050'W), ocupando posição central na costa, ao entremear o Litoral Norte, caracterizado por costas altas, extremamente recortadas, com inúmeras enseadas, ilhas e cabos, e o Litoral Sul, dominantemente retilíneo com costas baixas, extensas e monótonas (Penteado, 1965). A região metropolitana da Baixada Santista engloba os municípios de Praia Grande, São Vicente, Cubatão, Santos, Guarujá e Bertioga (Figura 5).

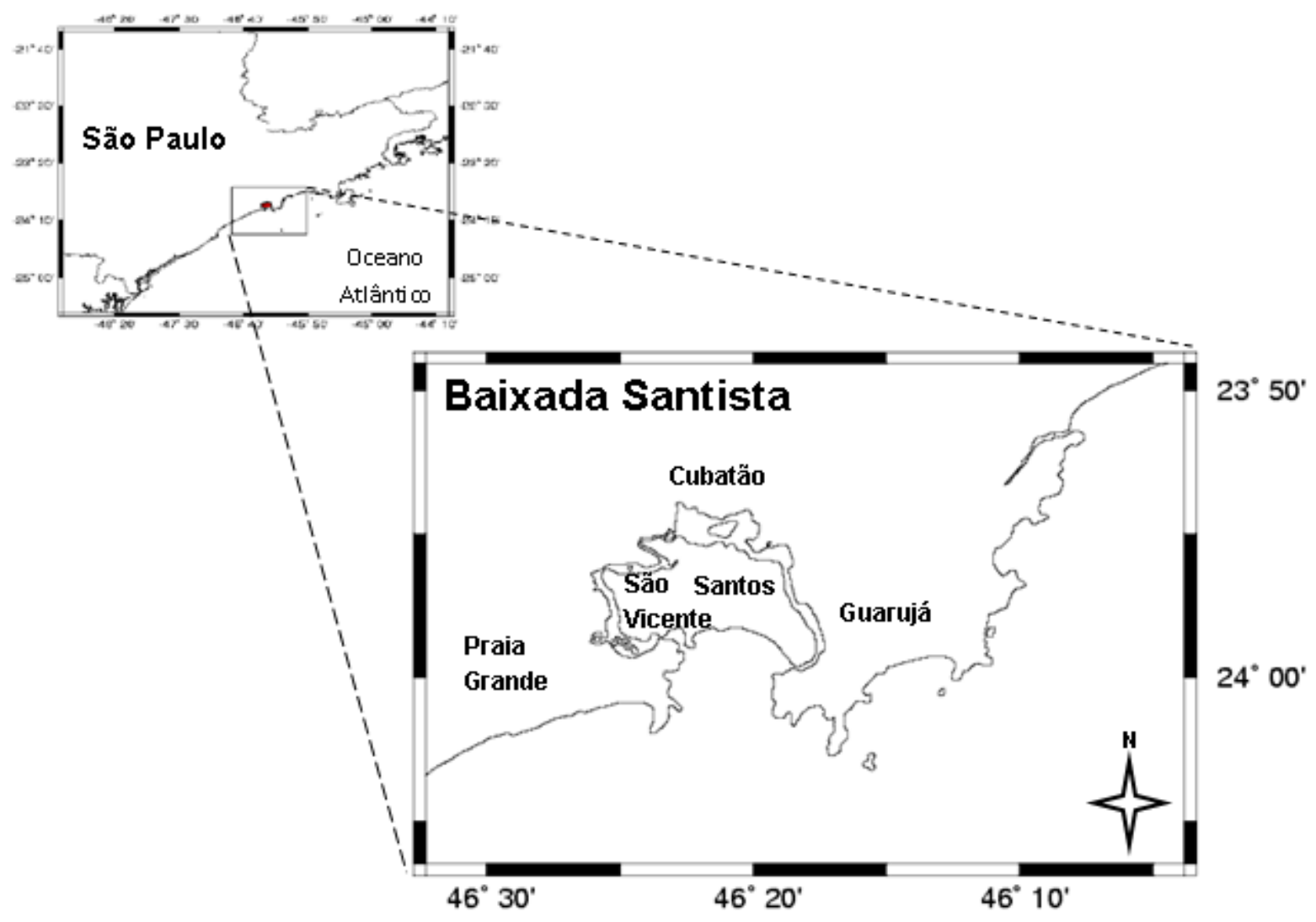

Figura 5 - Localização da área de estudo (Baixada Santista). 


\section{1 - CARACTERÍSTICAS GEOMORFOLÓGICAS}

Este setor do litoral de São Paulo apresenta, basicamente, duas formações geológicas principais: a área da escarpa da Serra do Mar e a planície sedimentar litorânea (Figura 6). Em frente à serra e circundando os morros e maciços isolados, desenvolve-se a planície sedimentar formada originalmente por aluviões, material de mangues atuais e antigos e por sedimentos de praias em geral (Rodrigues, 1965).

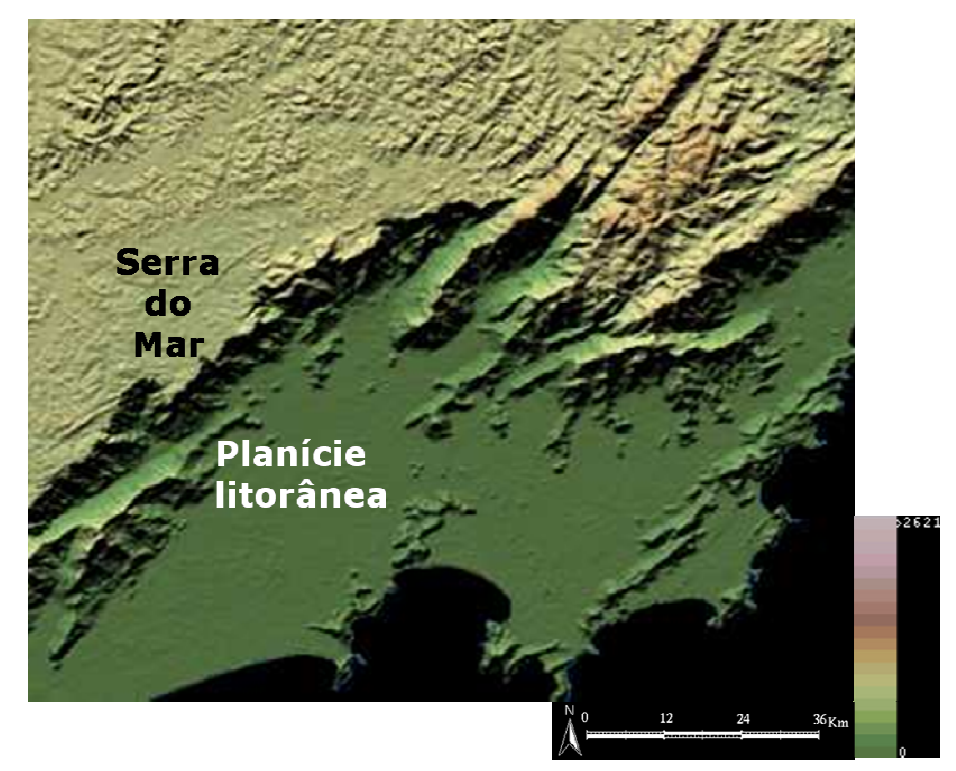

Figura 6 - Mapa de relevo da região da Baixada Santista, mostrando a escarpa da Serra do Mar e a planície litorânea. Extraído de Miranda (2005).

A gênese deste sistema costeiro está ligada segundo Suguiu \& Martin (1978) aos eventos transgressivo-regressivos do nível do mar ocorridos ao longo do Quaternário Superior, onde por ocasião do máximo da Transgressão Cananéia ( \pm 120.000 anos A.P.), que atingiu na região cotas entre 8 e 10 metros acima do nível do mar atual, areias marinhas foram depositadas sobre sedimentos continentais e transicionais.

Em seguida, durante a regressão que se seguiu no Último Máximo Glacial (quando o nível do mar atingiu aproximadamente 130 metros abaixo do atual) as atuais planícies costeiras e quase toda a plataforma 
continental paulista ficou exposta, ocorrendo um intenso retrabalhamento dos sedimentos.

No máximo holocênico (Transgressão Santos - 5.100 anos A.P.), o nível do mar esteve a 4,6 metros acima do atual, sendo que sua penetração nas zonas baixas criou uma série de lagunas e canais de maré que propiciaram a deposição de sedimentos finos associados à presença de matéria orgânica que foram colonizadas por manguezais. Há 3.800 anos A.P. ocorreu um mínimo próximo ao nível atual, após o qual foi reestabelecido o nível em cerca de 4 metros (3.500 anos A.P.) e observado uma tendência geral regressiva (Suguiu \& Martin, 1978).

\section{2 - CARACTERÍSTICAS CLIMÁTICAS}

A região apresenta características climáticas bastante individualizadas, sob domínio alternado dos sistemas tropical e polar atlântico, podendo ser classificado como clima quente e úmido, com temperatura máxima absoluta de $39^{\circ} \mathrm{C}$ e mínima absoluta de $10^{\circ} \mathrm{C}$, com temperatura média anual de $22^{\circ} \mathrm{C}$. A temperatura média no mês mais quente (fevereiro) é superior a $25^{\circ} \mathrm{C}$ e a média no mês mais frio (julho) é acima de $18^{\circ} \mathrm{C}$. Trata-se de região chuvosa, com valores mensais de precipitação acima de $100 \mathrm{~mm}$, durante todo o ano. A precipitação é maior no verão (janeiro-março) decrescendo no inverno (julho-agosto). A região não apresenta estação seca definida, com precipitação média anual entre 2000 e 2500 mm. A umidade relativa do ar é alta, alcançando cerca de $80 \%$ durante o ano (Figura 7) (Santos,1965). 


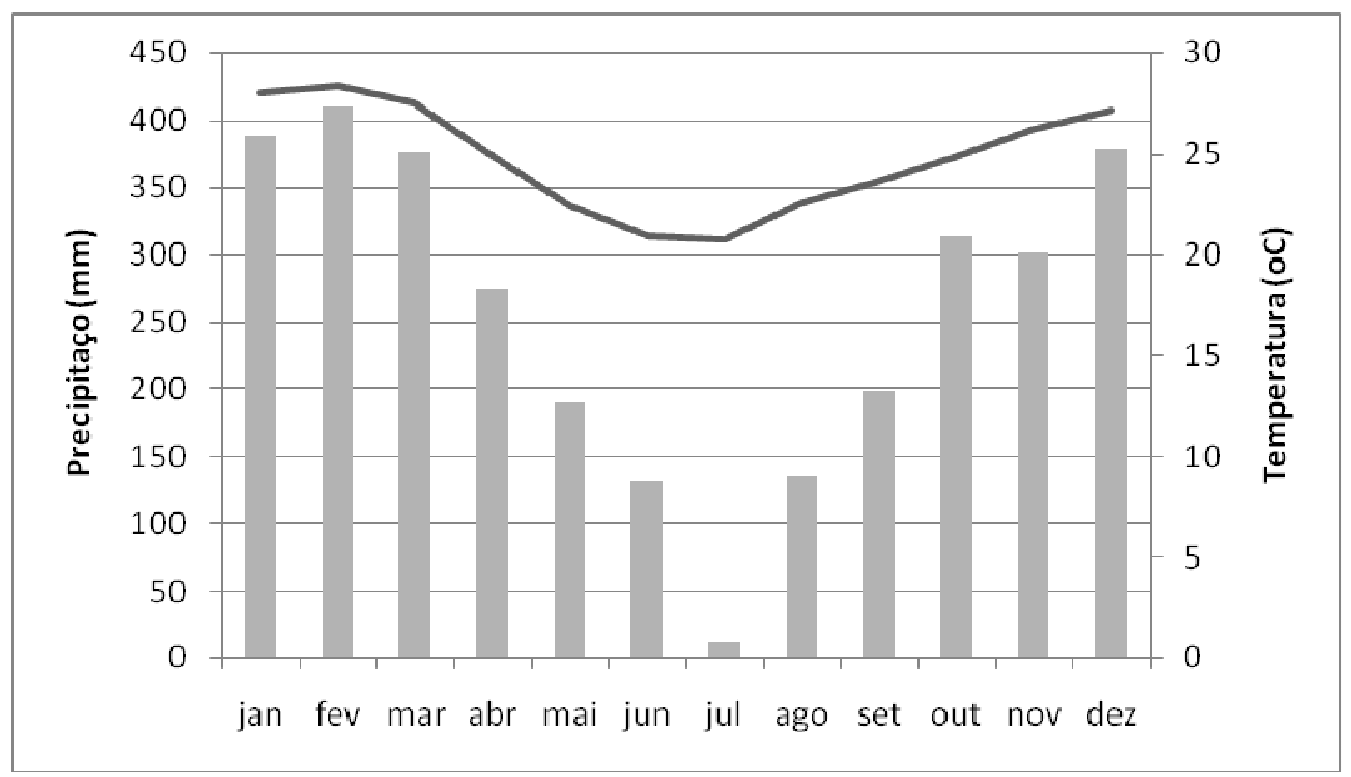

Figura 7 - Médias mensais de precipitação (barras) e temperatura (linha) para o município de Santos no período de 1941 a 1970 (Fonte: www.bdclima.cnpm.embrapa.br).

Quanto ao regime de ventos, há predomínio da situação de calmas, sem vento, em $51,8 \%$ do período, seguidos do vento Sul $(11,6 \%)$ e do quadrante Leste $(7,9 \%)$, oriundos respectivamente do anticiclone polar e do anticiclone atlântico. Como ocorre em todo o litoral sudeste do Brasil, a região está sujeita à constante ação das massas de ar e das perturbações frontais que, freqüentemente, atuam na região (Santos, 1965).

\section{3 - CARACTERÍSTICAS HIDROLÓGICAS}

A proximidade com a Serra do Mar responde pelas características dos rios que deságuam na região, cujos fluxos são rápidos e intensos. Esta energia é perdida quando os cursos de água chegam à planície costeira com pouca ou nenhuma declividade, diminuindo sensivelmente este fluxo. Como resultado, córregos e canais são formados gerando uma complexa rede hidrológica, transformando vastas regiões em áreas úmidas sob influência de efetivo aporte de água doce e de águas salgadas 
trazidas pelas marés. Esse ambiente costeiro tropical torna-se propício ao desenvolvimento de extensos manguezais (Goldentein, 1972).

As principais bacias supridoras de água doce são: Cubatão, MogiPiaçaguera, Perequê, Quilombo, Jurubatuba, Branco (ou Buturoca), DianaSandi, Onça e Piaçabuçu, estando todas encaixadas nas vertentes da Serra do Mar (Bonetti, 1996).

As marés são de caráter misto e semi-diurnas, com período de $12 \mathrm{~h}$ $42 \mathrm{~min}$. A amplitude média de sizígia é de $1,23 \mathrm{~m}$ e a e quadratura é igual a 0,27 $\mathrm{m}$ (para o Porto de Santos). As frentes frias porém, produzem alterações no nível médio da maré, que podem ultrapassar 0,5 m. (Harari, et al, 1990). Segundo Tommasi (1979), a maré na região da Torre Grande oscila, em condições extremas ao longo do tempo, entre $+1,4 \mathrm{~m}$ e $-1,8 \mathrm{~m}$, correspondendo desta forma a uma desigualdade máxima de 3,2m.

A onda de maré local propaga-se simultaneamente pelos estuários de Santos e São Vicente, encontrando-se no Canal do Casqueiro, uma área de tombo de maré que divide dinamicamente as cabeceiras dos estuários (DAEE/CETESB, 1977).

Quanto à circulação das águas, existe um regime de circulação de água que caracteriza os braços dos Portos de Santos e de São Vicente, como parcialmente misturados. A fração de água doce que chega ao braço do Porto de Santos diminui das cabeceiras (63\%) para a boca da entrada do canal $(21 \%)$, sendo que o tempo médio de renovação de $99 \%$ das águas varia entre cinco (na região que corresponde à desembocadura do canal) e dois dias (na região que corresponde às cabeceiras), admitindose um modelo de estuário parcialmente misturado, sendo necessários dez ciclos de maré de sizígia para renovar essa quantidade de água. A vazão média efluente que escoa pela boca do canal do porto é de $690 \mathrm{~m}^{3} / \mathrm{s}$, sendo $130 \mathrm{~m}^{3} / \mathrm{s}$ aproximadamente de água doce, e $560 \mathrm{~m}^{3} / \mathrm{s}$ de água salgada provenientes do oceano (CETESB, 1978). 
Tommasi (1979) aponta a existência de uma área de assoreamento em frente ao cais do Valongo e de Paquetá e entre o primeiro e a Ilha Barnabé, contribuindo à formação de um giro de água no largo, em frente ao Canal de Bertioga, Ilha Barnabé, Ilha de São Vicente e Ilha de Santo Amaro. Este grande giro, neste ponto do estuário, já havia sido descrito por Kutner (1976), a partir de análises granulométricas dos sedimentos de fundo da região.

\section{4 - QUALIDADE AMBIENTAL}

A Baixada Santista apresenta importância socioeconômica nos contextos nacional-regional-metropolitano, devido ao parque poliindustrial de Cubatão e aos terminais marítimos em Cubatão, Santos e Vicente de Carvalho (Guarujá) (Schaeffer-Novelli et al., 2003).

A atividade industrial teve início na década de 50, com a implantação de diversas indústrias de base (siderúrgica, petroquímica e fertilizantes), com alto potencial poluidor e fazendo dos estuários de Santos e São Vicente grandes receptores de resíduos tóxicos e efluentes líquidos contaminados (CETESB, 2001).

Segundo Azevedo (1965), as principais razões que favoreceram a escolha da Baixada Santista como sede do primeiro complexo industrial nacional foram:

- Pré-existência de redes ferroviárias e rodoviárias e de um porto marítimo, fundamentais para o recebimento e escoamento de matérias-primas e produtos.

- Proximidade de um grande centro consumidor (a cidade de São Paulo). 
- Disponibilidade de água e presença da Usina Hidrelétrica de Henry Borden, gerando energia local.

A Usina Hidrelétrica de Henry Borden da mesma forma que abastece a Baixada Santista com energia elétrica, também já foi uma grande fonte poluidora para a região, pois segundo Tomassi (1987) na década de 70, os esgotos sem tratamento da Grande São Paulo eram descarregados nos rios Tietê, Pinheiros e Tamanduateí, passando para o Reservatório Billings, de onde as águas poluídas chegavam ao estuário de Santos através desta Usina Hidrelétrica.

Dentre as diversas fontes de poluição na Baixada Santista, destacase a de origem industrial como a principal fonte de contaminantes químicos para a região (CETESB, 2001). A Tabela I relaciona as principais fontes industriais de contaminação existentes na Baixada Santista.

Fontes de origem portuária (Tabela II) são, também, bastante diversificadas em virtude da ampla pauta de produtos manipulados pelos terminais, especialmente os de granéis líquidos (CETESB, op. cit.).

Cabe ressaltar que acidentes ocorridos nestes terminais acabam despejando grandes quantidades de produtos químicos no ambiente, comprometendo seriamente as regiões envolvidas. 


\section{Tabela I - Principais fontes de poluição industrial na Baixada Santista (adaptado de CETESB, 2001).}

\begin{tabular}{|c|c|c|}
\hline Indústria & Produção Principal & Contaminante* \\
\hline Alba ${ }^{(1)}$ & Resinas, formol & $\mathrm{N}$, Fenóis, Cr \\
\hline Carbocloro & Cloro, soda, EDC & Fenóis, Solventes halogenados, $\mathrm{Cr}, \mathrm{Hg}, \mathrm{Zn}$ \\
\hline CBE & Estireno & $\mathrm{N}$, Fenóis, Solventes aromáticos, $\mathrm{Cu}, \mathrm{Cr}, \mathrm{Hg}, \mathrm{Zn}$ \\
\hline Cia Santista de Papel & Papel & Fenóis, $\mathrm{Cd}, \mathrm{Cu}, \mathrm{Mn}, \mathrm{Hg}, \mathrm{Ni}, \mathrm{Cr}, \mathrm{Hg}, \mathrm{Zn}$ \\
\hline CIEL & Coque verde & $\mathrm{Mn}, \mathrm{Ni}, \mathrm{Zn}$ \\
\hline Columbia & Negro de fumo & \\
\hline Copebrás & Ácido fosfórico, fertilizantes & $\mathrm{P}, \mathrm{N}$, Fluoreto \\
\hline Cosipa & Aços & $\begin{array}{l}\text { N, CN, Fluoreto, Fenóis, Solventes aromáticos, Ar, Cd, } \\
\qquad \mathrm{Pb}, \mathrm{Cu}, \mathrm{Cr}, \mathrm{Mn}, \mathrm{Hg}, \mathrm{Ni}, \mathrm{Zn}\end{array}$ \\
\hline Dow Química & Látex, polióis, poliestireno & $\begin{array}{l}\mathrm{N}, \mathrm{CN} \text {, Fluoreto, Fenóis, Solventes aromáticos, Solventes } \\
\text { halogenados, } \mathrm{Ar}, \mathrm{Cd}, \mathrm{Pb}, \mathrm{Cu}, \mathrm{Cr}, \mathrm{Mn}, \mathrm{Hg}, \mathrm{Ni}, \mathrm{Zn}\end{array}$ \\
\hline IFC & Fertilizantes & $\mathrm{P}, \mathrm{N}$, Fluoreto \\
\hline Liquid Química & Ácido benzóico & N, Fenóis, Solventes aromáticos, Mn, Hg, \\
\hline Manah & Fertilizantes & $\mathrm{P}, \mathrm{N}$, Fluoreto \\
\hline Petrobrás/RPBC & Derivados de petróleo & $\begin{array}{l}\mathrm{N}, \mathrm{CN} \text {, Fluoreto, Fenóis, Solventes aromáticos, } \mathrm{Cd}, \mathrm{Pb}, \mathrm{Cu}, \mathrm{Hg} \text {, } \\
\qquad \mathrm{Ni}, \mathrm{Zn}\end{array}$ \\
\hline Petrocoque & Coque verde & $\mathrm{N}$, Fenóis, $\mathrm{Ar}, \mathrm{Cu}, \mathrm{Cr}, \mathrm{Ni}, \mathrm{Zn}$ \\
\hline Rhodia - Agro (1) & Pesticidas carbamatos & Carbamatos \\
\hline Rhodia - UQC (1) & Organoclorados & $\begin{array}{l}\text { Fenóis, Solventes halogenados, Organoclorados } \\
\text { aromáticos, pesticidas organoclorados }\end{array}$ \\
\hline Serrana & Fertilizantes & $\mathrm{P}, \mathrm{N}$, Fluoreto \\
\hline Solorrico & Fertilizantes & $\mathrm{P}, \mathrm{N}$, Fluoreto, $\mathrm{Cd}$ \\
\hline Ultrafértil - CB & Fertilizantes & $\mathrm{P}, \mathrm{N}$, Fluoreto, Fenóis, $\mathrm{Ar}, \mathrm{Pb}, \mathrm{Cu}, \mathrm{Cr}, \mathrm{Ni}, \mathrm{Zn}$ \\
\hline Ultrafértil - PG & Fertilizantes & $\mathrm{P}, \mathrm{N}$, Fluoreto \\
\hline Union Carbide & Polietileno & Fluoreto, Fenóis, Carbamatos, Mn, Zn \\
\hline
\end{tabular}

(1) Industrias desativadas

* - O contaminante constitui matéria prima, produto ou insumo do processo produtivo, ou é resíduo obrigatório do processo produtivo, ou foi verificado em análises químicas dos efluentes entre 1979 e 1999. 
Tabela II - Principais fontes de poluição nos terminais portuários da Baixada Santista (adaptado de CETESB, 2001).

\begin{tabular}{|c|c|}
\hline Empresa & Contaminante* \\
\hline Brasterminais & $\begin{array}{l}\mathrm{N}, \mathrm{CN} \text {, Fluoreto, Sulfeto, Solventes aromáticos, Solventes } \\
\text { halogenados, fenóis, } \mathrm{Cd}, \mathrm{Pb}, \mathrm{Cu}, \mathrm{Mn}, \mathrm{Hg}, \mathrm{Zn}\end{array}$ \\
\hline Dibal & $\begin{array}{l}\mathrm{N}, \mathrm{CN} \text {, Fluoreto, Sulfeto, Solventes aromáticos, Solventes } \\
\text { halogenados, fenóis, } \mathrm{Cd}, \mathrm{Pb}, \mathrm{Cu}, \mathrm{Mn}, \mathrm{Hg}, \mathrm{Zn}\end{array}$ \\
\hline Granel Química & $\begin{array}{l}\mathrm{N}, \mathrm{CN} \text {, Fluoreto, Sulfeto, Solventes aromáticos, Solventes } \\
\text { halogenados, fenóis, } \mathrm{Cd}, \mathrm{Pb}, \mathrm{Cu}, \mathrm{Mn}, \mathrm{Hg}, \mathrm{Ni}, \mathrm{Zn}\end{array}$ \\
\hline Hamilton Fox ${ }^{(1)}$ & Solventes aromáticos \\
\hline Maia (2) & $\begin{array}{l}\mathrm{N}, \mathrm{CN} \text {, Fluoreto, Sulfeto, Solventes aromáticos, Solventes } \\
\text { halogenados, fenóis, } \mathrm{Cd}, \mathrm{Pb}, \mathrm{Cu}, \mathrm{Mn}, \mathrm{Hg}, \mathrm{Ni}, \mathrm{Zn}\end{array}$ \\
\hline Móbil & $\begin{array}{l}\mathrm{N}, \mathrm{CN} \text {, Fluoreto, Sulfeto, Solventes aromáticos, Solventes } \\
\text { halogenados, fenóis, } \mathrm{Cd}, \mathrm{Pb}, \mathrm{Cu}, \mathrm{Mn}, \mathrm{Hg}, \mathrm{Ni}, \mathrm{Zn}\end{array}$ \\
\hline Petrobrás/DTCS - Alamoa & $\begin{array}{l}\mathrm{N}, \mathrm{CN} \text {, Fluoreto, Sulfeto, Solventes aromáticos, fenóis, } \\
\qquad \mathrm{Cd}, \mathrm{Pb}, \mathrm{Cu}, \mathrm{Mn}, \mathrm{Hg}, \mathrm{Zn}\end{array}$ \\
\hline Petrobrás/DTCS - Cubatão & $\mathrm{N}, \mathrm{CN}, \mathrm{S}$, Solventes halogenados, $\mathrm{Pb}$ \\
\hline Stolthaven & $\begin{array}{l}\mathrm{N}, \mathrm{CN} \text {, Fluoreto, Sulfeto, Solventes aromáticos, Solventes } \\
\text { halogenados, fenóis, } \mathrm{Cd}, \mathrm{Pb}, \mathrm{Cu}, \mathrm{Mn}, \mathrm{Hg}, \mathrm{Zn}\end{array}$ \\
\hline Tefer & S, Fluoreto \\
\hline Ultrafértil - Terminal Marítimo & $\mathrm{N}, \mathrm{S}$ \\
\hline Ùnião & $\begin{array}{l}\text { P, N, CN, Fluoreto, Sulfeto, Solventes aromáticos, } \\
\text { Solventes halogenados, fenóis, } \mathrm{Cd}, \mathrm{Pb}, \mathrm{Cu}, \mathrm{Mn}, \mathrm{Hg}, \mathrm{Zn}\end{array}$ \\
\hline
\end{tabular}

(1) - Terminal de granéis líquidos paralisado

(2) - Empresa de lavagem de isocontâiners

* - O contaminante constitui matéria prima, produto ou insumo manipulado ou armazenado, ou foi verificado em análises químicas dos efluentes entre 1979 e 1999, mesmo que dentro dos padrões legais.

As áreas com solos contaminados, descritas na Tabela III, constituem fontes de alto risco, devido à alta toxicidade, persistência e potencial de bioacumulação de alguns dos resíduos industriais depositados de forma irregular em diversos pontos da região (CETESB, op. cit.), sendo comum o afloramento destes resíduos no entorno das áreas de deposição, demonstrando a contaminação do lençol freático. Outro fator de risco nestas áreas deve-se a grande parte delas terem sido recobertas naturalmente por vegetação e não apresentarem nenhum aviso à população de serem áreas contaminadas, sendo comum à presença de pessoas nestas áreas com o intuito de lazer. 


\section{Tabela III - Principais fontes de poluição relacionadas às áreas contaminadas da Baixada Santista (adaptado de CETESB, 2001).}

\begin{tabular}{|c|c|c|}
\hline Empresa/Local & $\begin{array}{l}\text { Natureza da } \\
\text { área } \\
\text { contaminada \# }\end{array}$ & Contaminante* \\
\hline Aterro sanitário / Cubatão & DRSD & $\mathrm{N}, \mathrm{Cu}, \mathrm{Mn}$ e $\mathrm{Zn}$ \\
\hline Lixão de Pilões ${ }^{(1)}$ & DRSD & $\begin{array}{l}\mathrm{P}, \mathrm{N}, \mathrm{CN} \text {, Fluoreto, sulfetos, fenóis, solventes aromáticos } \\
\text { solventes halogenados, organoclorados aromáticos, } \\
\text { pesticidas organoclorados, } \mathrm{Ar}, \mathrm{Cd}, \mathrm{Pb}, \mathrm{Cu}, \mathrm{Cr}, \mathrm{Mn}, \mathrm{Hg}, \mathrm{Ni} \text { e } \mathrm{Zn}\end{array}$ \\
\hline Carbocloro & AIC & $\mathrm{Hg}$ \\
\hline Dow Química & AIC & Solventes halogenados \\
\hline CBE & AIC & Fenóis e solventes aromáticos \\
\hline Cosipa (Carboquímica) & AIC & $\mathrm{N}, \mathrm{CN}$, fenóis e solventes aromáticos \\
\hline Petrobrás / RPBC & AIC & Fenóis, solventes aromáticos e Cd \\
\hline Profundir ${ }^{(2)}$ & AIC & $\mathrm{Ar}, \mathrm{Cd}, \mathrm{Pb}, \mathrm{Hg}$ e $\mathrm{Zn}$ \\
\hline Petrobrás / DTCS / Cubatão & DIRSI & $\mathrm{Pb}$ \\
\hline Rhodia - UQC & DIRSI & $\begin{array}{l}\text { Solventes halogenados, organoclorados aromáticos e } \\
\text { pesticidas organoclorados }\end{array}$ \\
\hline Rhodia - Perequê & DIRSI & $\begin{array}{l}\text { Solventes halogenados, organoclorados aromáticos e } \\
\text { pesticidas organoclorados }\end{array}$ \\
\hline Rhodia - Km 67 & DIRSI & $\begin{array}{l}\text { Solventes halogenados, organoclorados aromáticos e } \\
\text { pesticidas organoclorados }\end{array}$ \\
\hline Rhodia - Km 69 & DIRSI & $\begin{array}{l}\text { Solventes halogenados, organoclorados aromáticos e } \\
\text { pesticidas organoclorados }\end{array}$ \\
\hline Rhodia Quarentenário & DIRSI & $\begin{array}{l}\text { Solventes halogenados, organoclorados aromáticos e } \\
\text { pesticidas organoclorados }\end{array}$ \\
\hline Rhodia PI - 05 & DIRSI & $\begin{array}{l}\text { Solventes halogenados, organoclorados aromáticos e } \\
\text { pesticidas organoclorados }\end{array}$ \\
\hline Rhodia PI - 06 & DIRSI & $\begin{array}{l}\text { Solventes halogenados, organoclorados aromáticos e } \\
\text { pesticidas organoclorados }\end{array}$ \\
\hline Cosipa - Dique do Furadinho & DSC & $\mathrm{N}$, sulfetos, solventes aromáticos, $\mathrm{Ar}, \mathrm{Cd}, \mathrm{Pb}, \mathrm{Cu}, \mathrm{Cr}, \mathrm{Mn}, \mathrm{Hg}, \mathrm{Ni}$ e $\mathrm{Zn}$ \\
\hline Polígono 1 (até 1974) & DSC & $\mathrm{P}, \mathrm{N}$, organoclorados aromáticos, $\mathrm{Cd}, \mathrm{Pb}, \mathrm{Cu}, \mathrm{Cr}, \mathrm{Mn}, \mathrm{Hg}, \mathrm{Ni}$ e $\mathrm{Zn}$ \\
\hline Polígono 2 (1974 - 1996) & DSC & $\mathrm{P}, \mathrm{N}$, organoclorados aromáticos, $\mathrm{Cd}, \mathrm{Pb}, \mathrm{Cu}, \mathrm{Cr}, \mathrm{Mn}, \mathrm{Hg}, \mathrm{Ni}$ e $\mathrm{Zn}$ \\
\hline Polígono 3 (após 1996) & DSC & $\mathrm{P}, \mathrm{N}$, organoclorados aromáticos, $\mathrm{Cd}, \mathrm{Pb}, \mathrm{Cu}, \mathrm{Cr}, \mathrm{Mn}, \mathrm{Hg}, \mathrm{Ni}$ e $\mathrm{Zn}$ \\
\hline Copebrás & PG & P e fluoreto \\
\hline Ultrafértil & PG & P e fluoreto \\
\hline
\end{tabular}

(1) -indica a disposição conjunta de resíduos industriais perigosos

(2) - industrias desativadas

\# - DRSD = Disposição de resíduos sólidos domésticos; AIC = Áreas industriais contaminadas; DIRSI = Disposição irregular de resíduos sólidos industriais; DSC = Disposição de sedimentos contaminados; PG = Pilhas de gesso.

*- indica contaminação do poluente na área. 
A contribuição de esgoto doméstico pelos assentamentos humanos às margens do estuário (palafitas) que carecem de saneamento básico é grande, e pelo fato de estarem localizados em áreas confinadas (dentro do estuário), a sua dispersão torna-se comprometida.

Dados recentes revelam o crescimento populacional dos municípios da Baixada Santista entre os anos de 1996 e 2007 (Tabela IV). O conglomerado populacional (quase 1,5 milhão de pessoas) presente atualmente nos municípios da Baixada Santista, acarreta também um maior aporte de esgotos domésticos e outras formas de poluição para a região.

Tabela IV - Dados populacionais dos municípios da Baixada Santista para os anos de 1996 e 2007.

\begin{tabular}{cccccccc}
\hline Cidade & Santos & $\begin{array}{c}\text { São } \\
\text { Vicente }\end{array}$ & Guarujá & Cubatão & Bertioga & $\begin{array}{c}\text { Praia } \\
\text { Grande }\end{array}$ & Total \\
\hline $\begin{array}{c}\text { População } \\
(\mathbf{1 9 9 6 )}\end{array}$ & 412.243 & 279.528 & 226.365 & 97.257 & 17.002 & 150.388 & 1.182 .783 \\
$\begin{array}{c}\text { População } \\
(\mathbf{2 0 0 7 )}\end{array}$ & 418.288 & 323.599 & 296.150 & 120.271 & 39.091 & 233.806 & 1.431 .205 \\
\hline
\end{tabular}

Fonte: IBGE, 2007.

A atual forma de crescimento econômico no país, sem um planejamento a longo prazo e sem um maior comprometimento ambiental, geram uma enorme pressão para uma expansão do Porto de Santos que continua em contínuo crescimento, como pode ser observado na Tabela $\mathrm{V}$. 
Tabela V - Movimentação anual de cargas do Porto de Santos (em toneladas).

\begin{tabular}{cccccccc}
\hline & 2000 & 2001 & 2002 & 2003 & 2004 & 2005 & 2006 \\
\hline Total & 43.084 .383 & 48.161 .593 & 53.474 .268 & 60.077 .073 & 67.609 .753 & 71.902 .494 & 79.297 .193 \\
Exportação & 22.353 .811 & 28.030 .470 & 33.822 .484 & 39.126 .666 & 45.809 .828 & 50.399 .621 & 52.243 .709 \\
Importação & 20.730 .572 & 20.131 .123 & 19.651 .784 & 20.950 .407 & 21.799 .925 & 21.502 .873 & 24.053 .484 \\
\hline
\end{tabular}

Fonte: CODESP, 2007

A demanda exercida pelo crescimento da atividade portuária levou a construção da $2^{\circ}$ pista da Rodovia dos Imigrantes em 2002, interligando as regiões metropolitanas de São Paulo e da Baixada Santista, assim como diversos projetos de expansão portuária que estão sendo desenvolvidos e planejados.

As formas de ocupação industrial e portuária, juntamente com a falta de planejamento no que tange ao crescimento das áreas urbanas, são os principais meios de contaminação, além das constantes dragagens e aterros do complexo portuário, constituindo os principais agentes de perturbação do equilíbrio natural da região, afetando direta e indiretamente várias espécies de organismos aquáticos, com conseqüências diretas às populações ribeirinhas tradicionais que subsistem da pesca (Menghini, 2004).

\section{5 - MANGUEZAIS DA BAIXADA SANTISTA}

A área total da Baixada Santista é de $1.329 \mathrm{~km}^{2}$, sendo que $10 \%$ $\left(133 \mathrm{~km}^{2}\right.$ ) foram ocupados originalmente por manguezais (CETESB, 1991). Segundo Herz (1987), os manguezais da Baixada Santista representam cerca de $43 \%$ dos $231 \mathrm{~km}^{2}$ de manguezais do litoral paulista. 
Uma das primeiras descrições dos manguezais da Baixada Santista, é a belíssima obra do naturalista Luederwaldt (1919), intitulada "Os maguesaes de Santos", onde o autor descreve a paisagem desta forma:"Emmoldurada pelas montanhas longíquas amplia-se a região pantanosa em pitoresca irregularidade! $A^{\prime}$ retaguarda a vultuosa Serra do Mar com os alcantis do Morrão sobranceiando as grimpas mais próximas, á frente uma superfície líquida com a largura de vários kilometros e comprimento avaliado em uma légua ou légua e meia, a qual se estende até Santos, á esquerda, atrahido o olhar por uma colina, a Ilha Barnabé. Vê-se logo a esquerda uma grande extensão repleta de mangues... A magnífica paisagem que temos deante dos olhos anima-se com as canoas e barcos de vela..." Com base na descrição acima podemos ter uma idéia da maravilhosa paisagem da Baixada Santista que estava aos olhos do autor a época.

Porém todo o processo de ocupação industrial, mudanças na paisagem e deterioração da qualidade ambiental ocorrido a partir da década de 50, mudou drasticamente estas características naturais da região.

Levantamento do estado de conservação dos manguezais nesta região, baseado em fotografias aéreas do período compreendido entre 1958 e 1989 (CETESB 1990, 1991) demonstrou que:

- $16 \%$ (21 $\mathrm{km}^{2}$ ) haviam sido aterrados para ocupação urbana e industrial.

- $31 \%\left(42 \mathrm{~km}^{2}\right)$ estão ocupados por manguezais degradados.

- $13 \%\left(17 \mathrm{~km}^{2}\right)$ estão ocupados por manguezais altamente degradados, localizados principalmente no estuário de Santos.

- $40 \%\left(53 \mathrm{~km}^{2}\right)$ destes manguezais encontram-se razoavelmente bem conservados, principalmente em Bertioga e São Vicente. 
A partir de dados da estrutura dos bosques de mangue e do nível de contaminação por metais pesados (levantados no período entre 1982 e 1984, em 33 pontos da Baixada Santista), foram identificados locais altamente contaminados e bosques de mangue bastante alterados pela poluição (CETESB, 1988).

Alguns trabalhos descreveram aspectos ecológicos importantes dos bosques de mangue da região da Baixada Santista, destacando:

Estudo de produção de serapilheira realizado durante dois anos consecutivos por Lamparelli (1995) em bosques de mangue do Canal de Bertioga encontrando baixos valores de queda de serapilheira.

Comelli et al. (1996) e Peria et al (1997), realizaram a caracterização estrutural de bosques localizados em Cubatão e no Canal de Bertioga, respectivamente, encontrando algumas características que indicam possivelmente que alguns destes bosques estariam apresentando sinais de estresse.

Soares (1997) realizou estudo da biomassa aérea em manguezais do Canal de Bertioga, contribuindo desta forma com possíveis estudos futuros acerca da biomassa aérea em outros bosques da Baixada Santista.

Trabalho realizado por Menezes (2000) avaliou a possível viabilidade de replantio de espécies típicas de mangue em Cubatão, destacando o aspecto social do seu trabalho que teve como objetivo a inclusão da população local em todas as etapas do replantio.

Em relação aos diversos vazamentos de óleo ocorridos na Baixada Santista, Ponte et al. (1987; 1990) e Rodrigues et al. (1990) realizaram estudos visando quantificar as respostas da cobertura vegetal e PozziNeto (2001) realizou um trabalho de valoração econômica ecológica buscando avaliar as perdas econômicas e ecológicas causadas em decorrência de tais eventos. 
O mesmo bosque de mangue localizado no Rio Iriri estudado por Ponte et al. (op cit) e Rodrigues et al. (op cit.) foi estudado por Santos (2007) e Santos et al. (2007). Em ambos os trabalhos os autores analisaram a variação espaço-temporal ocorrida nos bosques de mangue do Rio Iriri e do seu entorno no Canal de Bertioga. Estes estudos visaram às mudanças ocorridas nos bosques de mangue após derramamento de petróleo e devido às diversas ocupações humanas nas margens do Canal de Bertioga para construção de marinas e conglomerados populacionais.

Cabe destaque o trabalho realizado por Menghini (2004) que avaliou os impactos causados por derramamento de produto químico em bosque de mangue da Ilha Barnabé, encontrando valores altos de área basal morta e deformações foliares na vegetação.

Os rios da região ainda são muito usados para a pesca profissional e recreativa. Estima-se que haja 10.000 pessoas vivendo direta ou indiretamente da pesca artesanal na Baixada Santista, distribuídos em 17 comunidades, sendo que diversos pescadores relatam uma nítida diminuição na oferta do pescado na região interna do estuário (Gefe et al., 2004).

Este declínio da pesca está estreitamente correlacionado com os impactos antrópicos exercidos aos manguezais da região, que em decorrência destes impactos, estão cada vez menos subsidiando as águas estuarinas com detritos orgânicos, que são à base das cadeias tróficas estuarinas. 


\section{6 - ILHA BARNABÉ}

A Ilha Barnabé encontra-se localizada, na parte central do estuário de Santos (Figura 8) perto da desembocadura dos rios Jurubatuba, Sandi e Diana e em frente ao Canal de Santos. A Ilha Barnabé apresenta apenas um maciço cristalino na porção sul-sudoeste, onde se iniciou sua ocupação antrópica, o restante de sua área era inteiramente ocupada por manguezais.

Na Ilha Barnabé está localizado um Terminal de Granéis Líquidos do Porto de Santos, onde operam atualmente as empresas Vopak Brasterminais, Odfjell Terminals Granel Química Ltda, Potenza Terminais e Argemil, concentrando desta forma o maior volume de produtos químicos do Brasil em uma mesma área (cerca de 170 milhões de litros).

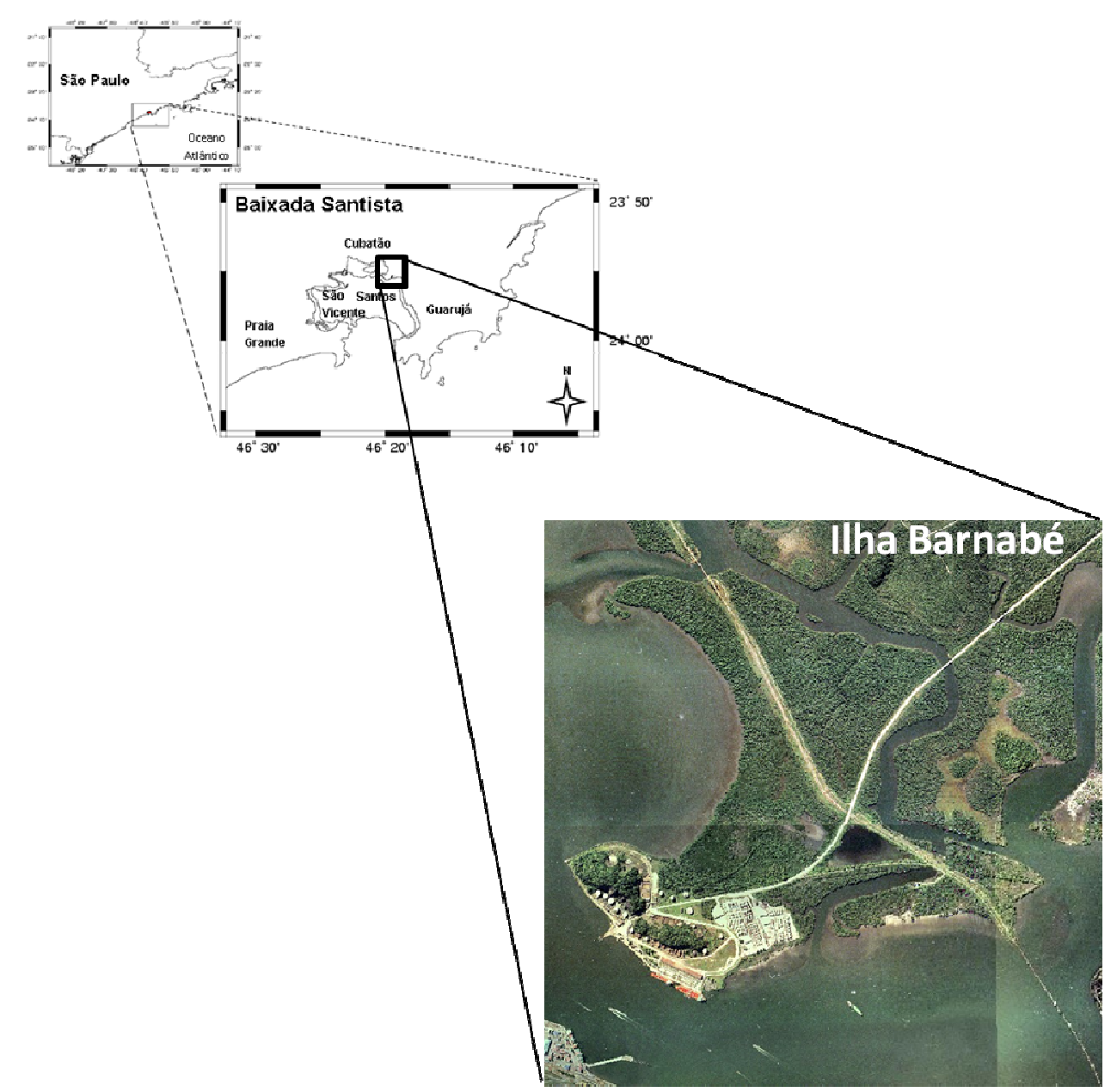

Figura 8 - Localização da Ilha Barnabé na Baixada Santista. 
Analisando a qualidade ambiental da Ilha Barnabé, observamos que já foram registrados diversos eventos (acidentes, derramamentos e incêndios) envolvendo produtos químicos na região.

O primeiro grande evento na Ilha Barnabé ocorreu em 24 de janeiro de 1954, onde o petroleiro "Cerro Gordo", durante manobra de descarga de combustíveis (óleo diesel, petróleo bruto, querosene e gasolina de aviação) incendiou-se a poucos metros da ilha. Aos 2 de setembro de 1969 o petroleiro "Guaporé" incendiou enquanto atracado no píer da ilha. Em 29 de julho de 1974, evento envolvendo explosão na ilha, ocasionou vazamento de 3.150 litros de tolueno nas águas do Estuário de Santos, além de causar a morte de um funcionário e ferimento em outros. Em 10 de outubro de 1991, dois tanques da empresa Granel Química, contendo acetato de vinila e acrilonitrila pegaram fogo após serem atingidos por um raio (Jornal A Tribuna, 4 de setembro de 1998, caderno Região, p.A9A14).

No dia 3 de setembro de 1998, incendiou-se caminhão-tanque ao ser carregado com 80 toneladas do líquido inflamável diciclopentadieno (DCPD). O incêndio foi provocado por vazamento na casa de bombas da empresa Vopak Brasterminais, instalada ao lado dos 66 tanques desta empresa. O líquido alcançou a área de manguezal fronteiriça à empresa, espalhando-se em direção ao bosque de mangue às margens do estuário (Figura 9), provocando graves danos, não somente à vegetação, pela queima dos troncos, galhos e folhas de indivíduos jovens e adultos, como também a fauna associada (CETESB, 1998; 1999). 


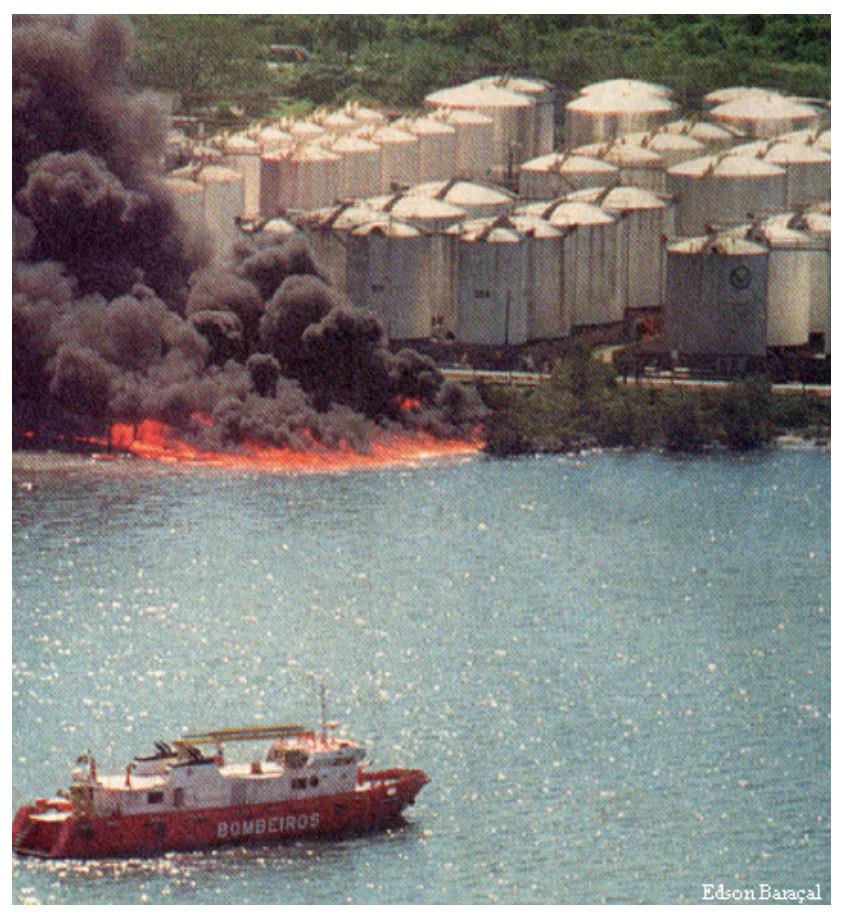

Figura 9 - Visão do evento ocorrido na área de estudo, 3 de setembro de 1998, com derramamento e combustão de produto químico (DCPD - diciclopentadieno).

Cabe destacar que o diciclopentadieno é obtido como subproduto na produção de etileno, possuindo fórmula estrutural $\mathrm{C}_{10} \mathrm{H}_{12}$, apresentando como rotas principais de contaminação o contato com a pele, olhos, inalação e ingestão. A exposição aguda pode provocar entre outras reações, depressão do sistema nervoso central, podendo ser fatal se ingerido em grandes quantidades, e o contato prolongado pode ser depressor do sistema nervoso central, além de comprometer pulmões e rins, sendo que pessoas que já tiveram problemas nestes órgãos têm maior predisposição a eventuais danos à saúde. O diciclopentadieno pode ser classificado como substância possivelmente carcinogênica para seres humanos (Equistar, 2003; Texmark, 2003).

Quanto às propriedades ecotoxicológicas é moderadamente tóxica para peixes, sendo possível a ocorrência de grande mortandade se alcançado o ambiente aquático. Sua adsorsão em matéria orgânica e no sedimento pode ser significante, sendo que quando esta última ocorre, 
pode tornar lento o processo de volatização. A biodegradação e a hidrólise não são esperadas como fatores importantes. Possui fator de bioacumulação de 93.2, indicando que o diciclopentadieno pode se bioacumular em peixes e outros organismos aquáticos (Equistar op cit.; Texmark op cit.).

O evento ocorrido na Ilha Barnabé em 1998 foi o de maior proporção, entretanto, aos 19 de abril de 1999 ocorreu novo acidente no interior da empresa Brasterminais seguido de explosão e incêndio durante operação de carregamento com coperaf I (hidrocarboneto halifático, obtido da industria petroquímica). Como o produto vazado foi consumido pelo incêndio, o volume não pôde ser estimado, porém observou-se grandes danos à vegetação de Hibiscus sp., espécie característica da transição entre o ecossistema manguezal e os ecossistemas terrestres (CETESB, 1999).

Altas concentrações de vapores do produto vazado (coperaf I), causam irritação ao trato respiratório, à pele e aos olhos, podendo provocar tonturas e dores de cabeça, além de depressor do sistema nervoso central, entretanto, sendo um hexano, não apresenta potencial de concentração na cadeia alimentar (CETESB, op cit.).

Menghini (2004) estudou o bosque de mangue impactado diretamente pelo evento de 1998. A caracterização estrutural mostrou a dominância da espécie Laguncularia racemosa com grande contribuição de área basal morta (28,5-61,3\%). Pode-se observar também uma grande quantidade de deformações foliares ( $L$. racemosa e Avicennia schaueriana) e de propágulos deformados e abortados de Rhizophora mangle, demonstrando a magnitude do impacto ocorrido. 


\section{7 - PERSPECTIVAS PARA A ILHA BARNABÉ}

Atualmente, o Plano de Desenvolvimento e Zoneamento do Porto de Santos (CODESP, 2006) prevê dois projetos de expansão da área portuária localizados na Ilha Barnabé e no seu entorno.

O Terminal Embraport (Empresa Brasileira de Terminais Portuários S.A.), de propriedade privada, está localizado na Ilha Diana, à jusante da Ilha Barnabé, O projeto deverá ocupar uma área total de $803 \mathrm{mil} \mathrm{m}^{2}$, dos quais 309 mil $\mathrm{m}^{2}$ serão viabilizados por meio de aterro de área de mangue e parte do Canal do Estuário (CODESP, 2006) e já se encontra em fase de construção.

Entre a Ilha Barnabé e a Ilha dos Bagres, incluído o Largo de Santa Rita, está previsto a construção de até 28 novos berços de atracação

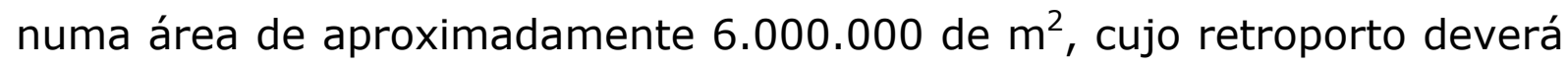
ocupar uma área pouco inferior a 4.000 .000 de $\mathrm{m}^{2}$ (CODESP, op. cit.). Este projeto foi idealizado pela CODESP na década de 1990, sendo que a previsão de conclusão do projeto é de 10 anos e, quando concluído, possibilitará dobrar a capacidade atual do Porto de Santos. O investimento deverá ser viabilizado em grande parte com capital privado (Rodrigues, 2004). A Figura 10 mostra a localização de tais empreendimentos. 


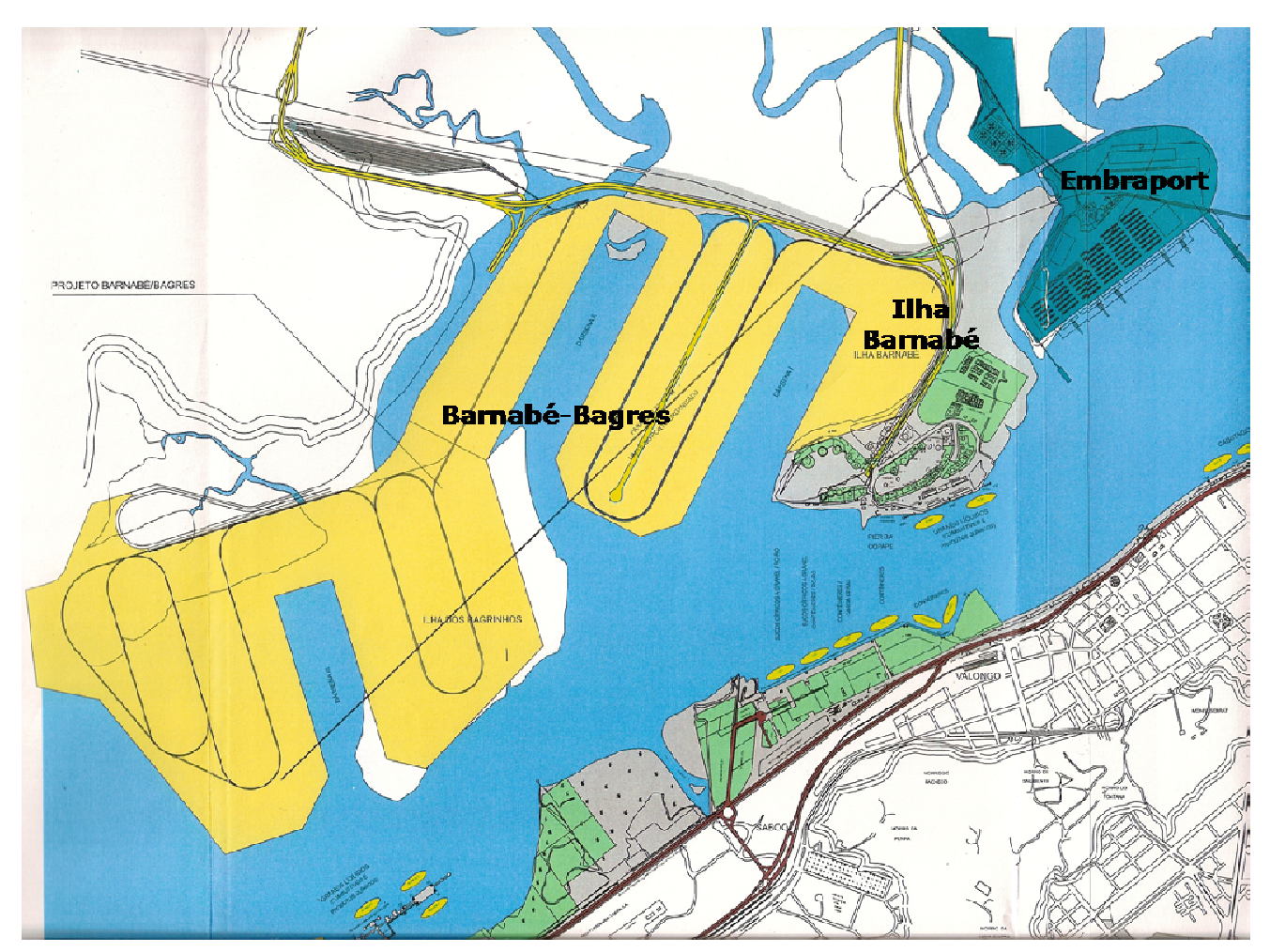

Figura 10 - Localização dos empreendimentos Embraport (azul) já em construção, Barnabé-Bagres (amarelo) e da Ilha Barnabé. Extraído de Costa (2005).

Cabe ressaltar que o mesmo Plano de Desenvolvimento e Zoneamento do Porto de Santos prevê para o ecossistema manguezal as seguintes diretrizes de atuação:

- Limpar os manguezais;

- Fiscalizar e controlar de forma efetiva a freqüência, invasão e desmatamento dos manguezais em áreas portuárias;

- Diagnosticar o nível de degradação dos manguezais bem como a sua importância para os ecossistemas existentes na região do estuário;

- Preservar as áreas contínuas de manguezais;

- Fazer o replantio de manguezais; 
- Estudar os impactos de desmatamentos sobre os recursos pesqueiros na região.

Com base nos fatos supracitados, e no amplo levantamento feito por Costa (2005), fica claro que as políticas públicas que fomentam o desenvolvimento do Porto de Santos não consideram as questões ou restrições ambientais como impeditivos para a realização de novos empreendimentos em áreas de manguezais e as chamadas diretrizes de atuação para com o ecossistema manguezal não passam de argumentos pouco convincentes.

Averiguando todos os episódios ocorridos no passado e os que estão ocorrendo no presente, podemos chegar à conclusão que muitos dos erros cometidos quanto ao descaso com as questões ambientais podem ter acontecido por falta de conhecimento das conseqüências negativas de uma expansão industrial ocorrida numa época que as questões ambientais eram pouco conhecidas e estudadas. Porém cometer os mesmo erros atualmente é um equívoco enorme, pois desta forma estamos simplesmente ignorando os conhecimentos adquiridos com os erros do passado. 


\section{5 - MATERIAIS E MÉTODOS}

A fim de avaliar a dinâmica da recomposição natural dos bosques de mangue da Ilha Barnabé, utilizou-se diferentes estudos em níveis hierárquicos distintos, segundo proposta de Schaeffer-Novelli et al. (2005).

Estes autores caracterizaram cinco níveis de organização hierárquica dos manguezais, em função da escala espacial adotada: Large Marine Ecosystems, Coastal Domain, Setting, Stand, e Site. O nível hierárquico mais alto seria representado pelos Large Marine Ecosystems - LME's, conceito proposto por Longhurst (1998) que equivale às regiões biogeográficas para oceanos e áreas costeiras. O nível seguinte, Coastal Domain (segmentos costeiros), correspondem no Brasil, aos oito segmentos costeiros propostos por Schaeffer-Novelli et al., (1990), ocupando entre 500 a $1000 \mathrm{~km}$ de costa. Em seguida os Settings (paisagem), termo cunhado por Thom (1982; 1984), representado por extensões de 10 a $100 \mathrm{~km}$. O nível hierárquico seguinte refere-se às unidades da paisagem ou bosque (Stand), de 0,1 a 100 ha. O nível mais inferior dessa hierarquia (Site) consiste na parcela do bosque ou árvore, ocupando entre 0,01 e 0,1 ha.

No presente trabalho foram adotados os níveis hierárquicos: Setting, aqui representado pela caracterização da Baixada Santista; Stand, representado pelo estudo multitemporal com fotografias aéreas (Ilha Barnabé) e Site, que foi o monitoramento da recomposição natural, serapilheira e microtopografia da área impactada pelo evento de 1998 e pela caracterização estrutural dos bosques de mangue em diferentes estágios sucessionais apontados através do estudo multi-temporal das fotografias aéreas. 


\section{1 - MONITORAMENTO DA ÁREA IMPACTADA PELO EVENTO OCORRIDO EM 1998}

\subsection{1 - RECOMPOSIÇÃO NATURAL DA COBERTURA VEGETAL}

Durante a realização da caracterização estrutural do bosque de mangue realizada por Menghini (2004), foram selecionadas três parcelas para se avaliar os impactos ocorridos pelo evento de 1998 na vegetação e outras três parcelas com a finalidade de caracterizar a recomposição natural do bosque que já vinha ocorrendo na ocasião. Destas, foram selecionadas duas parcelas, intituladas R2 e R3 (Figura 11) para realizar um monitoramento da dinâmica desta recomposição natural à longo prazo.

Em cada parcela todos os indivíduos foram devidamente lacrados e de quatro em quatro meses realizou-se medições de altura dos indivíduos vivos, segundo metodologia proposta por Coelho-Jr (2003). O monitoramento teve início em fevereiro e março de 2002 e término em novembro de 2007, totalizando seis anos de monitoramento. Os dois primeiros anos foram previamente analisados por Menghini (2004).

\subsection{2 - PRODUÇÃO DE SERAPILHEIRA}

No bosque de mangue remanescente ao evento ocorrido em 1998, foram dispostas nove cestas coletoras de acordo com a caracterização estrutural realizada por Menghini (2004) (Figura 11). Devido cuidado foi tomado durante a instalação das cestas coletoras para que não fossem lavadas pela ação das preamares. As cestas possuem estrutura em PVC $\left(0,25 \mathrm{~m}^{2}\right.$ de área) e tela de náilon com $2 \times 2 \mathrm{~mm}$ de malha (SchaefferNovelli \& Cintrón, 1986).

Cada cesta teve seu material recolhido mensalmente (de agosto de 2002 a setembro de 2007, totalizando cinco anos de monitoramento), 
transportado até o laboratório onde as frações folhas, flores e propágulos /frutos foram separadas por espécie, além de madeiras, estípulas e detritos não identificáveis. Posteriormente, todo material foi seco em estufa de circulação forçada QUÍMIS (Mod. Q-314D) à $70^{\circ} \mathrm{C}$, até atingir peso constante e pesado em balança digital QUÍMIS (Mod. BG 400, precisão $0,001 \mathrm{~g}$ ).

Posteriormente os dados foram plotados em planilhas para tratamento dos dados. Em alguns gráficos e tabelas as frações flores, estípulas e detritos não identificáveis foram agrupados na fração "miscelânia", por possuírem menor representatividade e para facilitar a análise das demais frações.

\subsection{3 - MICROTOPOGRAFIA}

O estudo da microtopografia foi realizado com equipamento fundamentado no princípio físico dos vasos comunicantes. Esse método tem sido empregado pelo BIOMA - Centro de Ensino e Informação sobre Zonas Úmidas Costeiras Tropicais, com ênfase no Ecossistema Manguezal, do Instituto Oceanográfico da Universidade de São Paulo (IOUSP) e pelo Núcleo de Estudos em Manguezais (NEMA), do Departamento de Oceanografia, da Universidade do Estado do Rio de Janeiro (UERJ). Foi descrito por Pellegrini (2000) e utilizado por Cunha-Lignon (2001) e Menghini (2004).

Estudo prévio da microtopografia da área afetada pelo evento em 1998 foi realizado em fevereiro de 2004 por Menghini (op. cit.). No intuito de se avaliar a continuidade do processo erosivo constatado na franja do bosque, foi realizado novo estudo microtopográfico na mesma área, utilizando mesma metodologia em fevereiro de 2008. 
Essa metodologia utiliza duas réguas de alumínio, graduadas a cada centímetro, de 0 (zero) a $200 \mathrm{~cm}$, e uma mangueira de borracha flexível e transparente, com diâmetro de $5 \mathrm{~mm}$ e comprimento de $25 \mathrm{~m}$.

A partir de um valor e de um ponto de referência, fixa-se a réguabase com a leitura do nível da água na mangueira, associado a um valor na régua. Em seguida, fixa-se a segunda régua no local a ter seu nível determinado. $O$ valor de referência na régua-base é restabelecido, e feita a leitura na segunda régua, com precisão de $0,1 \mathrm{~cm}$. A variação dos valores na segunda régua corresponde, em ordem inversa, à elevação ou depressão do terreno.

A topografia foi caracterizada com rede amostral regular abrangendo a totalidade do bosque, além das áreas ao redor, incluindo a antiga franja onde ocorreu a grande mortandade de árvores no evento de 1998.

Após determinado o rumo com auxílio de bússola (as transversais foram traçadas no sentido sul-norte), utilizou-se trena de $50 \mathrm{~m}$, esticada na direção a ser seguida e as medidas da cota do terreno foram feitas a cada $2 \mathrm{~m}$ (Figura 11). Foram realizadas no total, 29 transversais paralelas com $2 \mathrm{~m}$ de distância ente elas.

Para o processamento dos dados levantados foi utilizado o software SURFER 8.0 (2002), da Golden Software, Inc., visando elaboração de modelos numéricos do terreno de ambas da datas.

Para ajustar a malha amostral da coleta de dados de 2004 e 2008, padronizou-se um ponto fixo ao final do bosque onde os valores de ambas as datas foram igualados e a partir deste ponto as diferenças topográficas entre cada ponto de coleta foram estabelecidas. 


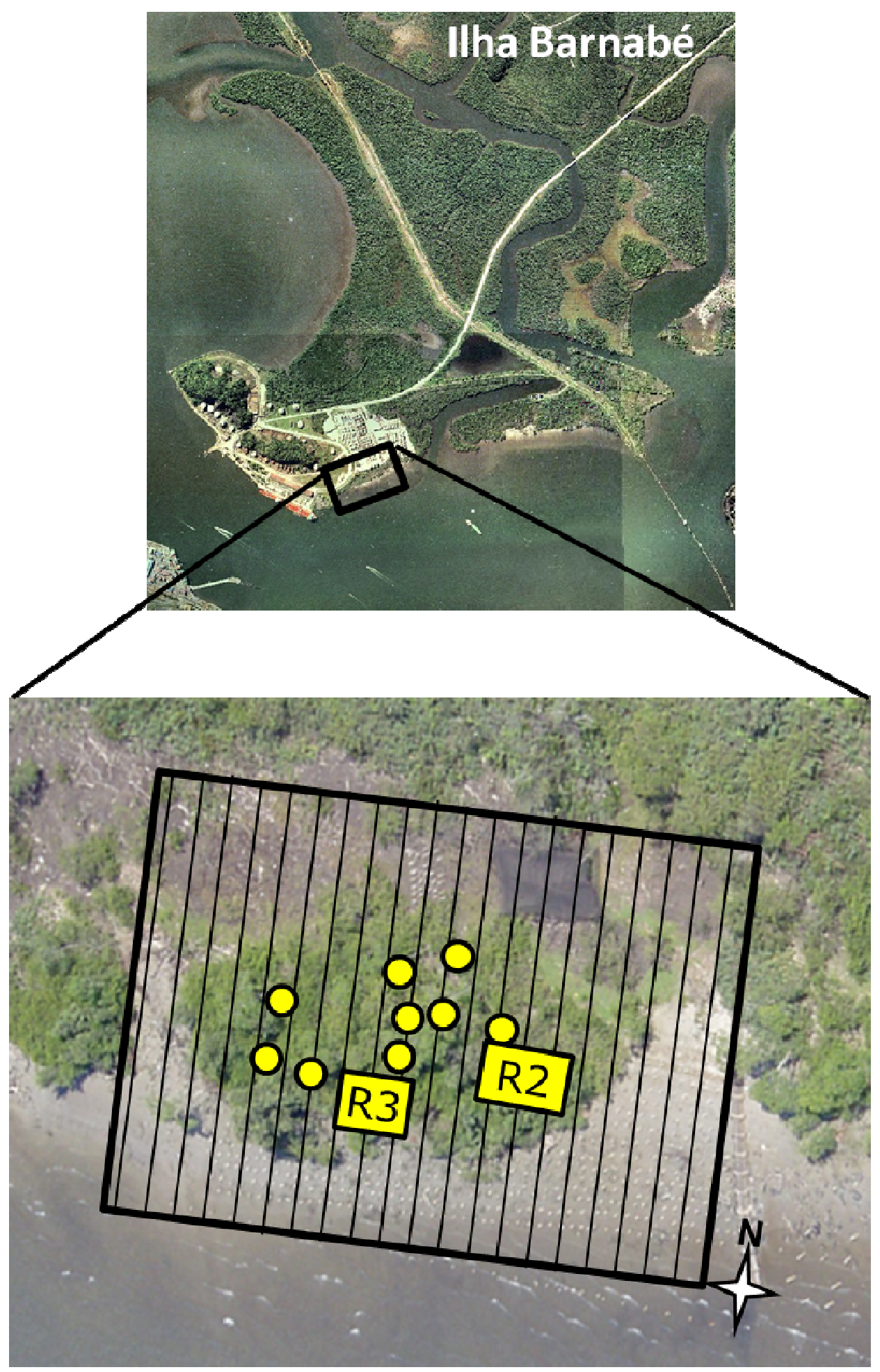

Figura 11 - Localização do bosque de mangue impactado pelo evento de 1998 (derramamento e combustão de DCPD) e dos experimentos realizados para o monitoramento da área: parcelas R2 e R3; cestas coletoras de serapilheira (círculo amarelos) e grade regular utilizada no levantamento microtopográfico. 


\section{2 - BOSQUES DE MANGUE DA ILHA BARNABÉ}

\subsection{1 - ANÁLISE MULTITEMPORAL DE FOTOGRAFIAS AÉREAS}

Foram utilizadas fotografias aéreas da região da Baixada Santista correspondentes aos sobrevôos da IBC-GERCA (1962 e 1972) e BASE (1994) pancromáticas na escala 1:25.000 e quatro fotografias aéreas de 2003 coloridas na escala de 1:10.000, fornecidas pelo Projeto Santos Digital, uma parceria da empresa Funcate com a prefeitura do município de Santos. As características do material fotográfico encontram-se resumidas abaixo (Tabela VI).

Tabela VI - Características das fotografias aéreas utilizadas.

\begin{tabular}{crlll}
\hline \multicolumn{1}{c}{ Ano } & Escala & Sobrevôo & Tipo de Foto & \multicolumn{1}{c}{ Acervo } \\
\hline 1962 & $1: 25.000$ & IBC-GERCA & pancromática & Geografia/USP \\
1972 & $1: 25.000$ & IBC-GERCA & pancromática & Geografia/USP \\
1994 & $1: 25.000$ & BASE & pancromática & Geografia/USP \\
2003 & $1: 10.000$ & Funcate & colorida & Funcate \\
\hline
\end{tabular}

Foi realizado escaneamento nas fotografias (1962, 1972 e 1994) em scanner AO modelo ScanPlus III (1200t), com resolução de 600 dpi. As fotografias aéreas de 2003 já foram adquiridas em formato digital.

Para efetuar o georeferenciamento das fotografias aéreas, utilizouse carta topográfica em formato digital adquirida no site do IBGE: (www.biblioteca.ibge.gov.br). A carta topográfica é do município de Santos com escala de 1:50.000, tendo sido elaborada pela empresa Terracota a partir de sobrevôo e cobertura de campo nos anos de 1972 e 1974 respectivamente e posteriormente restituída, desenhada e impressa pelo IBGE no ano de 1984. A numeração da carta é SF.23-Y-D-IV3/SG.23-V-B-I-1/MI-2794-3/MI-2815-1. 
Para o tratamento das fotografias aéreas foi utilizado o programa SPRING (Sistema de Processamento de Informações Geográficas - INPE), versão 4.3.1 para Windows. Esse SIG foi desenvolvido a partir de 1991, a fim de monitorar alterações naturais e antrópicas em regiões do Brasil (Câmara et al., 1996). O programa é composto por três módulos: IMPIMA, SPRING e SCARTA. No IMPIMA faz-se leitura de imagens de satélite e fotos aéreas em formato digital. O SPRING é o módulo principal de entrada, manipulação e transformação dos dados geográficos. Enquanto que no SCARTA faz-se a edição de carta e gera-se arquivos para impressão.

No IMPIMA, os arquivos das fotografias aéreas (formato TIFF) foram transformados em arquivos GRIB, assim como da carta topográfica do município de Santos.

Foi realizado tratamento digital das fotografias aéreas no SPRING. O registro da carta topográfica foi realizado no modo teclado. As fotografias aéreas foram registradas no modo tela, sendo que a do ano de 1962 foi registrada a partir da carta topográfica já registrada; 1972 a partir de 1962 já registrada; de 1994 a partir de 1972 já registrada e as de 2003 a partir de 1994 já registrada. Realizou-se um mosaico com as quatro fotografias aéreas de 2003 para poder englobar a Ilha Barnabé e seus arredores.

O retângulo envolvente do projeto, que inicialmente era referente à carta topográfica, foi reduzido a fim de detalhar a Ilha Barnabé. Os contrastes das fotografias aéreas de 1962, 1972 e 1994 foram tratados utilizando o realce linear.

Foram feitas composições coloridas das fotografias aéreas de datas diferentes, a fim de destacar: ampliações de áreas portuárias, construções de ferrovias e estradas, assim como os respectivos impactos causados nos manguezais da região em decorrência de tais construções e avaliar a capacidade de recomposição natural destes manguezais. 
O próximo passo adotado foi elaborar mapas temáticos para cada fotografia aérea, a fim de quantificar a área correspondente de manguezal em cada ano e dos respectivos impactos possíveis de serem observados. Para esta tarefa, utilizou-se a ferramenta de edição vetorial para cada ano, onde as áreas de manguezal, clareiras, aterros e demais impactos antrópicos foram reconhecidos e suas respectivas áreas delimitadas, formando polígonos. Cada polígono foi classificado posteriormente e a área correspondente de cada polígono foi mensurada em hectares (ha).

Para auxiliar esta delimitação e posterior classificação, foram realizadas saídas a campo em três datas diferentes entre os meses de agosto e outubro de 2006 a fim de reconhecer a área de estudo com auxílio de GPS. Esta verificação de campo foi fundamental para uma melhor compreensão de toda a extensão da Ilha Barnabé e para a delimitação posterior dos polígonos e de suas classificações.

O último passo realizado até o momento foi uma análise criteriosa de todas as cartas elaboradas e foram escolhidas algumas áreas onde está sendo realizada uma caracterização estrutural da vegetação, a fim de avaliar os diferentes estágios sucessionais que os bosques de mangue da Ilha Barnabé se encontram.

Estas áreas foram divididas em três grupos, de acordo com a análise das fotografias áreas e a nomenclatura dos estágios sucessionais está de acordo com o proposto por Jimenez et al. (1985) e utilizado por Fromard et al. (1998):

- Bosque em estágio maduro: Aquele que não sofreu nenhuma alteração desde 1962, ou seja, está presente em todas as fotografias (bosque com idade estimada superior a 45 anos); 
- Bosque em estágio final de desenvolvimento inicial: Aquele que iniciou processo de recomposição natural antes de 1994, ou seja, aparece em 1994 em estágios iniciais de recomposição (bosque com idade estimada entre 15-17 anos);

- Bosque em estágio inicial de desenvolvimento inicial: Aquele que só aparece em 2003, recompondo as clareiras presentes na fotografia de 1994 (bosque com idade estimada menor que 13 anos).

Cabe ressaltar que auxiliará esta análise o monitoramento que vem sendo realizado desde 2001 na área impactada por acidente com produto químico em 1998, onde o autor possui dados do bosque desde o período em que este apresentava entre 2 a 3 anos até o presente, onde o bosque possui idade estimada de 7 a 8 anos.

\subsection{2 - CARACTERIZAÇÃO ESTRUTURAL DOS BOSQUES EM DIFERENTES ESTÁGIOS SUCESSIONAIS}

Para realizar a caracterização estrutural dos bosques em diferentes estágios sucessionais, adotou-se metodologia padronizada por Cintrón \& Schaeffer-Novelli (1984) e Schaeffer-Novelli \& Cintrón (1986).

Foram delimitadas parcelas que variaram de $20 \mathrm{~m} \times 15 \mathrm{~m}$ à $7 \mathrm{~m} \times 7 \mathrm{~m}$, dependendo da densidade de indivíduos e da heterogeneidade estrutural do bosque. Em cada parcela, foi medido o diâmetro à altura do peito (dap) e altura total, da base da árvore à extremidade superior da copa, dos indivíduos com altura superior a $1 \mathrm{~m}$.

Com base nos dados obtidos em campo, é calculado para cada parcela: densidades de troncos vivos e mortos de cada espécie, área basal viva e morta, dominância em área basal de troncos vivos e mortos, dap médio e altura média do bosque. 
As medidas obtidas in situ são registradas em fichas de campo e posteriormente transferidas para planilha Excel para tratamento de dados estruturais de manguezal.

Para cálculo de área basal, utiliza-se a seguinte fórmula:

$$
A B=0,00007854(\text { dap })^{2}
$$

Onde: $A B=$ área basal $\left(\mathrm{m}^{2}\right)$

$$
\text { dap }=\text { diâmetro à altura do peito }(\mathrm{cm})
$$

A área basal do bosque é a soma das áreas basais de todos os troncos medidos por unidade de área. A área total da parcela $\left(e m \mathrm{~m}^{2}\right.$ ) é convertida em 1 hectare (ha). Esta medida é um ótimo índice do grau de desenvolvimento estrutural do bosque, pois está relacionada ao volume de madeira e biomassa, assim como indicadora de eventuais impactos ocorridos na estrutura, neste caso refletindo nos valores de área basal morta.

$\mathrm{A}$ área basal média $(\overline{\mathrm{AB}})$ é obtida dividindo-se o valor da área basal pelo número de troncos medidos:

$$
\overline{(A B)}=\frac{A B}{n}
$$

O diâmetro médio ( $\overline{\mathrm{dap}}$ ) de um bosque considera o diâmetro da árvore de área basal média. O valor do diâmetro médio é sempre maior do que a média dos diâmetros. O diâmetro médio é uma medida descritiva, permitindo comparações entre bosques de mangue. Calcula-se o diâmetro médio pela expressão:

$$
\overline{\text { dap }}=(\overline{A B})(12732,39)
$$


Onde: $A B=$ área basal;

$\mathrm{n}$ = número de indivíduos por hectare.

A comunidade pode ser descrita ainda, pela contribuição do número de espécies para o bosque, registrada em densidade:

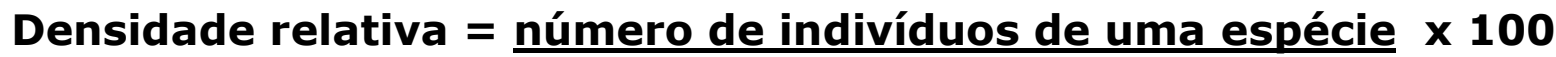
número total de indivíduos

Dominância relativa $=$ dominância de uma espécie $\times 100$ dominância total (AB)

O cálculo para a altura média é obtida a partir da média aritmética de todas as árvores vivas de cada parcela. 


\section{6 - RESULTADOS}

\section{1 - MONITORAMENTO DA ÁREA IMPACTADA PELO EVENTO DE}

1998

\subsection{1 - RECOMPOSIÇÃO NATURAL DA COBERTURA VEGETAL}

O monitoramento da recomposição natural da cobertura vegetal no bosque de mangue impactado pelo evento de 1998 foi realizado de fevereiro de 2002 até novembro de 2007, totalizando seis anos de estudos.

Nas Tabelas de VII a VIII estão plotados os dados de número de indivíduos vivos e a taxa de sobrevivência por espécie e total das parcelas R2 e R3, respectivamente. As Figuras 12 e 13 demonstram graficamente as respectivas taxas de sobrevivência.

Tabela VII - Número de indivíduos vivos e taxa de sobrevivência (\%) por espécie e total dos indivíduos da parcela R2.

\begin{tabular}{|c|c|c|c|c|c|c|}
\hline \multicolumn{7}{|c|}{ Parcela R2 } \\
\hline \multirow[b]{2}{*}{ Datas } & \multicolumn{2}{|c|}{ L. racemosa } & \multicolumn{2}{|c|}{ A. schaueriana } & \multicolumn{2}{|c|}{ Total } \\
\hline & $\begin{array}{c}\text { indivíduos } \\
\text { vivos }\end{array}$ & $\begin{array}{c}\text { taxa de } \\
\text { sobrev. (\%) }\end{array}$ & $\begin{array}{c}\text { indivíduos } \\
\text { vivos }\end{array}$ & $\begin{array}{c}\text { taxa de } \\
\text { sobrev. (\%) }\end{array}$ & $\begin{array}{c}\text { indivíduos } \\
\text { vivos }\end{array}$ & $\begin{array}{c}\text { taxa de } \\
\text { sobrev. (\%) }\end{array}$ \\
\hline $27 / 03 / 02$ & 54 & 100,00 & 14 & 100,00 & 68 & 100,00 \\
\hline $04 / 06 / 02$ & 51 & 94,44 & 14 & 100,00 & 65 & 95,59 \\
\hline $28 / 10 / 02$ & 44 & 81,48 & 14 & 100,00 & 58 & 85,29 \\
\hline $05 / 02 / 03$ & 37 & 68,52 & 12 & 85,71 & 49 & 72,06 \\
\hline $25 / 06 / 03$ & 33 & 61,11 & 12 & 85,71 & 45 & 66,18 \\
\hline $09 / 10 / 03$ & 21 & 38,89 & 12 & 85,71 & 33 & 48,53 \\
\hline $18 / 02 / 04$ & 18 & 33,33 & 12 & 85,71 & 30 & 44,12 \\
\hline $29 / 06 / 04$ & 17 & 31,48 & 12 & 85,71 & 29 & 42,65 \\
\hline $29 / 10 / 04$ & 17 & 31,48 & 12 & 85,71 & 29 & 42,65 \\
\hline $28 / 02 / 05$ & 17 & 31,48 & 12 & 85,71 & 29 & 42,65 \\
\hline $14 / 07 / 05$ & 15 & 27,78 & 11 & 78,57 & 26 & 38,24 \\
\hline $11 / 11 / 05$ & 15 & 27,78 & 11 & 78,57 & 26 & 38,24 \\
\hline $21 / 02 / 06$ & 15 & 27,78 & 10 & 71,43 & 25 & 36,76 \\
\hline $29 / 06 / 06$ & 15 & 27,78 & 7 & 50,00 & 22 & 32,35 \\
\hline $23 / 10 / 06$ & 15 & 27,78 & 6 & 42,86 & 21 & 30,88 \\
\hline $28 / 02 / 07$ & 14 & 25,93 & 6 & 42,86 & 20 & 29,14 \\
\hline $02 / 07 / 07$ & 13 & 24,07 & 6 & 42,86 & 19 & 27,94 \\
\hline $18 / 10 / 07$ & 12 & 22,22 & 6 & 42,86 & 18 & 26,47 \\
\hline
\end{tabular}


Tabela VIII - Número de indivíduos vivos e taxa de sobrevivência (\%) por espécie e total dos indivíduos da parcela R3.

Parcela R3

\begin{tabular}{|c|c|c|c|c|c|c|c|c|}
\hline \multirow[b]{2}{*}{ Datas } & \multicolumn{2}{|c|}{ L. racemosa } & \multicolumn{2}{|c|}{ A. schaueriana } & \multicolumn{2}{|c|}{ R. mangle } & \multicolumn{2}{|c|}{ Total } \\
\hline & $\begin{array}{l}\text { indivíduos } \\
\text { vivos }\end{array}$ & $\begin{array}{c}\text { taxa de } \\
\text { sobrev. } \\
(\%)\end{array}$ & $\begin{array}{c}\text { indivíduos } \\
\text { vivos }\end{array}$ & $\begin{array}{c}\text { taxa de } \\
\text { sobrev. } \\
(\%)\end{array}$ & $\begin{array}{l}\text { indivíduos } \\
\text { vivos }\end{array}$ & $\begin{array}{c}\text { taxa de } \\
\text { sobrev. } \\
(\%)\end{array}$ & $\begin{array}{l}\text { indivíduos } \\
\text { vivos }\end{array}$ & $\begin{array}{c}\text { taxa de } \\
\text { sobrev. } \\
(\%)\end{array}$ \\
\hline $28 / 02 / 02$ & 7 & 100,00 & 37 & 100,00 & 1 & 100,00 & 45 & 100,00 \\
\hline $04 / 06 / 02$ & 7 & 100,00 & 36 & 94,74 & 1 & 100,00 & 44 & 97,78 \\
\hline $28 / 10 / 02$ & 7 & 100,00 & 36 & 94,74 & 1 & 100,00 & 44 & 97,78 \\
\hline 05/02/03 & 7 & 100,00 & 36 & 94,74 & 1 & 100,00 & 44 & 97,78 \\
\hline $25 / 06 / 03$ & 6 & 85,71 & 36 & 94,74 & 1 & 100,00 & 43 & 95,56 \\
\hline $09 / 10 / 03$ & 6 & 85,71 & 35 & 92,11 & 1 & 100,00 & 42 & 93,33 \\
\hline $18 / 02 / 04$ & 6 & 85,71 & 35 & 92,11 & 1 & 100,00 & 42 & 93,33 \\
\hline $29 / 06 / 04$ & 6 & 85,71 & 34 & 89,47 & 1 & 100,00 & 41 & 91,11 \\
\hline $29 / 10 / 04$ & 6 & 85,71 & 34 & 89,47 & 1 & 100,00 & 41 & 91,11 \\
\hline $28 / 02 / 05$ & 6 & 85,71 & 34 & 89,47 & 0 & 0,00 & 40 & 88,89 \\
\hline $14 / 07 / 05$ & 6 & 85,71 & 33 & 86,84 & 0 & 0,00 & 39 & 86,67 \\
\hline $11 / 11 / 05$ & 6 & 85,71 & 32 & 84,21 & 0 & 0,00 & 38 & 84,44 \\
\hline $21 / 02 / 06$ & 6 & 85,71 & 30 & 78,95 & 0 & 0,00 & 36 & 80,00 \\
\hline $29 / 06 / 06$ & 6 & 85,71 & 29 & 76,32 & 0 & 0,00 & 35 & 77,78 \\
\hline $23 / 10 / 06$ & 5 & 71,43 & 22 & 57,89 & 0 & 0,00 & 27 & 60,00 \\
\hline $28 / 02 / 07$ & 4 & 57,14 & 21 & 55,25 & 0 & 0,00 & 25 & 55,56 \\
\hline 02/07/07 & 1 & 14,29 & 21 & 55,26 & 0 & 0,00 & 22 & 48,89 \\
\hline $18 / 10 / 07$ & 1 & 14,29 & 20 & 52,63 & 0 & 0,00 & 21 & 46,67 \\
\hline
\end{tabular}




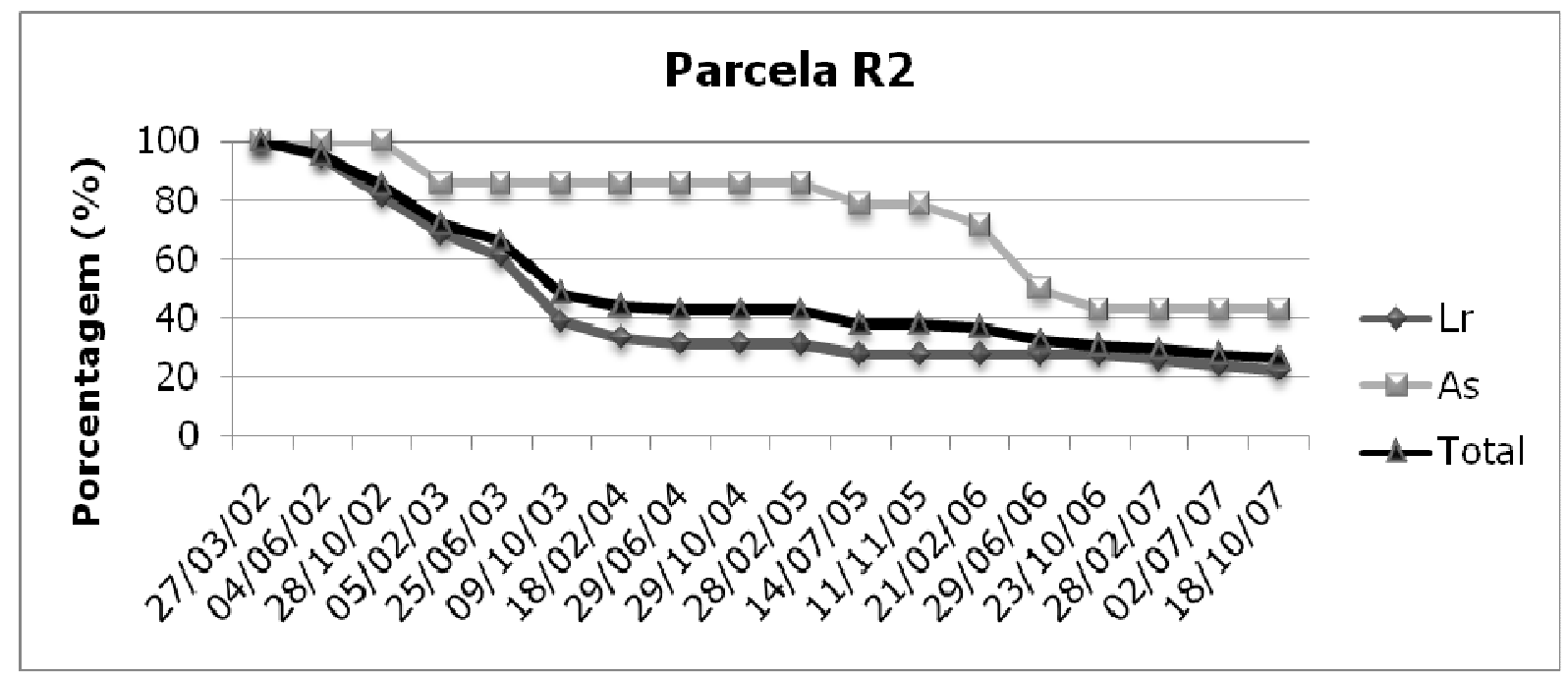

Figura 12 - Taxa de sobrevivência por espécie e total dos indivíduos da parcela R2.

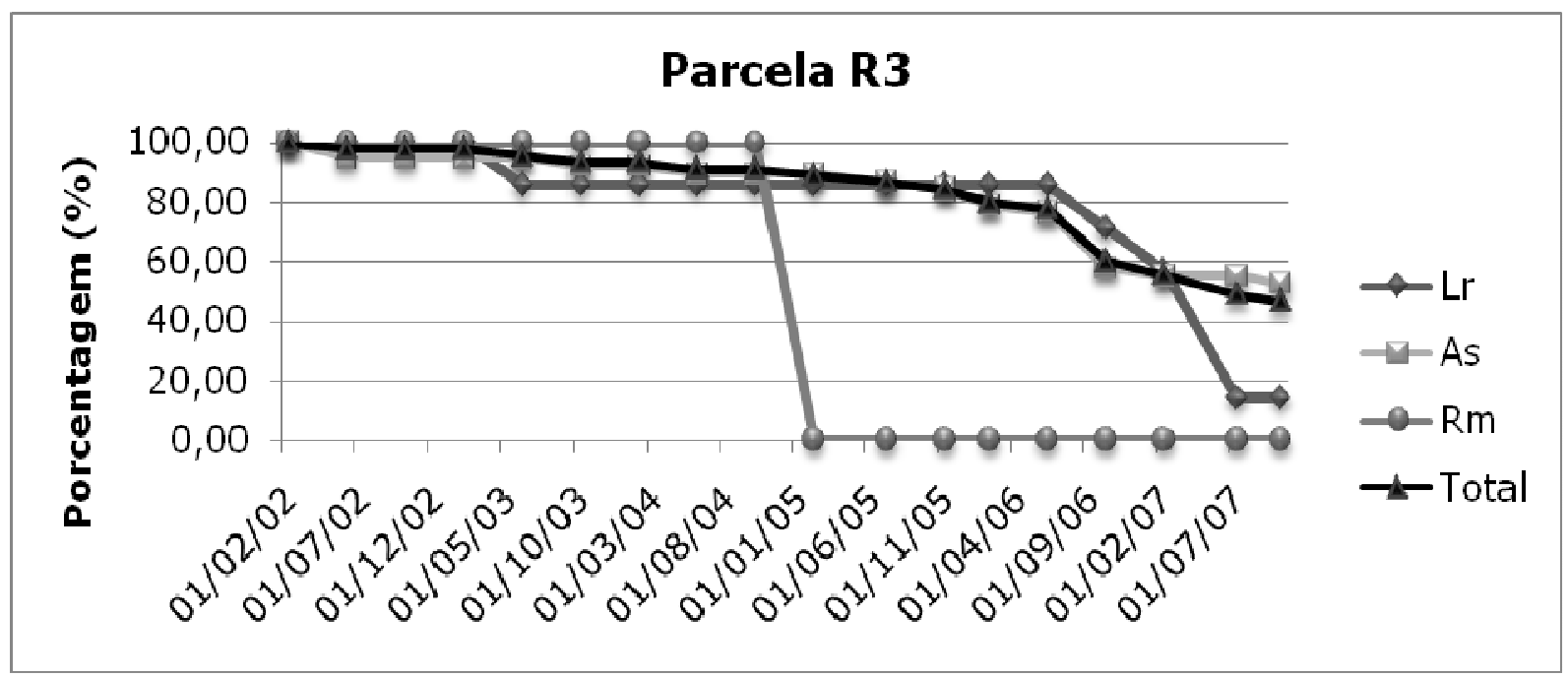

Figura 13 - Taxa de sobrevivência por espécie e total dos indivíduos da parcela R3. 
Podemos observar que a parcela R2 (Tabela VII e Figura 12) inicialmente era dominada por Laguncularia racemosa, com 54 indivíduos, além de 14 indivíduos de Avicennia schaueriana.

Nos dois primeiros anos de monitoramento (2002-2003), L. racemosa sofreu diminuição significativa na densidade dos indivíduos, acarretando queda na taxa de sobrevivência total. Esta tendência se manteve no ano seguinte (2004) de forma menos acentuada, porém no final deste ano a taxa de sobrevivência total da parcela já apresentava valores reduzidos, de apenas $42,65 \%$. Neste período, a parcela R2 que inicialmente era dominada por $L$. racemosa já apresentava número similar de indivíduos de ambas às espécies. Após este período a mortalidade de indivíduos da espécie $L$. racemosa diminuiu bruscamente, mantendo-se por três anos (2005-2007) com baixas taxas de mortalidade. Entre os anos 2006-2007, a espécie que mais contribuiu com a taxa de mortalidade foi $A$. schaueriana, porém de forma mais reduzida. Ao final do monitoramento a parcela R2 apresentou uma taxa de sobrevivência de 26,47\%, com apenas 12 indivíduos de L. racemosa e 6 de $A$. schaueriana.

Na parcela R3 (Tabela VIII e Figura 13), podemos observar que $A$. schaueriana era a espécie dominante no início do monitoramento e esta dominância se manteve durante os seis anos de estudo. Cabe destacar a presença de apenas um indivíduo de $R$. mangle que se manteve vivo na parcela até final de 2004. Esta parcela, quando comparada com a R2 apresentou uma menor taxa de mortalidade. Até metade de 2006, a taxa de sobrevivência era alta $(77,76 \%)$. No final deste mesmo ano ocorreu expressiva mortalidade de $A$. schaueriana e no ano de 2007 de $L$. racemosa, acarretando uma taxa de sobrevivência no final do monitoramento de $46,67 \%$ dos indivíduos, com apenas 1 indivíduo de $L$. racemosa e 20 de $A$. schaueriana.

Nas Tabelas IX e $X$ estão plotados os dados de altura média dos indivíduos e altura média dos indivíduos emergentes (cinco maiores 
indivíduos), taxa de crescimento ( $\left.\mathrm{mm} \cdot \mathrm{dia}^{-1}\right)$ e densidade de indivíduos por metro quadrado das parcelas R2 e R3. As Figuras 14 e 15 demonstram graficamente $o$ incremento na altura média dos indivíduos e dos indivíduos emergentes das respectivas parcelas.

Tabela IX - Altura média dos indivíduos e dos indivíduos emergentes, taxa de crescimento e densidade de indivíduos da parcelas R2.

\section{Parcela R2}

\begin{tabular}{|c|c|c|c|c|}
\hline Datas & $\begin{array}{c}\text { Altura } \\
\text { média (m) }\end{array}$ & $\begin{array}{l}\text { Altura média } \\
\text { emerg. }(m)\end{array}$ & $\begin{array}{c}\text { Taxa de cresc. } \\
\left(\mathrm{mm} \mathrm{dia}^{-1}\right)\end{array}$ & $\begin{array}{c}\text { Densidade } \\
\text { (ind. } \mathbf{m}^{2} \text { ) }\end{array}$ \\
\hline $27 / 03 / 02$ & 1,56 & 2,40 & $\#$ & 5,67 \\
\hline $04 / 06 / 02$ & 1,63 & 2,60 & 1,02 & 5,42 \\
\hline $28 / 10 / 02$ & 1,88 & 2,92 & 1,70 & 4,83 \\
\hline $05 / 02 / 03$ & 2,25 & 3,09 & 3,67 & 4,08 \\
\hline $25 / 06 / 03$ & 2,48 & 3,40 & 1,68 & 3,75 \\
\hline $09 / 10 / 03$ & 2,48 & 3,53 & 0,07 & 2,75 \\
\hline $18 / 02 / 04$ & 2,51 & 3,66 & 0,22 & 2,50 \\
\hline $29 / 06 / 04$ & 2,58 & 3,82 & 0,53 & 2,42 \\
\hline $29 / 10 / 04$ & 2,66 & 4,03 & 0,64 & 2,42 \\
\hline $28 / 02 / 05$ & 2,71 & 4,13 & 0,44 & 2,42 \\
\hline $14 / 07 / 05$ & 3,08 & 4,34 & 2,73 & 2,17 \\
\hline $11 / 11 / 05$ & 3,17 & 4,46 & 0,74 & 2,17 \\
\hline $21 / 02 / 06$ & 3,25 & 4,64 & 0,73 & 2,08 \\
\hline $29 / 06 / 06$ & 3,52 & 4,88 & 2,13 & 1,83 \\
\hline $23 / 10 / 06$ & 3,65 & 4,97 & 1,10 & 1,75 \\
\hline $28 / 02 / 07$ & 3,84 & 5,24 & 1,50 & 1,67 \\
\hline $02 / 07 / 07$ & 3,98 & 5,44 & 1,15 & 1,58 \\
\hline $18 / 10 / 07$ & 3,94 & 5,38 & $-0,42$ & 1,50 \\
\hline
\end{tabular}


Tabela X - Altura média dos indivíduos e dos indivíduos emergentes, taxa de crescimento e densidade de indivíduos da parcelas R3.

Parcela R3

\begin{tabular}{ccccc}
\hline Datas & $\begin{array}{c}\text { Altura } \\
\text { média }(\mathbf{m})\end{array}$ & $\begin{array}{c}\text { Altura média } \\
\text { emerg. }(\mathbf{m})\end{array}$ & $\begin{array}{c}\text { Taxa de cresc. } \\
(\mathbf{m m} / \mathbf{d i a})\end{array}$ & $\begin{array}{c}\text { Densidade } \\
\text { (ind. } \mathbf{~}^{\mathbf{}}\end{array}$ \\
\hline $\mathbf{2 8 / 0 2 / 0 2}$ & 1,88 & 3,07 & $\#$ & 7,50 \\
$\mathbf{0 4 / 0 6 / 0 2}$ & 1,96 & 3,34 & 0,77 & 7,33 \\
$\mathbf{2 8 / 1 0 / 0 2}$ & 2,03 & 3,60 & 0,48 & 7,33 \\
$\mathbf{0 5 / 0 2 / 0 3}$ & 1,95 & 3,57 & $-0,75$ & 7,33 \\
$\mathbf{2 5 / 0 6 / 0 3}$ & 2,03 & 4,03 & 0,57 & 7,17 \\
$\mathbf{0 9 / 1 0 / 0 3}$ & 2,12 & 4,21 & 0,81 & 7,00 \\
$\mathbf{1 8 / 0 2 / 0 4}$ & 2,09 & 4,02 & $-0,24$ & 7,00 \\
$\mathbf{2 9 / 0 6 / 0 4}$ & 2,15 & 4,36 & 0,48 & 6,83 \\
$\mathbf{2 9 / 1 0 / 0 4}$ & 2,16 & 4,27 & 0,09 & 6,83 \\
$\mathbf{2 8 / 0 2 / 0 5}$ & 2,23 & 4,50 & 0,61 & 6,67 \\
$\mathbf{1 4 / 0 7 / 0 5}$ & 2,35 & 4,54 & 0,83 & 6,50 \\
$\mathbf{1 1 / 1 1 / 0 5}$ & 2,41 & 4,76 & 0,54 & 6,33 \\
$\mathbf{2 1 / 0 2 / 0 6}$ & 2,42 & 4,92 & 0,06 & 6,00 \\
$\mathbf{2 9 / 0 6 / 0 6}$ & 2,47 & 5,10 & 0,38 & 5,83 \\
$\mathbf{2 3 / 1 0 / 0 6}$ & 2,76 & 5,16 & 2,58 & 4,50 \\
$\mathbf{2 8 / 0 2 / 0 7}$ & 2,86 & 5,32 & 0,74 & 4,17 \\
$\mathbf{0 2 / 0 7 / 0 7}$ & 2,85 & 5,56 & $-0,12$ & 3,67 \\
$\mathbf{1 8 / 1 0 / 0 7}$ & 2,85 & 5,62 & 0,06 & 3,50 \\
\hline
\end{tabular}




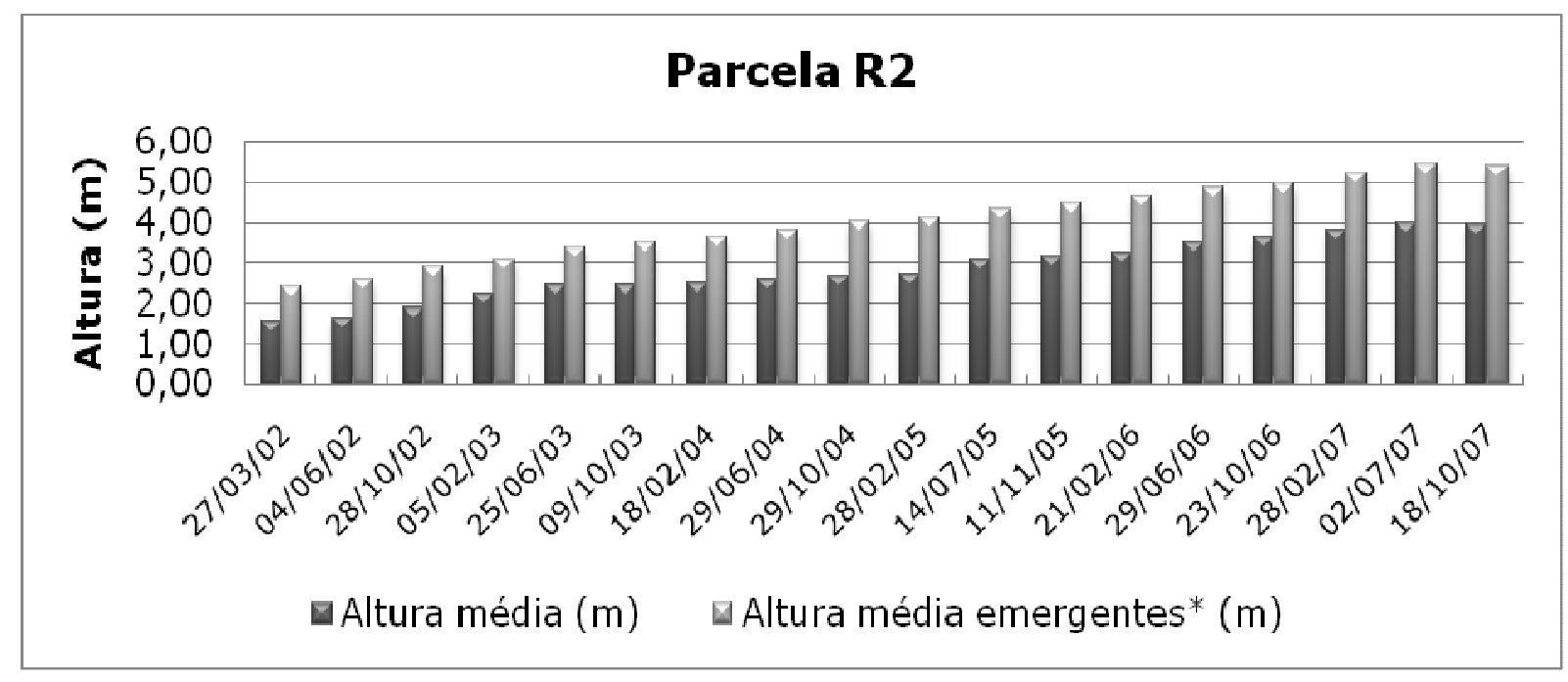

Figura 14 - Incremento na altura média dos indivíduos e dos indivíduos emergentes da parcela R2.

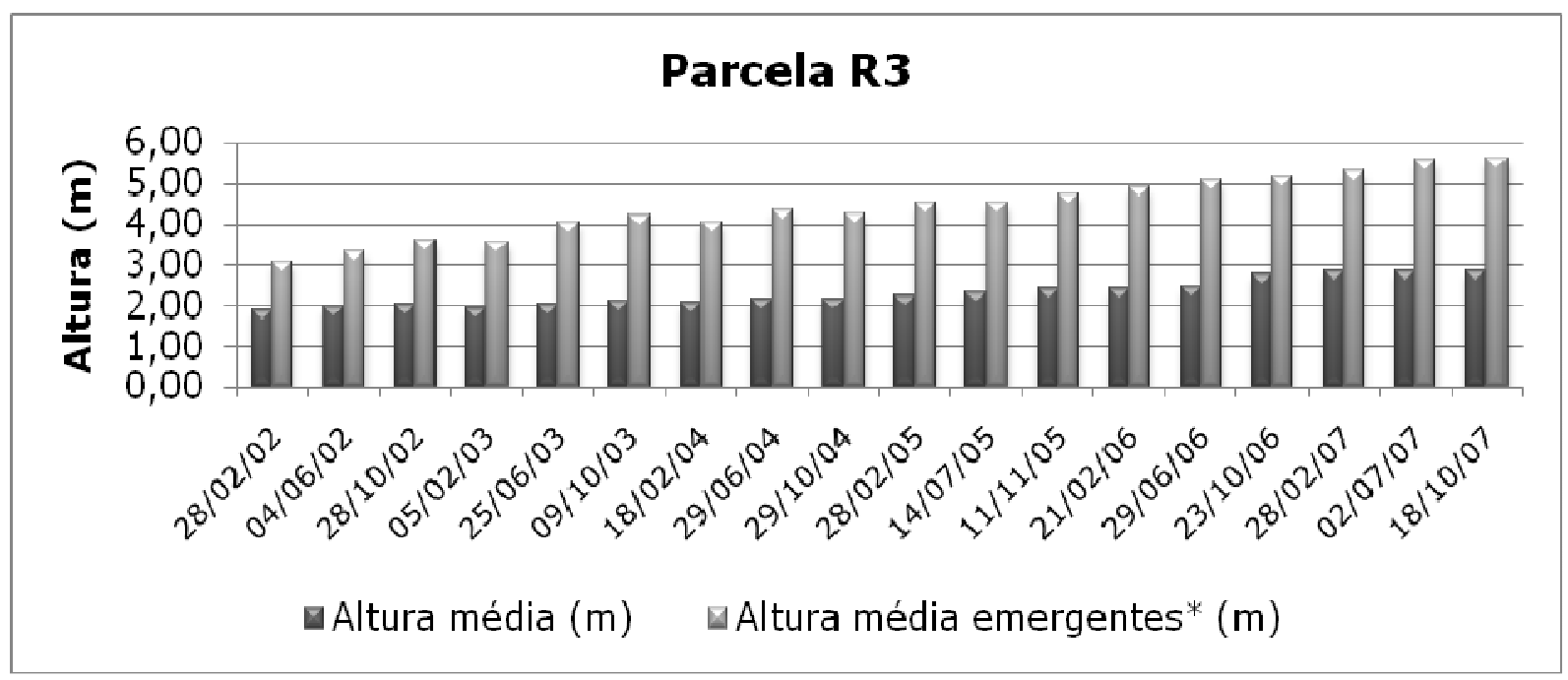

Figura 15 - Incremento na altura média dos indivíduos e dos indivíduos emergentes da parcela R3.

Analisando as Tabelas IX e X e as Figuras 14 e 15, observamos que durante o período de monitoramento, a parcela $\mathrm{R} 2$ teve um aumento na altura média dos indivíduos de 1,56 para 3,65 metros (234\%) e a parcela R3 de 1,88 para 2,76 metros (147\%). O incremento na altura média dos indivíduos emergentes foi de 2,40 para 4,97 metros (207\%) na parcela R2 e de 3,07 para 5,16 metros (168\%) na parcela R3. 
O maior crescimento na altura média dos indivíduos da parcela R2, comparado com a parcela R3, torna-se claro quando observamos os valores das taxas de crescimento de ambas as parcelas. Os maiores valores são encontrados na parcela R2, principalmente nos primeiros anos de monitoramento e a altura média teve um decréscimo (taxa de crescimento negativa) apenas no último período de estudo. A parcela R3, por sua vez, apresentou taxas de crescimento menores durante todo o monitoramento e apresentou uma maior ocorrência de períodos com taxa de crescimento negativa.

A densidade de indivíduos em ambas as parcelas vem diminuindo progressivamente nas parcelas $R 2$ (5,67 a 1,50 indivíduos. $\left.\mathrm{m}^{-2}\right)$ e R3 (7,50 a 3,50 indivíduos. $\mathrm{m}^{-2}$ ). Esta é uma característica comum em bosques em recomposição natural e em fase inicial de crescimento e possui forte correlação com o incremento na altura média dos indivíduos de ambas as parcelas (Figuras 16 e 17).

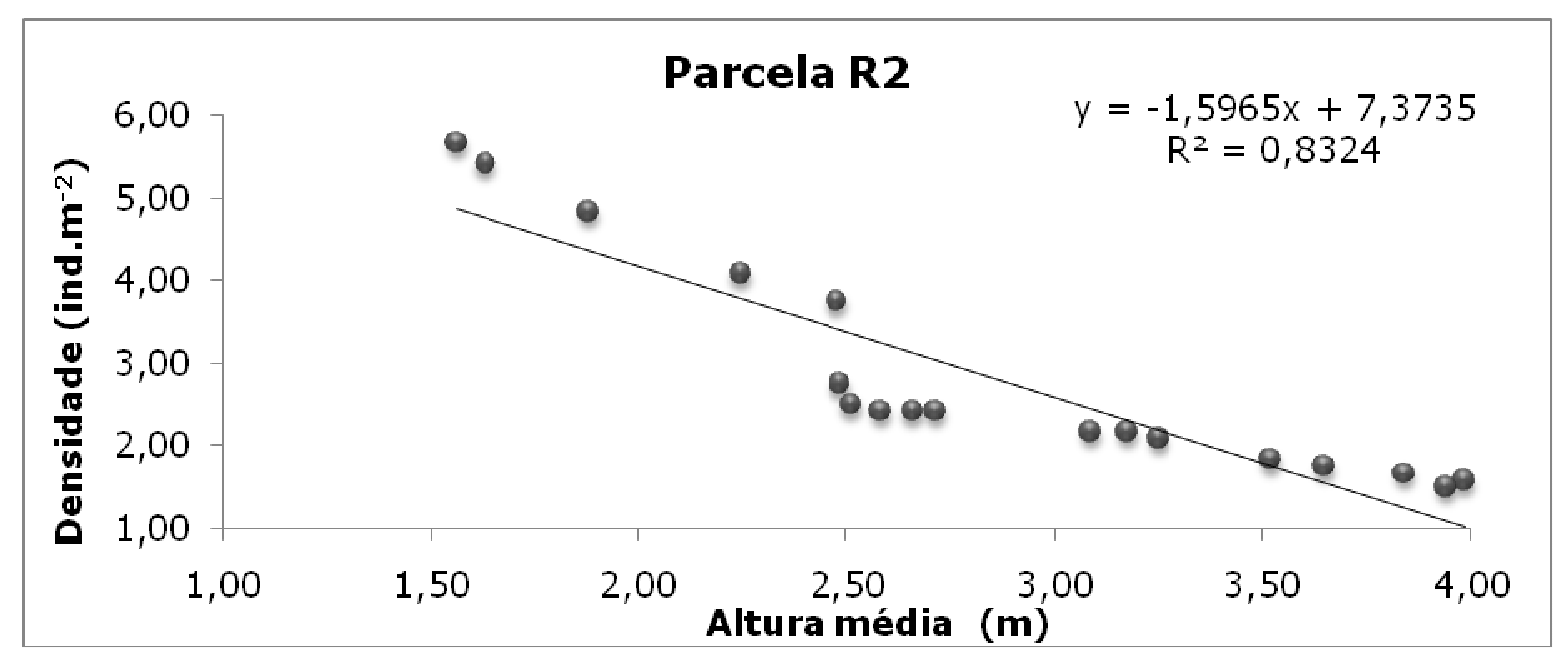

Figura 16 - Correlação entre incremento na altura média e a densidade de indivíduos da parcela R2. 


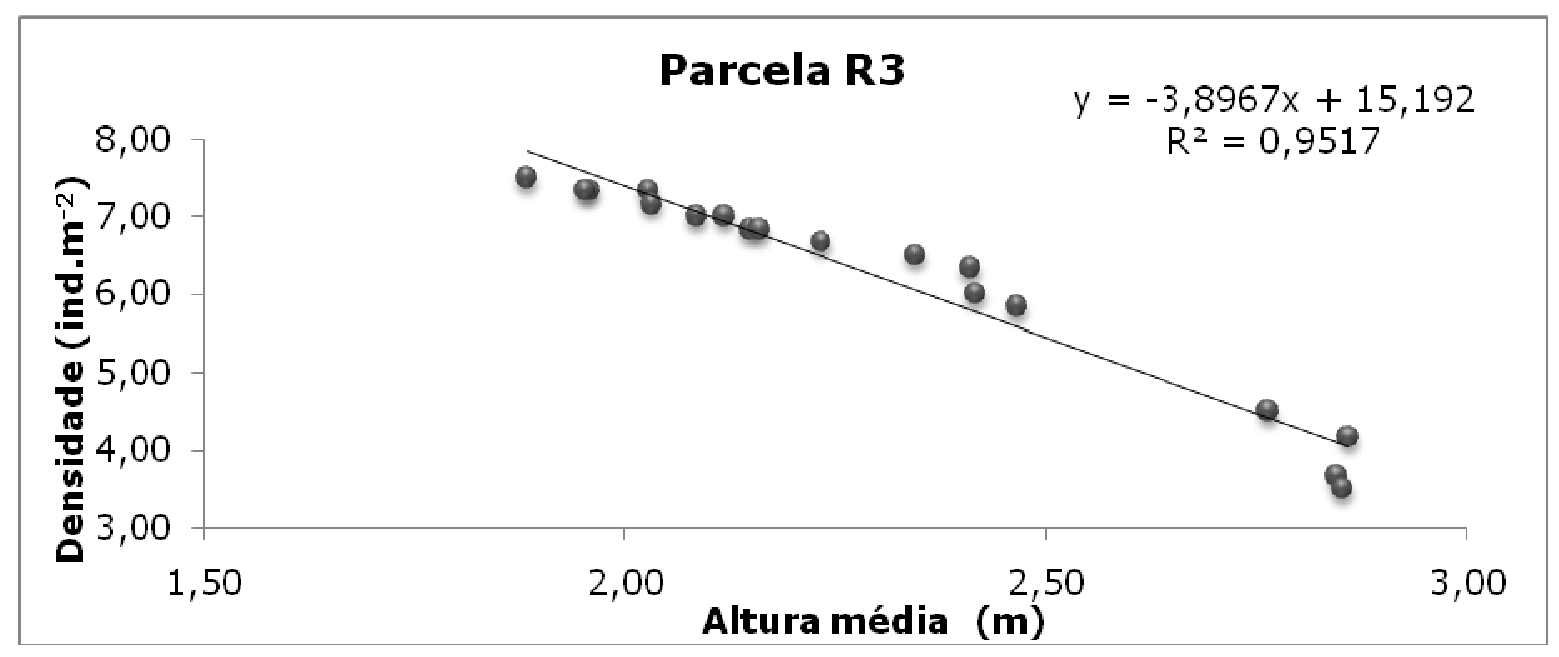

Figura 17 - Correlação entre incremento na altura média e a densidade de indivíduos da parcela R3.

\subsection{2 - PRODUÇÃO DE SERAPILHEIRA}

O monitoramento da produção de serapilheira do bosque de mangue impactado pelo evento de 1998 teve início em setembro de 2002 e término em agosto de 2007, completando desta forma cinco anos de estudo, sendo que o primeiro ano foi previamente analisado por Menghini (2004).

Uma característica marcante da produção de serapilheira no manguezal da Ilha Barnabé foi uma grande variabilidade dos dados obtidos a partir das cestas coletoras. Todas as frações constituintes da serapilheira (folhas, flores, propágulos/frutos, madeiras, estípulas e detritos não identificáveis) apresentaram valores elevados de desvio padrão, em alguns casos, superior ao da própria média (Tabelas XI a XVII). Esta constatação significa que muitas vezes os coeficientes de variação foram superiores a $100 \%$. Somente coeficientes abaixo de $10 \%$ representariam casos de baixa variabilidade. 
Tabelas XI - Estimativas das taxas mensais (fração total) de serapilheira do manguezal da Ilha Barnabé (médias e desvios padrões).

\begin{tabular}{|c|c|c|c|c|c|}
\hline \multicolumn{6}{|c|}{ Serapilheira (Fração Total) $\left(\mathrm{g} \cdot \mathrm{m}^{-2} \cdot \mathrm{dia}^{-1}\right)$} \\
\hline MÊS & ANO I & ANO II & ANO III & ANO IV & ANO V \\
\hline SETEMBRO & $0,65 \pm 0,31$ & $1,23 \pm 0,99$ & $1,82 \pm 2,10$ & $2,09 \pm 0,56$ & $2,22 \pm 0,56$ \\
\hline OUTUBRO & $0,62 \pm 0,30$ & $0,92 \pm 0,69$ & $1,53 \pm 1,65$ & $1,02 \pm 1,07$ & $1,66 \pm 0,62$ \\
\hline NOVEMBRO & $1,51 \pm 0,86$ & $1,21 \pm 0,53$ & $2,89 \pm 1,95$ & $1,68 \pm 1,82$ & $4,87 \pm 1,04$ \\
\hline DEZEMBRO & $3,10 \pm 1,79$ & $3,37 \pm 1,56$ & $2,05 \pm 1,16$ & $4,25 \pm 1,76$ & $4,75 \pm 2,26$ \\
\hline JANEIRO & $2,41 \pm 1,42$ & $3,42 \pm 1,25$ & $5,26 \pm 2,95$ & $3,34 \pm 1,06$ & $6,22 \pm 1,70$ \\
\hline FEVEREIRO & $3,35 \pm 2,47$ & $3,17 \pm 1,81$ & $3,57 \pm 1,73$ & $3,72 \pm 1,25$ & $5,92 \pm 3,35$ \\
\hline MARÇO & $7,36 \pm 6,48$ & $2,99 \pm 2,51$ & $6,10 \pm 6,33$ & $8,64 \pm 3,41$ & $11,68 \pm 8,02$ \\
\hline ABRIL & $4,38 \pm 4,57$ & $3,22 \pm 2,10$ & $9,14 \pm 7,68$ & $4,98 \pm 3,53$ & $5,31 \pm 3,14$ \\
\hline MAIO & $2,41 \pm 1,70$ & $3,29 \pm 2,56$ & $3,23 \pm 2,11$ & $1,80 \pm 0,65$ & $4,07 \pm 4,11$ \\
\hline JUNHO & $2,17 \pm 1,94$ & $1,84 \pm 1,37$ & $2,67 \pm 1,13$ & $1,85 \pm 2,10$ & $2,56 \pm 2,16$ \\
\hline JULHO & $0,84 \pm 0,52$ & $1,22 \pm 0,83$ & $1,44 \pm 0,67$ & $5,07 \pm 3,05$ & $1,74 \pm 0,74$ \\
\hline AGOSTO & $1,48 \pm 1,03$ & $2,55 \pm 5,02$ & $2,51 \pm 1,26$ & $7,29 \pm 15,84$ & $7,30 \pm 3,11$ \\
\hline$\left(\mathrm{g} \cdot \mathrm{m}^{-2} \cdot \mathrm{dia}^{-1}\right)$ & $2,52 \pm 1,91$ & $2,37 \pm 1,00$ & $3,52 \pm 2,27$ & $3,81 \pm 2,37$ & $4,86 \pm 2,84$ \\
\hline ANUAL (ton. ha ${ }^{-1} \cdot$ ano $^{-1}$ ) & 9,00 & 8,56 & 12,76 & 13,96 & 17,70 \\
\hline
\end{tabular}

Tabelas XII - Estimativas das taxas mensais (fração folhas) de serapilheira do manguezal da Ilha Barnabé (médias e desvios padrões).

\begin{tabular}{ccccccc}
\hline \multicolumn{7}{c}{ Serapilheira (Fração Folhas) $\left(\mathrm{g} \cdot \mathrm{m}^{-2} \cdot\right.$ dia $\left.^{-1}\right)$} \\
\hline MÊS & ANO I & ANO II & ANO III & ANO IV & ANO V \\
SETEMBRO & $0,18 \pm 0,21$ & $0,39 \pm 0,71$ & $0,27 \pm 0,33$ & $0,45 \pm 0,59$ & $0,62 \pm 0,67$ \\
OUTUBRO & $0,17 \pm 0,18$ & $0,27 \pm 0,47$ & $0,26 \pm 0,28$ & $0,30 \pm 0,67$ & $0,42 \pm 0,44$ \\
NOVEMBRO & $0,41 \pm 0,45$ & $0,34 \pm 0,43$ & $0,69 \pm 0,89$ & $0,29 \pm 0,31$ & $1,42 \pm 1,41$ \\
DEZEMBRO & $0,80 \pm 1,19$ & $0,97 \pm 1,27$ & $0,57 \pm 0,79$ & $1,24 \pm 1,65$ & $1,69 \pm 2,05$ \\
JANEIRO & $0,47 \pm 0,75$ & $0,85 \pm 0,97$ & $1,47 \pm 2,16$ & $0,97 \pm 1,30$ & $1,06 \pm 1,11$ \\
FEVEREIRO & $0,55 \pm 0,79$ & $0,91 \pm 1,41$ & $0,99 \pm 1,33$ & $0,99 \pm 1,26$ & $0,47 \pm 0,45$ \\
MARÇO & $0,38 \pm 0,42$ & $0,57 \pm 0,82$ & $0,82 \pm 0,97$ & $1,12 \pm 1,29$ & $0,40 \pm 0,39$ \\
ABRIL & $0,20 \pm 0,36$ & $0,44 \pm 0,57$ & $0,52 \pm 0,60$ & $0,66 \pm 0,71$ & $0,64 \pm 0,68$ \\
MAIO & $0,20 \pm 0,25$ & $0,28 \pm 0,36$ & $0,39 \pm 0,48$ & $0,40 \pm 0,42$ & $0,47 \pm 0,45$ \\
JUNHO & $0,35 \pm 0,39$ & $0,19 \pm 0,24$ & $0,57 \pm 0,67$ & $0,30 \pm 0,37$ & $0,33 \pm 0,36$ \\
JULHO & $0,22 \pm 0,28$ & $0,22 \pm 0,32$ & $0,41 \pm 0,45$ & $0,73 \pm 0,80$ & $0,40 \pm 0,39$ \\
AGOSTO & $0,42 \pm 0,71$ & $0,13 \pm 0,14$ & $0,61 \pm 0,78$ & $0,49 \pm 0,56$ & $1,44 \pm 1,92$ \\
\hline MÉDIA $\quad\left(\right.$ g.m ${ }^{-2} \cdot$ dia $^{-1}$ ) & $0,36 \pm 0,19$ & $0,46 \pm 0,29$ & $0,63 \pm 0,34$ & $0,66 \pm 0,34$ & $0,78 \pm 0,49$ \\
\hline
\end{tabular}


Tabelas XIII - Estimativas das taxas mensais (fração flores) de serapilheira do manguezal da Ilha Barnabé (médias e desvios padrões).

\begin{tabular}{|c|c|c|c|c|c|}
\hline \multicolumn{6}{|c|}{ Serapilheira (Fração Flores) $\left(\mathrm{g} \cdot \mathrm{m}^{-2} \cdot \mathrm{dia}^{-1}\right)$} \\
\hline MÊS & ANO I & ANO II & ANO III & ANO IV & ANO V \\
\hline SETEMBRO & $0,00 \pm 0,00$ & $0,00 \pm 0,00$ & $0,01 \pm 0,02$ & $0,00 \pm 0,00$ & $0,00 \pm 0,01$ \\
\hline OUTUBRO & $0,00 \pm 0,00$ & $0,00 \pm 0,01$ & $0,00 \pm 0,00$ & $0,00 \pm 0,02$ & $0,01 \pm 0,02$ \\
\hline NOVEMBRO & $0,00 \pm 0,00$ & $0,00 \pm 0,01$ & $0,00 \pm 0,00$ & $0,00 \pm 0,00$ & $0,01 \pm 0,03$ \\
\hline DEZEMBRO & $0,05 \pm 0,11$ & $0,02 \pm 0,07$ & $0,01 \pm 0,03$ & $0,03 \pm 0,07$ & $0,05 \pm 0,13$ \\
\hline JANEIRO & $0,11 \pm 0,57$ & $0,08 \pm 0,17$ & $0,06 \pm 0,14$ & $0,05 \pm 0,10$ & $0,08 \pm 0,14$ \\
\hline FEVEREIRO & $0,02 \pm 0,04$ & $0,04 \pm 0,07$ & $0,04 \pm 0,08$ & $0,03 \pm 0,09$ & $0,04 \pm 0,17$ \\
\hline MARÇO & $0,01 \pm 0,03$ & $0,03 \pm 0,06$ & $0,02 \pm 0,05$ & $0,05 \pm 0,19$ & $0,02 \pm 0,09$ \\
\hline ABRIL & $0,01 \pm 0,02$ & $0,02 \pm 0,05$ & $0,00 \pm 0,01$ & $0,02 \pm 0,08$ & $0,00 \pm 0,00$ \\
\hline MAIO & $0,00 \pm 0,01$ & $0,02 \pm 0,05$ & $0,00 \pm 0,01$ & $0,00 \pm 0,01$ & $0,00 \pm 0,00$ \\
\hline JUNHO & $0,00 \pm 0,01$ & $0,01 \pm 0,02$ & $0,00 \pm 0,01$ & $0,00 \pm 0,01$ & $0,00 \pm 0,00$ \\
\hline JULHO & $0,00 \pm 0,00$ & $0,00 \pm 0,01$ & $0,00 \pm 0,00$ & $0,01 \pm 0,02$ & $0,00 \pm 0,00$ \\
\hline AGOSTO & $0,00 \pm 0,00$ & $0,00 \pm 0,00$ & $0,00 \pm 0,00$ & $0,01 \pm 0,02$ & $0,00 \pm 0,01$ \\
\hline$\left(\mathrm{g} \cdot \mathrm{m}^{-2} \cdot \mathrm{dia}^{-1}\right)$ & $0,02 \pm 0,03$ & $0,02 \pm 0,02$ & $0,01 \pm 0,02$ & $0,02 \pm 0,02$ & $0,02 \pm 0,03$ \\
\hline
\end{tabular}

Tabelas XIV - Estimativas das taxas mensais (fração propágulos/frutos) de serapilheira do manguezal da Ilha Barnabé (médias e desvios padrões).

\begin{tabular}{cccccccc}
\hline \multicolumn{7}{c}{ Serapilheira (Fração Propágulos/Frutos) $\left(\mathrm{g} \cdot \mathrm{m}^{-2}\right.$. dia $\left.^{-1}\right)$} \\
\hline MÊS & ANO I & ANO II & ANO III & ANO IV & ANO V \\
SETEMBRO & 0,01 & $\pm 0,03$ & $0,00 \pm 0,00$ & $0,25 \pm 1,17$ & $0,01 \pm 0,04$ & $0,04 \pm 0,13$ \\
OUTUBRO & $0,01 \pm 0,06$ & $0,01 \pm 0,07$ & $0,19 \pm 0,86$ & $0,00 \pm 0,01$ & $0,06 \pm 0,24$ \\
NOVEMBRO & $0,03 \pm 0,45$ & $0,01 \pm 0,04$ & $0,08 \pm 0,33$ & $0,21 \pm 0,94$ & $0,06 \pm 0,17$ \\
DEZEMBRO & $0,78 \pm 1,20$ & $0,00 \pm 0,00$ & $0,06 \pm 0,18$ & $0,01 \pm 0,02$ & $0,15 \pm 0,54$ \\
JANEIRO & $0,15 \pm 0,53$ & $0,00 \pm 0,02$ & $0,07 \pm 0,26$ & $0,02 \pm 0,03$ & $0,09 \pm 0,29$ \\
FEVEREIRO & $0,39 \pm 1,05$ & $0,05 \pm 0,17$ & $0,09 \pm 0,25$ & $0,12 \pm 0,24$ & $0,86 \pm 2,25$ \\
MARÇO & $1,84 \pm 3,82$ & $0,33 \pm 0,97$ & $1,09 \pm 3,10$ & $1,51 \pm 2,67$ & $2,69 \pm 4,65$ \\
ABRIL & $1,20 \pm 2,62$ & $0,56 \pm 1,00$ & $2,01 \pm 4,15$ & $0,55 \pm 1,24$ & $1,03 \pm 2,14$ \\
MAIO & $0,46 \pm 1,09$ & $0,69 \pm 1,57$ & $0,60 \pm 1,39$ & $0,10 \pm 0,32$ & $0,72 \pm 1,95$ \\
JUNHO & $0,04 \pm 0,10$ & $0,35 \pm 0,79$ & $0,19 \pm 0,35$ & $0,25 \pm 1,07$ & $0,25 \pm 1,14$ \\
JULHO & $0,04 \pm 0,12$ & $0,15 \pm 0,38$ & $0,02 \pm 0,12$ & $0,36 \pm 1,42$ & $0,05 \pm 0,27$ \\
AGOSTO & $0,02 \pm 0,05$ & $0,11 \pm 0,47$ & $0,01 \pm 0,04$ & $0,11 \pm 0,49$ & $0,03 \pm 0,06$ \\
\hline MÉDIA $\quad$ (g.m $^{-2} \cdot$ dia $^{-1}$ ) & 0,41 & $\pm 0,59$ & $0,19 \pm 0,24$ & $0,39 \pm 0,60$ & $0,27 \pm 0,42$ & $0,50 \pm 0,78$ \\
\hline
\end{tabular}


Tabelas XV - Estimativas das taxas mensais (fração madeiras) de serapilheira do manguezal da Ilha Barnabé (médias e desvios padrões).

\begin{tabular}{ccccccc}
\hline \multicolumn{7}{c}{ Serapilheira (Fração Madeiras) $\left(\mathrm{g} . \mathrm{m}^{-2} \cdot\right.$ dia $\left.^{-1}\right)$} \\
\hline MÊS & ANO I & ANO II & ANO III & ANO IV & ANO V \\
SETEMBRO & $0,02 \pm 0,02$ & $0,01 \pm 0,02$ & $0,18 \pm 0,30$ & $0,59 \pm 0,71$ & $0,16 \pm 0,12$ \\
OUTUBRO & $0,03 \pm 0,03$ & $0,01 \pm 0,01$ & $0,10 \pm 0,18$ & $0,03 \pm 0,06$ & $0,12 \pm 0,09$ \\
NOVEMBRO & $0,11 \pm 0,16$ & $0,08 \pm 0,07$ & $0,42 \pm 0,73$ & $0,11 \pm 0,20$ & $0,29 \pm 0,27$ \\
DEZEMBRO & $0,12 \pm 0,09$ & $0,26 \pm 0,40$ & $0,04 \pm 0,04$ & $0,29 \pm 0,39$ & $0,13 \pm 0,12$ \\
JANEIRO & $0,19 \pm 0,41$ & $0,50 \pm 1,09$ & $0,30 \pm 0,62$ & $0,08 \pm 0,06$ & $0,45 \pm 0,43$ \\
FEVEREIRO & $0,38 \pm 0,58$ & $0,04 \pm 0,03$ & $0,12 \pm 0,14$ & $0,12 \pm 0,12$ & $0,38 \pm 0,43$ \\
MARÇO & $0,59 \pm 1,47$ & $0,12 \pm 0,10$ & $0,24 \pm 0,32$ & $0,43 \pm 0,45$ & $0,29 \pm 0,20$ \\
ABRIL & $0,13 \pm 0,09$ & $0,10 \pm 0,07$ & $0,88 \pm 2,07$ & $1,10 \pm 1,85$ & $0,23 \pm 0,14$ \\
MAIO & $0,36 \pm 0,78$ & $0,23 \pm 0,15$ & $0,10 \pm 0,07$ & $0,19 \pm 0,26$ & $0,42 \pm 0,33$ \\
JUNHO & $0,92 \pm 2,07$ & $0,16 \pm 0,10$ & $0,14 \pm 0,22$ & $0,12 \pm 0,11$ & $0,74 \pm 1,15$ \\
JULHO & $0,02 \pm 0,02$ & $0,06 \pm 0,04$ & $0,05 \pm 0,06$ & $1,64 \pm 2,08$ & $0,30 \pm 0,26$ \\
AGOSTO & $0,13 \pm 0,27$ & $1,77 \pm 5,16$ & $0,50 \pm 0,48$ & $5,41 \pm 15,98$ & $2,71 \pm 1,84$ \\
\hline MÉDIA $\quad\left(\right.$ g.m ${ }^{-2}$.dia $\left.{ }^{-1}\right)$ & 0,25 & $\pm 0,27$ & $0,28 \pm 0,49$ & $0,26 \pm 0,24$ & $0,84 \pm 1,52$ & $0,52 \pm 0,71$ \\
\hline
\end{tabular}

Tabelas XVI - Estimativas das taxas mensais (fração estípulas) de serapilheira do manguezal da Ilha Barnabé (médias e desvios padrões).

\begin{tabular}{ccccccc}
\hline \multicolumn{7}{c}{ Serapilheira (Fração Estípulas) $\left(\mathrm{g} \cdot \mathrm{m}^{-2} \cdot\right.$ dia $\left.^{-1}\right)$} \\
\hline MÊS & ANO I & ANO II & ANO III & ANO IV & ANO V \\
SETEMBRO & $0,03 \pm 0,04$ & $0,03 \pm 0,06$ & $0,04 \pm 0,06$ & $0,03 \pm 0,04$ & $0,02 \pm 0,04$ \\
OUTUBRO & $0,02 \pm 0,04$ & $0,03 \pm 0,06$ & $0,03 \pm 0,06$ & $0,03 \pm 0,07$ & $0,03 \pm 0,06$ \\
NOVEMBRO & $0,04 \pm 0,06$ & $0,05 \pm 0,10$ & $0,04 \pm 0,07$ & $0,04 \pm 0,07$ & $0,06 \pm 0,11$ \\
DEZEMBRO & $0,03 \pm 0,06$ & $0,06 \pm 0,11$ & $0,04 \pm 0,08$ & $0,05 \pm 0,09$ & $0,04 \pm 0,08$ \\
JANEIRO & $0,02 \pm 0,04$ & $0,06 \pm 0,11$ & $0,05 \pm 0,08$ & $0,05 \pm 0,09$ & $0,04 \pm 0,07$ \\
FEVEREIRO & $0,02 \pm 0,03$ & $0,09 \pm 0,18$ & $0,03 \pm 0,06$ & $0,09 \pm 0,16$ & $0,02 \pm 0,03$ \\
MARÇO & $0,03 \pm 0,04$ & $0,06 \pm 0,11$ & $0,03 \pm 0,05$ & $0,08 \pm 0,14$ & $0,03 \pm 0,04$ \\
ABRIL & $0,02 \pm 0,02$ & $0,06 \pm 0,11$ & $0,03 \pm 0,05$ & $0,08 \pm 0,13$ & $0,03 \pm 0,05$ \\
MAIO & $0,04 \pm 0,08$ & $0,06 \pm 0,10$ & $0,03 \pm 0,06$ & $0,05 \pm 0,09$ & $0,04 \pm 0,07$ \\
JUNHO & $0,03 \pm 0,04$ & $0,02 \pm 0,03$ & $0,04 \pm 0,07$ & $0,04 \pm 0,07$ & $0,03 \pm 0,05$ \\
JULHO & $0,02 \pm 0,05$ & $0,04 \pm 0,08$ & $0,03 \pm 0,06$ & $0,04 \pm 0,06$ & $0,05 \pm 0,08$ \\
AGOSTO & $0,02 \pm 0,03$ & $0,03 \pm 0,05$ & $0,03 \pm 0,05$ & $0,03 \pm 0,05$ & $0,02 \pm 0,03$ \\
\hline MÉDIA $\quad$ g.m $^{-2}$. diaa $\left.^{-1}\right)$ & $0,03 \pm 0,01$ & $0,05 \pm 0,02$ & $0,04 \pm 0,01$ & $0,05 \pm 0,02$ & $0,03 \pm 0,01$ \\
\hline
\end{tabular}


Tabela XVII - Estimativas das taxas mensais (fração detritos) de serapilheira do manguezal da Ilha Barnabé (médias e desvios padrões).

\begin{tabular}{ccccccc}
\hline \multicolumn{7}{c}{ Serapilheira (Fração Detritos) $\left(\mathrm{g} \cdot \mathrm{m}^{-2} \cdot \mathrm{dia}^{-1}\right)$} \\
\hline MÊS & ANO I & ANO II & ANO III & ANO IV & ANO V \\
SETEMBRO & $0,03 \pm 0,02$ & $0,00 \pm 0,00$ & $0,02 \pm 0,02$ & $0,08 \pm 0,04$ & $0,06 \pm 0,02$ \\
OUTUBRO & $0,03 \pm 0,02$ & $0,01 \pm 0,01$ & $0,02 \pm 0,01$ & $0,02 \pm 0,01$ & $0,04 \pm 0,02$ \\
NOVEMBRO & $0,05 \pm 0,02$ & $0,02 \pm 0,01$ & $0,11 \pm 0,09$ & $0,02 \pm 0,01$ & $0,06 \pm 0,01$ \\
DEZEMBRO & $0,07 \pm 0,04$ & $0,08 \pm 0,05$ & $0,06 \pm 0,03$ & $0,08 \pm 0,05$ & $0,14 \pm 0,10$ \\
JANEIRO & $0,02 \pm 0,02$ & $0,07 \pm 0,04$ & $0,10 \pm 0,07$ & $0,08 \pm 0,04$ & $0,17 \pm 0,11$ \\
FEVEREIRO & $0,05 \pm 0,03$ & $0,04 \pm 0,03$ & $0,07 \pm 0,04$ & $0,09 \pm 0,04$ & $0,07 \pm 0,04$ \\
MARÇO & $0,02 \pm 0,01$ & $0,03 \pm 0,03$ & $0,03 \pm 0,02$ & $0,09 \pm 0,05$ & $0,04 \pm 0,04$ \\
ABRIL & $0,01 \pm 0,01$ & $0,02 \pm 0,02$ & $0,65 \pm 1,81$ & $0,11 \pm 0,07$ & $0,05 \pm 0,02$ \\
MAIO & $0,02 \pm 0,03$ & $0,02 \pm 0,01$ & $0,12 \pm 0,28$ & $0,04 \pm 0,02$ & $0,05 \pm 0,04$ \\
JUNHO & $0,04 \pm 0,02$ & $0,02 \pm 0,02$ & $0,21 \pm 0,38$ & $0,03 \pm 0,02$ & $0,04 \pm 0,05$ \\
JULHO & $0,01 \pm 0,01$ & $0,02 \pm 0,01$ & $0,07 \pm 0,15$ & $0,10 \pm 0,05$ & $0,04 \pm 0,03$ \\
AGOSTO & $0,02 \pm 0,05$ & $0,01 \pm 0,01$ & $0,10 \pm 0,13$ & $0,04 \pm 0,06$ & $0,16 \pm 0,07$ \\
\hline MÉDIA $\left(\mathrm{g} \cdot \mathrm{m}^{-2} \cdot\right.$ dia $\left.^{-1}\right)$ & $0,03 \pm 0,02$ & $0,03 \pm 0,02$ & $0,13 \pm 0,17$ & $0,07 \pm 0,03$ & $0,08 \pm 0,05$ \\
\hline
\end{tabular}




\subsubsection{1 - VARIAÇÃO INTERANUAL}

Observamos ao longo destes cinco anos, grande variação interanual na produção de serapilheira (Tabela XVIII): $2,52 \mathrm{~g} \cdot \mathrm{m}^{-2} \cdot \mathrm{dia}^{-1}$ (ANO I); 2,37 $\mathrm{g} \cdot \mathrm{m}^{-2} \cdot \mathrm{dia}^{-1}$ (ANO II); 3,52 g.m. $\mathrm{m}^{-2} \cdot \mathrm{dia}^{-1}$ (ANO III); 3,81 g.m $\mathrm{m}^{-2} \cdot \mathrm{dia}^{-1}$ (ANO IV) e $4,86 \mathrm{~g} \cdot \mathrm{m}^{-2} \cdot \mathrm{dia}^{-1}$ (ANO IV), com uma tendência de aumento nos valores encontrados.

Tabela XVIII - Taxas anuais ( $\mathrm{g} \cdot \mathrm{m}^{-2} \cdot \mathrm{dia}^{-1}$ ) de cada fração e taxa anual total (ton.ha ${ }^{-1} \cdot$ ano $^{-1}$ ) da serapilheira do bosque de mangue da Ilha Barnabé.

\begin{tabular}{cccccc}
\hline FRAÇÕES & ANO I & ANO II & ANO III & ANO IV & ANO V \\
\hline FOLHAS Rm & 0,20 & 0,21 & 0,24 & 0,22 & 0,34 \\
FOLHAS Lr & 0,71 & 0,90 & 1,33 & 1,36 & 1,70 \\
FOLHAS As & 0,18 & 0,28 & 0,32 & 0,42 & 0,59 \\
FOLHAS TOTAL & 1,09 & 1,39 & 1,89 & 1,99 & 2,62 \\
FLORES Rm & 0,00 & 0,00 & 0,00 & 0,01 & 0,00 \\
FLORES Lr & 0,04 & 0,04 & 0,03 & 0,02 & 0,03 \\
FLORES As & 0,01 & 0,01 & 0,00 & 0,03 & 0,02 \\
FLORES TOTAL & 0,05 & 0,06 & 0,04 & 0,05 & 0,06 \\
PROPÁGULOS/FRUTOS Rm & 0,61 & 0,04 & 0,66 & 0,04 & 0,72 \\
PROPÁGULOS/FRUTOS Lr & 0,31 & 0,44 & 0,38 & 0,53 & 0,56 \\
PROPÁGULOS/FRUTOS As & 0,15 & 0,09 & 0,12 & 0,23 & 0,22 \\
PROPÁGULOS/FRUTOS TOTAL & 1,07 & 0,57 & 1,17 & 0,81 & 1,51 \\
MADEIRAS & 0,25 & 0,28 & 0,26 & 0,84 & 0,52 \\
ESTÍPULAS & 0,03 & 0,05 & 0,04 & 0,05 & 0,04 \\
DETRITOS $^{\text {MISCELANIA }}$ & 0,03 & 0,03 & 0,13 & 0,06 & 0,08 \\
TOTAL (g.m $^{-2}$.dia $^{-1}$ ) & 0,11 & 0,13 & 0,20 & 0,17 & 0,17 \\
TOTAL (ton.ha $^{-1}$ ano $^{-1}$ ) & 2,52 & 2,37 & 3,52 & 3,81 & 4,86 \\
\hline
\end{tabular}

A fração folhas também apresentou uma grande variabilidade interanual, sendo a fração que apresentou o maior crescimento nas taxas do primeiro ao quinto ano: $1,09 \mathrm{~g} \cdot \mathrm{m}^{-2} \cdot \mathrm{dia}^{-1}$ (ANO I); $1,39 \mathrm{~g} \cdot \mathrm{m}^{-2} \cdot \mathrm{dia}^{-1}$ (ANO II); $1,89 \mathrm{~g} \cdot \mathrm{m}^{-2} \cdot \mathrm{dia}^{-1}$ (ANO III); $1,99 \mathrm{~g} \cdot \mathrm{m}^{-2} \cdot \mathrm{dia}^{-1}$ (ANO IV) e $2,62 \mathrm{~g} \cdot \mathrm{m}^{-2} \cdot \mathrm{dia}^{-}$ ${ }^{1}$ (ANO V).

Analisando a fração folhas por espécie (Tabela XVIII), podemos observar que a espécie $L$. racemosa, apresentou grande incremento neste

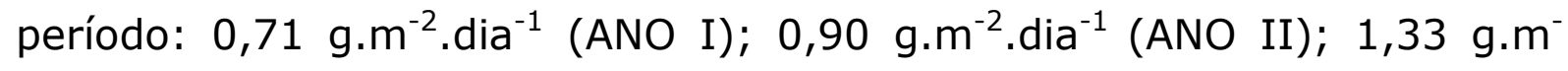
${ }^{2} \cdot \mathrm{dia}^{-1}$ (ANO III); $1,36 \mathrm{~g} \cdot \mathrm{m}^{-2} \cdot \mathrm{dia}^{-1}$ (ANO IV) e $1,70 \mathrm{~g} \cdot \mathrm{m}^{-2} \cdot \mathrm{dia}^{-1}$ (ANO V). A 
produção de folhas de Rhizophora mangle, manteve-se praticamente constante nos quatros primeiros anos (Tabela IV), variando os valores entre 0,20 a $0,24 \mathrm{~g} \cdot \mathrm{m}^{-2} \cdot \mathrm{dia}^{-1}$, porém no ANO $V$ apresentou um aumento considerável, chegando a $0,34 \mathrm{~g} \cdot \mathrm{m}^{-2} \cdot \mathrm{dia}^{-1}$. Avicennia schaueriana foi a espécie que apresentou o maior acréscimo nos valores de produção de folhas (Tabela XVIII), variando de: $0,18 \mathrm{~g} \cdot \mathrm{m}^{-2} \cdot \mathrm{dia}^{-1}$ (ANO I); 0,28 g.m

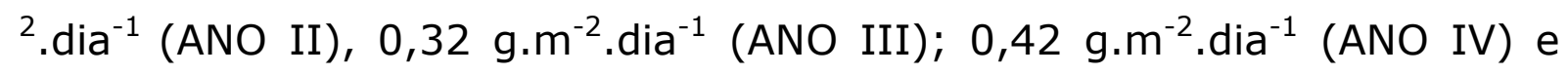
$0,59 \mathrm{~g} \cdot \mathrm{m}^{-2} \cdot \mathrm{dia}^{-1}$ (ANO V).

A produção de propágulos mostra também uma grande variabilidade interanual: $1,07 \mathrm{~g} \cdot \mathrm{m}^{-2} \cdot \mathrm{dia}^{-1}$ (ANO I); $0,57 \mathrm{~g} \cdot \mathrm{m}^{-2} \cdot \mathrm{dia}^{-1}$ (ANO II); $1,17 \mathrm{~g} \cdot \mathrm{m}^{-}$ ${ }^{2} \cdot \mathrm{dia}^{-1}$ (ANO III); 0,81 g.m $\mathrm{m}^{-2} \cdot \mathrm{dia}^{-1}$ (ANO IV) e $1,51 \mathrm{~g} \cdot \mathrm{m}^{-2} \cdot \mathrm{dia}^{-1}$ (ANO V).

A espécie $R$. mangle foi a que apresentou as maiores variações: $0,61 \mathrm{~g} \cdot \mathrm{m}^{-2} \cdot \mathrm{dia}^{-1}$ (ANO I); 0,04 g.m $\mathrm{m}^{-2} \cdot \mathrm{dia}^{-1}$ (ANO II); 0,66 g.m $\mathrm{m}^{-2} \cdot \mathrm{dia}^{-1}$ (ANO III); $0,04 \mathrm{~g} \cdot \mathrm{m}^{-2} \cdot \mathrm{dia}^{-1}$ (ANO IV) e $0,72 \mathrm{~g} \cdot \mathrm{m}^{-2} \cdot \mathrm{dia}^{-1}$ (ANO V), causando a baixa produção de propágulos totais no segundo e quarto ano, em comparação com os demais (Tabela IV). L. racemosa apresentou um acréscimo gradual (Tabela XVIII) nos valores de queda de propágulos: $0,31 \mathrm{~g} \cdot \mathrm{m}^{-2} \cdot \mathrm{dia}^{-1}$ (ANO I); $0,44 \mathrm{~g} \cdot \mathrm{m}^{-2} \cdot \mathrm{dia}^{-1}$ (ANO II); 0,38 g.m $\mathrm{m}^{-2} \cdot \mathrm{dia}^{-1}$ (ANO III); $0,53 \mathrm{~g} \cdot \mathrm{m}^{-2} \cdot \mathrm{dia}^{-1}$ (ANO IV) e $0,56 \mathrm{~g} \cdot \mathrm{m}^{-2} \cdot \mathrm{dia}^{-1}$ (ANO V). A. schaueriana apresentou produção de propágulos com pequena variação nos três primeiros anos e aumento nos dois últimos anos: $0,15 \mathrm{~g} \cdot \mathrm{m}^{-2} \cdot \mathrm{dia}^{-1}$ (ANO

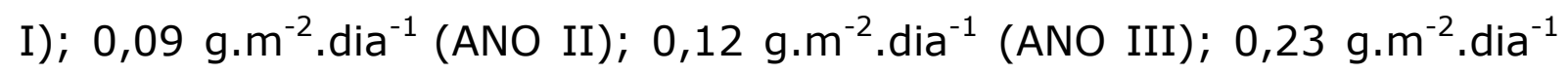
(ANO IV) e $0,22 \mathrm{~g} \cdot \mathrm{m}^{-2} \cdot \mathrm{dia}^{-1}$ (ANO V).

A fração madeira apresentou pouca variação nos três primeiros anos: $0,25 \mathrm{~g} \cdot \mathrm{m}^{-2} \cdot d i a^{-1}$ (ANO I); 0,28 g.m $\mathrm{m}^{-2} \cdot \mathrm{dia}^{-1}$ (ANO II) e 0,26 g.m $\mathrm{m}^{-2} \cdot \mathrm{dia}^{-}$ ${ }^{1}$ (ANO III). Porém nos dois últimos anos apresentou valores bem mais elevados: $0,84 \mathrm{~g} \cdot \mathrm{m}^{-2} \cdot \mathrm{dia}^{-1}$ (ANO IV) e 0,52 g.m $\mathrm{m}^{-2} \cdot \mathrm{dia}^{-1}$ (ANO V).

A fração detritos apresentou valores idênticos nos dois primeiros anos: $0,03 \mathrm{~g} \cdot \mathrm{m}^{-2} \cdot \mathrm{dia}^{-1} \mathrm{e}$ aumento nos anos seguintes: $0,13 \mathrm{~g} \cdot \mathrm{m}^{-2} \cdot \mathrm{dia}^{-1}$ 
(ANO III); 0,06 g.m - $^{-2} \cdot d i a^{-1}$ (ANO IV) e 0,08 g.m. ${ }^{-2} \cdot d i a^{-1}$ (ANO V). As frações (flores e estípulas) não apresentaram variação interanual nítida.

Além das altas taxas de variação interanual nos valores das frações (totais, folhas e propágulos/frutos) da serapilheira da Ilha Barnabé, outra característica marcante é a variação nas porcentagens que cada fração contribuiu com os valores totais ao longo dos anos de monitoramento e de cada espécie (Figuras 18 a 21 e Tabela XIX), principalmente no caso das frações folhas e propágulos/frutos, onde a contribuição de cada espécie variou bastante ao longo dos cinco anos de monitoramento.

A fração folhas (Figura 18) apresentou um acréscimo na contribuição da serapilheira total do ANO I $(43,11 \%)$ para o ANO II $(58,68 \%)$, e nos anos seguintes esta contribuição apresentou leve decréscimo e se manteve: ANO III $(53,83 \%)$; ANO IV $(52,33 \%)$ e ANO V $(55,93 \%)$.

A fração propágulos/frutos apresentou a maior variação nas porcentagens de contribuição da serapilheira total ao longo do monitoramento: ANO I (42,58\%); ANO II (23,97\%); ANO III $(33,17 \%)$, ANO IV $(21,18 \%)$ e ANO V $(31,99 \%)$.

A fração madeiras não apresentou uma variabilidade marcante nas porcentagens de contribuição, exceto no ANO IV, onde teve grande contribuição na serapilheira total $(21,18 \%)$. Nos demais anos esta porcentagem variou entre 7,29 e $11,75 \%$.

A fração miscelânia, composta pelas flores, estípulas e detritos apresentou baixa variabilidade na porcentagem de contribuição na serapilheira total, variando entre 3,55 a 5,71\%. 

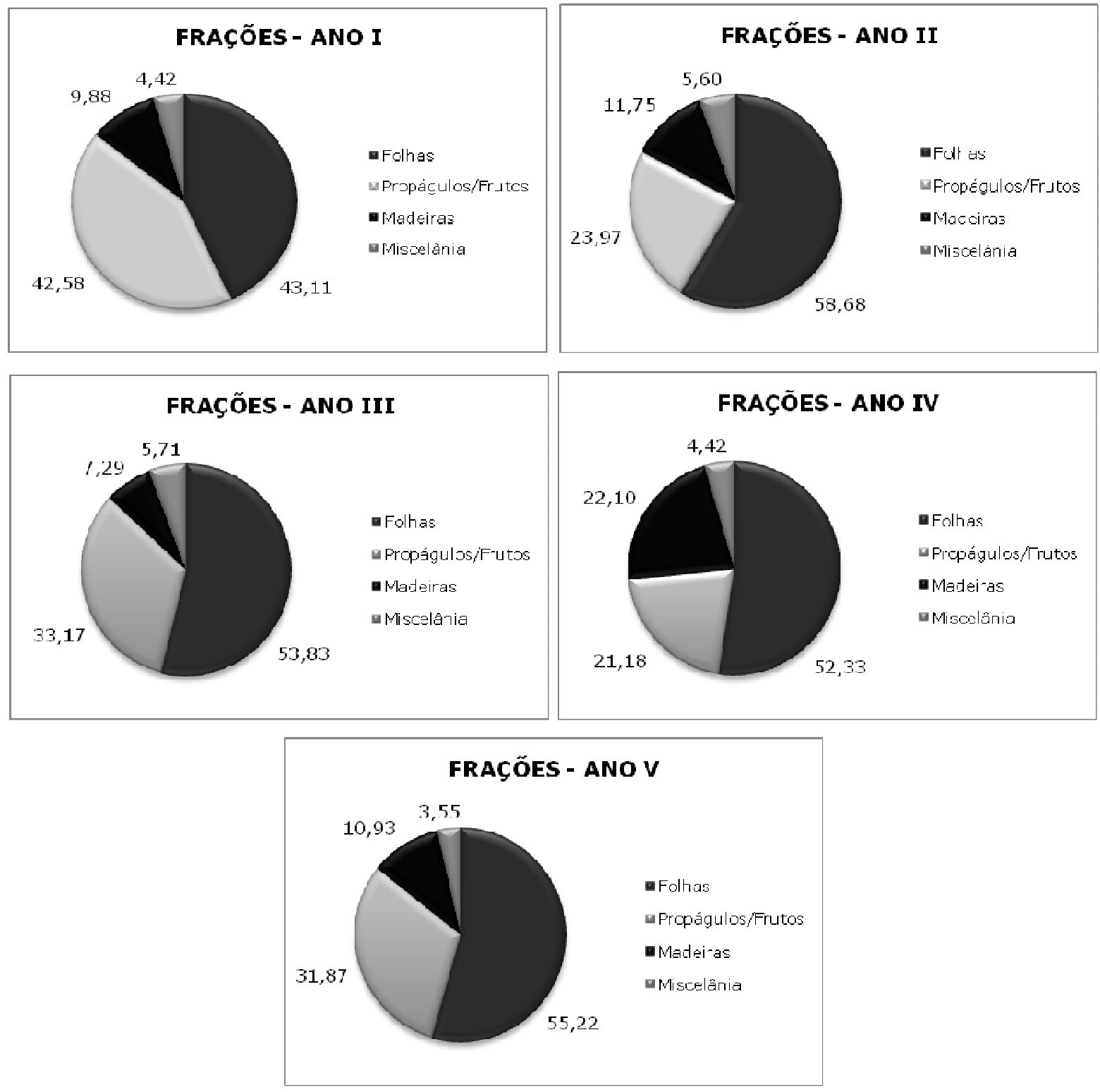

Figura 18 - Porcentagem (\%) correspondente a cada fração da serapilheira do bosque de mangue da Ilha Barnabé nos diferentes anos estudados.

Analisando a contribuição de cada espécie vegetal nas frações folhas, frutos e flores também podemos observar uma grande variabilidade ao longo dos anos de monitoramento.

$\mathrm{Na}$ fração folhas a espécie que mais contribuiu com a serapilheira total foi $L$. racemosa, seguida por $A$. schaueriana e por último $R$. mangle (Figura 19). 
Embora L. racemosa tenha sido a espécie que mais contribuiu com a serapilheira total, esta espécie apresentou baixa variabilidade nas porcentagens ao longo dos anos, variando os valores entre 64,75 e $70,45 \%$.

R. mangle apresentou leve decréscimo nos valores de contribuição ao longo dos anos: ANO I (18,12\%); ANO II (15,29\%); ANO III $(12,41 \%)$; ANO IV $(10,88 \%)$ e ANO V $(12,81 \%)$

O padrão inverso foi observado para $A$. schaueriana, que apresentou um leve acréscimo nos valores de contribuição ao longo dos anos: ANO I $(16,61 \%) ;$ ANO II $(19,82 \%) ;$ ANO III $(17,14 \%) ;$ ANO IV $(20,95 \%)$ e ANO V $(22,44 \%)$.

A fração frutos apresentou a maior variabilidade na porcentagem que cada espécie contribuiu com a serapilheira total (Figura 20). As espécies $L$. racemosa e $R$. mangle alternaram as maiores contribuições entre os anos do monitoramento.

L.racemosa foi a espécie com maior contribuição nos ANOS II $(77,91 \%)$ e IV $(66,26 \%)$, sendo que nos demais anos sua contribuição variou entre 28,49 a $37,33 \%$.

A contribuição de $R$. mangle foi maior nos ANOS I (57,22\%); ANO III $(56,93 \%)$ e ANO $\vee(47,90 \%)$. Nos outros anos esta espécie pouco contribuiu com a fração frutos: ANO II $(6,93 \%)$ e ANO IV $(5,07 \%)$.

A. schaueriana apresentou pouca variação quanto a sua contribuição na fração frutos: ANO I (14,29\%); ANO II (15,15\%); ANO III (10,47\%); ANO IV $(28,67 \%)$ e ANO $\vee(14,77 \%)$. Cabe destaque apenas o aumento na contribuição desta espécie no ANO IV. 

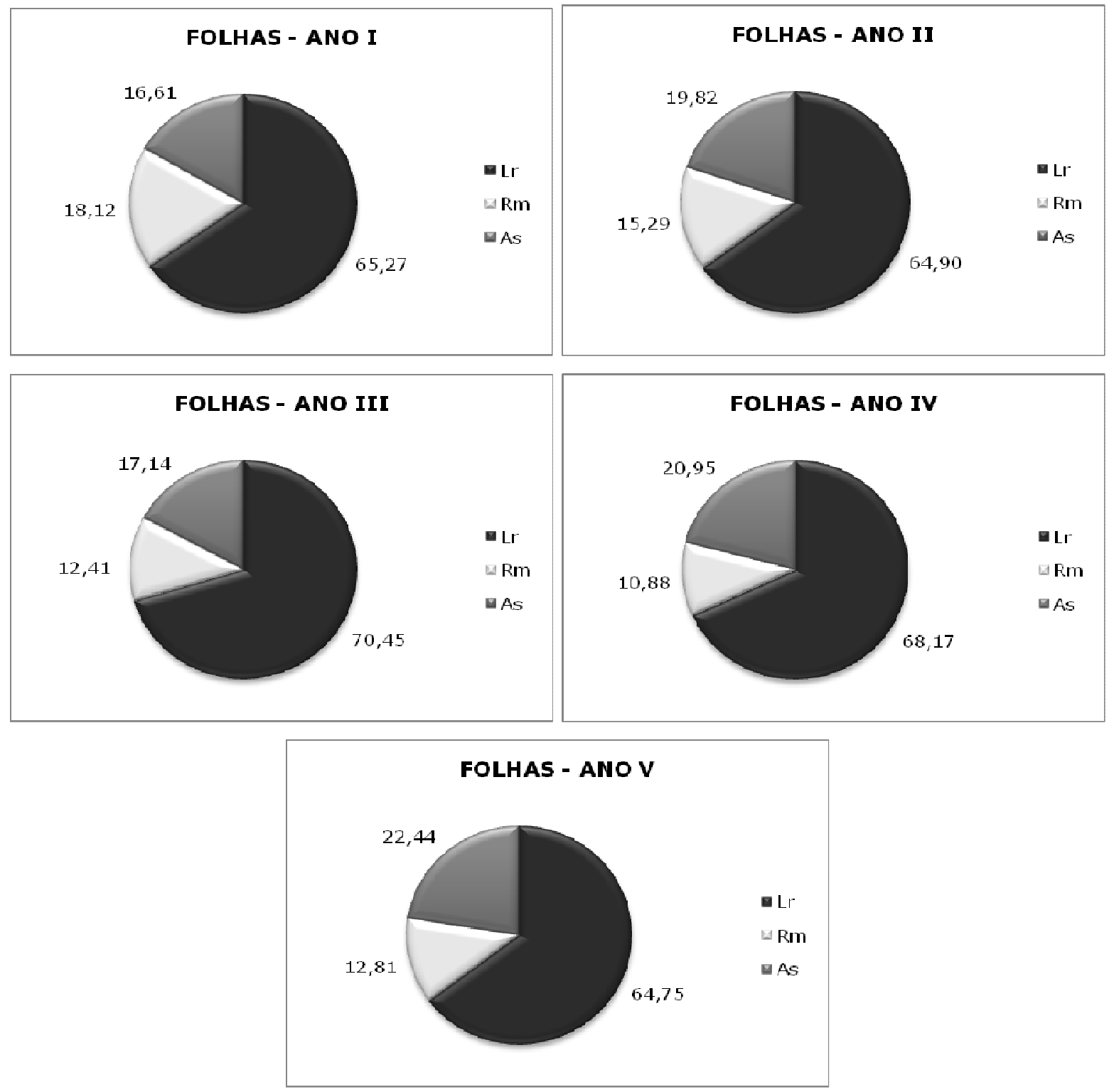

Figura 19 - Porcentagem (\%) correspondente a cada espécie na fração folhas da serapilheira do bosque de mangue da Ilha Barnabé nos diferentes anos estudados $(L r=L$. racemosa; $\mathrm{Rm}=R$. mangle; As = A. schaueriana) . 


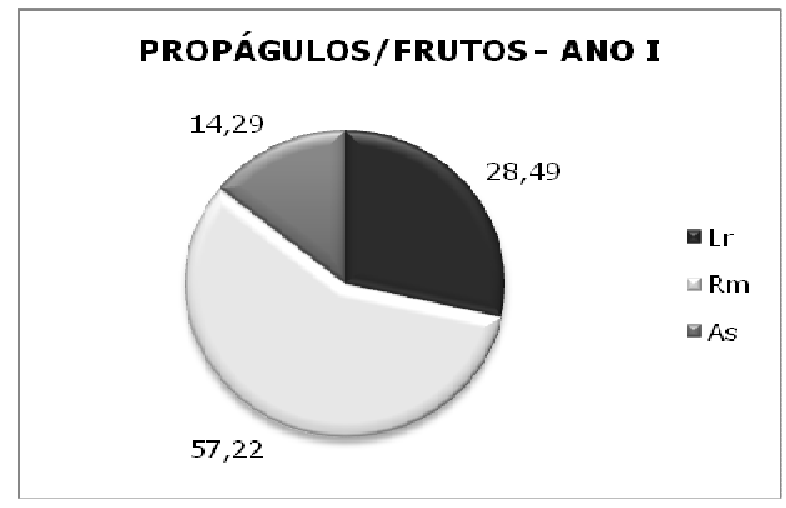

PROPÁGULOS/FRUTOS - ANO II

15,15

6,93

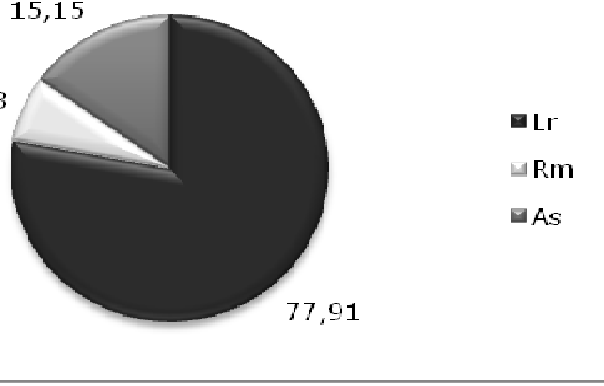

PROPÁGULOS/FRUTOS - ANO III

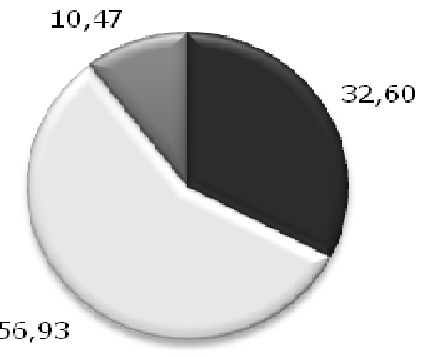

PROPÁGULOS/FRUTOS - ANO IV
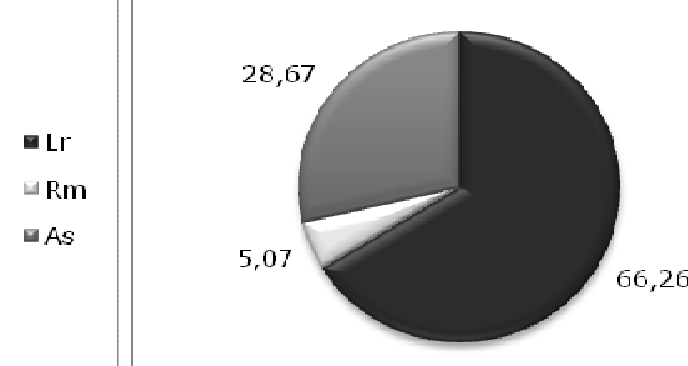

PROPÁGULOS/FRUTOS - ANO $V$

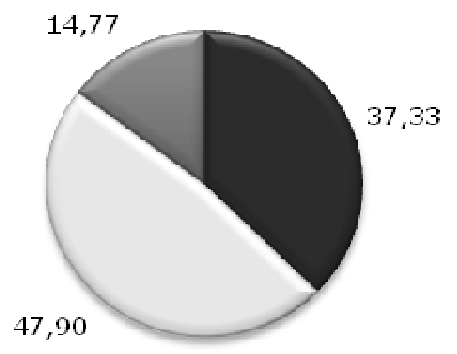

Figura 20 - Porcentagem (\%) correspondente a cada espécie na fração propágulos/frutos da serapilheira do bosque de mangue da Ilha Barnabé nos diferentes anos estudados ( $L r=L$. racemosa; $\mathrm{Rm}=R$. mangle; $\mathrm{As}=A$. schaueriana). 
$\mathrm{Na}$ fração flores (Figura 23) a espécie que mais contribuiu foi $L$. racemosa, principalmente nos três primeiros anos: ANO I $(78,90 \%)$; ANO II $(70,53 \%) ;$ ANO III $(94,15 \%) ;$ ANO IV $(43,71 \%)$ e ANO V $(61,18 \%)$.

A. schaueriana apresentou pouca variação nos dois primeiros ano, teve um grande decréscimo no terceiro ano e um grande crescimento na sua contribuição no quarto e quinto ano: ANO I $(20,51 \%)$; ANO II $(21,81) ;$ ANO III $(5,51 \%) ;$ ANO IV $(46,58 \%)$ e ANO V $(36,70 \%)$.

A espécie $R$. mangle devido as características estruturais das suas flores apresentou baixa contribuição ao longo dos anos monitorados, porém podemos observar que a produção de flores foi sempre maior um ano antes da ocorrência de grande produção de propágulos/frutos.

Tabela XIX - Porcentagem (\%) das frações ao longo dos cinco anos de monitoramento da serapilheira do bosque de mangue da Ilha Barnabé.

\begin{tabular}{cccccc}
\hline Frações & ANO I & ANO II & ANO III & ANO IV & ANO V \\
Folhas & 43,11 & 58,68 & 53,83 & 52,33 & 55,22 \\
Propágulos/Frutos & 42,58 & 23,97 & 33,17 & 21,18 & 31,87 \\
Madeiras & 9,88 & 11,75 & 7,29 & 22,10 & 10,93 \\
Miscelânea & 4,42 & 5,60 & 5,71 & 4,42 & 3,55 \\
Folhas Lr & 65,27 & 64,90 & 70,45 & 68,17 & 64,75 \\
Folhas Rm & 18,12 & 15,29 & 12,41 & 10,88 & 12,81 \\
Folhas As & 16,61 & 19,82 & 17,14 & 20,95 & 22,44 \\
Propágulos/Frutos Lr & 28,49 & 77,91 & 32,60 & 66,26 & 37,33 \\
Propágulos/Frutos Rm & 57,22 & 6,93 & 56,93 & 5,07 & 47,90 \\
Propágulos/Frutos As & 14,29 & 15,15 & 10,47 & 28,67 & 14,77 \\
Flores Lr & 78,90 & 70,53 & 94,15 & 43,71 & 61,18 \\
Flores Rm & 0,58 & 7,66 & 0,34 & 9,71 & 2,12 \\
Flores As & 20,51 & 21,81 & 5,51 & 46,58 & 36,70 \\
\hline
\end{tabular}



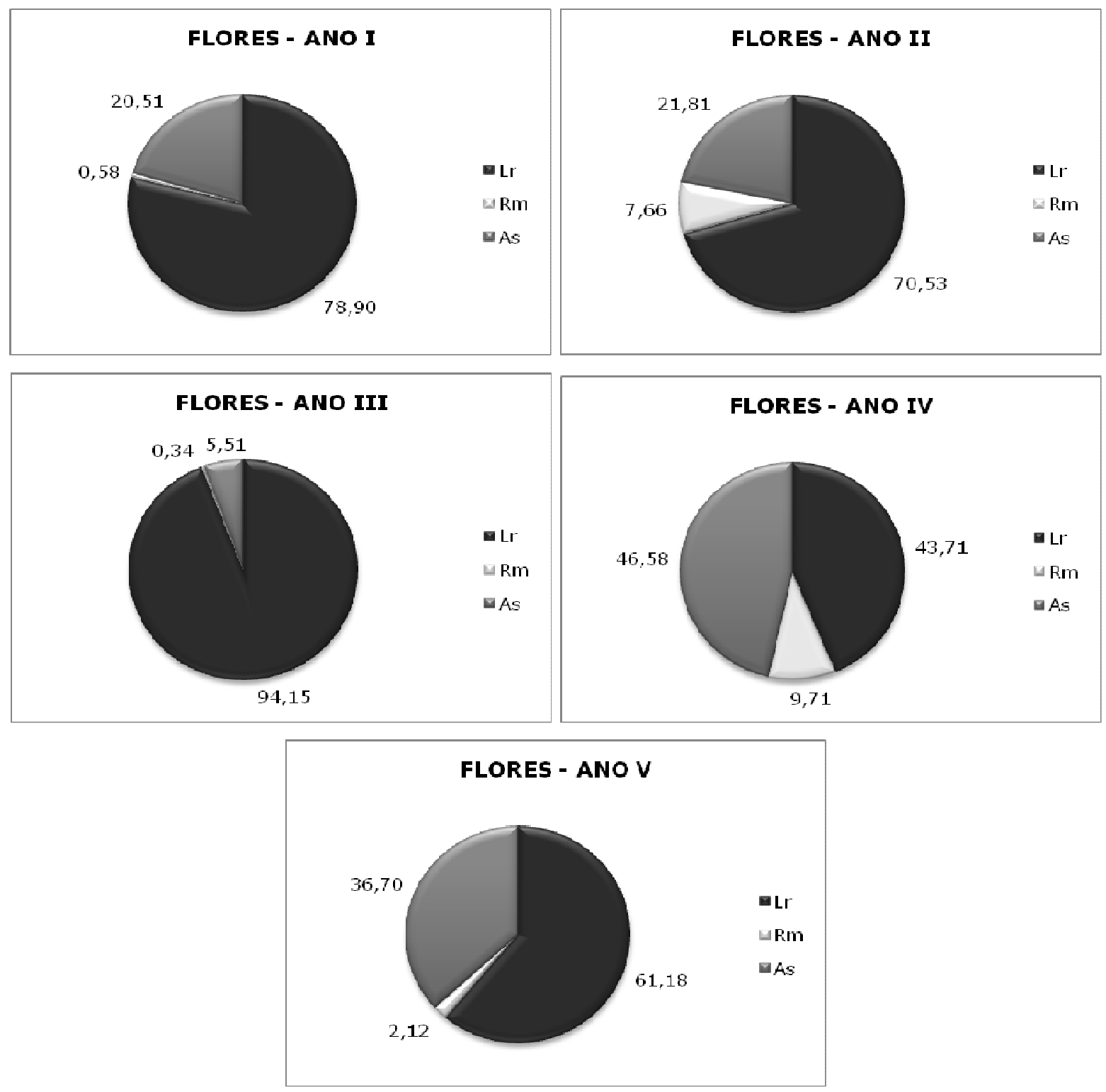

Figura 21 - Porcentagem (\%) correspondente a cada espécie na fração flores da serapilheira do bosque de mangue da Ilha Barnabé nos diferentes anos estudados $(\mathrm{Lr}=L$. racemosa; $\mathrm{Rm}=R$. mangle; As $=$ A. schaueriana $)$. 


\subsubsection{2 - SAZONALIDADE}

Os picos de produção de serapilheira foram observados durante os meses de novembro a junho (Figura 22), sendo os meses de julho a outubro os que apresentaram os menores valores, esta tendência foi observada nos cinco anos estudados. As únicas exceções foram um pico em agosto do ANO IV, devido a uma grande queda de fragmentos de madeira referentes à morte de uma árvore adulta e em agosto do ANO $\mathrm{V}$ em decorrência de uma grande queda de folhas verdes de $L$. racemosa.

Analisando a Figura 23, podemos concluir que este pico de produção é mantido durante estes meses devido à queda da fração folhas durante os meses de novembro a março, e depois pela queda de propágulos que ocorre durante os meses de fevereiro a junho.

As folhas da espécie $L$. racemosa são disponibilizadas em maior número nos meses de dezembro a março, exceto no ANO $\mathrm{V}$, onde a queda foi grande de novembro a abril, além de uma queda grande de folhas verdes ocorrida em agosto, no último mês de coleta.

As folhas de $R$. mangle são disponibilizadas principalmente entre fevereiro e abril, exceto no ANO $V$, onde a queda de folhas desta espécie teve um pico entre os meses de novembro e dezembro.

A espécie $A$. schaueriana não apresentou um padrão bem definido, com uma leve tendência a uma maior queda nos meses de verão, porém com alguns picos isolados em outros meses. Cabe destacar um pico de queda ocorrido em março do ANO II em decorrência da morte de uma árvore adulta desta espécie no entorno de uma cesta coletora de serapilheira, observação esta feita em campo. Assim como as duas outras espécies, ocorreu um pico de queda entre os meses de novembro e abril no ANO V (Figura 24). 


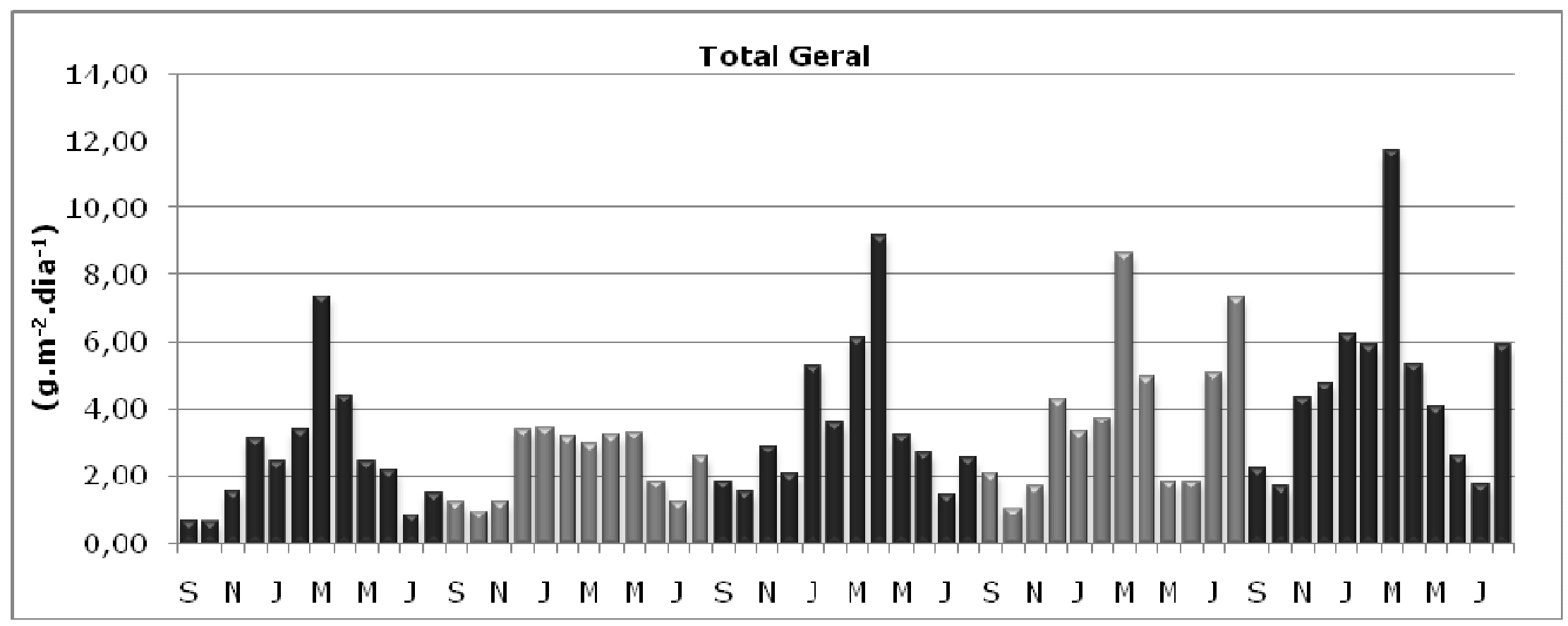

Figura 22 - Produção mensal $\left(\mathrm{g} \cdot \mathrm{m}^{-2} \cdot \mathrm{dia}^{-1}\right.$ ) de serapilheira total do bosque de mangue da Ilha Barnabé (as diferenças de cores representam cada ano de estudo). 


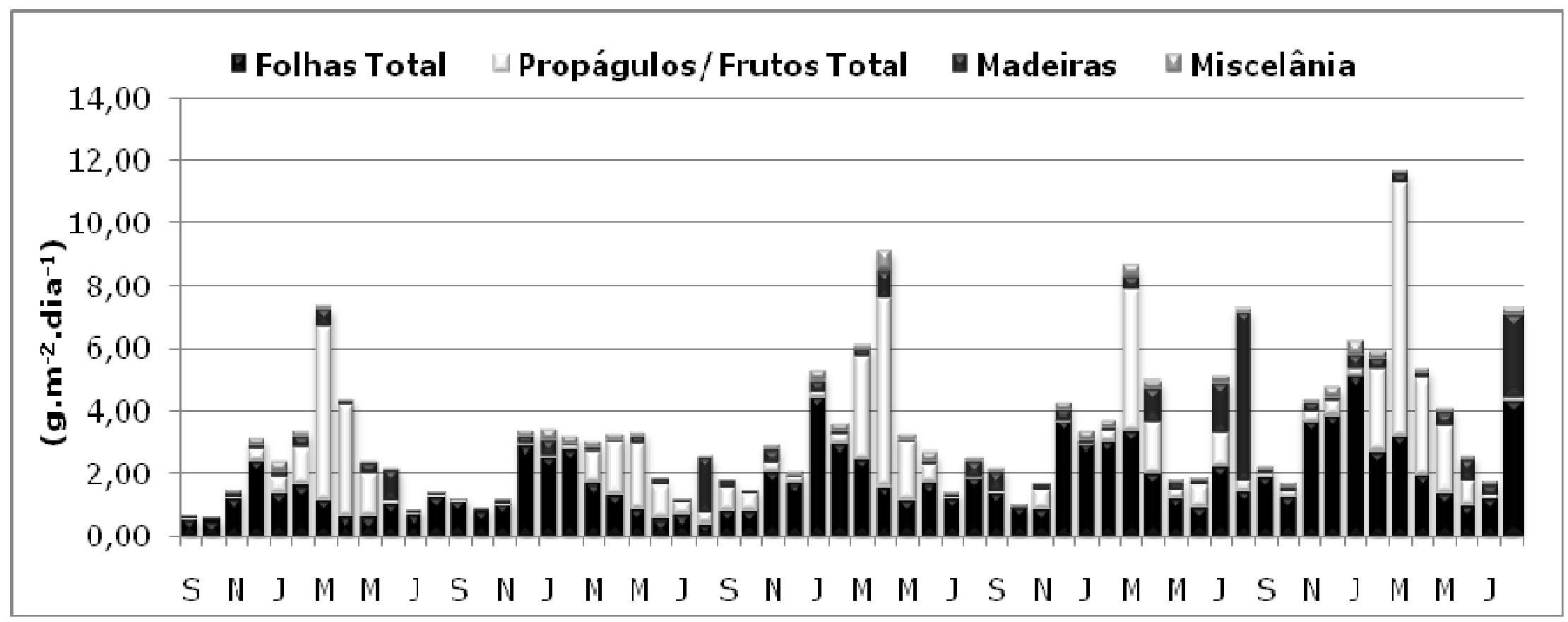

Figura 23 - Produção mensal $\left(\mathrm{g} \cdot \mathrm{m}^{-2} \cdot \mathrm{dia}^{-1}\right)$ das frações da serapilheira do bosque de mangue da Ilha Barnabé. 


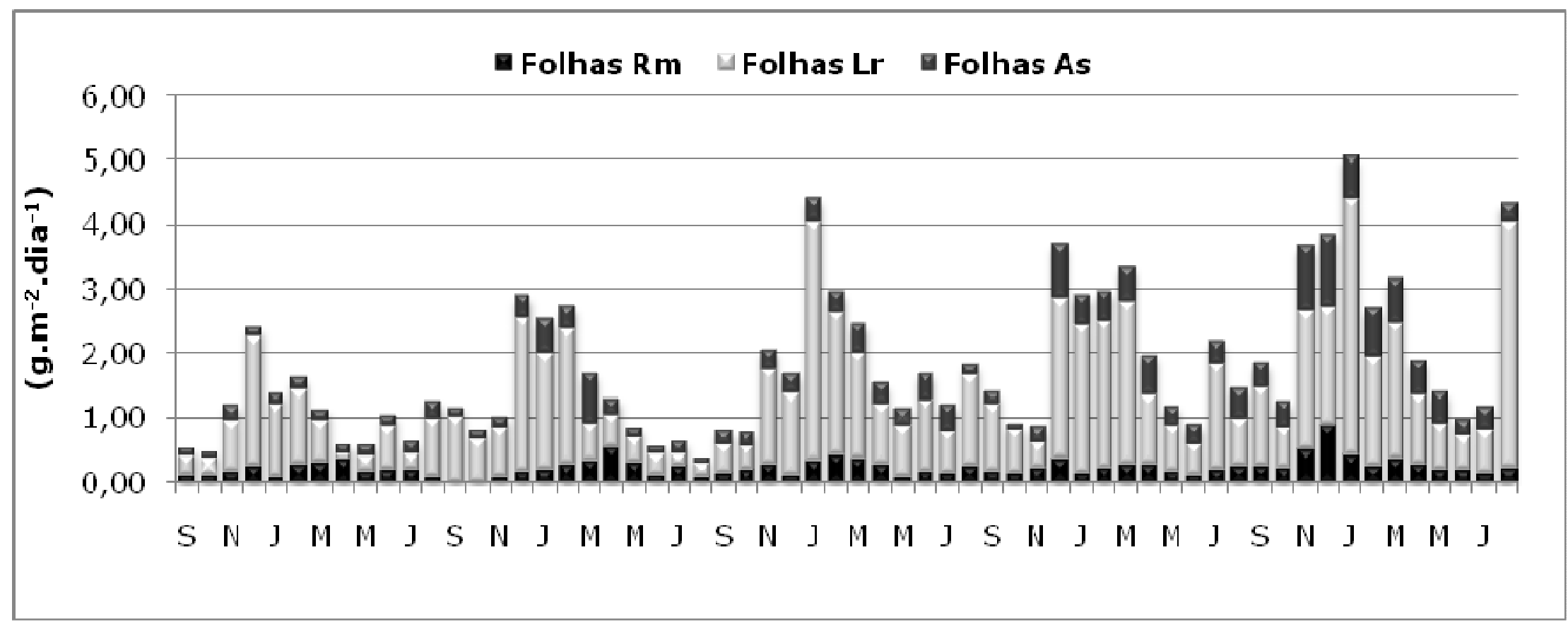

Figura 24 - Produção mensal $\left(\mathrm{g} \cdot \mathrm{m}^{-2} \cdot \mathrm{dia}^{-1}\right)$ de folhas por espécies da serapilheira do bosque de mangue da Ilha Barnabé. 
A fração propágulos/frutos apresenta um início de queda durante os meses de dezembro a fevereiro (Figura 25), durante estes meses iniciais é possível observar a maior parte dos propágulos abortados de $R$. mangle. Os propágulos viáveis desta espécie e de $L$. racemosa apresentam picos de queda entre março a maio. $A$. schaueriana assim como na fração folhas, não apresentou um padrão definido de queda de frutos, apresentando picos esporádicos entre março-abril (ANO I); setembro-outubro (ANO II); novembro (ANO III); junho-julho (ANO IV) e abril-junho (ANO V).

A fração flores (Figura 26) apresentou picos de queda entre dezembro e março, nos três primeiros anos e entre dezembro e fevereiro nos dois últimos anos para $L$. racemosa. Para $A$. schaueriana pôde-se observar pico de queda de flores no ANO I entre dezembro e março; ANO II entre março e maio; não apresentou picos de queda no ANO III; entre fevereiro e abril no ANO IV e entre janeiro e março no ANO $V$. A espécie $R$. mangle não apresentou picos significativos de queda de flores.

A fração estípulas (Figura 27) e detritos (Figura 28) apresentaram uma tendência maior de queda durante os meses de primavera/verão, porém sem um padrão bem definido, cabendo destacar o grande aumento na queda de detritos no terceiro ano durante os meses de abril a junho, devido ao fato que durante estes meses uma grande quantidade de restos de carapaças de caranguejos foram encontrados dentro de uma cesta coletora, ocasionando uma maior quantidade de detritos não identificáveis.

Os picos de queda de madeira (Figura 29) encontram-se distribuídos aleatoriamente durante os quatro anos, e devem-se principalmente pela queda de restos de árvores mortas ocasionados pela passagem de frentes frias ou a fortes ventanias de verão, destacando a queda de grande quantidade de fragmentos de madeira em agosto do ANO IV e V. 


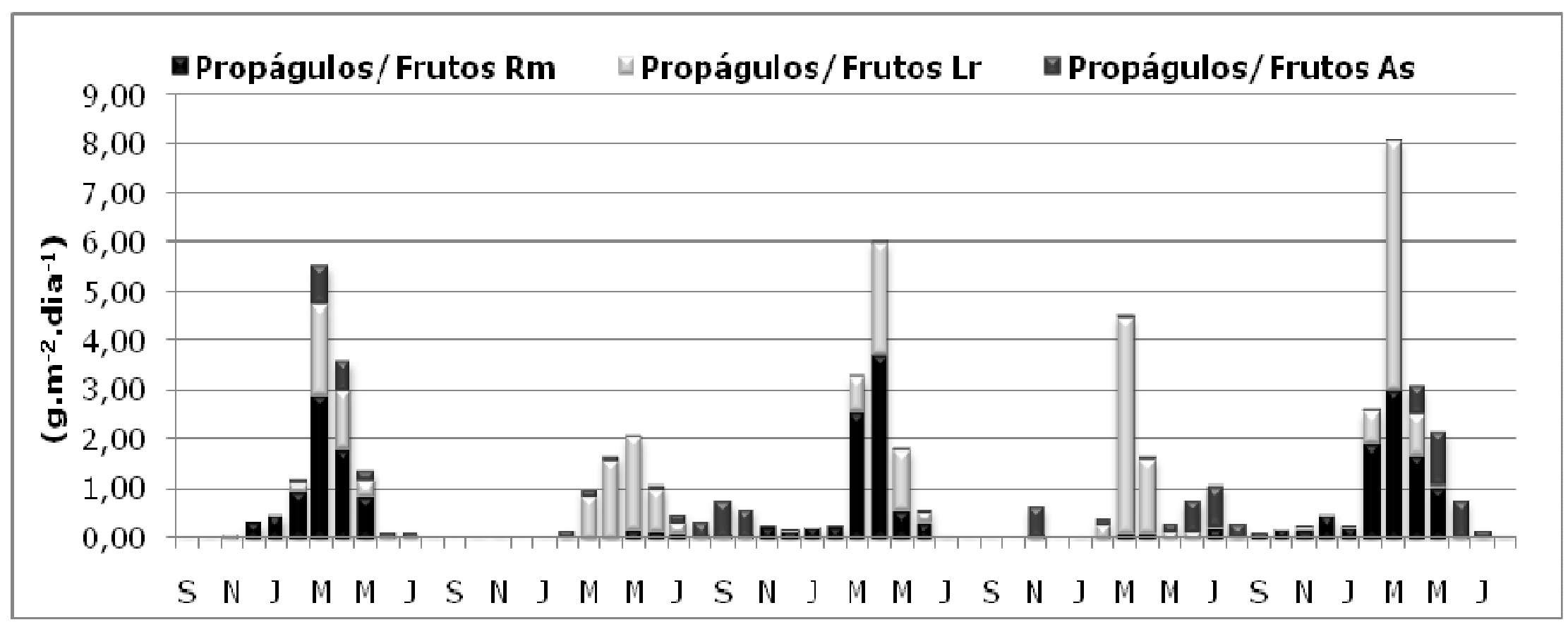

Figura 25 - Produção mensal $\left(\mathrm{g}_{\mathrm{m}} \mathrm{m}^{-2} \cdot \mathrm{dia}^{-1}\right)$ de propágulos/frutos por espécie da serapilheira do bosque de mangue da Ilha Barnabé. 


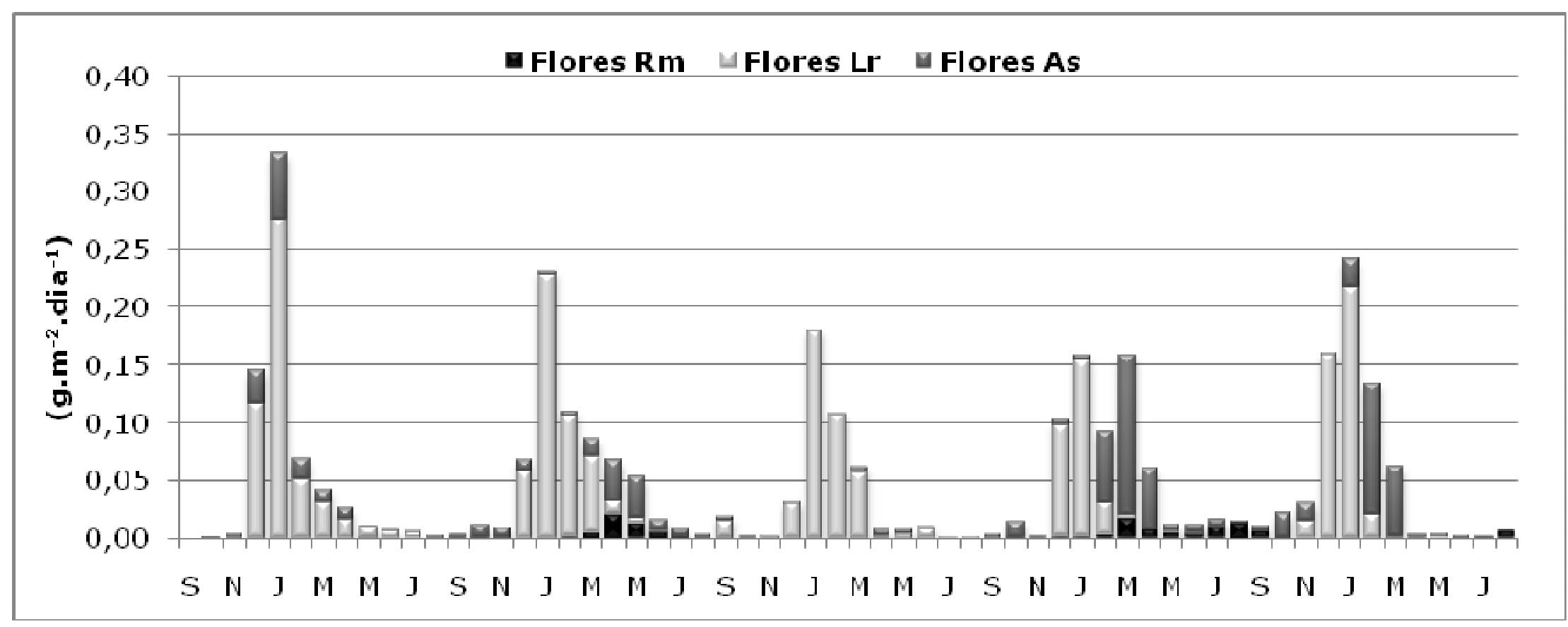

Figura 26 - Produção mensal $\left(\mathrm{g} \cdot \mathrm{m}^{-2} \cdot \mathrm{dia}^{-1}\right)$ de flores por espécie da serapilheira do bosque de mangue da Ilha Barnabé. 


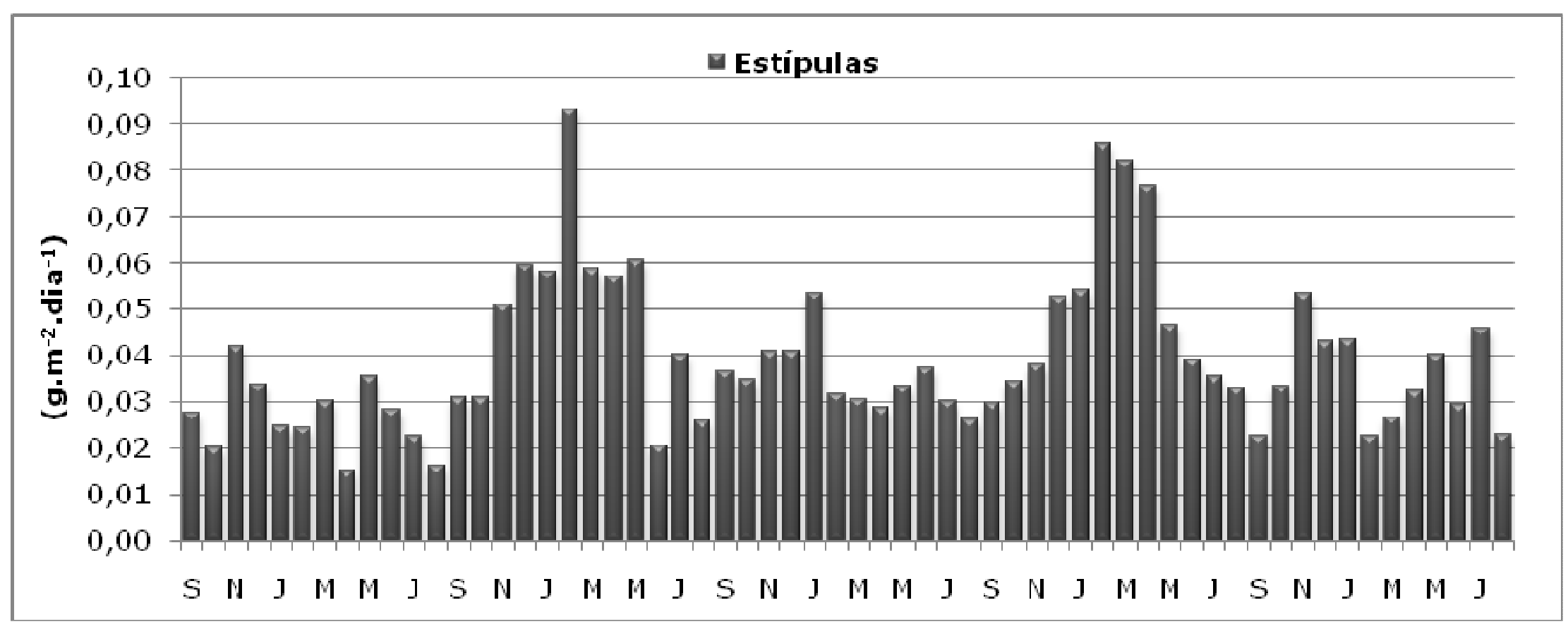

Figura 27 - Produção mensal $\left(\mathrm{g} \cdot \mathrm{m}^{-2} \cdot \mathrm{dia}^{-1}\right)$ de estípulas da serapilheira do bosque de mangue da Ilha Barnabé. 


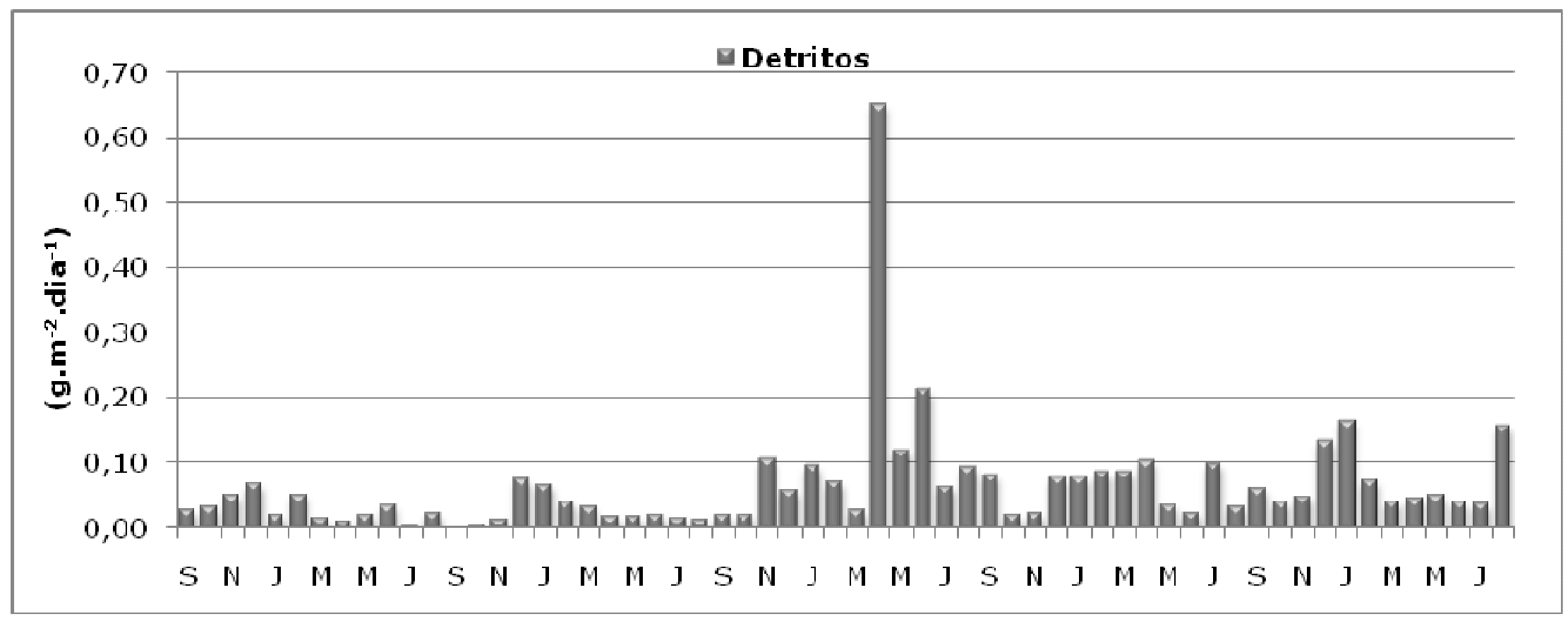

Figura 28 - Produção mensal $\left(\mathrm{g} \cdot \mathrm{m}^{-2} \cdot \mathrm{dia}^{-1}\right)$ de detritos da serapilheira do bosque de mangue da Ilha Barnabé. 


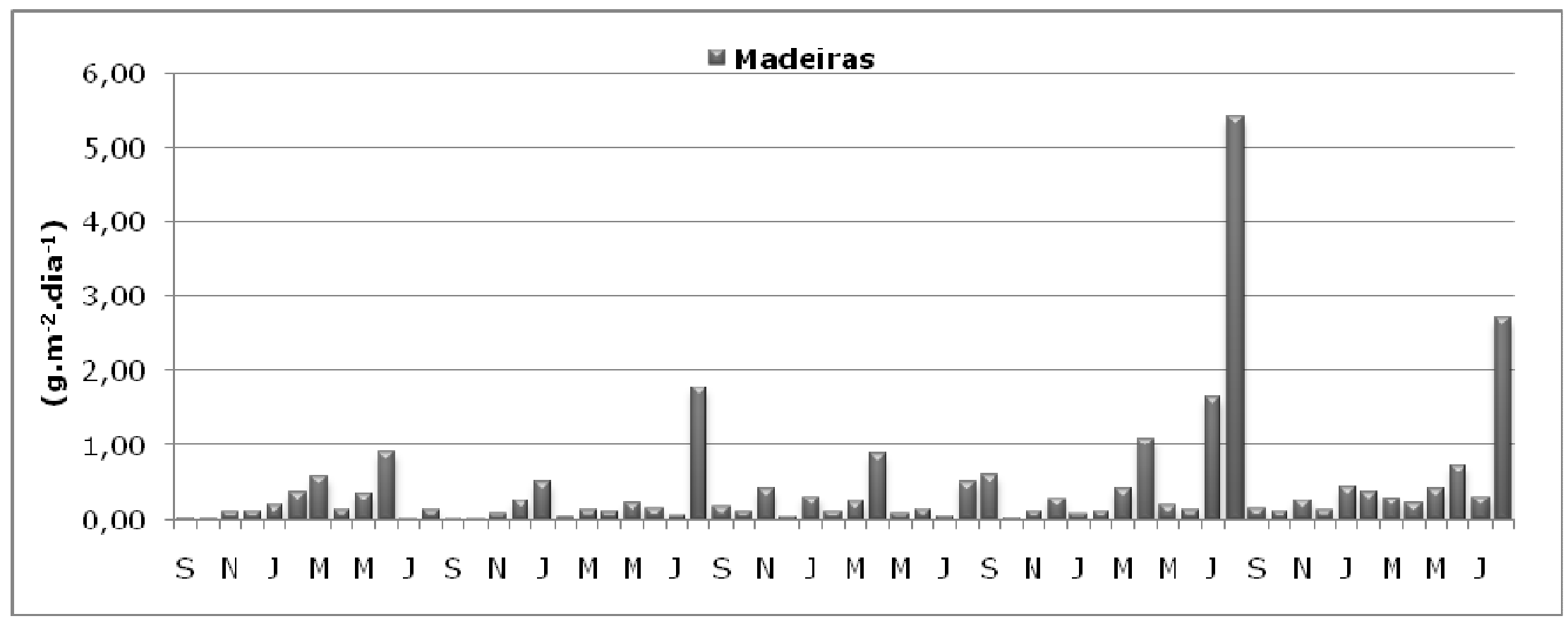

Figura 29 - Produção mensal $\left(\mathrm{g} \cdot \mathrm{m}^{-2} \cdot \mathrm{dia}^{-1}\right)$ de madeira da serapilheira do bosque de mangue da Ilha Barnabé. 


\section{3 - MICROTOPOGRAFIA}

A partir dos estudos da microtopografia local realizados nas datas de 2004 e 2008, os dados levantados foram tratados em planilhas e com auxílio do programa gráfico SURFER ${ }^{\circledR}$ v.8.0 (2002) foram gerados:

- Mapas de contorno topográfico com curvas de nível de 2004 e 2008 (Figuras 30 e 31).

- Mapas de contorno topográfico com curvas de nível e localização do bosque de mangue de 2004 e 2008 (Figuras 32 e 33). A localização do bosque em ambas as datas foi realizada através de anotações de campo realizadas no momento do levantamento topográfico.

- Modelo de superfície 3D (wireframe) de 2004 e 2008 (Figuras 34 e 35).

- Composição de mapa de contorno topográfico com curvas de nível e modelo de superfície 3D (wireframe) de 2004 e 2008 (Figuras 36 e 37).

- Modelo de superfície 3D (wireframe) com malha vetorial representando o sentido hipotético da drenagem terrestre no terreno (Figuras 39 e 40).

- Modelo do cálculo da dinâmica sedimentar ocorrida entre os anos de 2004 e 2008 (Figura 41). 


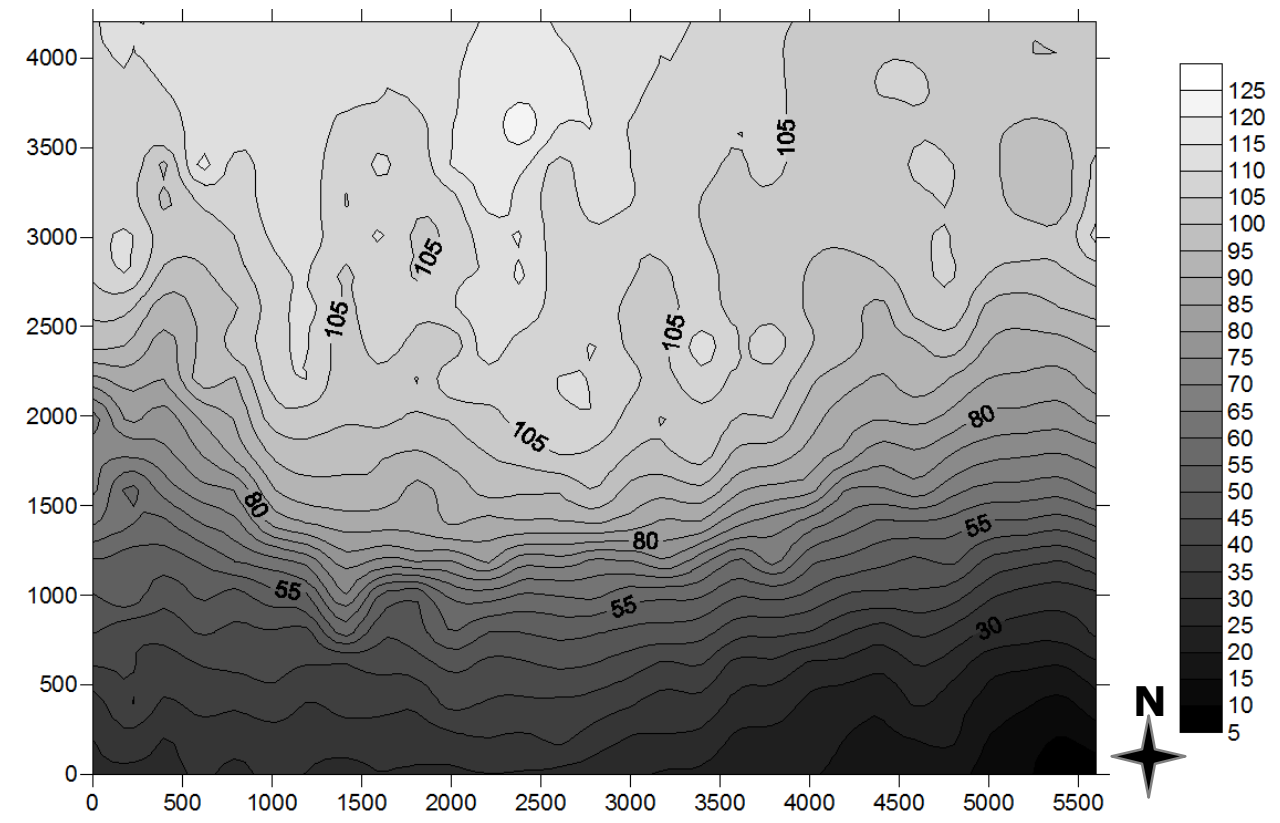

Figura 30 - Mapa de contorno topográfico com curvas de nível referente ao ano de 2004.

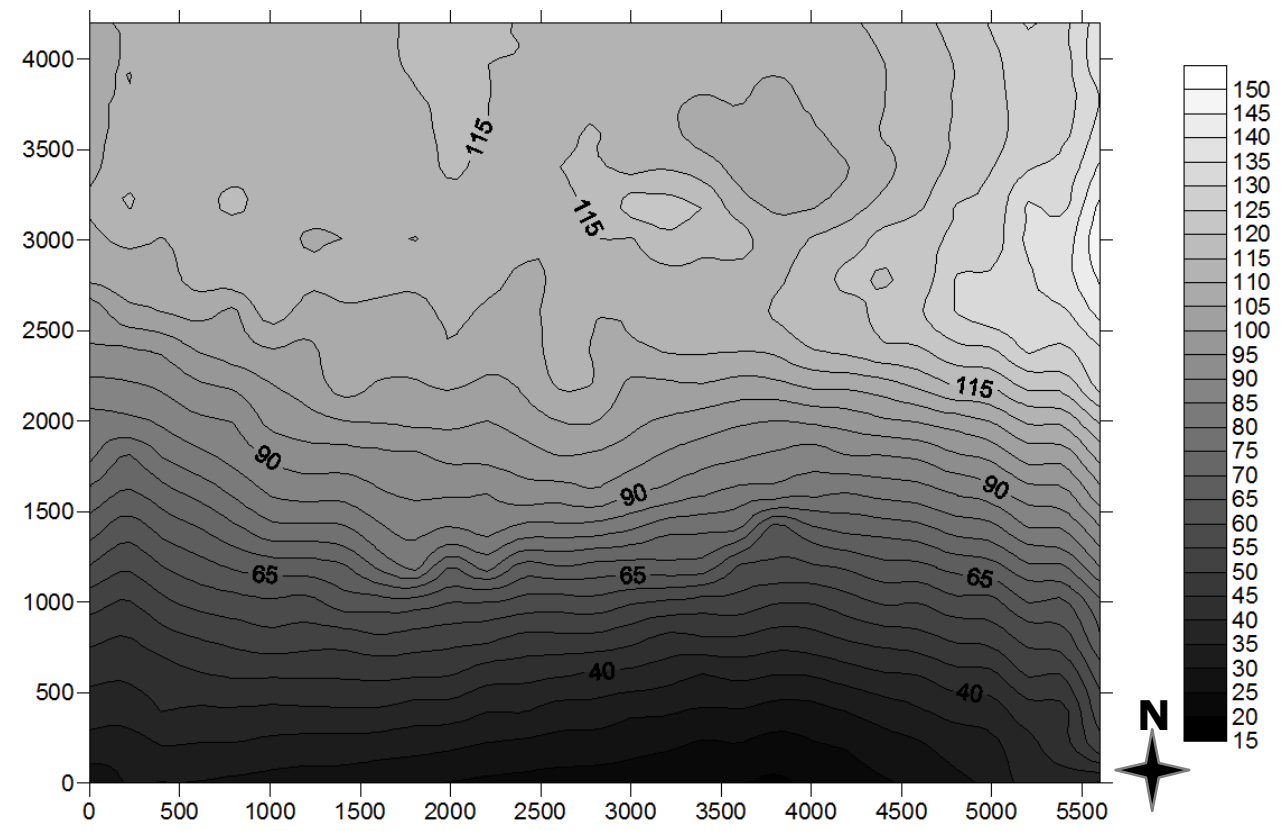

Figura 31 - Mapa de contorno topográfico com curvas de nível referente ao ano de 2008. 


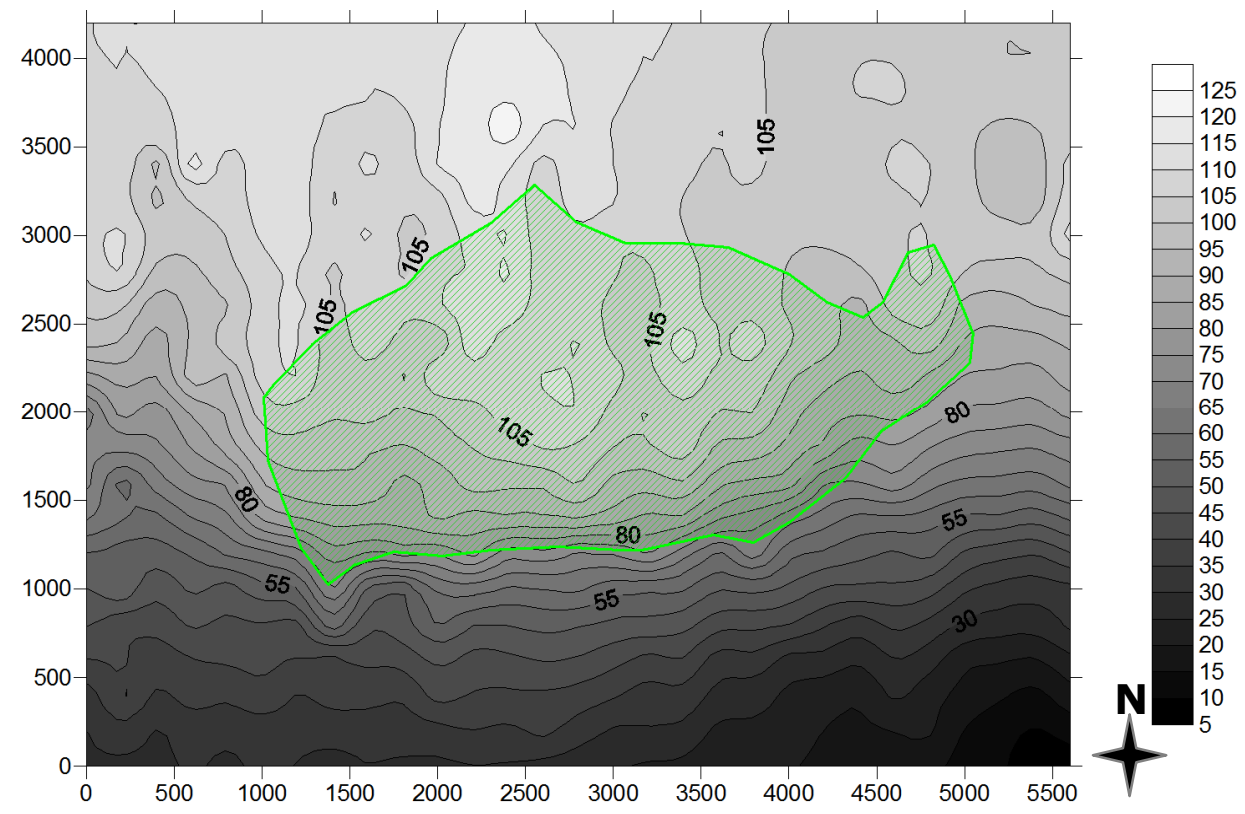

Figura 32 - Mapa de contorno topográfico com curvas de nível e localização do bosque de mangue (polígono verde) referente ao ano de 2004.

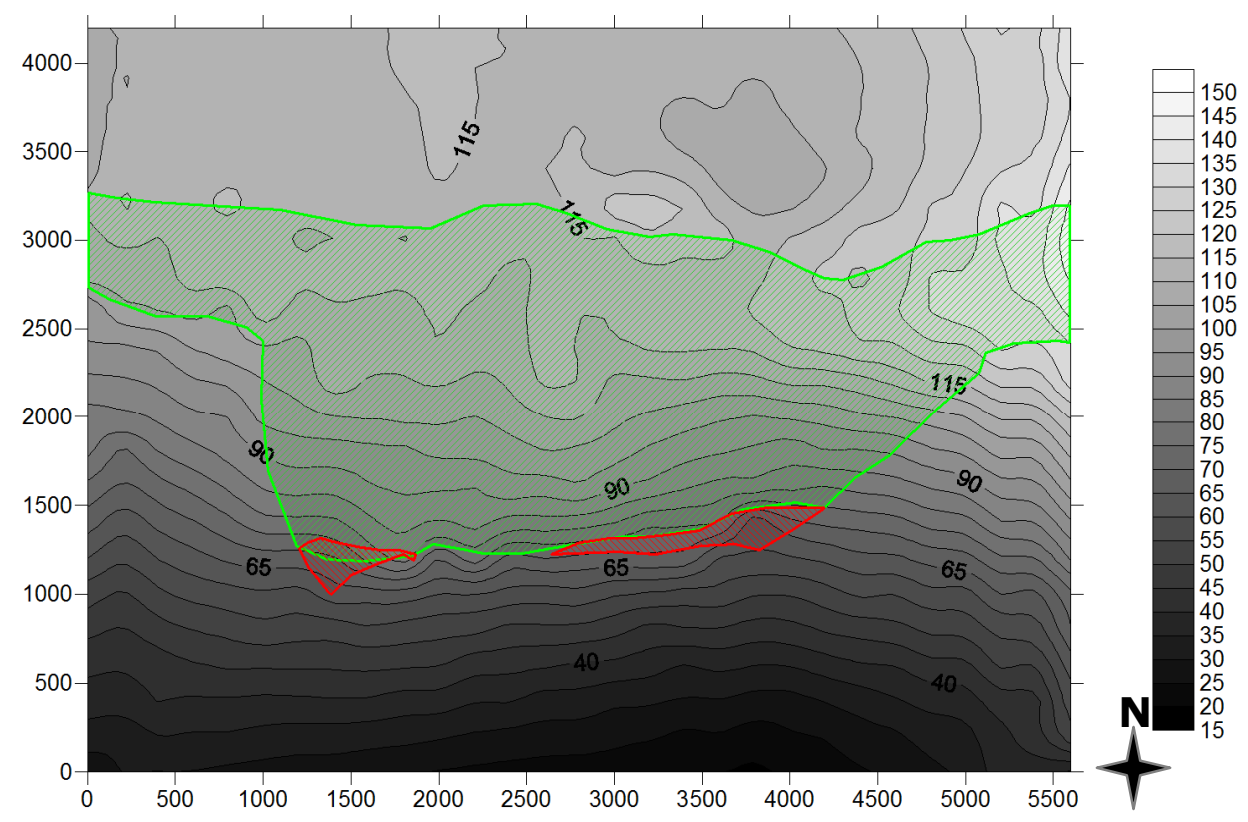

Figura 33 - Mapa de contorno topográfico com curvas de nível e localização do bosque de mangue (polígono verde) e áreas com mortalidade de indivíduos (polígonos vermelhos) referente ao ano de 2008. 


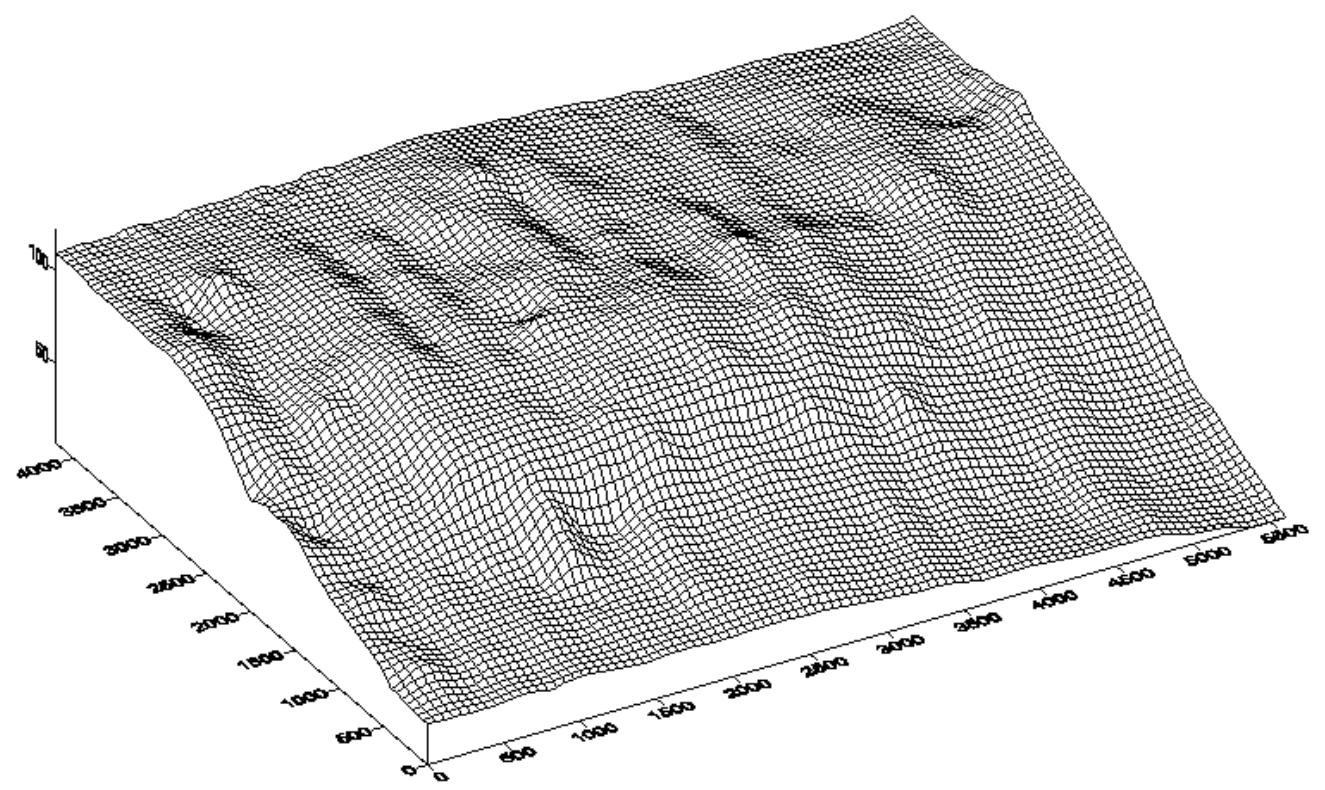

Figura 34 - Modelo de superfície 3D (wireframe) referente ao ano de 2004.

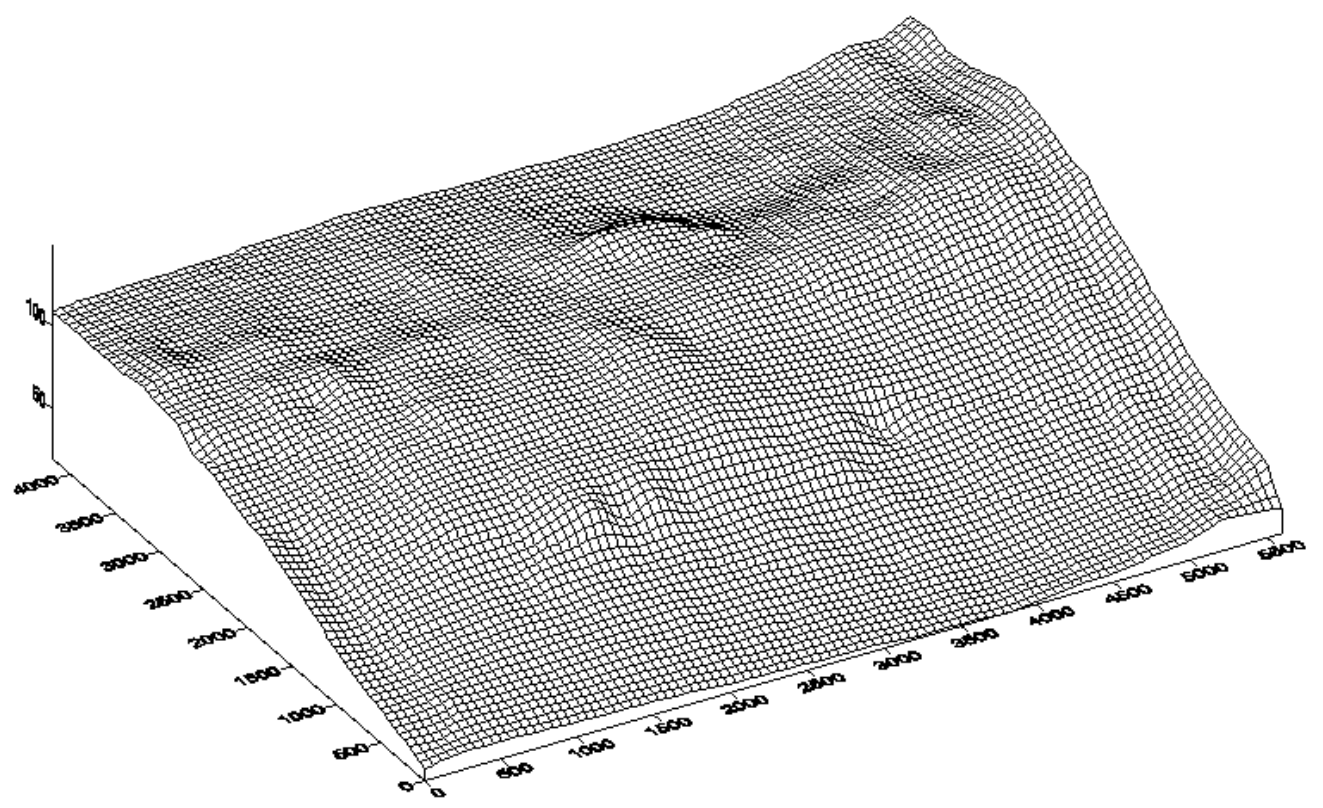

Figura 35 - Modelo de superfície 3D (wireframe) referente ao ano de 2008. 


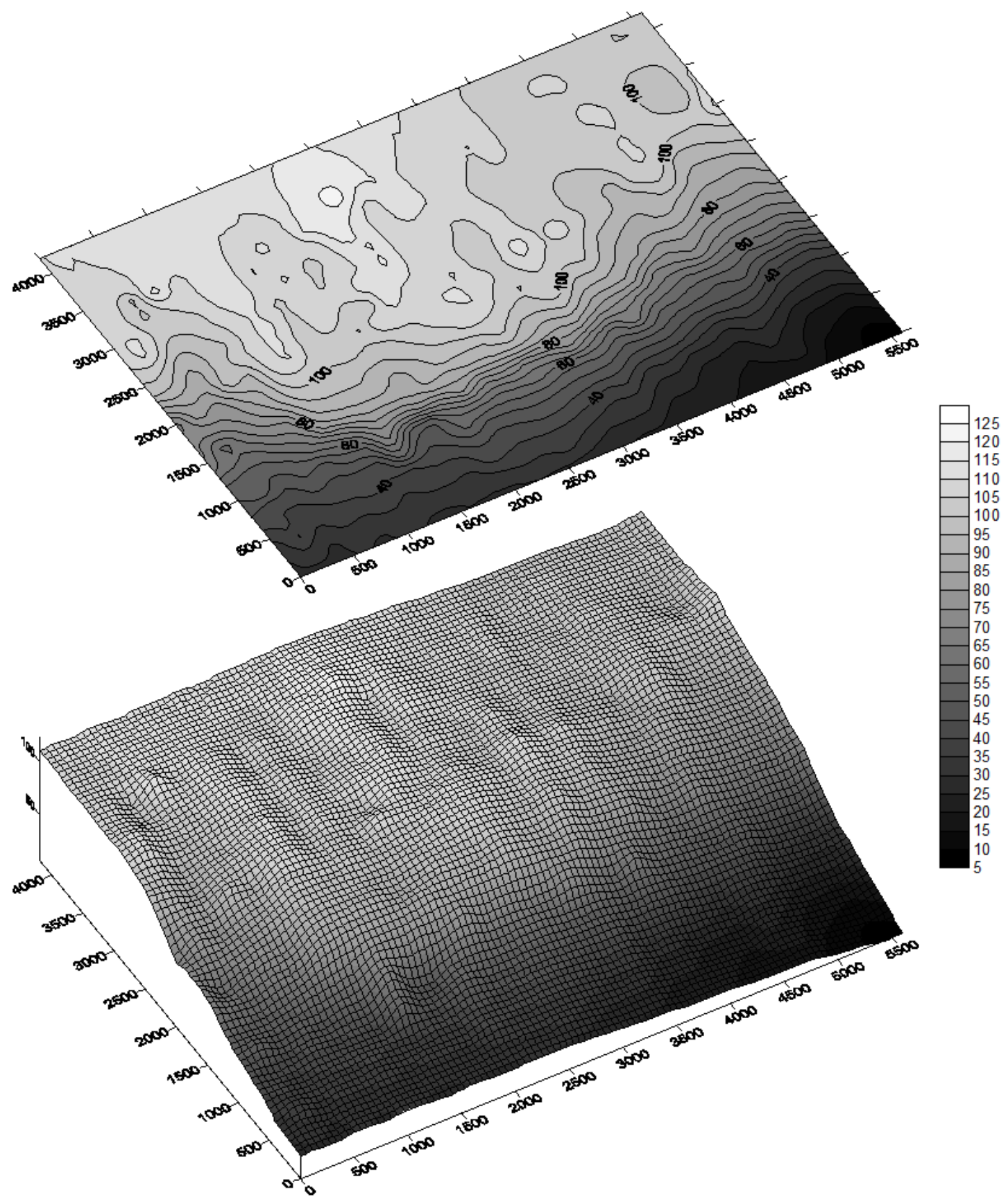

Figura 36 - Composição de mapa de contorno topográfico com curvas de nível (acima) e modelo de superfície 3D (wireframe) referente ao ano de 2004. 


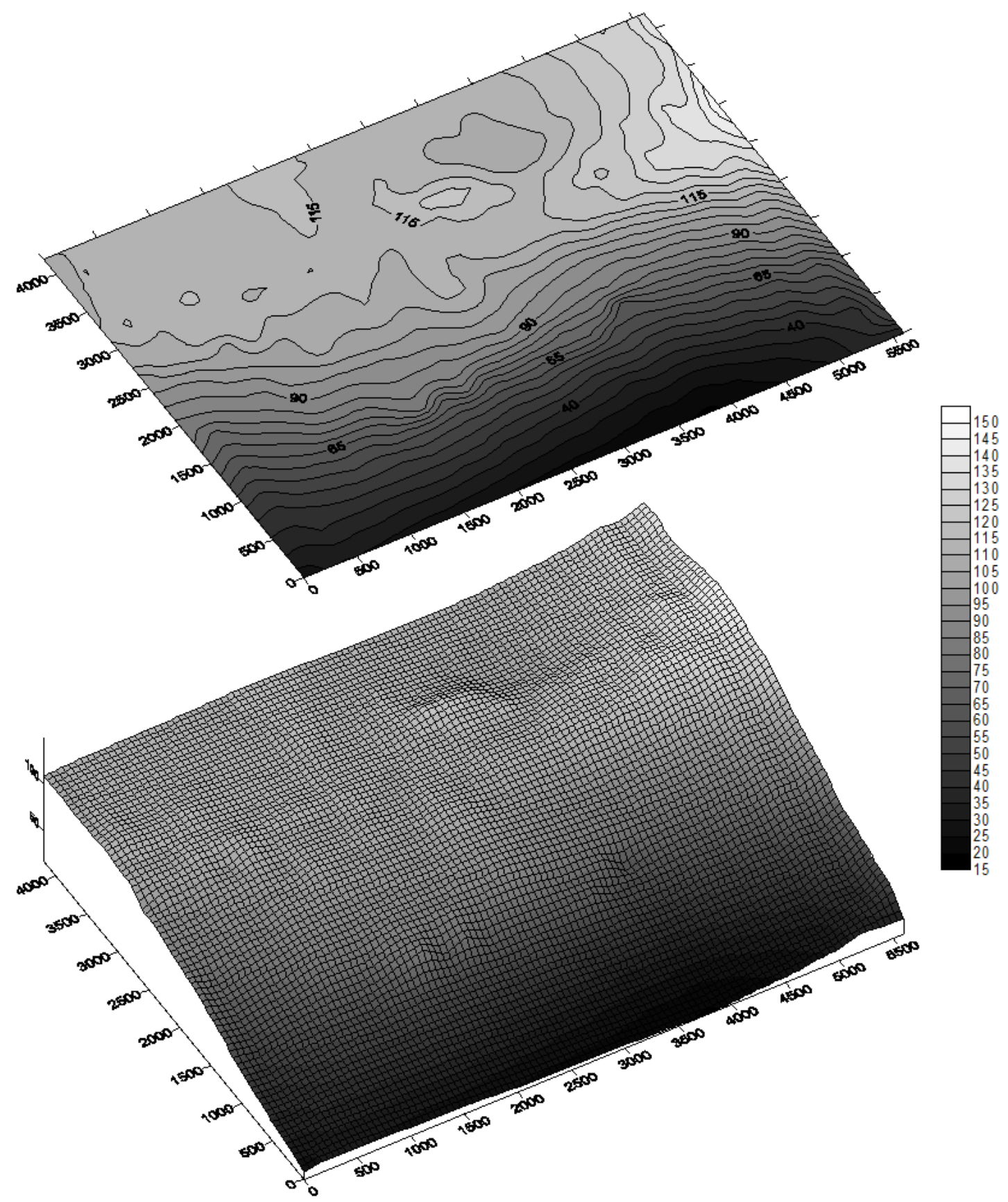

Figura 37 - Composição do mapa de contorno topográfico com curvas de nível e modelo de superfície 3D (wireframe) referente ao ano de 2008. 


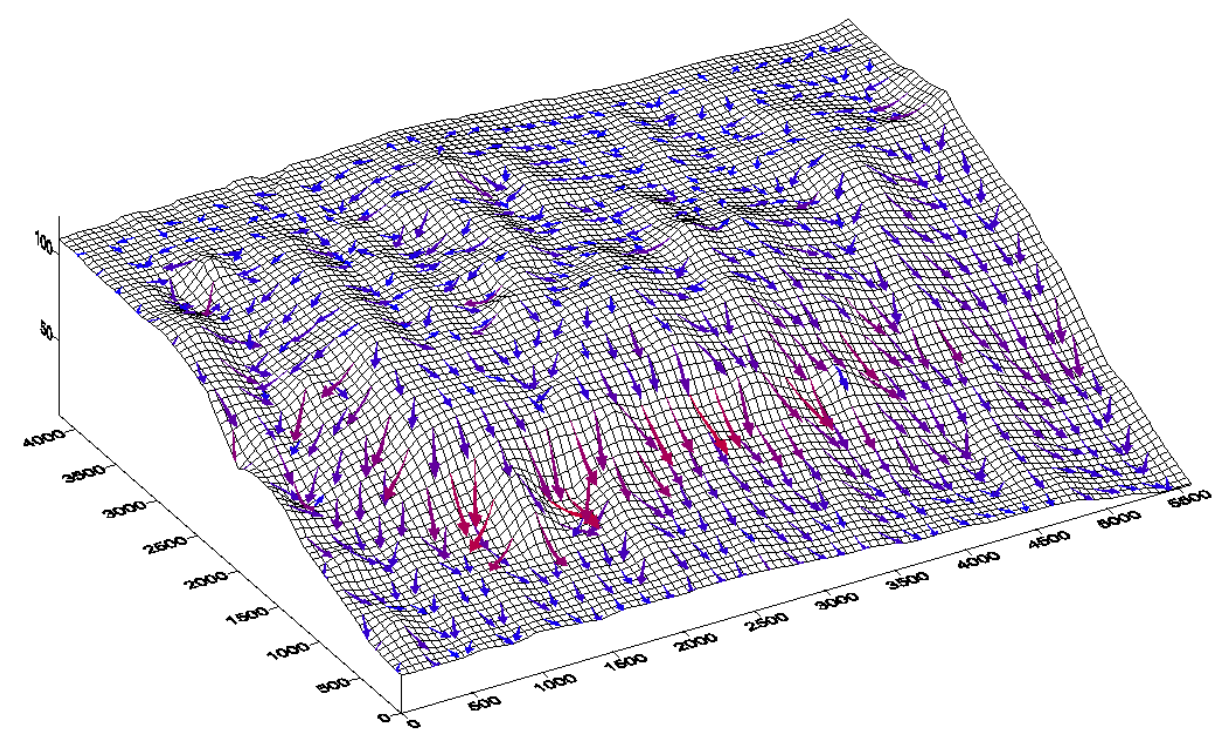

Figura 38 - Sobreposição do modelo de superfície 3D (wireframe) com malha vetorial representando o sentido da drenagem terrestre no terreno, referente a 2004.

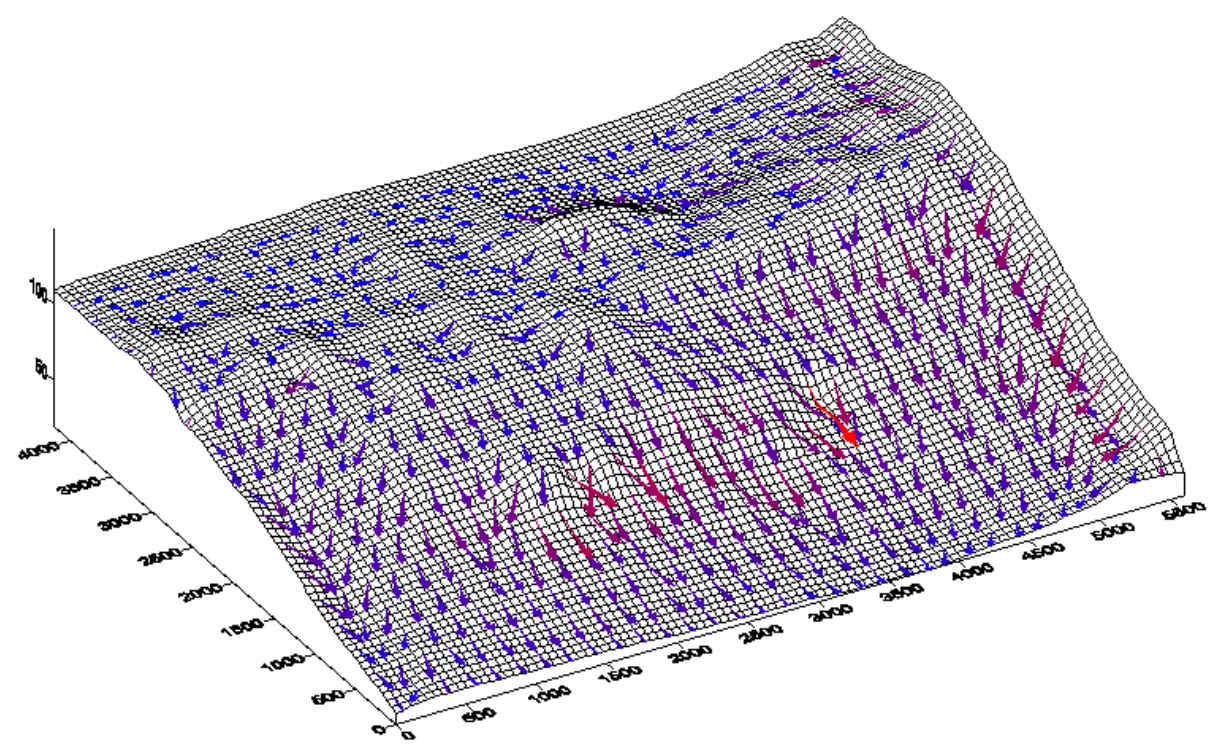

Figura 39 - Sobreposição do modelo de superfície 3D (wireframe) com malha vetorial representando o sentido da drenagem terrestre no terreno, referente a 2008. 


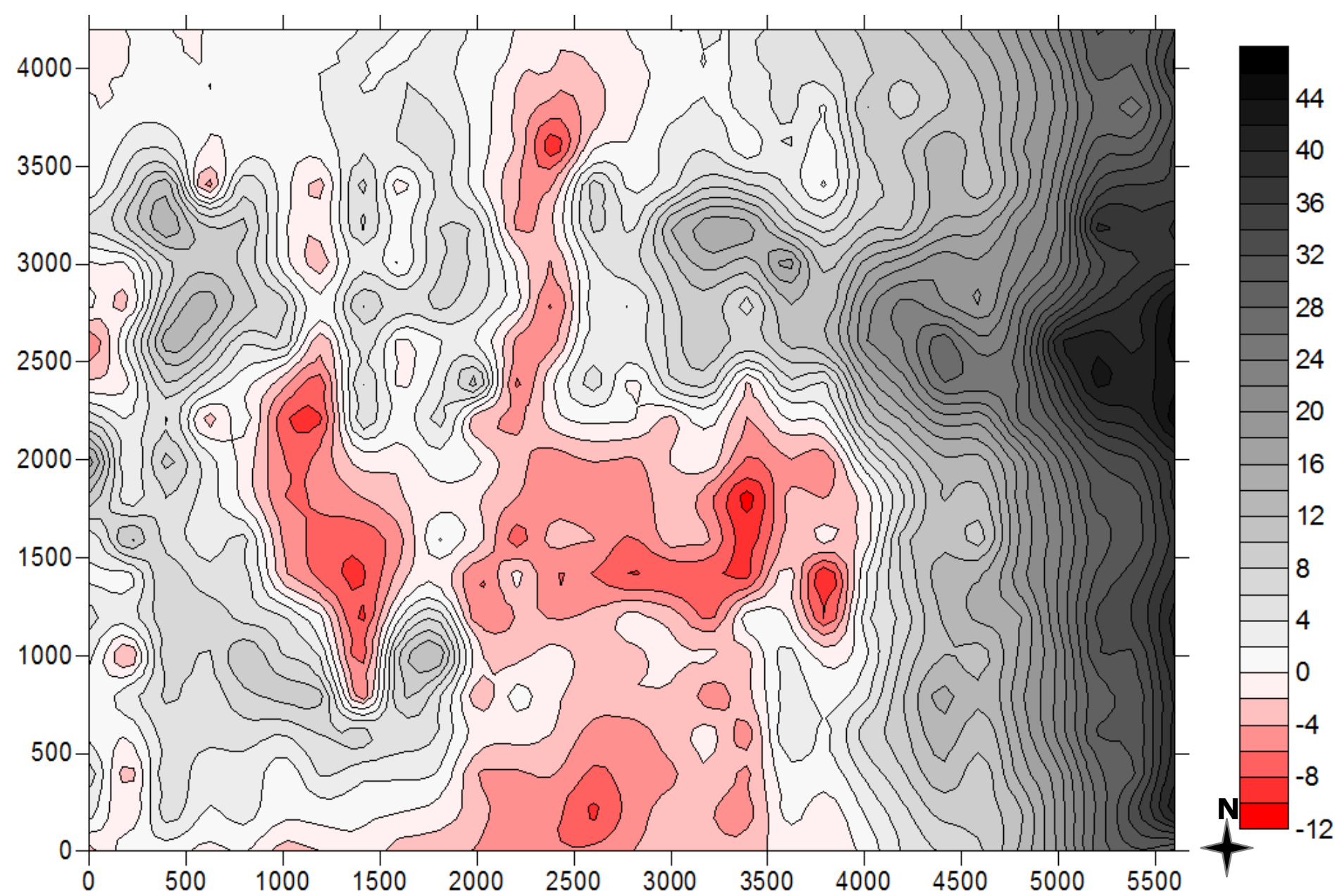

Figura 40 - Modelo gerado a partir do cálculo da dinâmica sedimentar ocorrida entre os anos de 2004 e 2008. Os valores (em centímetros) positivos (gradiente cinza) são referentes ao aumento na cota do terreno gerado por processo de sedimentação/colonização de vegetação e os valores (em centímetros) negativos (gradiente vermelho) referentes ao rebaixamento na cota do terreno por erosão/morte de vegetação. 
Conforme descrito anteriormente, todas as transversais realizadas para o estudo microtopográfico foram traçadas no sentido sul-norte, portanto todos os modelos gerados estão neste sentido de localização.

Os modelos gerados referentes ao ano de 2004 mostram claramente um grande desnível na topografia do terreno localizado entre a vegetação remanescente e a antiga franja do bosque que foi queimada no evento ocorrido em 1998. Nesta data também é possível observar cotas do terreno mais rebaixadas nas laterais (porção leste e oeste) do bosque de mangue.

Nos modelos de 2008, este desnível tornou-se mais suave, porém a cota do terreno mais baixa aumentou em direção ao bosque de mangue, provocando uma intensa mortalidade de indivíduos na franja do bosque.

Neste modelo também se pode observar algumas áreas onde ocorreu um intenso processo de sedimentação, localizadas nas porções leste e oeste da área estudada, onde nos modelos de 2004 se mostravam com cotas do terreno mais baixas. Justamente nestas áreas ocorreu um intenso processo de colonização pela espécie típica de mangue Laguncularia racemosa (observações de campo).

O modelo da Figura 42 demonstra claramente o intenso processo de dinâmica sedimentar que ocorreu na área de estudo entre os anos estudados (2004-2008).

Podemos observar a intensa sedimentação que ocorreu principalmente na porção leste da área de estudo e de forma menos acentuada na porção oeste. Justamente na porção leste que observamos 
as maiores mudanças na cota do terreno, onde podemos observar um aumento na cota do terreno de até 40 centímetros.

As áreas onde ocorreram as maiores taxas de erosão de sedimentos foram na porção central e sul, com a diminuição da cota do terreno nos casos mais extremos de até 12 centímetros.

A partir dos dados gerados também foi possível realizar uma avaliação do volume de sedimento presente nos dois modelos. Este levantamento foi realizado utilizando o programa gráfico SURFER ${ }^{\circledR}$ v.8.0 (2002).

A Tabela XX mostra a quantidade de sedimentos no terreno em ambas as datas:

Tabela XX - Volume estimado de sedimentos na área de estudo em 2004 e 2008.

\begin{tabular}{cc} 
Ano & Volume $\left(\mathbf{m}^{\mathbf{3}}\right)$ \\
\hline 2004 & $19.097 .583,72$ \\
2008 & $20.717 .533,22$ \\
Diferença entre 2008-2004 & $1.619 .949,50$ \\
\hline
\end{tabular}

Analisando os valores de volume de sedimento estimado, percebemos que a sedimentação foi mais intensa que a erosão, embora tenham ocorridos em regiões diferentes e específicas da área de estudo. O aumento no volume de sedimentos entre 2004 e 2008 foi de aproximadamente $7,82 \%$. 


\section{2 - ESTUDO DOS MANGUEZAIS DA ILHA BARNABÉ}

\subsection{1 - ANÁLISE MULTI-TEMPORAL DE FOTOGRAFIAS AÉREAS}

O registro tanto da carta topográfica como das fotografias aéreas (1962, 1972, 1994 e 2003) se mostrou eficaz, apresentando baixos valores de erro dos pontos de controle (Tabela XXI), resultando em exatidão na sobreposição das fotografias aéreas. Cabe destacar aqui que este procedimento de registro, sempre a partir de uma data anterior auxiliou o procedimento de registro das fotografias aéreas.

Tabela XXI - Dados do registro das fotografias aéreas.

\begin{tabular}{cccc}
\hline Data & $\begin{array}{c}\mathbf{N}^{\mathbf{0}} \text { de pontos } \\
\text { de controle }\end{array}$ & $\begin{array}{c}\text { Erro PC } \\
\text { (pixel) }\end{array}$ & $\begin{array}{c}\text { Erro no } \\
\text { terreno }(\mathbf{m})\end{array}$ \\
\hline 1962 & 12 & 1,643 & 1,74 \\
1972 & 13 & 1,369 & 1,45 \\
1994 & 15 & 1,134 & 1,20 \\
$2003 \mathrm{a}$ & 8 & 1,777 & 0,75 \\
$2003 \mathrm{~b}$ & 8 & 0,923 & 0,38 \\
$2003 \mathrm{c}$ & 7 & 1,695 & 0,72 \\
$2003 \mathrm{~d}$ & 7 & 0,856 & 0,36 \\
\hline
\end{tabular}

Foram geradas cartas no SCARTA de cada data (1962, 1972, 1994 e 2003), das composições coloridas (1962/1972, 1972/1994 e 1994/2003), dos mapas temáticos $(1962,1972,1994$ e 2003) e da localização das áreas de estudo para caracterização estrutural da cobertura vegetal.

Na fotografia aérea de 1962 (Figura 41), podemos ver que a Ilha Barnabé possuía ocupação apenas na sua porção sul, onde já existiam empresas operando (note os tanques, que aparecem na foto aérea como grandes círculos brancos), além de uma estrada que corta a parte sul da 
Ilha. Os manguezais da porção norte e leste da Ilha, ainda não apresentavam sinais claros de degradação.

A fotografia aérea de 1972 (Figura 42) mostra claramente o início da construção de uma estrada de acesso a Ilha, ligando esta a Rodovia SP-055. Pode-se notar também uma ampliação da área dos terminais que operam na Ilha na porção sul, aterrando desta forma área de manguezal. Estas diferenças ficam claras na composição colorida de ambas as datas. A fotografia aérea de 1962 em verde e a de 1972 em azul (Figura 43).

As maiores alterações na paisagem foram observadas na fotografia aérea de 1994 (Figura 44), assim como na composição colorida das datas de 1972 em verde e a de 1994 em azul (Figura 45).

Neste período (1972 a 1994) podemos ver a estrada de acesso a Rodovia SP-055 construída no sentido sudoeste-nordeste e uma ferrovia cortando toda a extensão da Ilha sentido sudeste-noroeste. Estas duas construções juntamente com a antiga estrada que cortava a Ilha na porção sul, interferiram na circulação, tanto da maré, como da drenagem em parte da Ilha, formando uma lagoa artificial aprisionada por estas três vias no centro da Ilha.

Nas mesmas figuras, é nítida a degradação dos manguezais da porção norte e leste da Ilha em decorrência destas construções. Podemos observar uma grande quantidade de clareiras no dossel da vegetação.

Outra construção que pode ser observada é a ampliação das empresas que operam na Ilha, em 1972, nota-se apenas o aterro e em 1994 a construção já realizada. 
A fotografia aérea de 2003 (Figura 46) pelo fato de ser colorida e estar numa escala menor facilitou muito a observação de maiores detalhes quanto ao estado de conservação dos manguezais. Podemos observar que algumas clareiras no dossel dos manguezais que eram visíveis na fotografia aérea de 1994 não aparecem mais em 2003.

A localização exata das áreas de recomposição da cobertura vegetal, assim como das clareiras ainda presentes na área são facilmente observadas na composição das fotografias aéreas de 1994 e 2003 (Figura 47). Nesta composição colorida, ao contrário das anteriores, utilizou-se a fotografia aérea de 1994 em azul e a de 2003 em verde, isto foi fundamental para destacar as áreas onde ocorreu recomposição natural nas clareiras do dossel.

Os mapas temáticos (Figuras 48, 49, 50 e 51), possibilitaram uma quantificação da área que o manguezal ocupava em 1962, e a perda parcial desta área em decorrência dos impactos antrópicos que atingiram o local (Tabela XXII).

Tabela XXII - Área estimada da cobertura vegetal do ecossistema manguezal ao longo dos anos de estudo e de seus respectivos impactos antrópicos.

\begin{tabular}{cccccc}
\hline \multirow{2}{*}{ Ano } & Manguezal & Clareiras & Aterramento & Área alagada & Abertura de canal \\
\hline 1962 & 190,41 & 0,23 & 0,00 & 0,00 & 0,00 \\
1972 & 181,71 & 0,00 & 7,08 & 0,00 & 0,00 \\
1994 & 130,00 & 19,27 & 26,38 & 6,32 & 4,70 \\
2003 & 143,66 & 5,08 & 20,02 & 6,21 & 4,76 \\
\hline
\end{tabular}


Observando as Figuras 48 a 51 e a Tabela XXII, podemos observar que a área de manguezal na Ilha Barnabé que foi estimada em 1962 em 190,41 ha, diminuiu para 129,43 ha em 1994, em decorrência do aterro feito para construção da rodovia e da estrada de ferro, que ocasionaram por conseqüência clareiras na vegetação, aprisionamento de água e também pela retilinização de um canal. Porém a recomposição natural que ocorreu após esta data acarretou um incremento na área de manguezal em 2003 (142,26 ha). Este aumento ocorreu principalmente devido a recomposição natural parcial de algumas clareiras, que como pode ser observado, diminuíram em área.

A Figura 52 aponta a localização das parcelas onde foi realizada a caracterização estrutural da cobertura vegetal. 


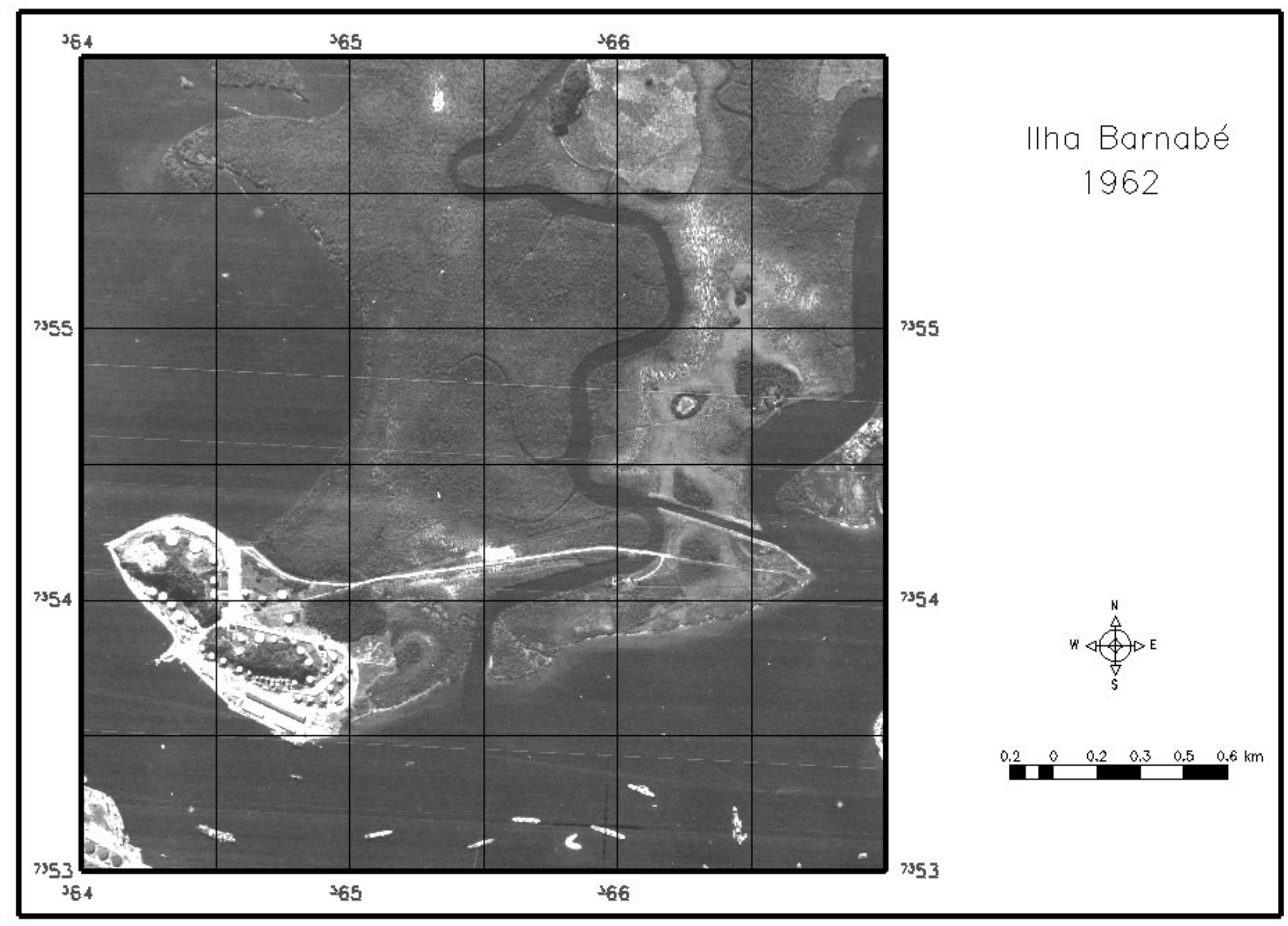

Figura 41 - Fotografia aérea de 1962. 


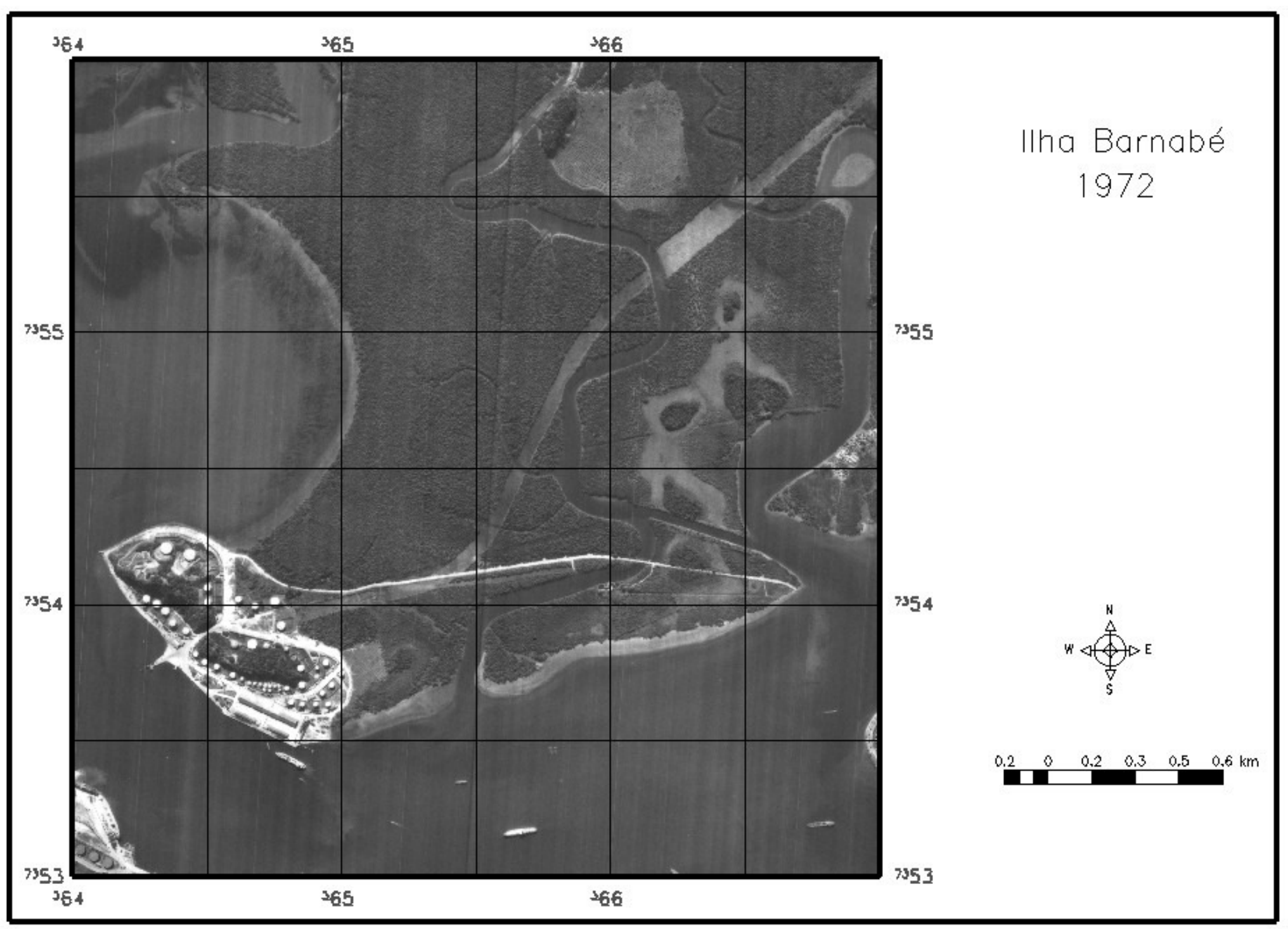

Figura 42 - Fotografia aérea de 1972. 


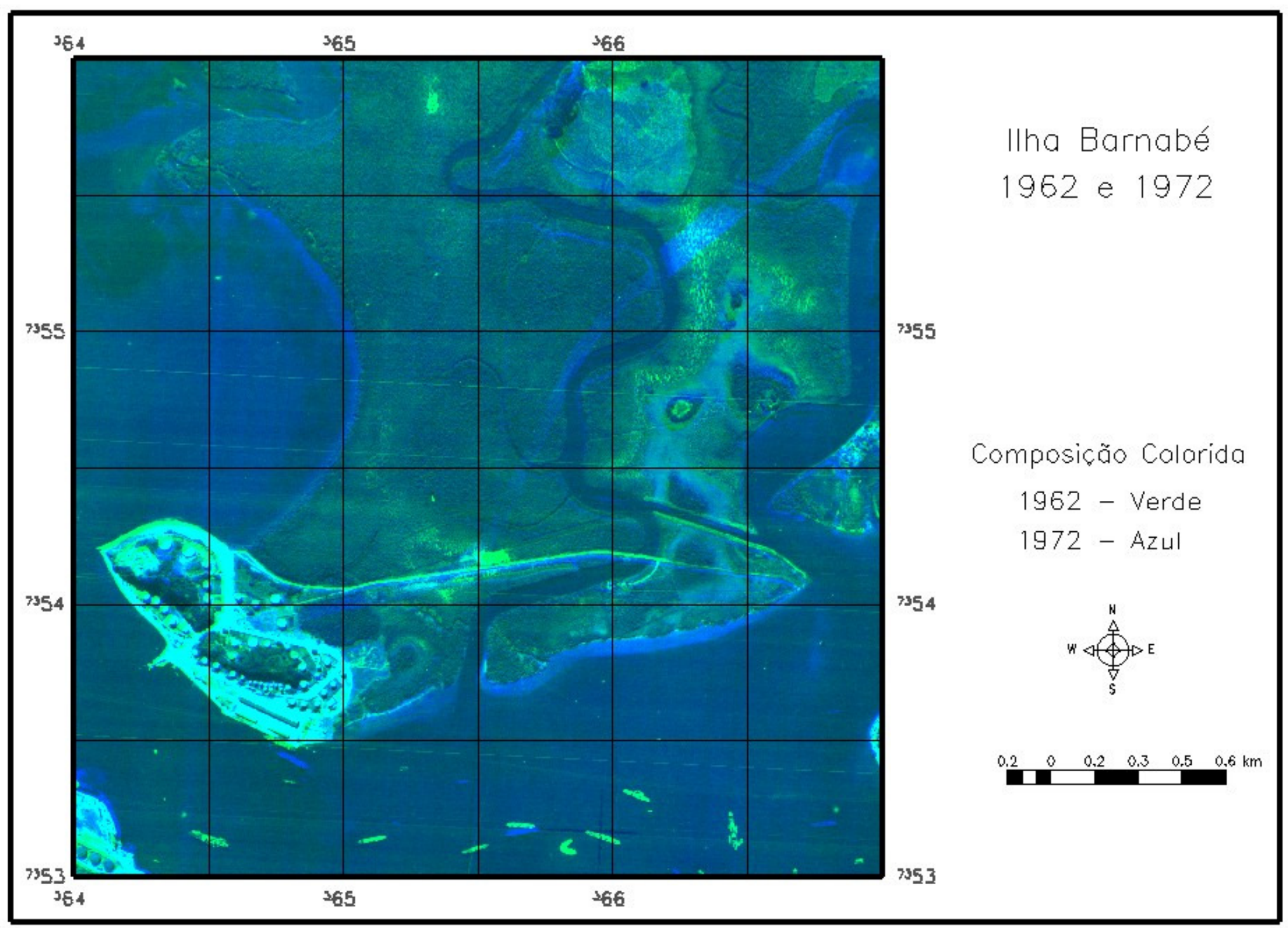

Figura 43 - Composição colorida das fotografias aéreas de 1962 e 1972. 


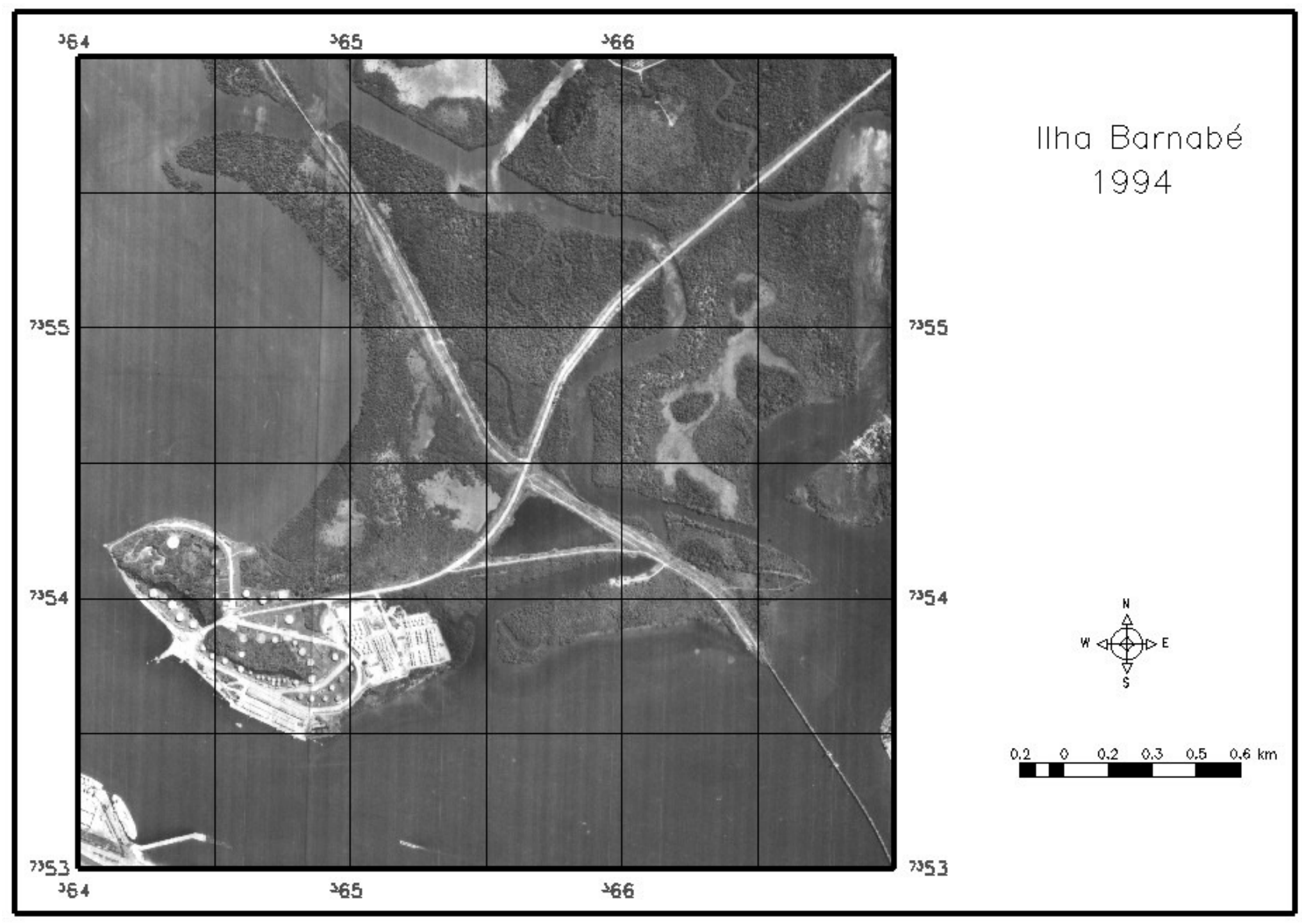

Figura 44 - Fotografia aérea de 1994. 


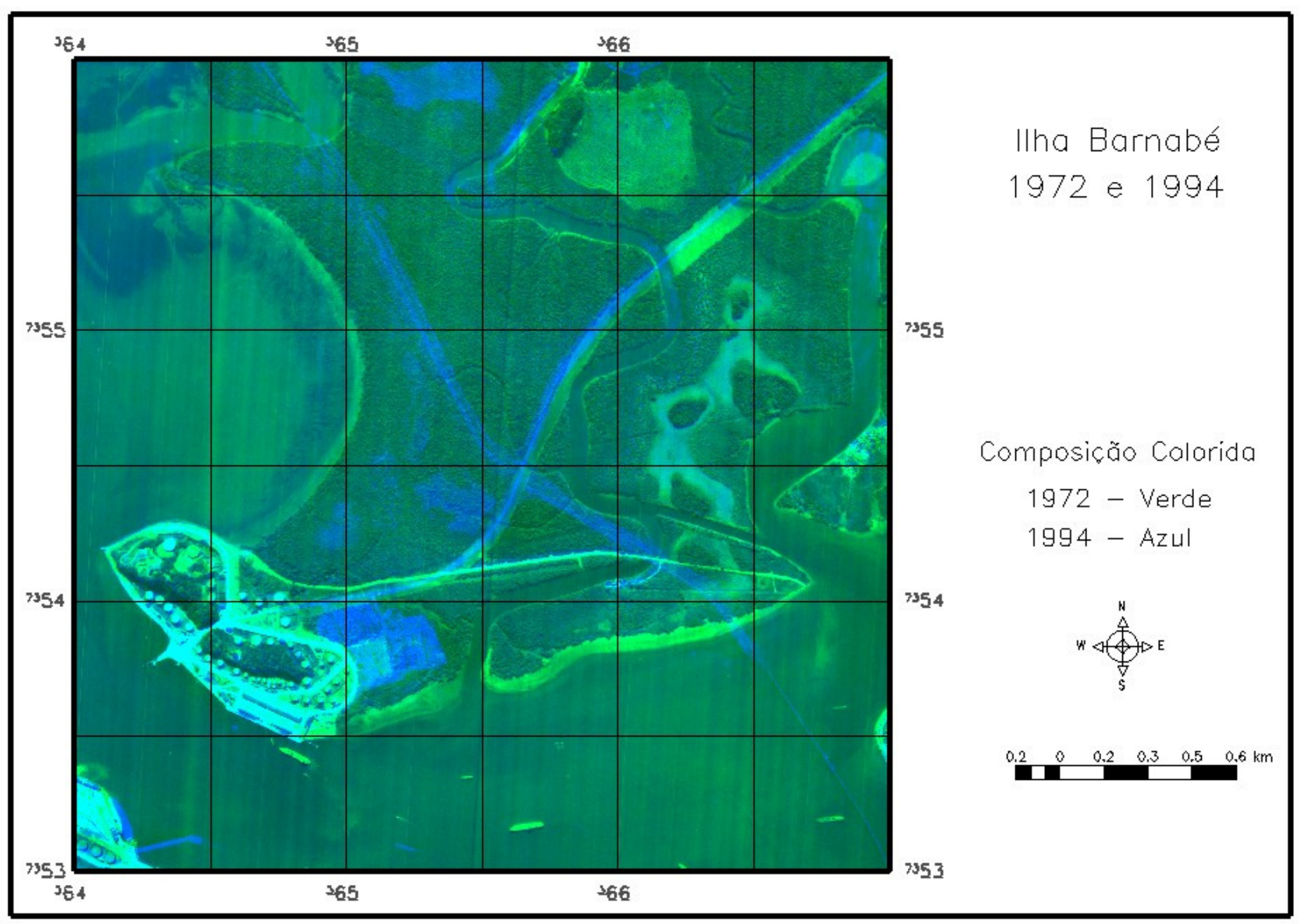

Figura 45 - Composição colorida das fotografias aéreas de 1972 e 1994. 


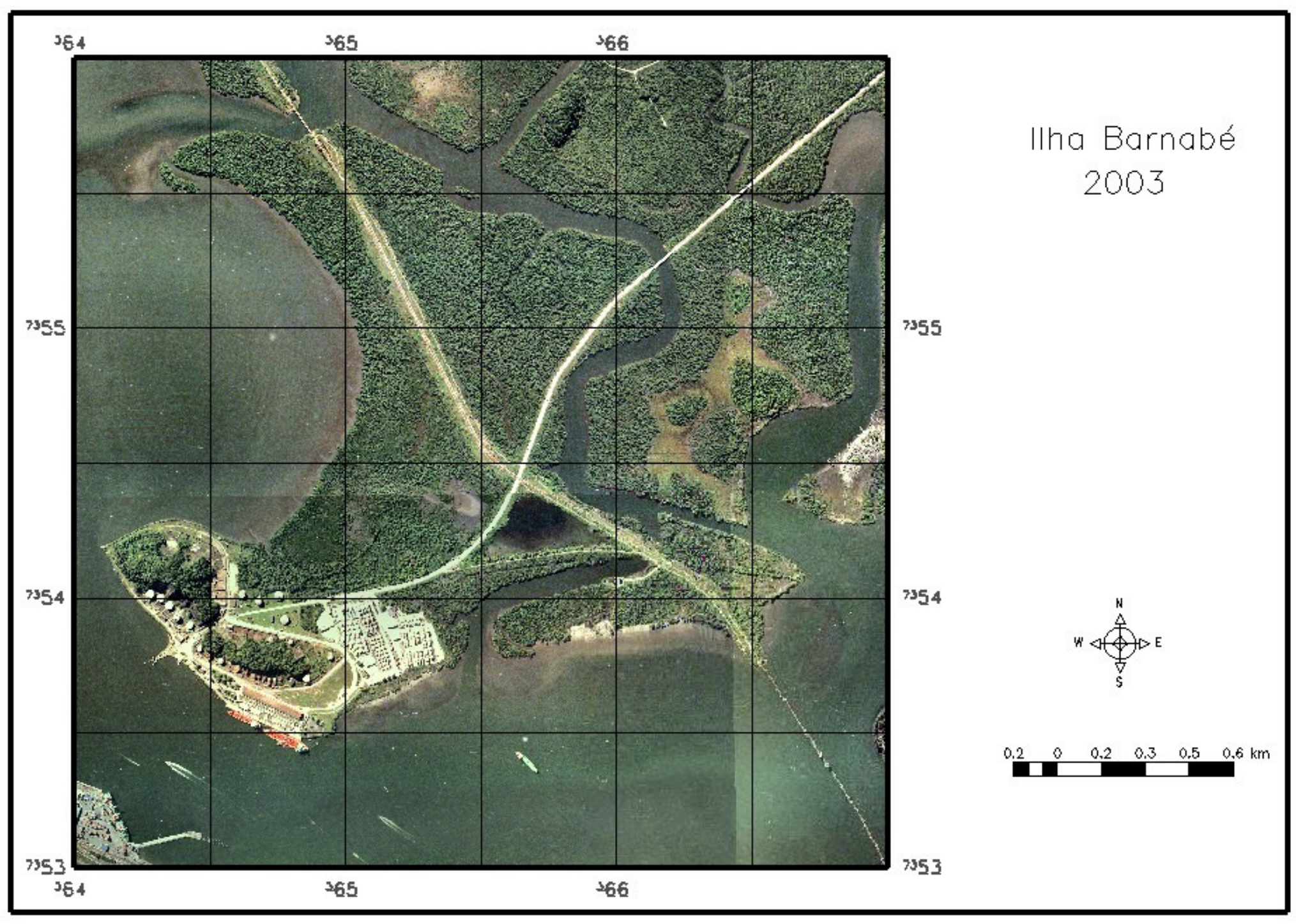

Figura 46 - Fotografia aérea de 2003. 


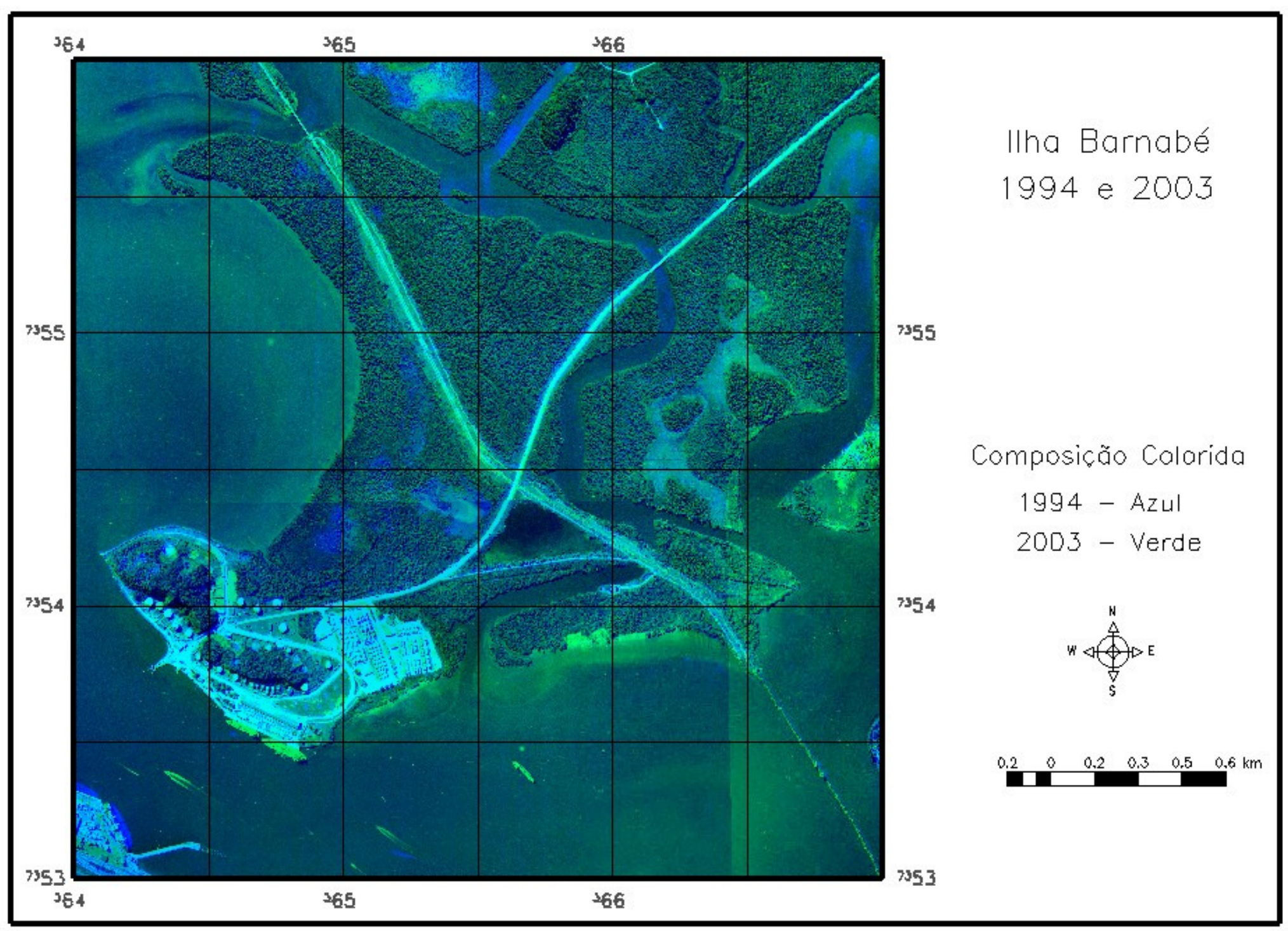

Figura 47 - Composição colorida das fotografias aéreas de 1994 e 2003. 


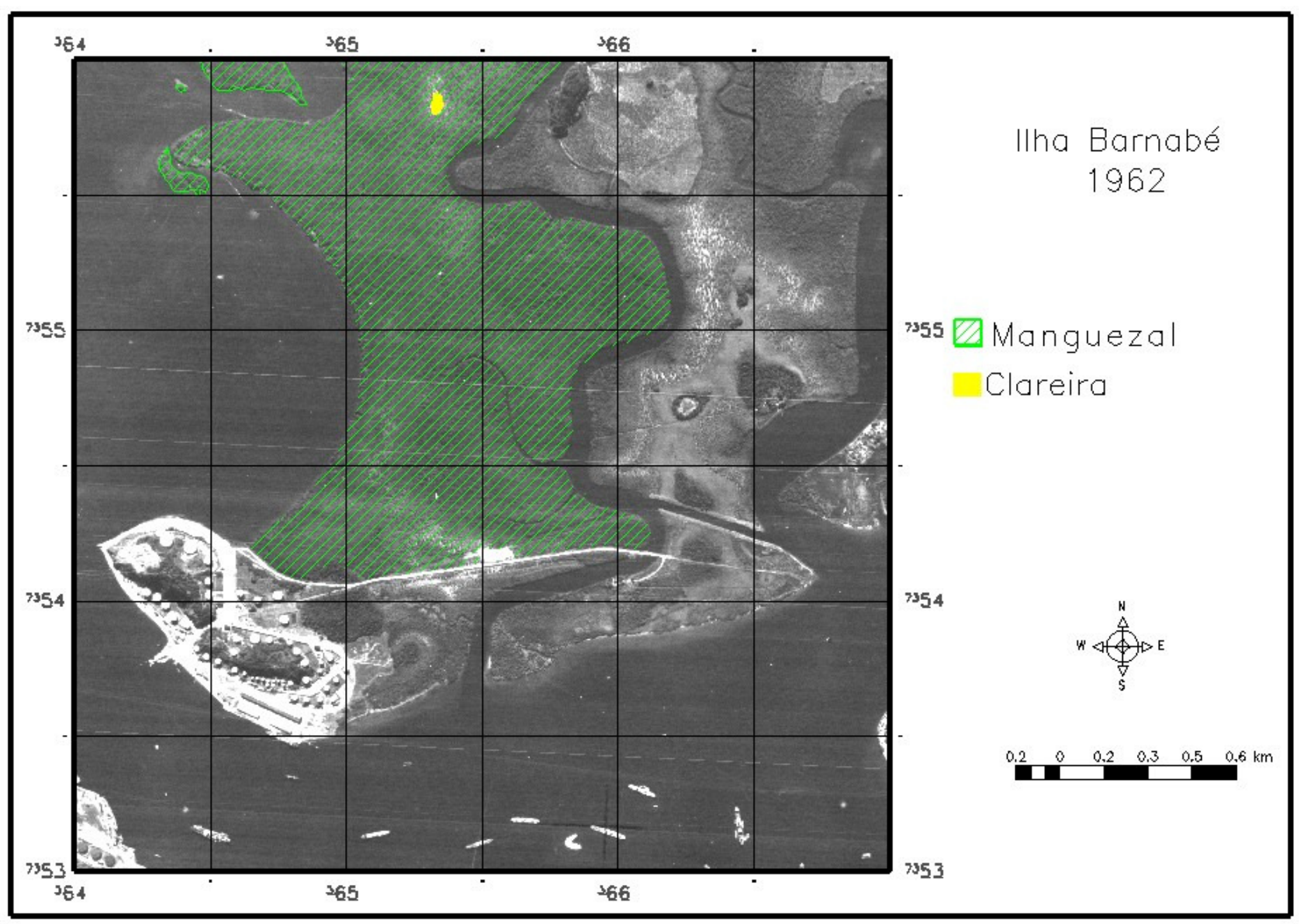

Figura 48 - Classificação das feições observadas na fotografia aérea de 1962. 


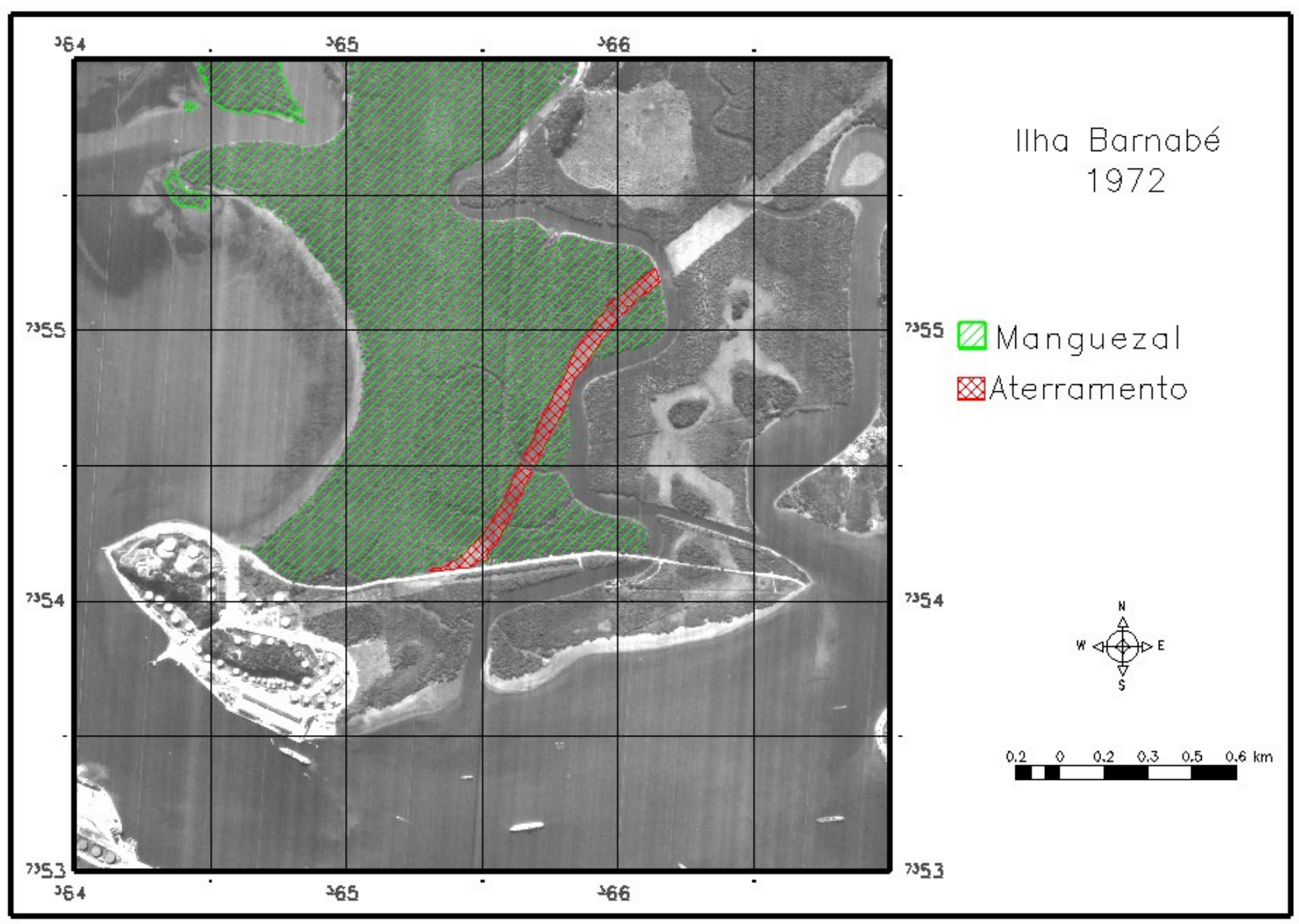

Figura 49 - Classificação das feições observadas na fotografia aérea de 1972. 


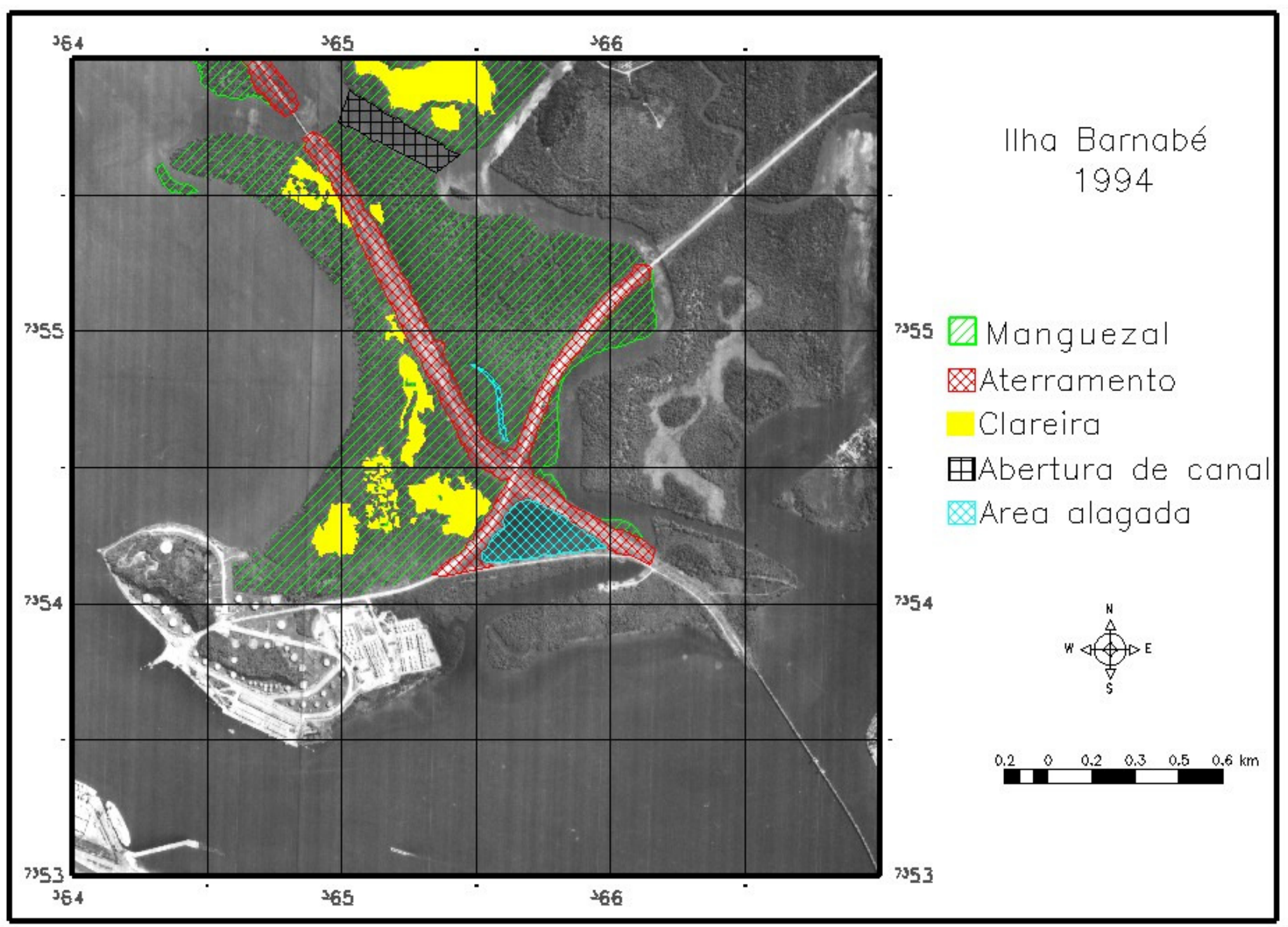

Figura 50 - Classificação das feições observadas na fotografia aérea de 1994. 


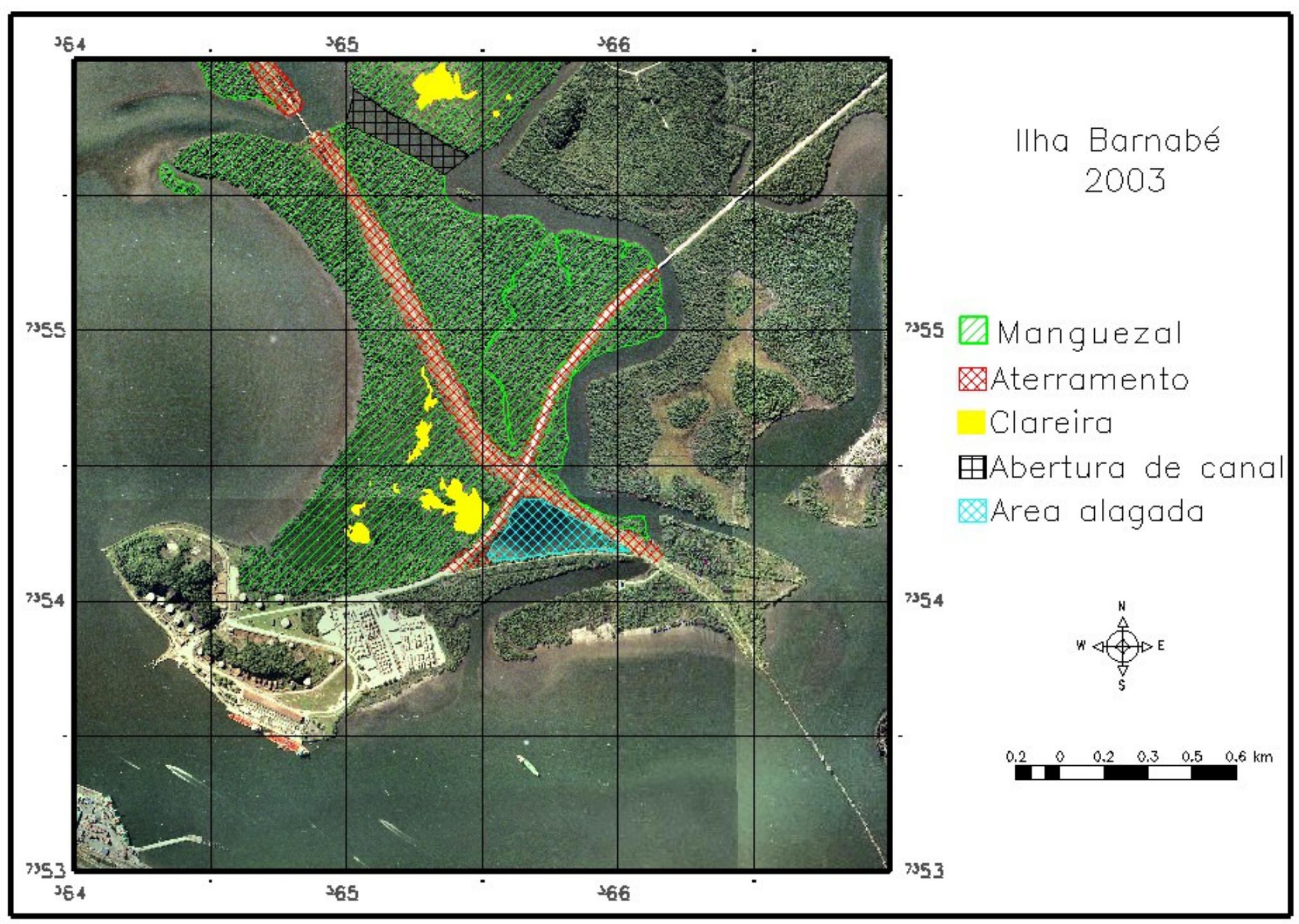

Figura 51 - Classificação das feições observadas na fotografia aérea de 2003. 


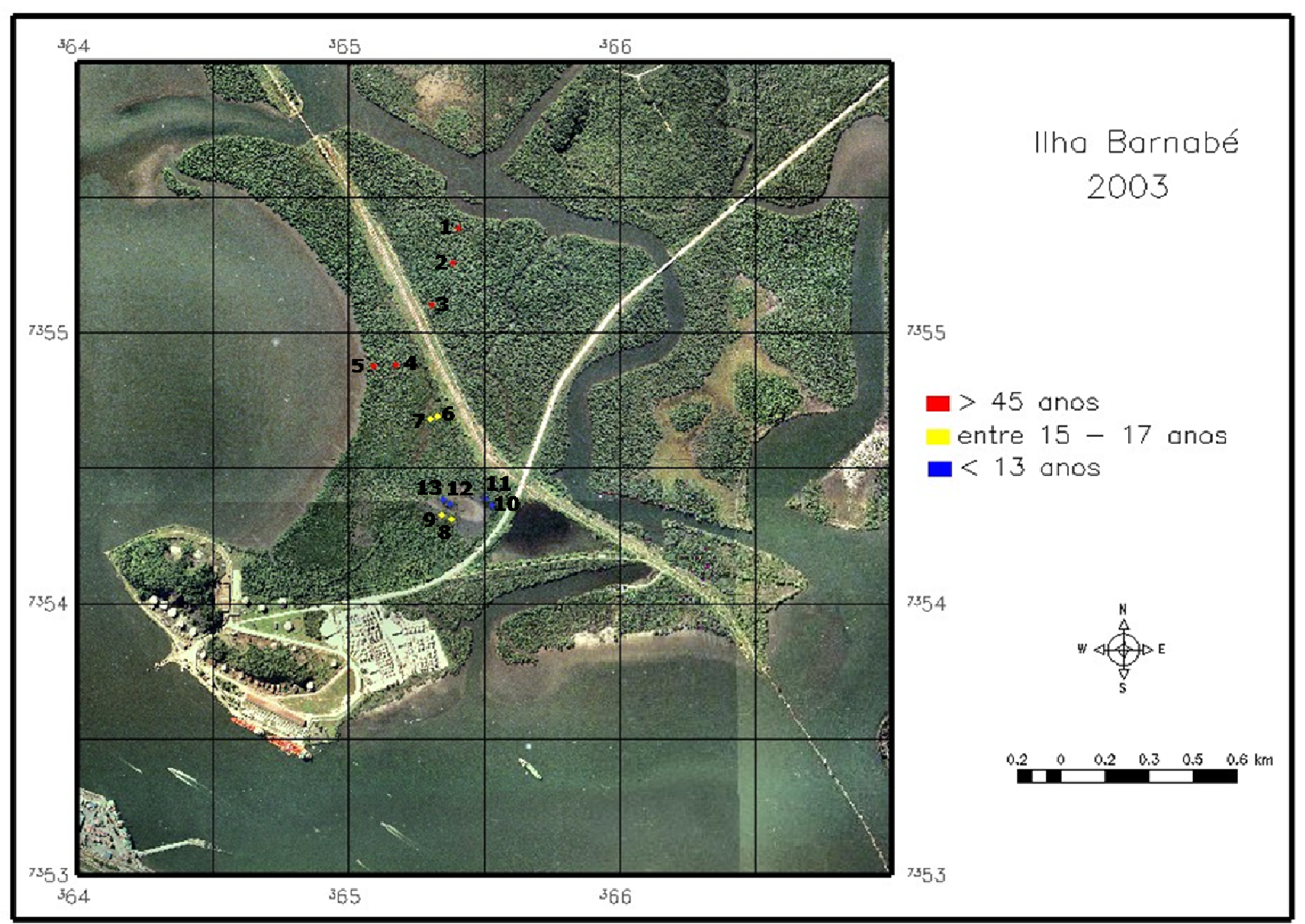

Figura 52 - Localização das parcelas onde foram realizadas a caracterização estrutural dos bosques de mangue em diferentes estágios sucessionais. 


\subsection{2 - CARACTERIZAÇÃO ESTRUTURAL DOS BOSQUES EM DIFERENTES ESTÁGIOS SUCESSIONAIS}

A idade para cada bosque foi estimada através do estudo em escala temporal das fotografias aéreas.

Na Tabela XXIII estão plotados as coordenadas geográficas de cada parcela e a idade estimada do bosque. Os dados estruturais estão plotados nas Tabelas XXIV a XXVII e nas Pranchas I a XXIV estão fotografias dos manguezais estudados, tabela com dados estruturais resumidos e figuras explicativas dos dados estruturais de cada parcela estudada.

Tabela XXIII - Coordenadas geográficas das parcelas e idade estimada dos respectivos bosques de mangue.

\begin{tabular}{cccc}
\hline Parcela & \multicolumn{2}{c}{ Coordenadas Geográficas } & Idade estimada \\
& Lat. & Long. & \\
\hline$\# 1$ & $23^{\circ} 54^{\prime} 35.8^{\prime \prime}$ & $46^{\circ} 19^{\prime} 23.7^{\prime \prime}$ & Superior a 45 anos \\
$\# 2$ & $23^{\circ} 54^{\prime} 30.8^{\prime \prime}$ & $46^{\circ} 19^{\prime} 20.9^{\prime \prime}$ & Superior a 45 anos \\
$\# 3$ & $23^{\circ} 54^{\prime} 26.7^{\prime \prime}$ & $46^{\circ} 19^{\prime} 20.1^{\prime \prime}$ & Superior a 45 anos \\
$\# 4$ & $23^{\circ} 54^{\prime} 42.9^{\prime \prime}$ & $46^{\circ} 19^{\prime} 28.5^{\prime \prime}$ & Superior a 45 anos \\
$\# 5$ & $23^{\circ} 54^{\prime} 43.1^{\prime \prime}$ & $46^{\circ} 19^{\prime} 31.4^{\prime \prime}$ & Superior a 45 anos \\
$\# 6$ & $23^{\circ} 54^{\prime} 49.2^{\prime \prime}$ & $46^{\circ} 19^{\prime} 23.2^{\prime \prime}$ & Entre $15-17$ anos \\
$\# 7$ & $23^{\circ} 54^{\prime} 49.4^{\prime \prime}$ & $46^{\circ} 19^{\prime} 24.0^{\prime}$ & Entre $15-17$ anos \\
$\# 8$ & $23^{\circ} 55^{\prime} 1.10^{\prime \prime}$ & $46^{\circ} 19^{\prime} 22.8^{\prime \prime}$ & Entre $15-17$ anos \\
$\# 9$ & $23^{\circ} 55^{\prime} 1.6^{\prime \prime}$ & $46^{\circ} 19^{\prime} 21.5^{\prime \prime}$ & Entre $15-17$ anos \\
$\# 10$ & $23^{\circ} 54^{\prime} 59.2^{\prime \prime}$ & $46^{\circ} 19^{\prime} 17.2^{\prime \prime}$ & Inferior a 13 anos \\
$\# 11$ & $23^{\circ} 55^{\prime} 60.0^{\prime \prime}$ & $46^{\circ} 19^{\prime} 16.3^{\prime \prime}$ & Inferior a 13 anos \\
$\# 12$ & $23^{\circ} 54^{\prime} 59.1^{\prime \prime}$ & $46^{\circ} 19^{\prime} 22.5^{\prime \prime}$ & Inferior a 13 anos \\
$\# 13$ & $23^{\circ} 54^{\prime} 59.7^{\prime \prime}$ & $46^{\circ} 19^{\prime} 21.5^{\prime \prime}$ & Inferior a 13 anos \\
\hline
\end{tabular}


Tabela XXIV - Número de indivíduos e de troncos amostrados, altura média e dap médio dos bosques de mangue da Ilha Barnabé.

\begin{tabular}{|c|c|c|c|c|c|c|c|c|}
\hline \multirow[b]{2}{*}{ Parcela } & \multirow{2}{*}{$\begin{array}{c}\mathbf{N}^{\circ} \\
\text { ind }^{s} \text {. }\end{array}$} & \multirow{2}{*}{$\begin{array}{c}\mathbf{N}^{\circ} \\
\text { troncos/ } \\
\mathbf{N}^{\circ} \text { ind. }\end{array}$} & \multirow{2}{*}{$\begin{array}{c}\text { Densidade } \\
\left(n^{\circ} \text { ind }^{5} \cdot m^{-2}\right)\end{array}$} & \multirow{2}{*}{$\begin{array}{c}\text { Densidade } \\
\left(\mathrm{N}^{\circ} \text { troncos. } \mathrm{m}^{-2}\right)\end{array}$} & \multicolumn{3}{|c|}{ Altura do bosque $(\mathrm{m})$} & \multirow{2}{*}{$\begin{array}{l}\text { dap } \\
\text { médio } \\
(\mathrm{cm})\end{array}$} \\
\hline & & & & & Inferior & Superior & Média & \\
\hline$\# 1$ & 39 & 1,21 & 3900 & 4700 & 1,60 & 13,60 & 5,77 & 8,21 \\
\hline \#2 & 35 & 1,34 & 1167 & 1567 & 1,70 & 13,60 & 9,03 & 13,64 \\
\hline \#3 & 40 & 1,80 & 1000 & 1800 & 1,60 & 12,60 & 6,17 & 10,96 \\
\hline \#4 & 40 & 1,13 & 1778 & 2000 & 1,60 & 12,00 & 6,36 & 9,60 \\
\hline \#5 & 38 & 1,32 & 1689 & 2222 & 1,60 & 12,80 & 8,15 & 11,40 \\
\hline \#6 & 36 & 1,17 & 14400 & 16800 & 1,00 & 5,20 & 3,90 & 4,31 \\
\hline \#7 & 22 & 1,50 & 8800 & 13200 & 2,20 & 5,40 & 3,91 & 3,55 \\
\hline \#8 & 30 & 1,67 & 6122 & 10204 & 0,50 & 5,40 & 1,71 & 5,76 \\
\hline$\# 9$ & 26 & 1,62 & 5306 & 8571 & 0,50 & 8,40 & 5,62 & 6,90 \\
\hline \#10 & 28 & 3,07 & 5600 & 17200 & 6,00 & 8,00 & 7,25 & 5,58 \\
\hline \#11 & 28 & 2,82 & 5600 & 15800 & 6,00 & 7,60 & 6,79 & 5,44 \\
\hline$\# 12$ & 27 & 1,44 & 5510 & 7959 & 1,70 & 6,40 & 4,47 & 4,56 \\
\hline \#13 & 33 & 1,88 & 6735 & 12653 & 2,10 & 5,20 & 4,36 & 5,14 \\
\hline
\end{tabular}


Tabela XXV - Densidade relativa (\%) de troncos vivos e mortos, por espécie e por classe de dap dos bosques de mangue da Ilha Barnabé.

\begin{tabular}{|c|c|c|c|c|c|c|c|c|c|c|}
\hline \multicolumn{11}{|c|}{ Troncos vivos } \\
\hline \multirow{2}{*}{ Parcela } & \multicolumn{3}{|c|}{$<2,5 \mathrm{~cm}$} & \multicolumn{3}{|c|}{$>2,5 \mathrm{~cm}$} & \multicolumn{3}{|c|}{$>10,0 \mathrm{~cm}$} & \multirow{2}{*}{$\begin{array}{c}\text { Total } \\
\text { (tronco/ha) }\end{array}$} \\
\hline & $\mathbf{R h}$ & Lg & Av & $\mathbf{R h}$ & Lg & Av & $\mathbf{R h}$ & Lg & Av & \\
\hline$\# 1$ & 21,28 & 0,00 & 4,26 & 17,02 & 0,00 & 38,30 & 2,13 & 0,00 & 14,89 & 97,87 \\
\hline$\# 2$ & 0,00 & 0,00 & 0,00 & 4,26 & 0,00 & 29,79 & 10,64 & 0,00 & 36,17 & 80,85 \\
\hline \#3 & 4,17 & 2,78 & 18,06 & 1,39 & 4,17 & 31,94 & 0,00 & 1,39 & 23,61 & 87,50 \\
\hline$\# 4$ & 0,00 & 0,00 & 15,56 & 0,00 & 8,89 & 35,56 & 0,00 & 0,00 & 28,89 & 88,89 \\
\hline \#5 & 0,00 & 0,00 & 2,04 & 0,00 & 6,12 & 32,65 & 0,00 & 6,12 & 22,45 & 69,39 \\
\hline \#6 & 0,00 & 14,29 & 0,00 & 0,00 & 76,19 & 2,38 & 0,00 & 0,00 & 0,00 & 92,86 \\
\hline$\# 7$ & 0,00 & 21,21 & 0,00 & 0,00 & 75,76 & 0,00 & 0,00 & 0,00 & 0,00 & 96,97 \\
\hline$\# 8$ & 0,00 & 0,00 & 0,00 & 0,00 & 16,67 & 0,00 & 0,00 & 0,00 & 0,00 & 16,67 \\
\hline \#9 & 0,00 & 0,00 & 2,38 & 0,00 & 35,71 & 0,00 & 0,00 & 0,00 & 0,00 & 38,10 \\
\hline \#10 & 0,00 & 0,00 & 0,00 & 0,00 & 61,63 & 0,00 & 0,00 & 0,00 & 0,00 & 61,63 \\
\hline \#11 & 0,00 & 0,00 & 0,00 & 0,00 & 69,62 & 0,00 & 0,00 & 0,00 & 0,00 & 69,62 \\
\hline \#12 & 2,56 & 0,00 & 12,82 & 10,26 & 46,15 & 0,00 & 0,00 & 0,00 & 0,00 & 71,79 \\
\hline \#13 & 0,00 & 1,61 & 6,45 & 0,00 & 66,13 & 0,00 & 0,00 & 0,00 & 0,00 & 74,19 \\
\hline \multicolumn{11}{|c|}{ Troncos Mortos } \\
\hline \multirow[t]{2}{*}{ Parcela } & \multicolumn{3}{|c|}{$<2,5 \mathrm{~cm}$} & \multicolumn{3}{|c|}{$>2,5 \mathrm{~cm}$} & \multicolumn{3}{|c|}{$>10,0 \mathrm{~cm}$} & $\begin{array}{c}\text { Total } \\
\text { (tronco/ha) }\end{array}$ \\
\hline & $\mathbf{R h}$ & Lg & Av & $\mathbf{R h}$ & Lg & Av & $\mathbf{R h}$ & Lg & Av & \\
\hline$\# 1$ & 0,00 & 0,00 & 0,00 & 0,00 & 0,00 & 2,13 & 0,00 & 0,00 & 0,00 & 2,13 \\
\hline$\# 2$ & 0,00 & 0,00 & 0,00 & 0,00 & 0,00 & 14,89 & 0,00 & 0,00 & 4,26 & 19,15 \\
\hline \#3 & 0,00 & 0,00 & 1,39 & 0,00 & 0,00 & 6,94 & 0,00 & 0,00 & 4,17 & 12,50 \\
\hline$\# 4$ & 0,00 & 0,00 & 0,00 & 0,00 & 0,00 & 6,67 & 0,00 & 0,00 & 4,44 & 11,11 \\
\hline \#5 & 0,00 & 0,00 & 0,00 & 0,00 & 8,16 & 16,33 & 2,04 & 2,04 & 2,04 & 30,61 \\
\hline \#6 & 0,00 & 0,00 & 0,00 & 0,00 & 7,14 & 0,00 & 0,00 & 0,00 & 0,00 & 7,14 \\
\hline \#7 & 0,00 & 3,03 & 0,00 & 0,00 & 0,00 & 0,00 & 0,00 & 0,00 & 0,00 & 3,03 \\
\hline \#8 & 0,00 & 2,08 & 0,00 & 0,00 & 81,25 & 0,00 & 0,00 & 0,00 & 0,00 & 83,33 \\
\hline$\# 9$ & 0,00 & 0,00 & 0,00 & 0,00 & 57,14 & 0,00 & 0,00 & 4,76 & 0,00 & 61,90 \\
\hline \#10 & 0,00 & 5,81 & 0,00 & 0,00 & 32,56 & 0,00 & 0,00 & 0,00 & 0,00 & 38,37 \\
\hline \#11 & 0,00 & 3,80 & 0,00 & 0,00 & 26,58 & 0,00 & 0,00 & 0,00 & 0,00 & 30,38 \\
\hline \#12 & 0,00 & 7,69 & 0,00 & 0,00 & 20,51 & 0,00 & 0,00 & 0,00 & 0,00 & 28,21 \\
\hline \#13 & 0,00 & 9,68 & 0,00 & 0,00 & 16,13 & 0,00 & 0,00 & 0,00 & 0,00 & 25,81 \\
\hline
\end{tabular}

$R h=$ Rhizophora mangle; $L g=$ Laguncularia racemosa; Av = Avicennia schaueriana 
Tabela XXVI - Área basal $\left(\mathrm{m}^{2} / \mathrm{ha}\right)$ viva e morta, por classe de dap dos bosques de mangue da Ilha Barnabé.

\begin{tabular}{|c|c|c|c|c|c|c|c|c|c|}
\hline \multirow{2}{*}{ Parcela } & \multicolumn{4}{|c|}{ Área basal viva $\left(\mathrm{m}^{2} / \mathrm{ha}\right)$} & \multicolumn{4}{|c|}{ Área basal morta $\left(\mathrm{m}^{2} / \mathrm{ha}\right)$} & \multirow{2}{*}{ Total geral } \\
\hline & $\begin{array}{c}<2.5 \\
\mathrm{~cm}\end{array}$ & $\begin{array}{c}2.5 \\
\mathrm{~cm}\end{array}$ & $\begin{array}{c}>10.0 \\
\mathrm{~cm}\end{array}$ & Total & $\begin{array}{c}<2.5 \\
\mathrm{~cm}\end{array}$ & $\begin{array}{c}2.5 \\
\mathrm{~cm}\end{array}$ & $\begin{array}{c}>10.0 \\
\mathrm{~cm}\end{array}$ & Total & \\
\hline$\# 1$ & 0,30 & 4,48 & 19,55 & 24,33 & 0,48 & 0,11 & 0,00 & 0,11 & 24,44 \\
\hline$\# 2$ & 0,00 & 1,75 & 16,77 & 18,52 & 0,00 & 0,47 & 0,91 & 1,38 & 19,90 \\
\hline \#3 & 0,14 & 1,49 & 13,23 & 14,87 & 0,05 & 0,33 & 2,56 & 2,89 & 17,76 \\
\hline \#4 & 0,10 & 1,92 & 10,84 & 12,86 & 0,00 & 0,08 & 2,30 & 2,38 & 15,24 \\
\hline \#5 & 0,02 & 2,28 & 13,13 & 15,43 & 0,00 & 1,62 & 2,79 & 4,41 & 19,84 \\
\hline \#6 & 0,75 & 22,03 & 0,00 & 22,78 & 0,00 & 1,76 & 0,00 & 1,76 & 24,44 \\
\hline \#7 & 0,81 & 11,88 & 0,00 & 12,69 & 0,05 & 0,00 & 0,00 & 0,05 & 12,75 \\
\hline$\# 8$ & 0,00 & 4,26 & 0,00 & 4,26 & 0,09 & 24,46 & 0,00 & 24,55 & 28,81 \\
\hline$\# 9$ & 0,04 & 12,17 & 0,00 & 12,21 & 0,00 & 15,91 & 3,54 & 19,45 & 31,65 \\
\hline$\# 10$ & 0,00 & 25,94 & 0,00 & 25,94 & 0,35 & 5,07 & 0,00 & 5,42 & 31,36 \\
\hline \#11 & 0,00 & 25,56 & 0,00 & 25,56 & 0,20 & 4,47 & 0,00 & 4,67 & 30,22 \\
\hline \#12 & 0,11 & 9,21 & 0,00 & 9,31 & 0,23 & 1,54 & 0,00 & 1,75 & 11,07 \\
\hline \#13 & 0,25 & 19,20 & 0,00 & 19,45 & 0,42 & 1,86 & 0,00 & 2,28 & 21,72 \\
\hline
\end{tabular}


Tabela XXVII - Dominância em área basal (\%) viva e morta por espécie e total dos bosques de mangue da Ilha Barnabé.

\begin{tabular}{ccccccccc}
\hline \multirow{2}{*}{ Parcela } & \multicolumn{3}{c}{ Área basal viva (\%) } & \multicolumn{3}{c}{ Área basal morta (\%) } \\
& Rh & Lg & Av & Total & Rh & Lg & Av & Total \\
\hline$\# 1$ & 7,78 & 0,00 & 91,76 & 99,54 & 0,00 & 0,00 & 0,46 & 0,46 \\
$\# 2$ & 16,63 & 0,00 & 76,43 & 93,06 & 0,00 & 0,00 & 6,94 & 6,94 \\
$\# 3$ & 0,20 & 5,63 & 77,88 & 83,70 & 0,00 & 0,00 & 16,30 & 16,30 \\
$\# 4$ & 0,00 & 3,73 & 80,64 & 84,37 & 0,00 & 0,00 & 15,63 & 15,63 \\
$\# 5$ & 0,00 & 11,14 & 66,64 & 77,78 & 2,53 & 6,26 & 13,43 & 22,22 \\
$\# 6$ & 0,00 & 91,88 & 0,93 & 92,81 & 0,00 & 7,19 & 0,00 & 7,19 \\
$\# 7$ & 0,00 & 99,58 & 0,00 & 99,58 & 0,00 & 0,42 & 0,00 & 0,42 \\
$\# 8$ & 0,00 & 14,79 & 0,00 & 14,79 & 0,00 & 85,21 & 0,00 & 85,21 \\
$\# 9$ & 0,00 & 38,45 & 0,11 & 38,57 & 0,00 & 61,43 & 0,00 & 61,43 \\
$\# 10$ & 0,00 & 82,71 & 0,00 & 82,71 & 0,00 & 17,29 & 0,00 & 17,29 \\
$\# 11$ & 0,00 & 84,55 & 0,00 & 84,55 & 0,00 & 15,45 & 0,00 & 15,45 \\
$\# 12$ & 16,42 & 66,84 & 0,90 & 84,16 & 0,00 & 15,84 & 0,00 & 15,84 \\
$\# 13$ & 0,00 & 88,78 & 0,74 & 89,52 & 0,00 & 10,48 & 0,00 & 10,48 \\
\hline
\end{tabular}

Rh = Rhizophora mangle; $L g=$ Laguncularia racemosa; Av = Avicennia schaueriana. 
Prancha I - Fotografias da parcela \#1: a) visão interna do bosque; b) sedimento; c) dossel.
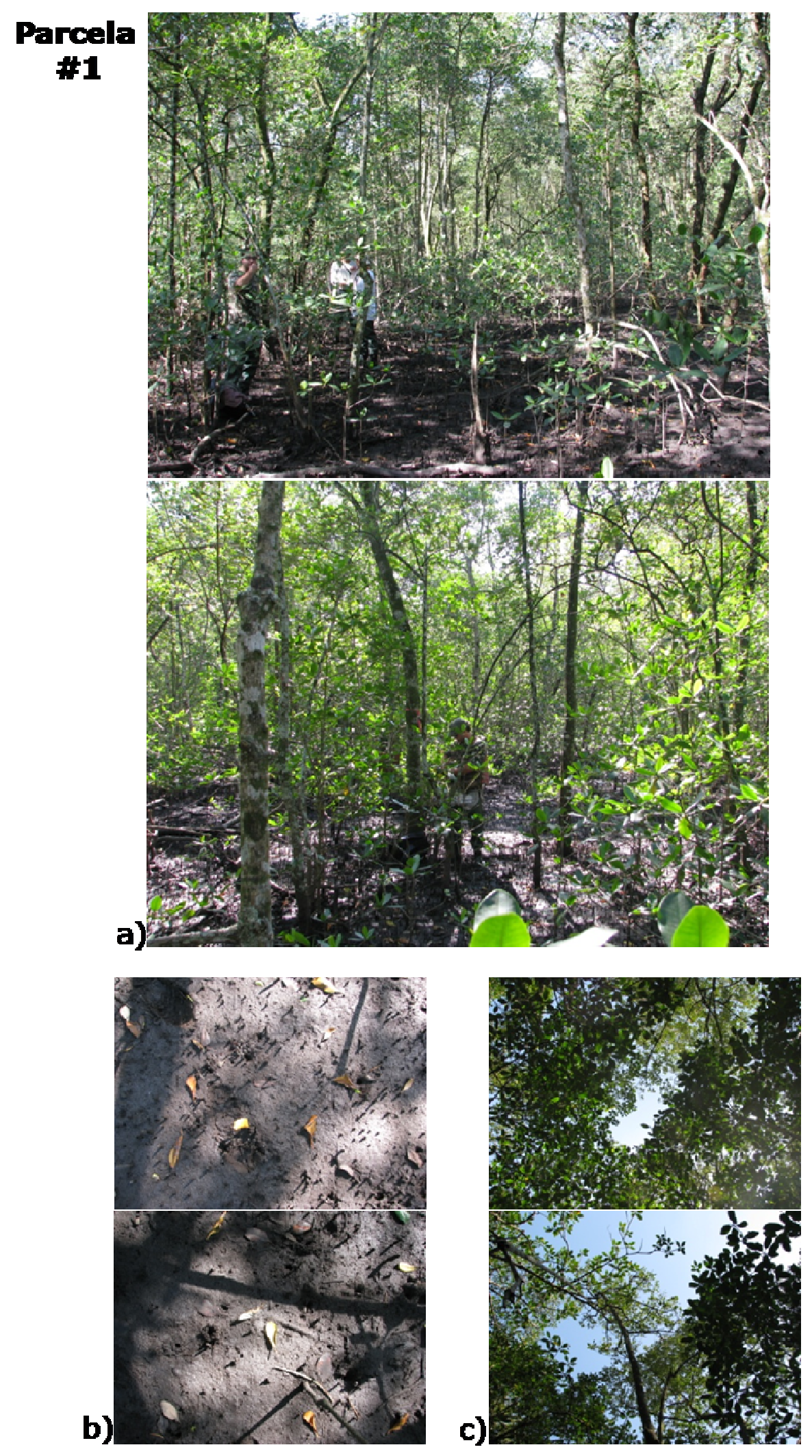
Prancha II - Características estruturais da parcela \#1: a) tabela com características estruturais; b) figura com a dominância (\%) dos indivíduos por classes de altura; c) figura com a dominância (\%) de troncos vivos e mortos por classes de dap.

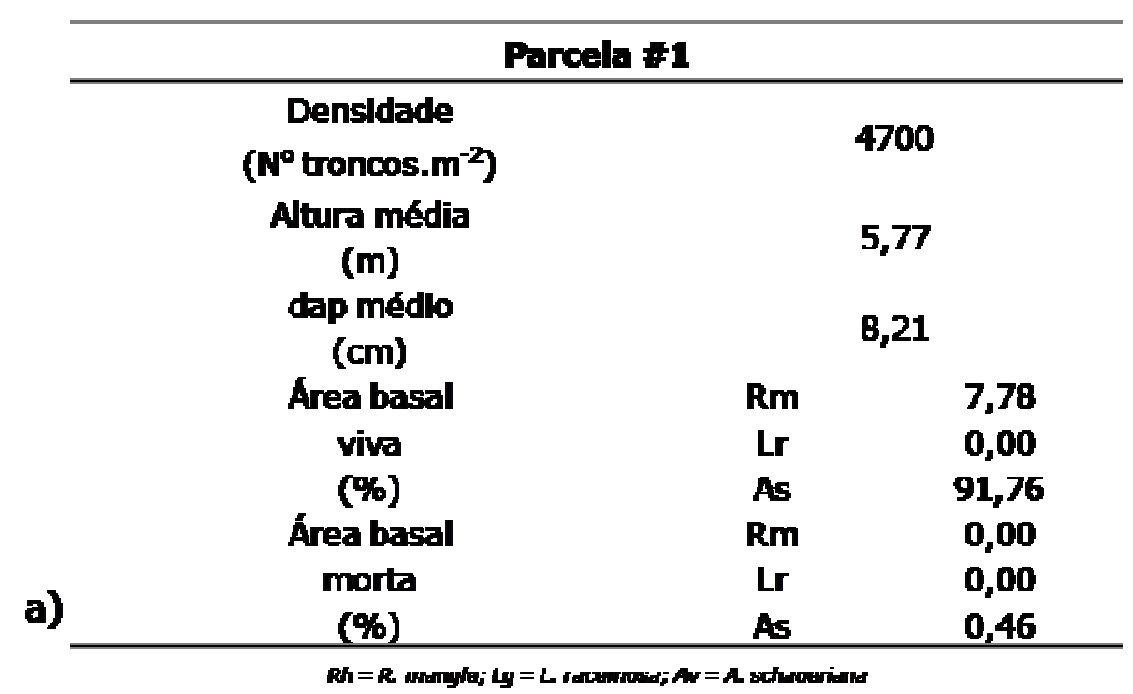

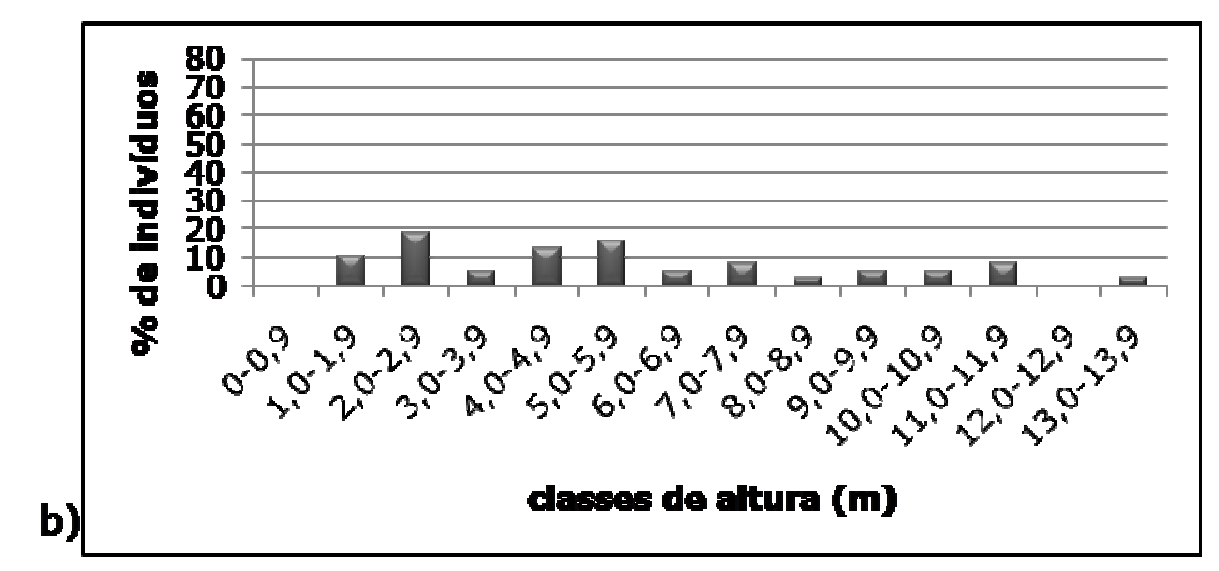

c)

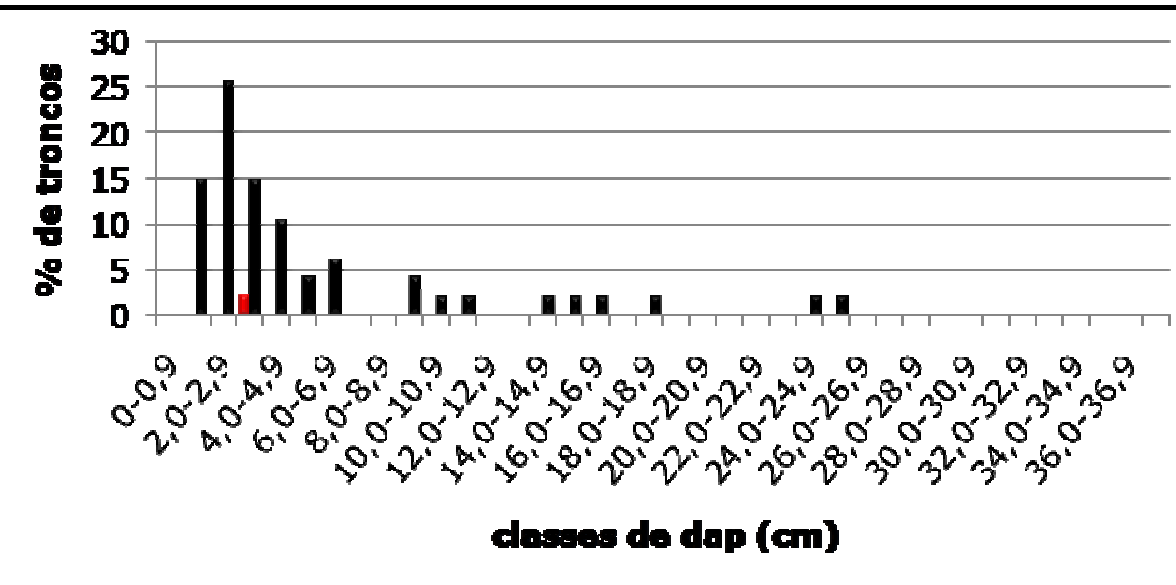

Mortos

a Vivos 
A parcela \#1 apresentou uma relação de 1,21 troncos por indivíduo. A densidade de indivíduos e de troncos por hectare foi de 4700 e de 3900, respectivamente.

A altura média dos indivíduos do bosque foi de 5,77 m, a inferior de $1,60 \mathrm{~m}$ e a superior de $13,60 \mathrm{~m}$, apresentando basicamente indivíduos em todas as faixas etárias de altura (de 1 a $13 \mathrm{~m}$ ), porém com dominância de indivíduos no intervalo de 2,0 a $6,0 \mathrm{~m}$ de altura.

O bosque apresentou uma grande dominância de indivíduos vivos com troncos de dap entre 1,0 a $6,9 \mathrm{~cm}$, com alguns indivíduos apresentando valores mais elevados de dap. $\mathrm{O}$ dap médio da parcela foi de $8,21 \mathrm{~cm}$.

A espécie que apresentou maior dominância de área basal viva foi $A$. schaueriana, principalmente de indivíduos com dap maior que $2,5 \mathrm{~cm}$. $R$. mangle apresentou dominância de área basal apenas nos indivíduos com dap menor que $2,5 \mathrm{~cm}$.

O dossel das árvores do bosque se mostrou bem fechado e o sedimento com poucas raízes respiratórias (pneumatóforos). 
Prancha III - Fotografias da parcela \#2: a) visão interna do bosque; b) sedimento; c) dossel.
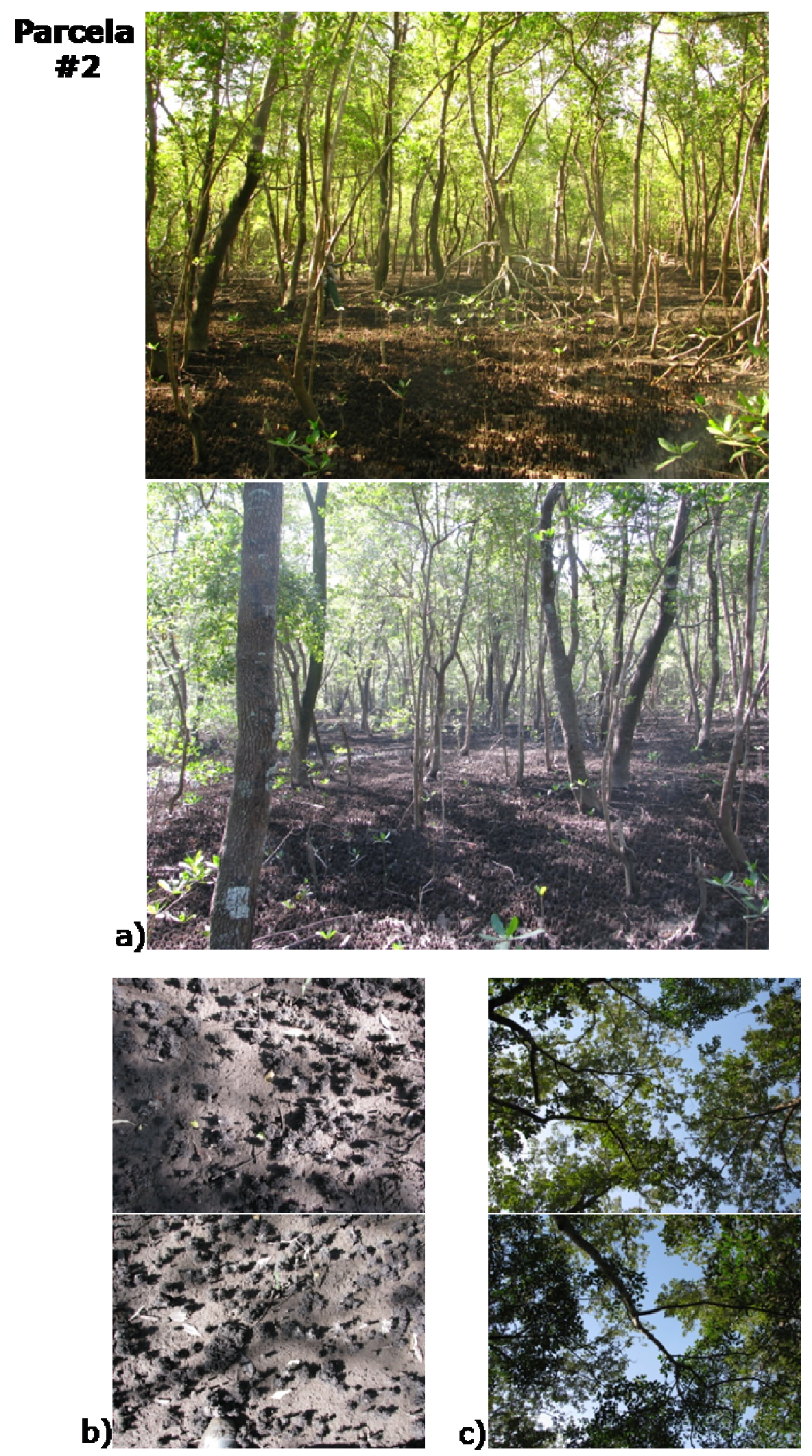
Prancha IV - Características estruturais da parcela \#2: a) tabela com características estruturais; b) figura com a dominância (\%) dos indivíduos por classes de altura; c) figura com a dominância (\%) de troncos vivos e mortos por classes de dap.

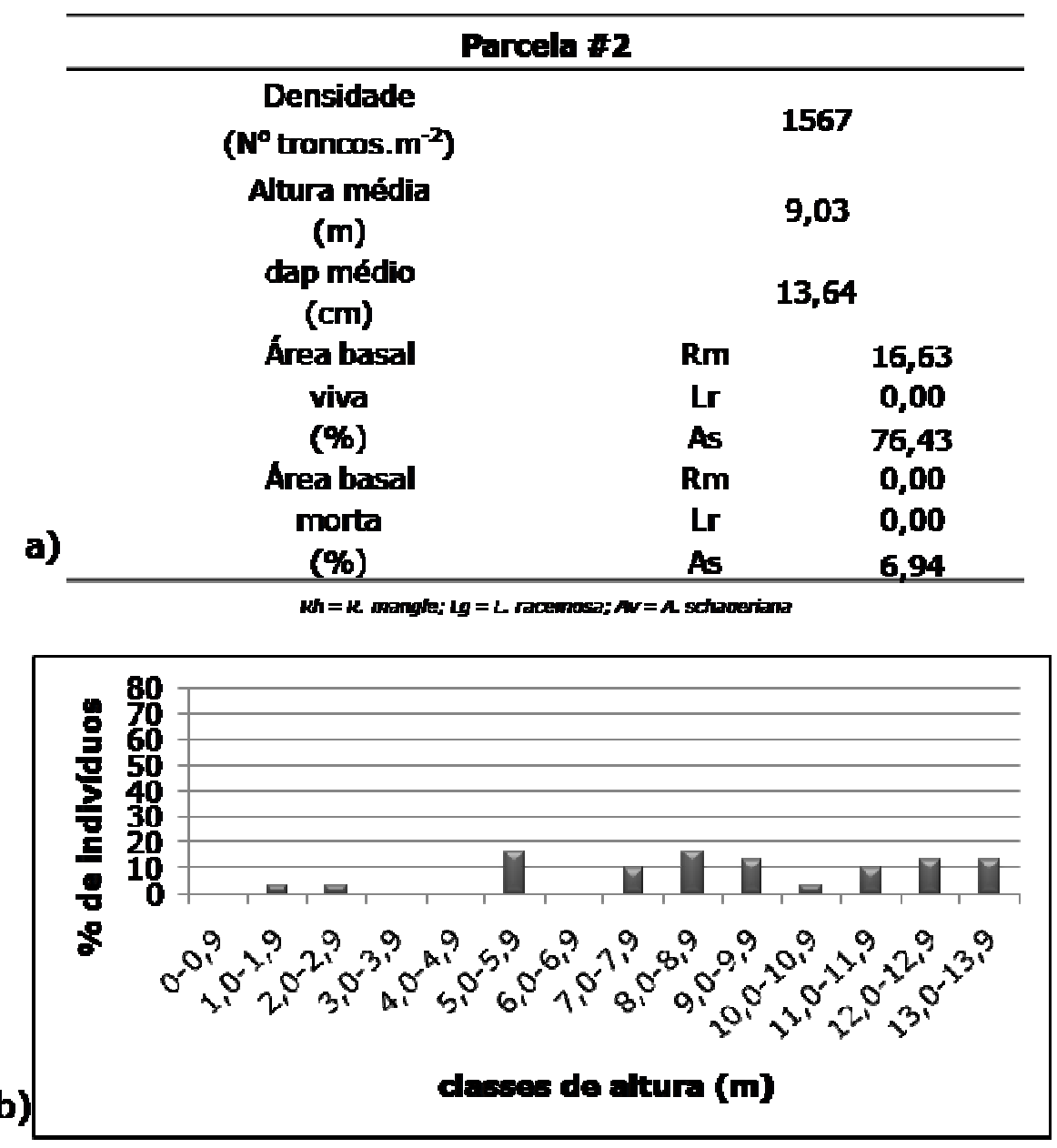

c)

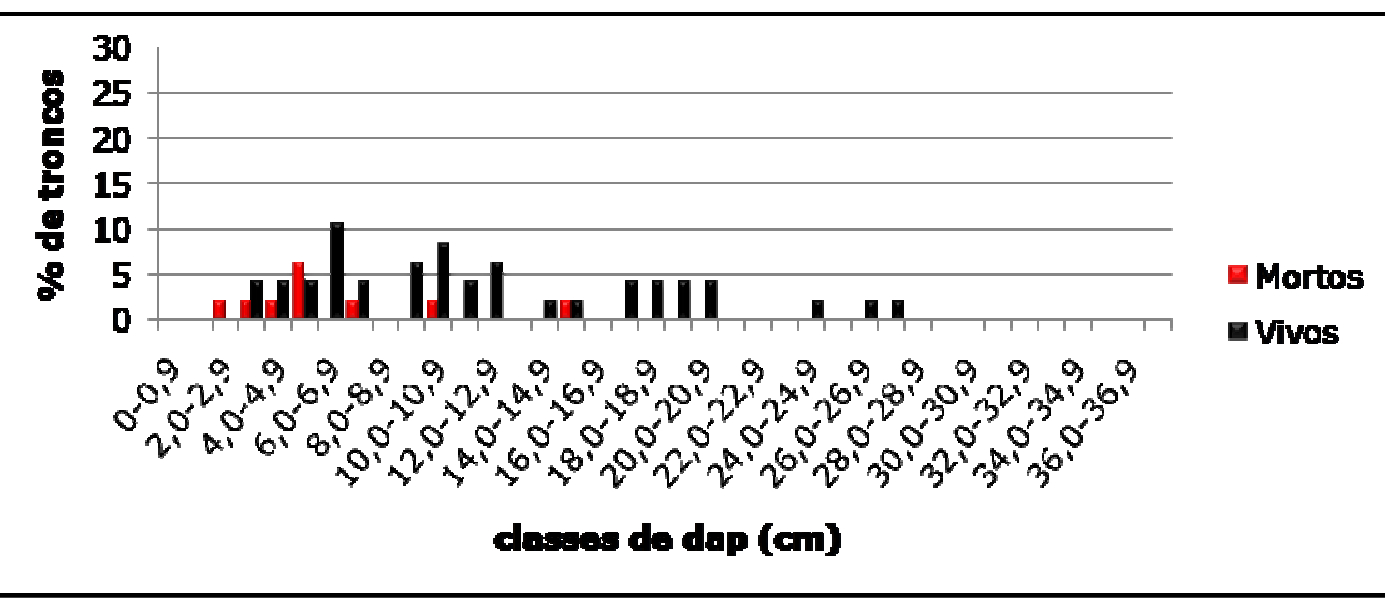


Na parcela \#2 a relação de troncos por indivíduo foi de 1,34, e a densidade de indivíduos e de troncos por hectare foi de 1167 e de 1567, respectivamente.

A altura média dos indivíduos do bosque foi de 9,03 m, a inferior de $1,70 \mathrm{~m}$ e a superior de $13,60 \mathrm{~m}$, apresentando predominância de indivíduos com altura superior a 5,0m, caracterizando um bosque bem desenvolvido, com indivíduos adultos de altura elevada e valores elevados de dap, esparsos dentro do bosque.

Este bosque apresentou dominância de indivíduos vivos com troncos com valores de dap superiores a $10,0 \mathrm{~cm}$ e poucos troncos e/ou indivíduos mortos, estes com valores reduzidos de dap. O dap médio deste bosque foi de $13,64 \mathrm{~cm}$.

A espécie que apresentou maior dominância tanto de área basal viva como área basal morta foi $A$. schaueriana. A espécies $R$. mangle apresentou uma pequena representatividade em área basal viva.

O dossel deste bosque também se mostrou bem fechado e o sedimento apresentou extensa cobertura de raízes respiratórias (pneumatóforos), referentes aos indivíduos adultos de $A$. schaueriana. 
Prancha V - Fotografias da parcela \#3: a) visão interna do bosque; b) sedimento; c) dossel.
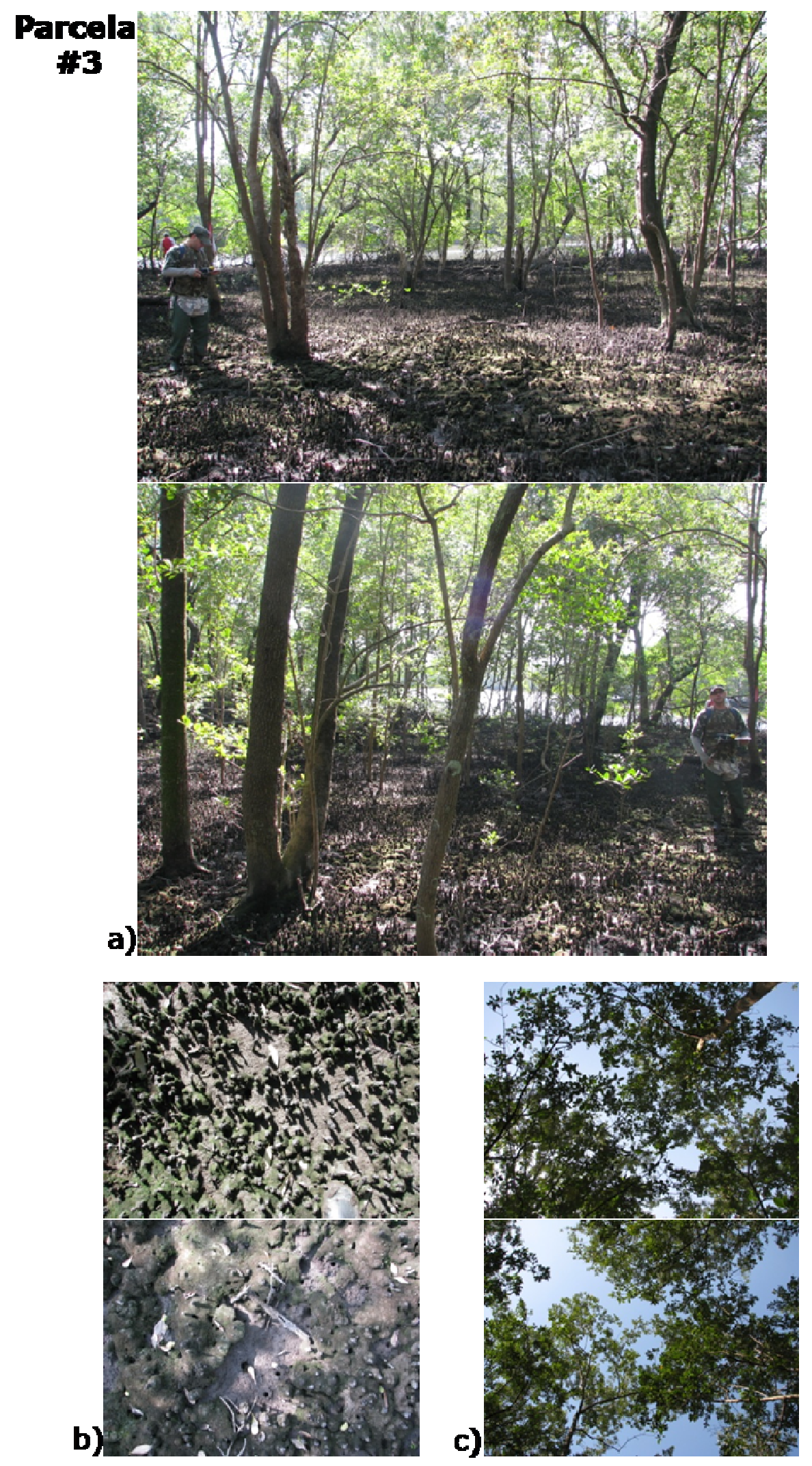
Prancha VI - Características estruturais da parcela \#3: a) tabela com características estruturais; b) figura com a dominância (\%) dos indivíduos por classes de altura; c) figura com a dominância (\%) de troncos vivos e mortos por classes de dap.

\begin{tabular}{|c|c|c|}
\hline \multicolumn{3}{|c|}{ Parcela \#3 } \\
\hline $\begin{array}{c}\text { Densidade } \\
\left(\mathbf{N}^{\circ} \text { troncos. } \mathbf{m}^{-2} \text { ) }\right.\end{array}$ & \multicolumn{2}{|c|}{1800} \\
\hline $\begin{array}{l}\text { Altura médià } \\
\text { (m) } \\
\text { dap médio } \\
\text { (cm) }\end{array}$ & \multicolumn{2}{|c|}{6,17} \\
\hline Area basal & Rm & 0,20 \\
\hline viva & $\mathbf{L r}$ & 5,63 \\
\hline (\%) & As & 77,88 \\
\hline Area basal & Rm & 0,00 \\
\hline morta & $\mathbf{L r}$ & 0,00 \\
\hline$(\%)$ & As & 16,30 \\
\hline
\end{tabular}
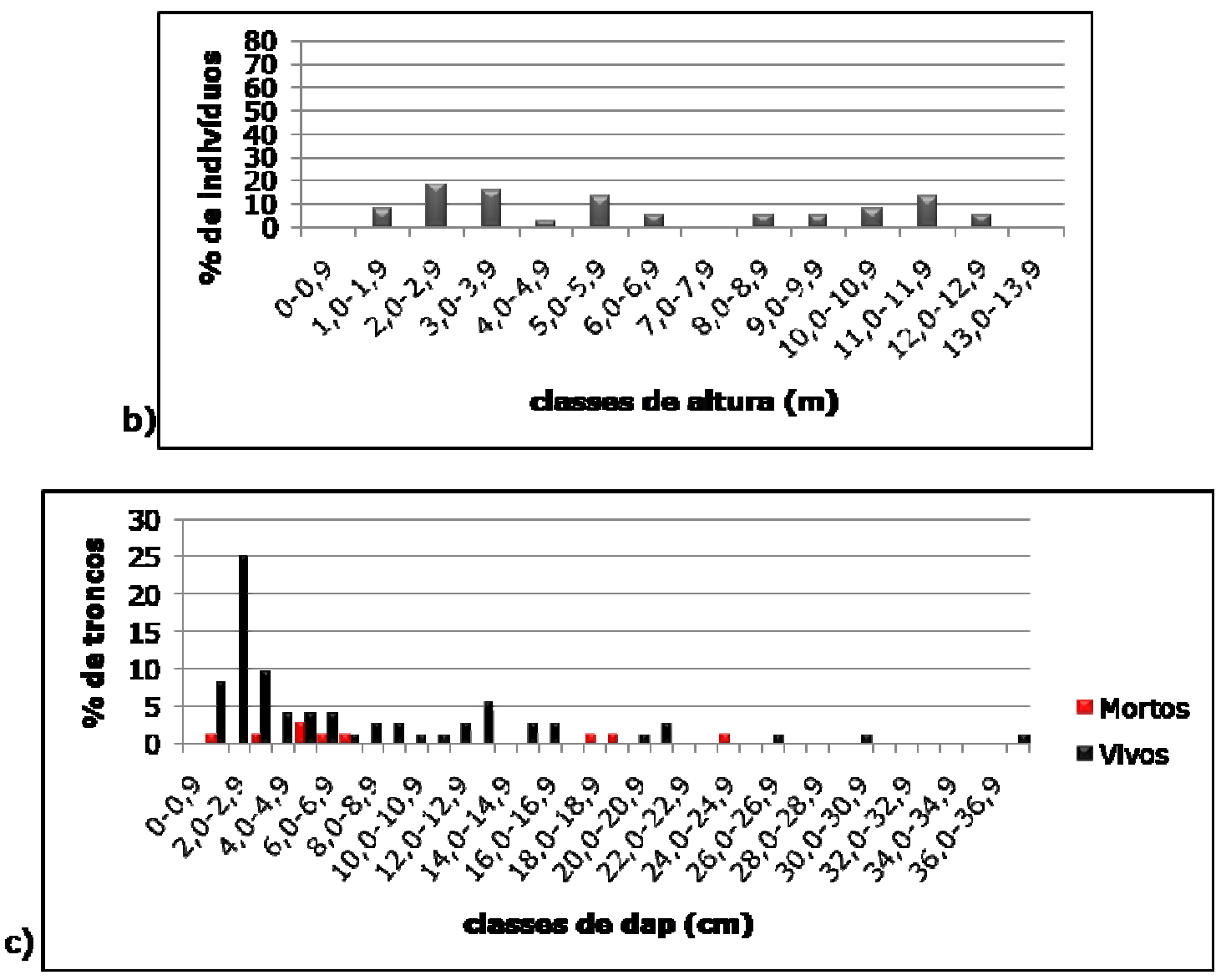
A parcela \#3 apresentou 1,80 troncos por indivíduo, e a densidade de indivíduos e de troncos por hectare foi de 1000 e de 1800, respectivamente.

A altura média dos indivíduos do bosque foi de $6,17 \mathrm{~m}$, a inferior de $1,60 \mathrm{~m}$ e a superior de $12,60 \mathrm{~m}$, apresentando predominância de indivíduos com altura entre 2,0 e 6,0m, com alguns indivíduos com altura superior, entre 8,0 a 13,0m, caracterizando também um bosque de mangue bem desenvolvido.

Neste bosque os indivíduos vivos apresentaram valores bem diversos de dap, com predominância de indivíduos com troncos com dap entre 1,0 e 14,0 cm, alguns poucos indivíduos com valores de dap superiores, destacando um indivíduo de $A$. schaueriana com três troncos vivos, sendo um de $37,6 \mathrm{~cm}$ de dap. Poucos troncos e/ou indivíduos mortos foram encontrados, todos de $A$. schaueriana, com valores diversos de dap. O dap médio desta parcela foi de $10,96 \mathrm{~cm}$.

A espécie que apresentou maior dominância de área basal viva e morta foi $A$. schaueriana. A espécie $L$. racemosa apresentou uma pequena representatividade em área basal viva, principalmente de indivíduos com valores reduzidos de dap.

O dossel deste bosque também se mostrou bem fechado e o sedimento apresentou extensa cobertura de raízes respiratórias (pneumatóforos), referentes principalmente aos indivíduos adultos de $A$. schaueriana. 
Prancha VII- Fotografias da parcela \#4: a) visão interna do bosque; b) sedimento; c) dossel.
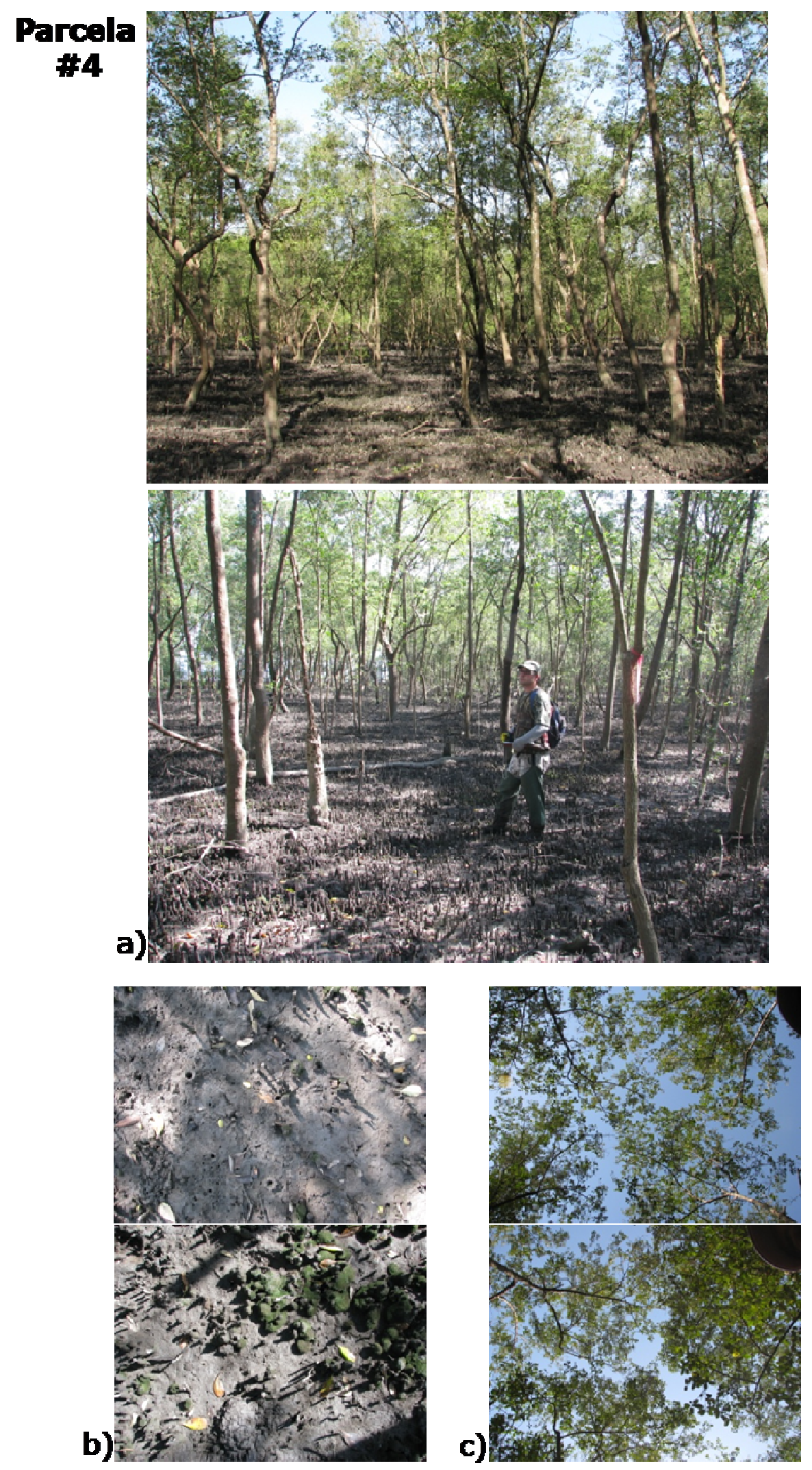
Prancha VIII - Características estruturais da parcela \#4: a) tabela com características estruturais; b) figura com a dominância (\%) dos indivíduos por classes de altura; c) figura com a dominância (\%) de troncos vivos e mortos por classes de dap.

\begin{tabular}{|c|c|c|c|}
\hline \multicolumn{4}{|c|}{ Parcala 4} \\
\hline & $\begin{array}{c}\text { Densidade } \\
\left(\mathbf{N}^{\mathbb{D}} \text { troncos. } \mathrm{m}^{-2} \text { ) }\right.\end{array}$ & \multicolumn{2}{|c|}{2000} \\
\hline & $\begin{array}{l}\text { Altura média } \\
\text { (m) } \\
\text { dap médlo } \\
\text { (cm) }\end{array}$ & \multicolumn{2}{|c|}{6,36} \\
\hline & Area basal & Rm & 0,00 \\
\hline & viva & $\mathbf{L r}$ & 3,73 \\
\hline & (\%) & As & 80,64 \\
\hline & Area basal & Rm & 0,00 \\
\hline \multirow{2}{*}{ a) } & morta & $\mathbf{L r}$ & 0,00 \\
\hline & $(\%)$ & As & 15,63 \\
\hline
\end{tabular}
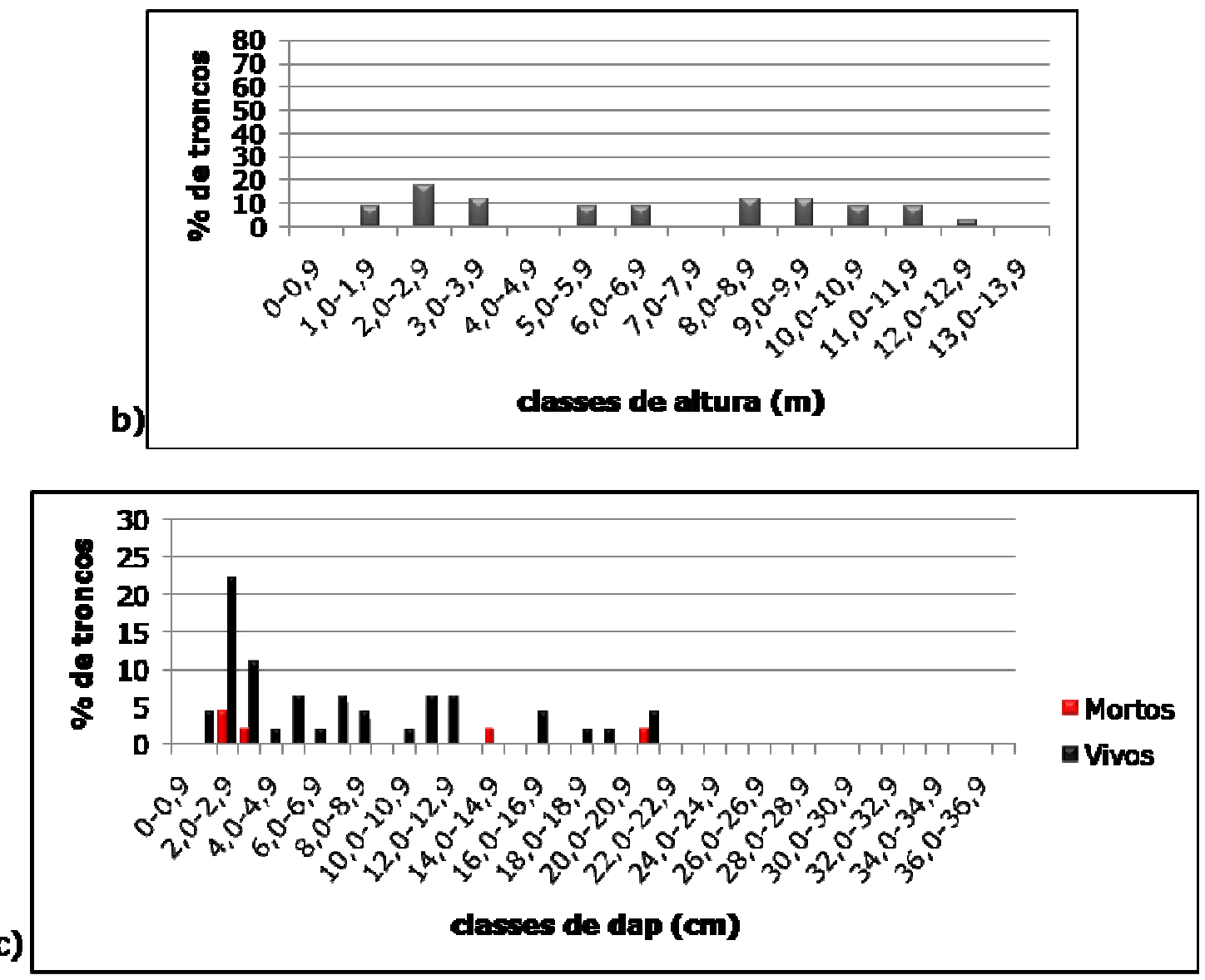
A parcela \#4 apresentou 1,13 troncos por indivíduo, e densidade de indivíduos e de troncos por hectare de 1778 e 2000, respectivamente.

A altura média dos indivíduos do bosque foi de $6,36 \mathrm{~m}$, a inferior de $1,60 \mathrm{~m}$ e a superior de $12,00 \mathrm{~m}$, apresentando indivíduos com alturas bem variadas, porém com predomínio de indivíduos ou com altura entre 2,0 e $4,0 \mathrm{~m}$ ou com altura entre 8,0 e $12,0 \mathrm{~m}$.

Neste bosque os indivíduos vivos apresentaram valores bem diversos de dap, com predominância de indivíduos com troncos com dap entre 3,0 e 9,0cm e alguns indivíduos com valores superiores de dap. Os poucos troncos e/ou indivíduos mortos encontrados foram de $A$. schaueriana, com valores diversos de dap. O dap médio desta parcela foi de $9,60 \mathrm{~cm}$.

A. schaueriana também foi a espécie que apresentou maior dominância de área basal viva e morta. A espécie $L$. racemosa apresentou uma pequena representatividade em área basal viva, principalmente de indivíduos com valores intermediários de dap (entre 2,5 e 10,0cm).

$O$ dossel deste bosque também se mostrou bem fechado e 0 sedimento se apresentou parcialmente coberto de raízes respiratórias (pneumatóforos), referentes principalmente aos indivíduos adultos de $A$. schaueriana. 
Prancha IX- Fotografias da parcela \#5: a) visão interna do bosque; b) sedimento; c) dossel.
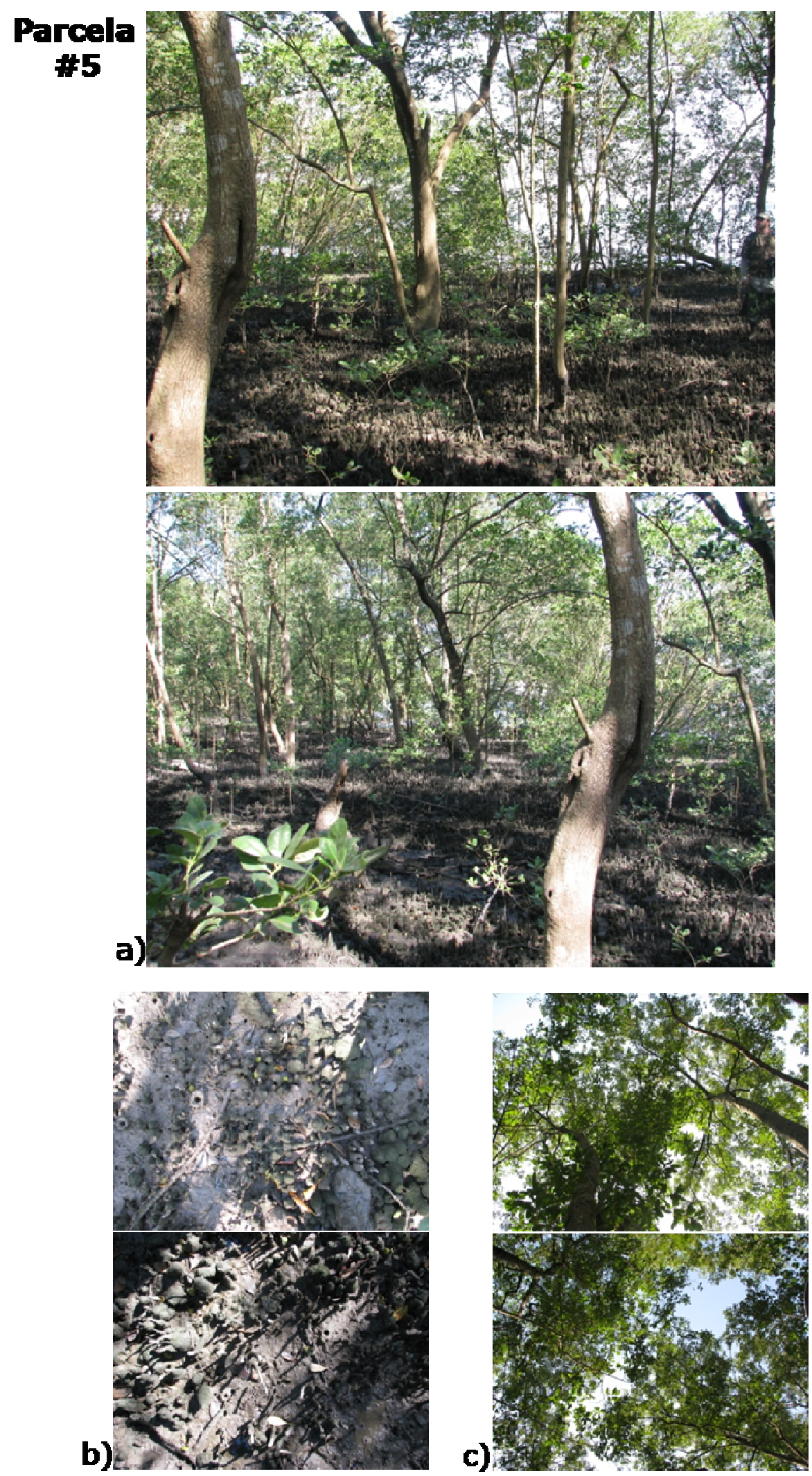
Prancha X - Características estruturais da parcela \#5: a) tabela com características estruturais; b) figura com a dominância (\%) dos indivíduos por classes de altura; c) figura com a dominância (\%) de troncos vivos e mortos por classes de dap.

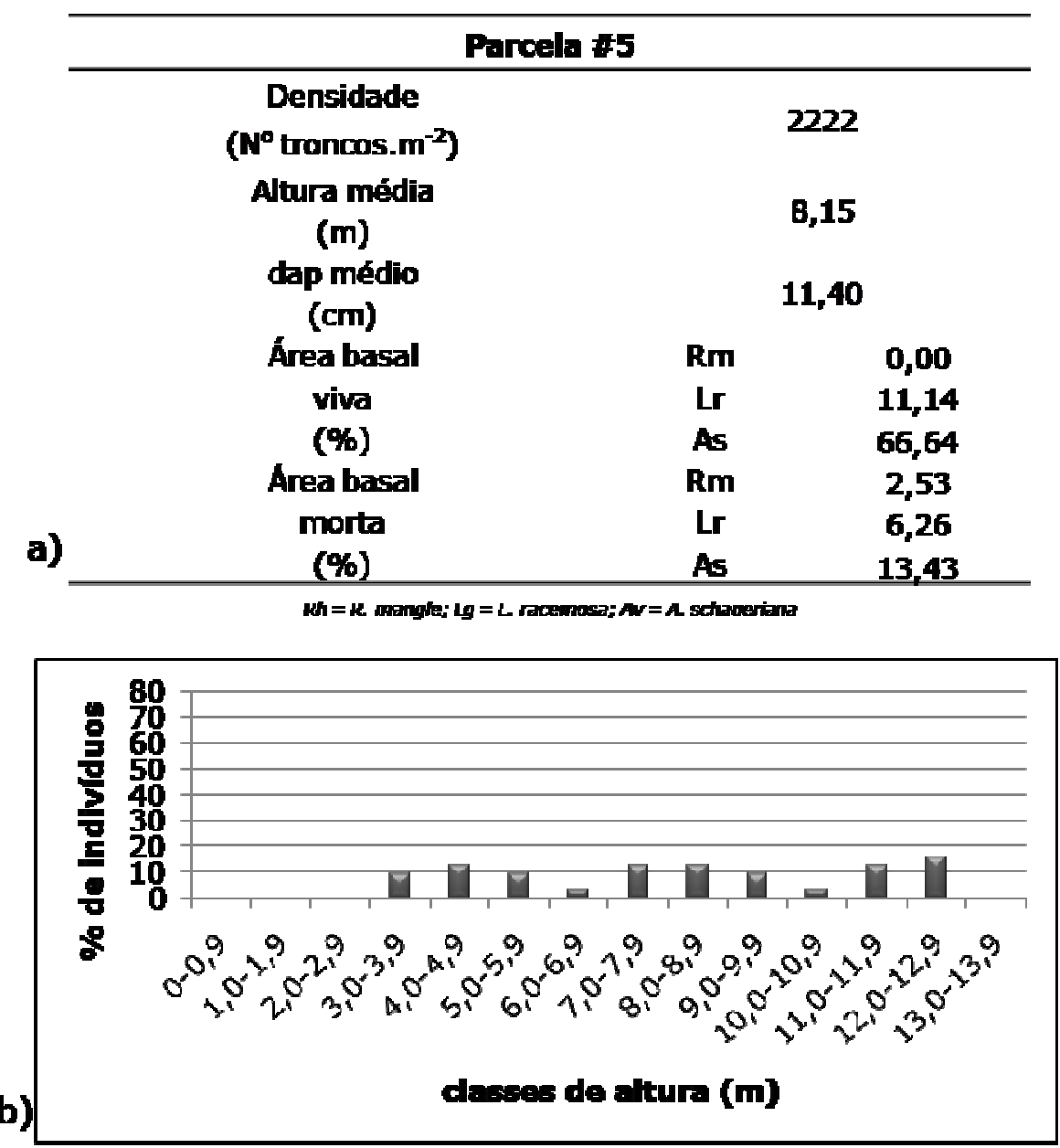

c)

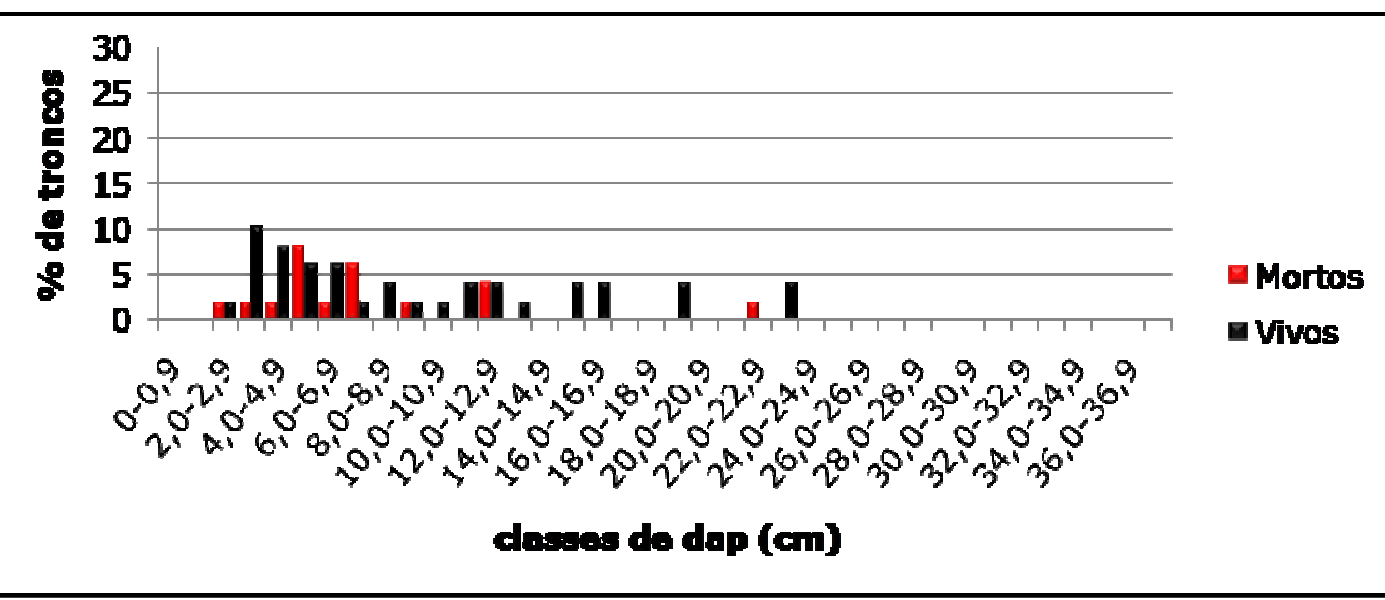


A parcela \#5 apresentou 1,32 troncos por indivíduo e uma densidade de 1689 indivíduos por hectare e de 2222 troncos por hectare.

A altura média dos indivíduos do bosque foi de $8,15 \mathrm{~m}$, a inferior de $1,60 \mathrm{~m}$ e a superior de $12,80 \mathrm{~m}$. Os indivíduos apresentaram alturas superiores a 3,0m, com predominância de indivíduos com altura entre 7,0 e $12,0 \mathrm{~m}$, caracterizando um bosque de mangue bem desenvolvido, com poucos indivíduos jovens.

Este bosque apresentou dominância de indivíduos vivos com valores diversos de dap e poucos troncos e/ou indivíduos mortos com valores reduzidos de dap. $O$ dap médio deste bosque foi de $11,40 \mathrm{~cm}$.

A espécie que apresentou maior dominância tanto de área basal viva como área basal morta foi $A$. schaueriana. A espécie $L$. racemosa apresentou uma pequena representatividade em área basal viva e morta e R. mangle em área basal morta.

O dossel deste bosque também se mostrou bem fechado e 0 sedimento apresentou extensa cobertura de raízes respiratórias (pneumatóforos), referentes aos indivíduos adultos de $A$. schaueriana e $L$. racemosa. 
Prancha XI- Fotografias da parcela \#6: a) visão interna do bosque; b) sedimento; c) dossel.
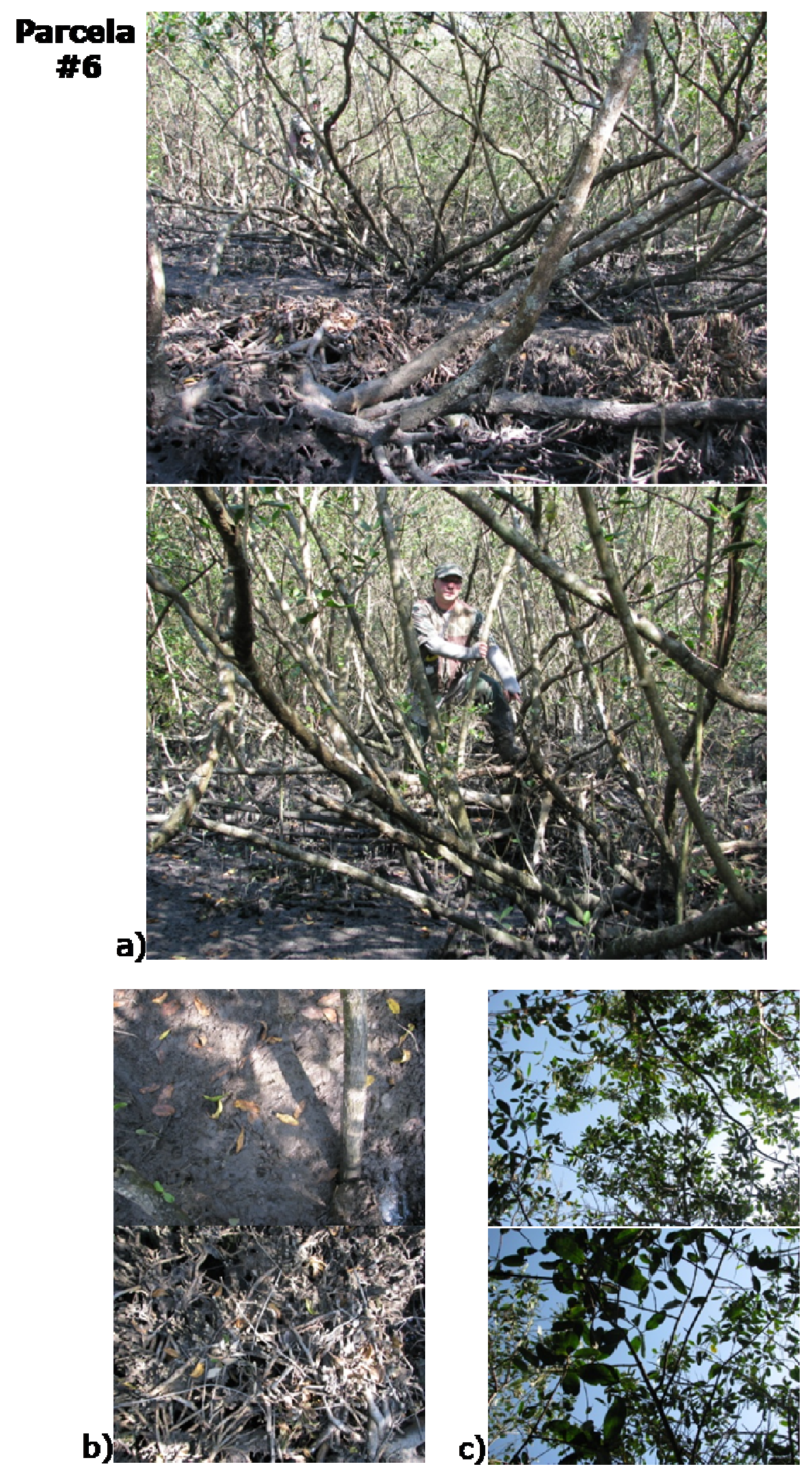
Prancha XII - Características estruturais da parcela \#6: a) tabela com características estruturais; b) figura com a dominância (\%) dos indivíduos por classes de altura; c) figura com a dominância (\%) de troncos vivos e mortos por classes de dap.

\begin{tabular}{|c|c|c|c|}
\hline & \multicolumn{3}{|c|}{ Parcela 6} \\
\hline & $\begin{array}{c}\text { Densidade } \\
\left(\mathrm{N}^{\mathbb{2}} \text { troncos. } \mathrm{m}^{-2} \text { ) }\right.\end{array}$ & \multicolumn{2}{|c|}{16800} \\
\hline & $\begin{array}{l}\text { Altura média } \\
\text { (m) } \\
\text { dap médio } \\
\text { (cm) }\end{array}$ & \multicolumn{2}{|c|}{3,9} \\
\hline & Área basal & $\mathbf{R m}$ & 0,00 \\
\hline & viva & $\mathbf{L r}$ & 91,88 \\
\hline & $(\%)$ & As & 0,93 \\
\hline & Area basal & $\mathbf{R m}$ & 0,00 \\
\hline & morta & $\mathbf{L r}$ & 7,19 \\
\hline & $(\%)$ & As & 0,00 \\
\hline
\end{tabular}

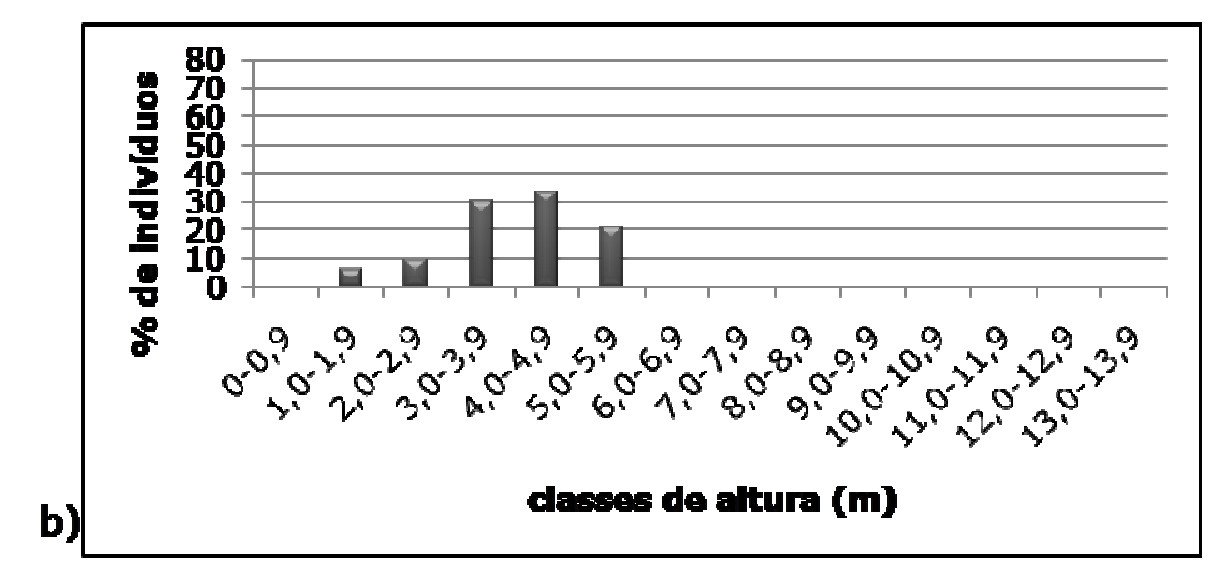

c)

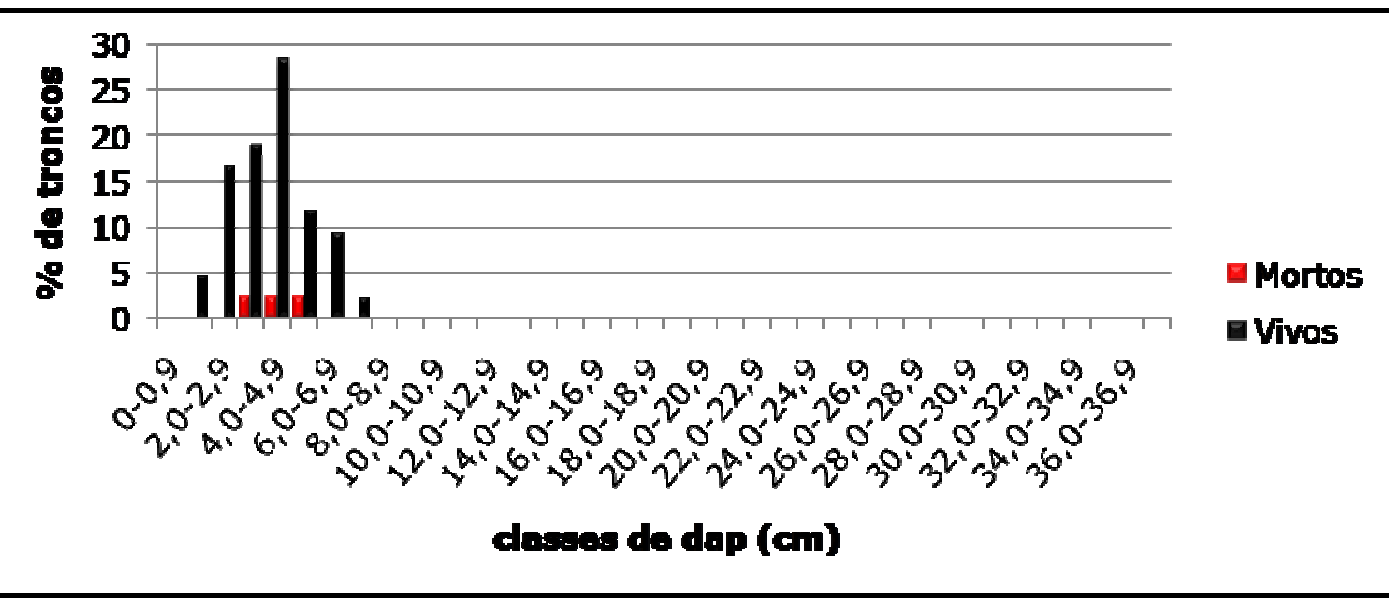

A parcela \#6 apresentou 1,17 troncos por indivíduo, e densidade de 14400 indivíduos por hectare e de 16800 troncos por hectare. 
A altura média dos indivíduos do bosque foi de 3,90m, a inferior de $1,0 \mathrm{~m}$ e a superior de 5,20m, apresentando predominância de indivíduos com altura variando entre 3,0 e 5,0m. A grande maioria destes indivíduos estava inclinado.

Neste bosque, a dominância foi de indivíduos vivos com valores reduzidos de dap (entre 1,0 e $7,0 \mathrm{~cm}$ ) e poucos troncos e/ou indivíduos mortos com valores de dap entre 3,0 e $5,0 \mathrm{~cm}$. O dap médio deste bosque foi de $4,31 \mathrm{~cm}$.

L. racemosa foi a espécie que apresentou dominância tanto de área basal viva como área basal morta.

O dossel deste bosque também se mostrou bem fechado e o sedimento apresentou uma grande quantidade de raízes expostas, fato este, referente a grande quantidade de indivíduos inclinados e/ou tombados. 
Prancha XIII- Fotografias da parcela \#7: a) visão interna do bosque; b) sedimento; c) dossel.
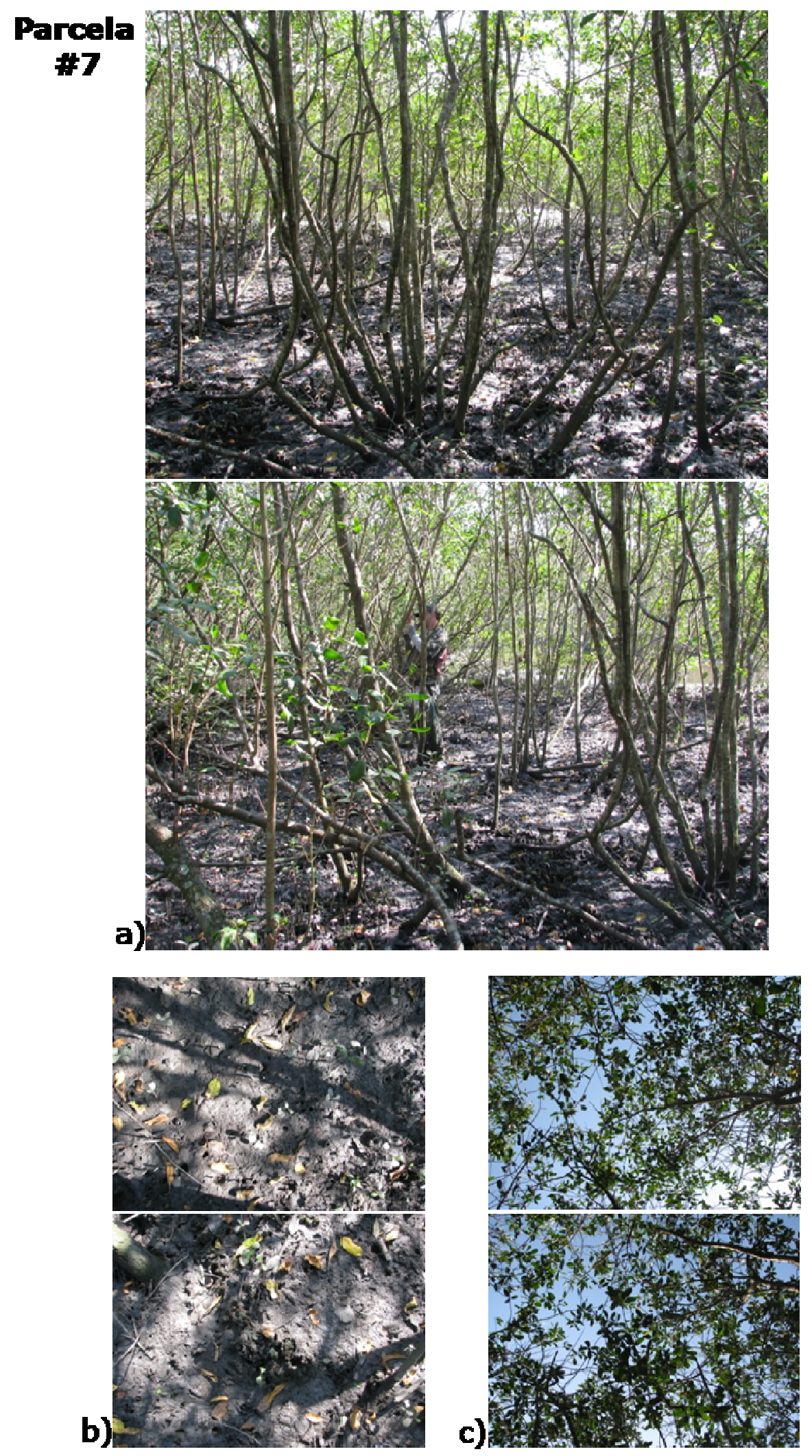
Prancha XIV - Características estruturais da parcela \#7: a) tabela com resumo das características estruturais; b) figura com a dominância (\%) dos indivíduos por classes de altura; c) figura com a dominância (\%) dos troncos vivos e mortos por classes de dap.

\begin{tabular}{|c|c|c|c|}
\hline \multicolumn{4}{|c|}{ Parcela \#7 } \\
\hline & $\begin{array}{c}\text { Densidade } \\
\left(\mathbf{N}^{0} \text { troncos. } \mathrm{m}^{-2}\right)\end{array}$ & \multicolumn{2}{|c|}{13200} \\
\hline & $\begin{array}{l}\text { Altura média } \\
\text { (m) } \\
\text { dap medlo } \\
\text { (cm) }\end{array}$ & \multicolumn{2}{|c|}{3,91} \\
\hline & Área basal & Rm & 0,00 \\
\hline & viva & $\mathbf{L r}$ & 99,58 \\
\hline & (\%) & As & 0,00 \\
\hline & Área basal & $\mathbf{R m}$ & 0,00 \\
\hline & morta & Lr & 0,42 \\
\hline & $(\%)$ & As & 0,00 \\
\hline
\end{tabular}

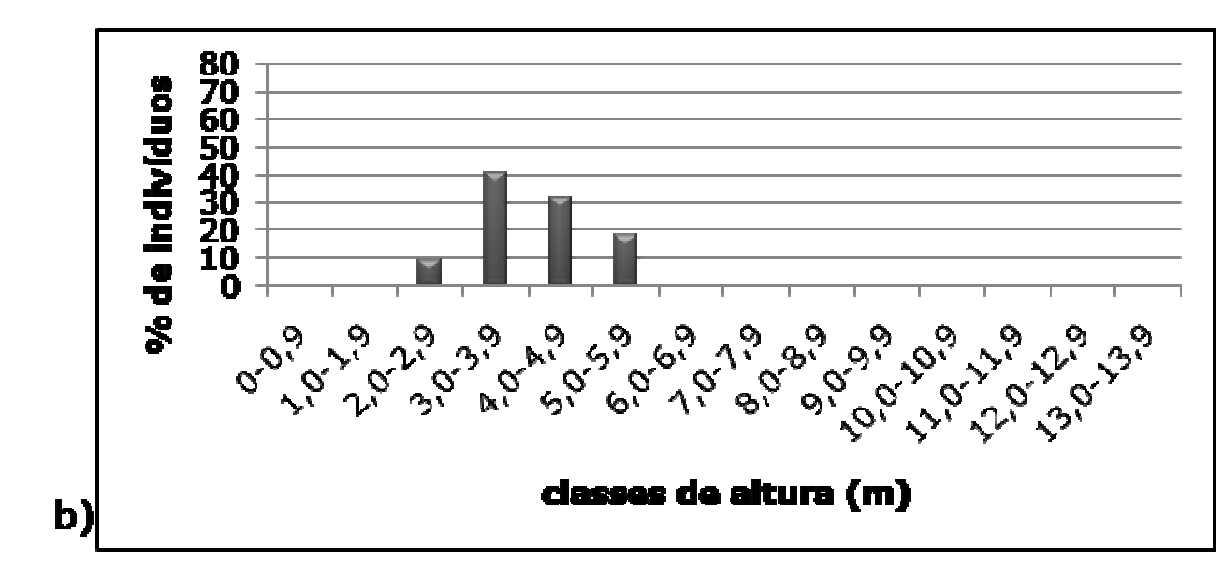

c)

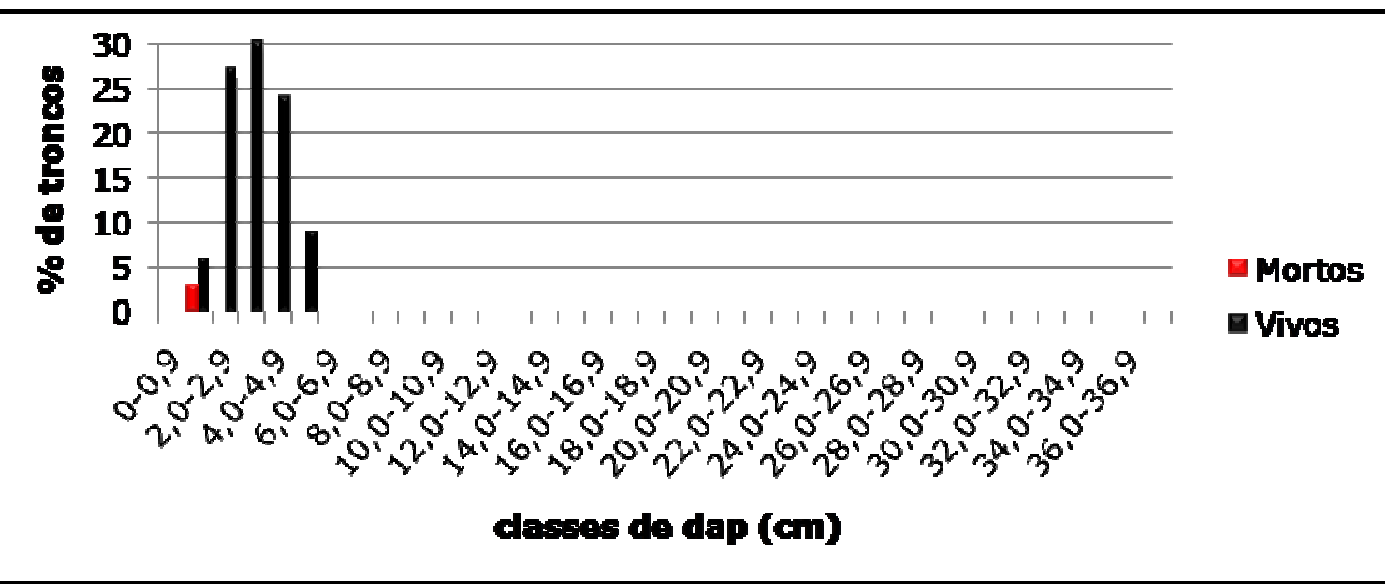


A parcela \#7 apresentou 1,50 troncos por indivíduo, e densidade de 8800 indivíduos por hectare e de 13200 troncos por hectare.

A altura média dos indivíduos do bosque foi de 3,91m, a inferior de 2,20m e a superior de 5,40m, apresentando predominância de indivíduos com altura variando entre 3,0 e 5,0m. Alguns destes indivíduos estavam inclinados, porém numa quantidade menor comparada com a parcela \#6.

Neste bosque, a quase totalidade dos indivíduos estava viva e apresentando valores reduzidos de dap (entre 1,0 e 5,0 cm). O dap médio desta parcela foi de $3,55 \mathrm{~cm}$.

L. racemosa foi a única espécie encontrada neste bosque, apresentando dominância de área basal viva.

O dossel deste bosque também se mostrou bem fechado e o sedimento apresentou uma pequena quantidade de raízes expostas, referentes aos poucos indivíduos inclinados e/ou tombados. 
Prancha XV- Fotografias da parcela \#8: a) visão do bosque; b) sedimento; c) dossel.
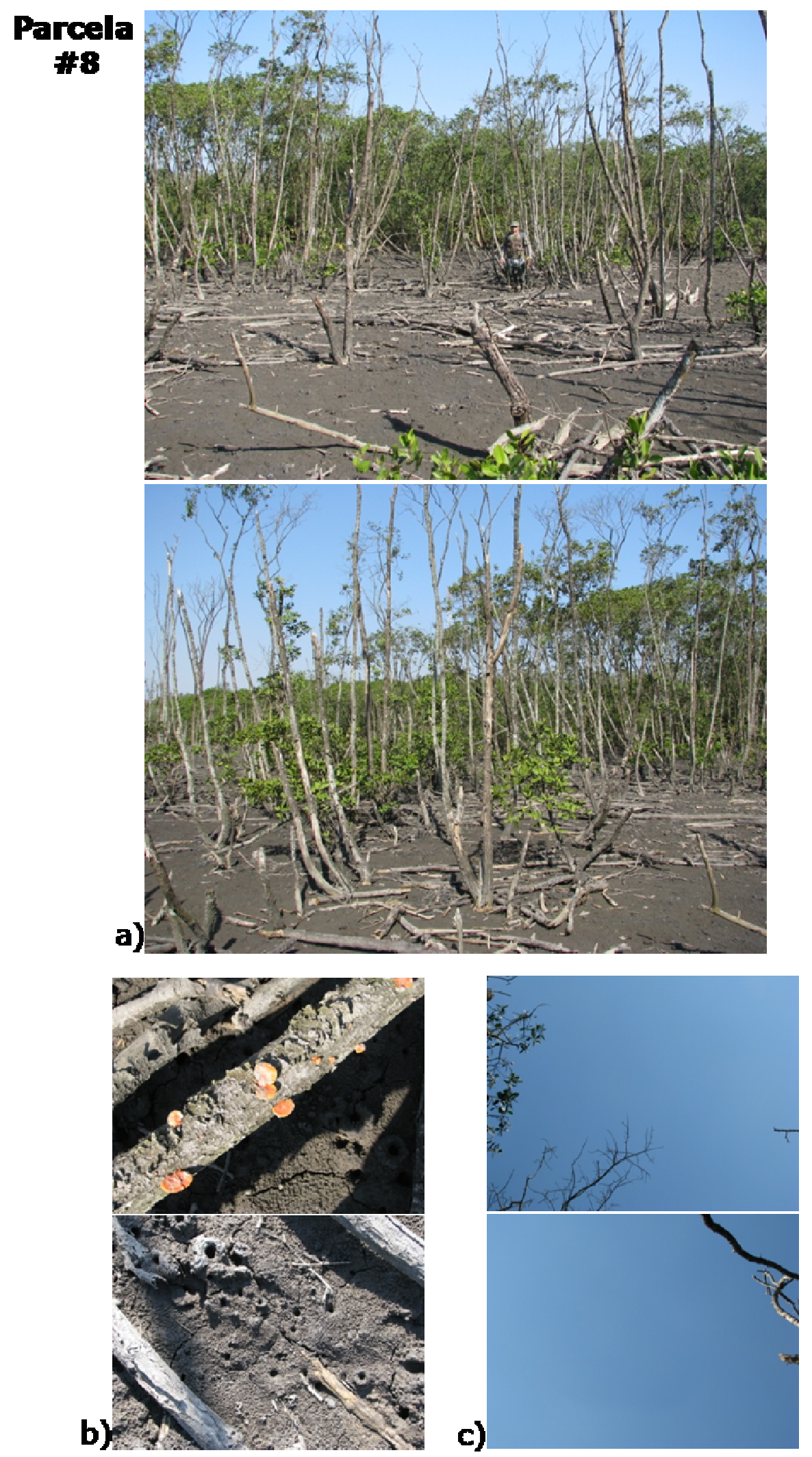
Prancha XVI - Características estruturais da parcela \#8: a) tabela com características estruturais; b) figura com a dominância (\%) dos indivíduos por classes de altura; c) figura com a dominância (\%) de troncos vivos e mortos por classes de dap.

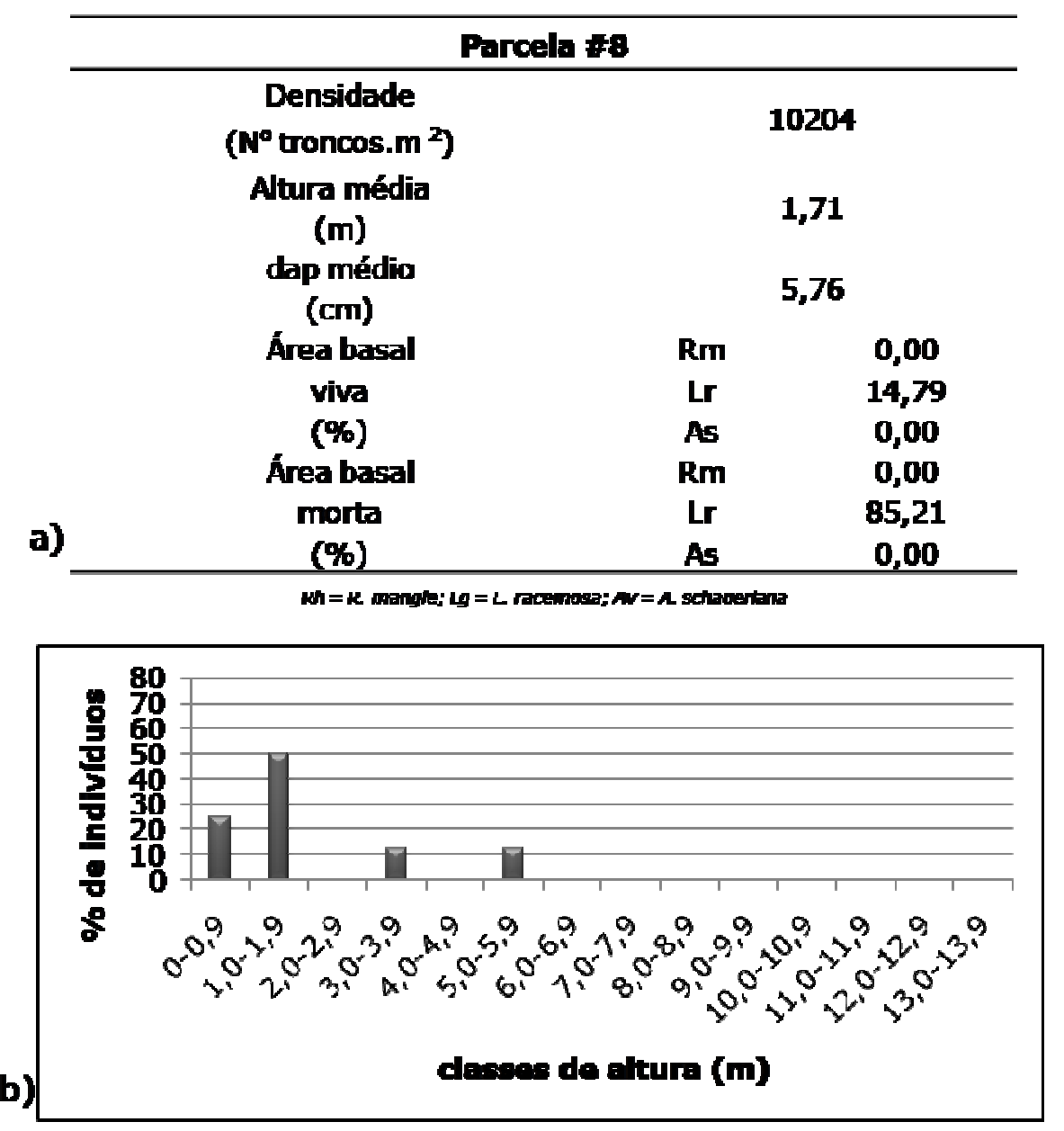

c)

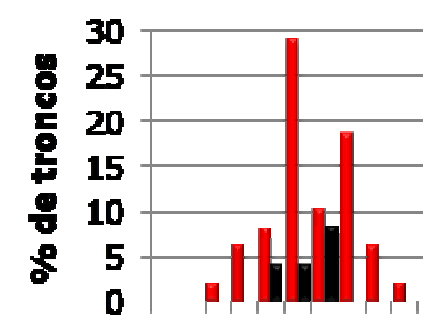

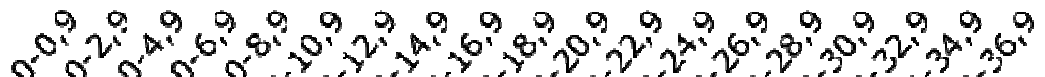

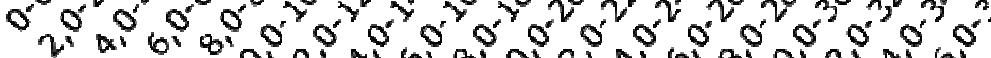

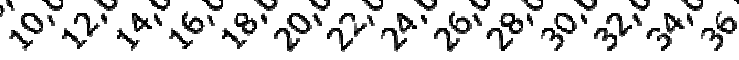

$$
\begin{aligned}
& \text { classes de dap (cm) }
\end{aligned}
$$


A parcela \#8 apresentou 1,67 troncos por indivíduo, e densidade de 6122 indivíduos por hectare e de 10204 troncos por hectare.

A altura média dos indivíduos do bosque foi de $1,71 \mathrm{~m}$, a inferior de $0,50 \mathrm{~m}$ e a superior de 5,40m. Estas alturas médias reduzidas são decorrência da grande quantidade de indivíduos mortos e de indivíduos que estavam com morte apical, mas apresentavam indícios de rebrotamento no tronco. Este rebrotamento geralmente estava a 0,5$1,0 \mathrm{~m}$ de altura no tronco. A altura superior de $5,40 \mathrm{~m}$ se refere ao único indivíduo vivo sem morte apical.

Neste bosque, a quase totalidade dos indivíduos estava morta e apresentando valores de dap entre 3,0 e $8,0 \mathrm{~cm}$. Os poucos indivíduos ainda vivos apresentaram dap entre 4,0 e $6,0 \mathrm{~cm}$. O dap médio desta parcela foi de $5,76 \mathrm{~cm}$.

L. racemosa foi a única espécie encontrada neste bosque, apresentando dominância em área basal viva e morta.

O dossel deste bosque estava bem aberto, em decorrência dos indivíduos mortos ou com morte apical. Esta intensa mortalidade também pôde ser observada sobre o sedimento, com uma enorme quantidade de troncos mortos se decompondo e pelo fato do sedimento estar extremamente seco e com rachaduras. 
Prancha XVII- Fotografias da parcela \#9: a) visão do bosque; b) sedimento; c) dossel.
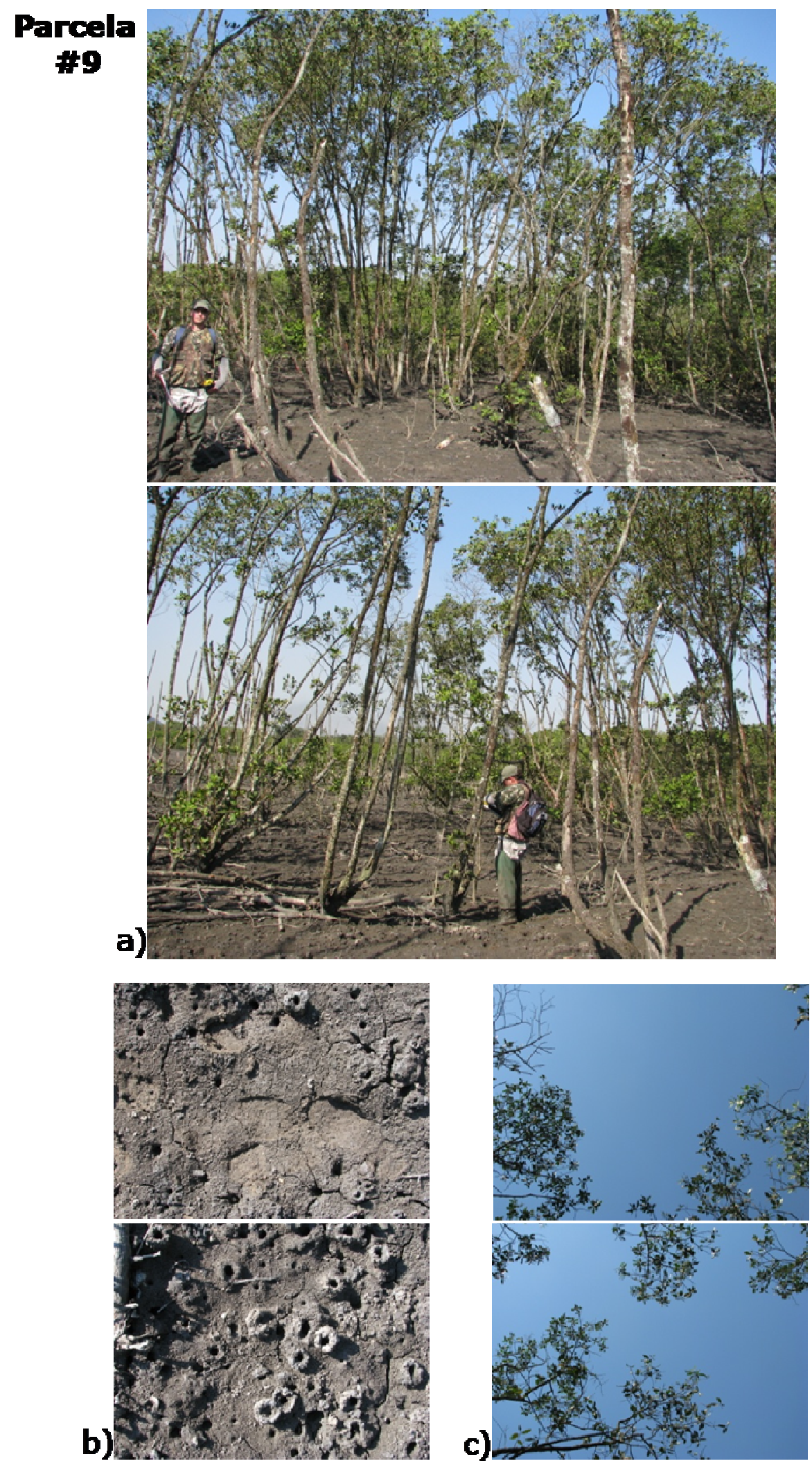
Prancha XVIII - Características estruturais da parcela \#9: a) tabela com características estruturais; b) figura com a dominância (\%) dos indivíduos por classes de altura; c) figura com a dominância (\%) dos troncos vivos e mortos por classes de dap.

\begin{tabular}{|c|c|c|}
\hline \multicolumn{3}{|c|}{ Parcela 49} \\
\hline $\begin{array}{c}\text { Densidade } \\
\left(\mathbf{N}^{0} \text { troncos. } \mathrm{m}^{-2}\right)\end{array}$ & \multicolumn{2}{|c|}{8571} \\
\hline $\begin{array}{l}\text { Altura média } \\
\text { (m) } \\
\text { dap médio } \\
\text { (cm) }\end{array}$ & \multicolumn{2}{|c|}{5,62} \\
\hline Área basal & Rm & 0,00 \\
\hline viva & $\mathbf{L r}$ & $\begin{array}{r}38,45 \\
011\end{array}$ \\
\hline Área basal & Rm & 0,00 \\
\hline morta & $\mathbf{L r}$ & 61,43 \\
\hline$(\%)$ & As & 0,00 \\
\hline
\end{tabular}
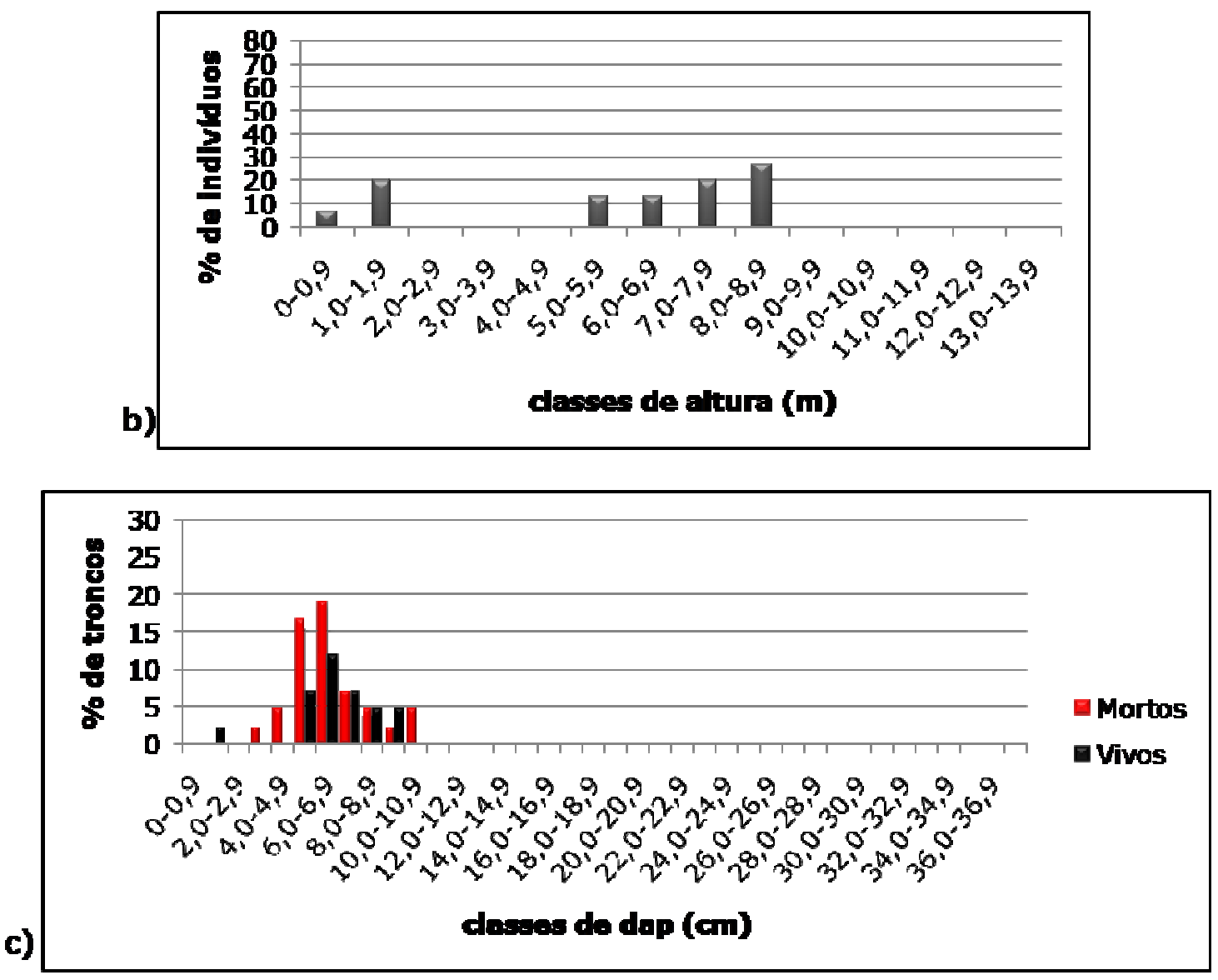
A parcela \#9 apresentou 1,62 troncos por indivíduo, e densidade de 5306 indivíduos por hectare e de 8571 troncos por hectare.

A altura média dos indivíduos do bosque foi de 5,62m, a inferior de $0,50 \mathrm{~m}$ e a superior de $8,40 \mathrm{~m}$. A altura média inferior reduzida é em decorrência da presença de indivíduos que estavam com morte apical, mas apresentavam indícios de rebrotamento no tronco a cerca de 0,5$1,0 \mathrm{~m}$ de altura.

Neste bosque, a maioria dos indivíduos estava viva, porém estes indivíduos apresentavam uma grande quantidade de troncos mortos. Estes troncos apresentaram valores de dap entre 4,0 e $10,0 \mathrm{~cm}$, sendo que os troncos vivos apresentaram valores um pouco superiores de dap quando comparados com os troncos mortos. Também observamos alguns poucos indivíduos vivos com apenas um tronco. O dap médio desta parcela foi de $6,90 \mathrm{~cm}$.

L. racemosa também foi a espécie dominante neste bosque, apresentando dominância em área basal viva e morta. Apenas um indivíduo de $A$. schaueriana jovem foi encontrado, apresentando desta forma, pouca representatividade.

O dossel deste bosque estava semi-aberto, em decorrência dos troncos mortos ou com morte apical. Esta mortalidade também pôde ser observada no sedimento extremamente seco e com rachaduras. 
Prancha XIX- Fotografias das parcelas \#10 e \#11: a) visão interna do bosque; b) sedimento; c) dossel.
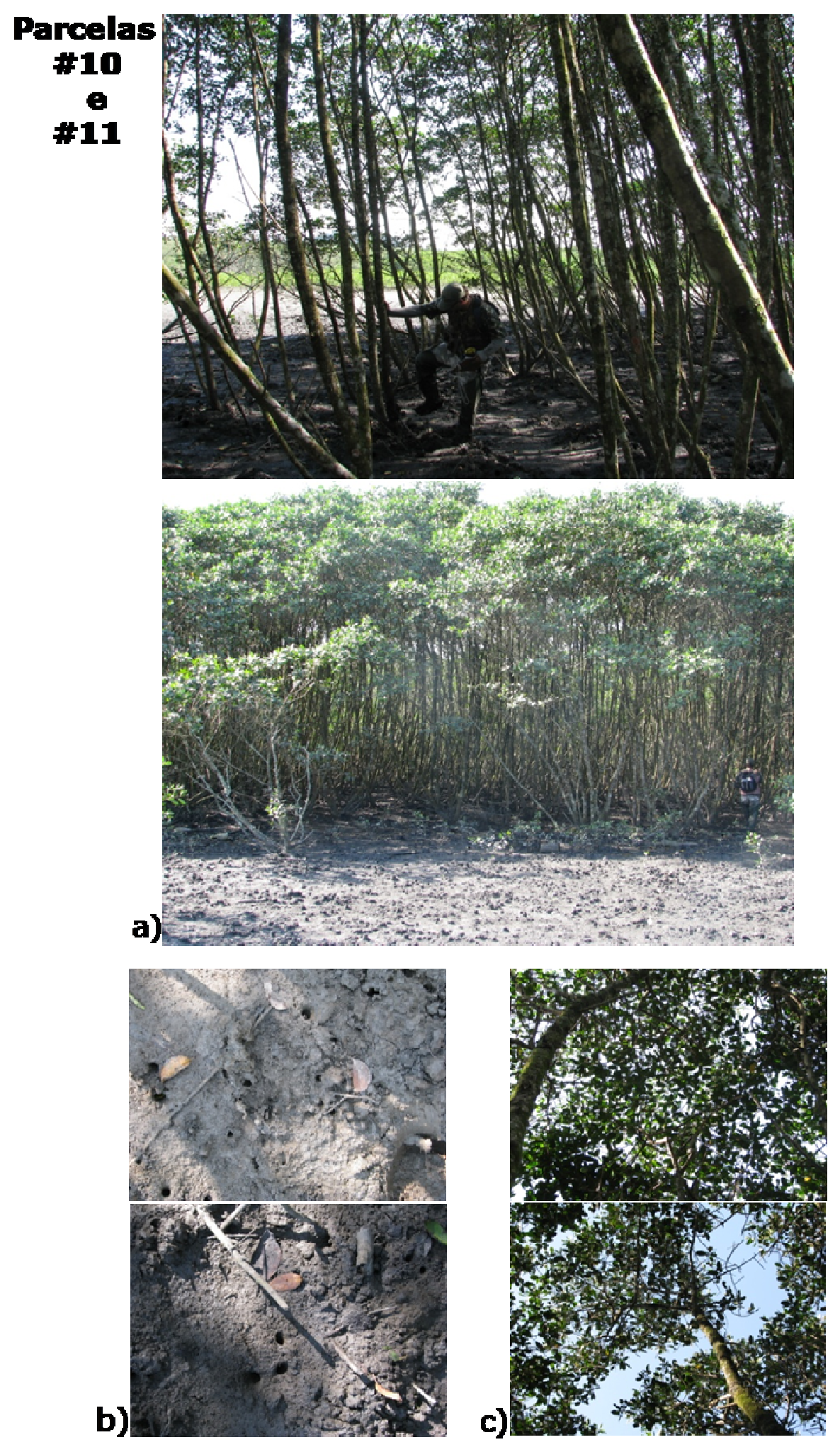
Prancha XX - Características estruturais da parcela \#10: a) tabela com resumo das características estruturais; b) figura com a dominância (\%) dos indivíduos por classes de altura; c) figura com a dominância (\%) dos troncos vivos e mortos por classes de dap.

\begin{tabular}{|c|c|c|c|}
\hline & \multicolumn{3}{|c|}{ Parcela \#10 } \\
\hline & Densidade & \multirow{2}{*}{\multicolumn{2}{|c|}{17200}} \\
\hline & ( $N^{0}$ troncos. $m^{-2}$ ) & & \\
\hline & $\begin{array}{l}\text { Altura média } \\
\text { (m) }\end{array}$ & \multicolumn{2}{|c|}{7,25} \\
\hline & $\begin{array}{l}\text { dap médio } \\
\text { (cm) }\end{array}$ & \multicolumn{2}{|c|}{5,58} \\
\hline & Área basal & $\mathbf{R m}$ & 0,00 \\
\hline & viva & $\mathbf{L r}$ & 82,71 \\
\hline & (\%) & As & 0,00 \\
\hline & Area basal & $\mathbf{R m}$ & 0,00 \\
\hline & morta & $\mathbf{L r}$ & 17,29 \\
\hline & $(\%)$ & As & 00 \\
\hline
\end{tabular}

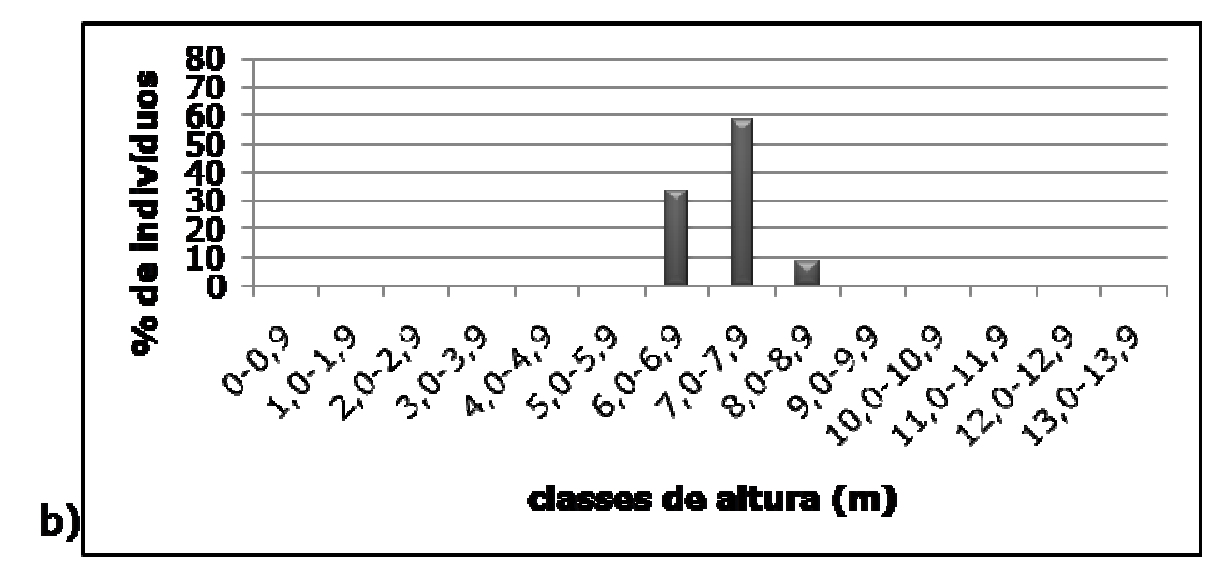

c)

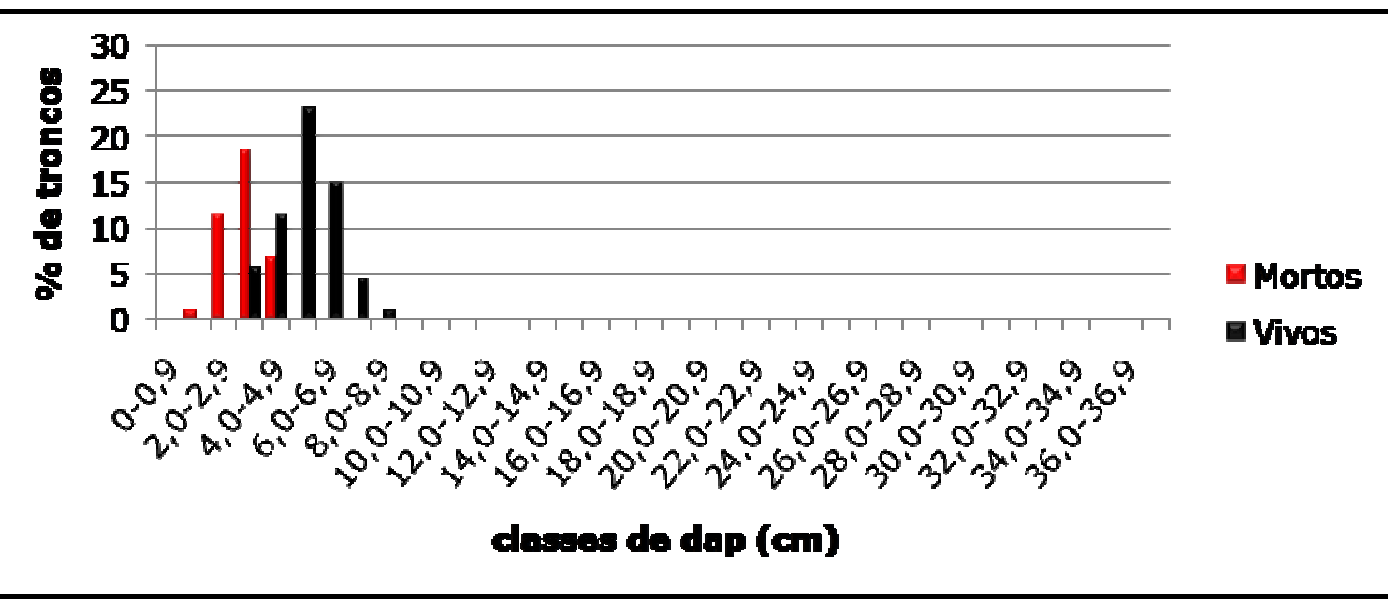


Prancha XXI - Características estruturais da parcela \#11: a) tabela com características estruturais; b) figura com a dominância (\%) dos indivíduos por classes de altura; c) figura com a dominância (\%) de troncos vivos e mortos por classes de dap.

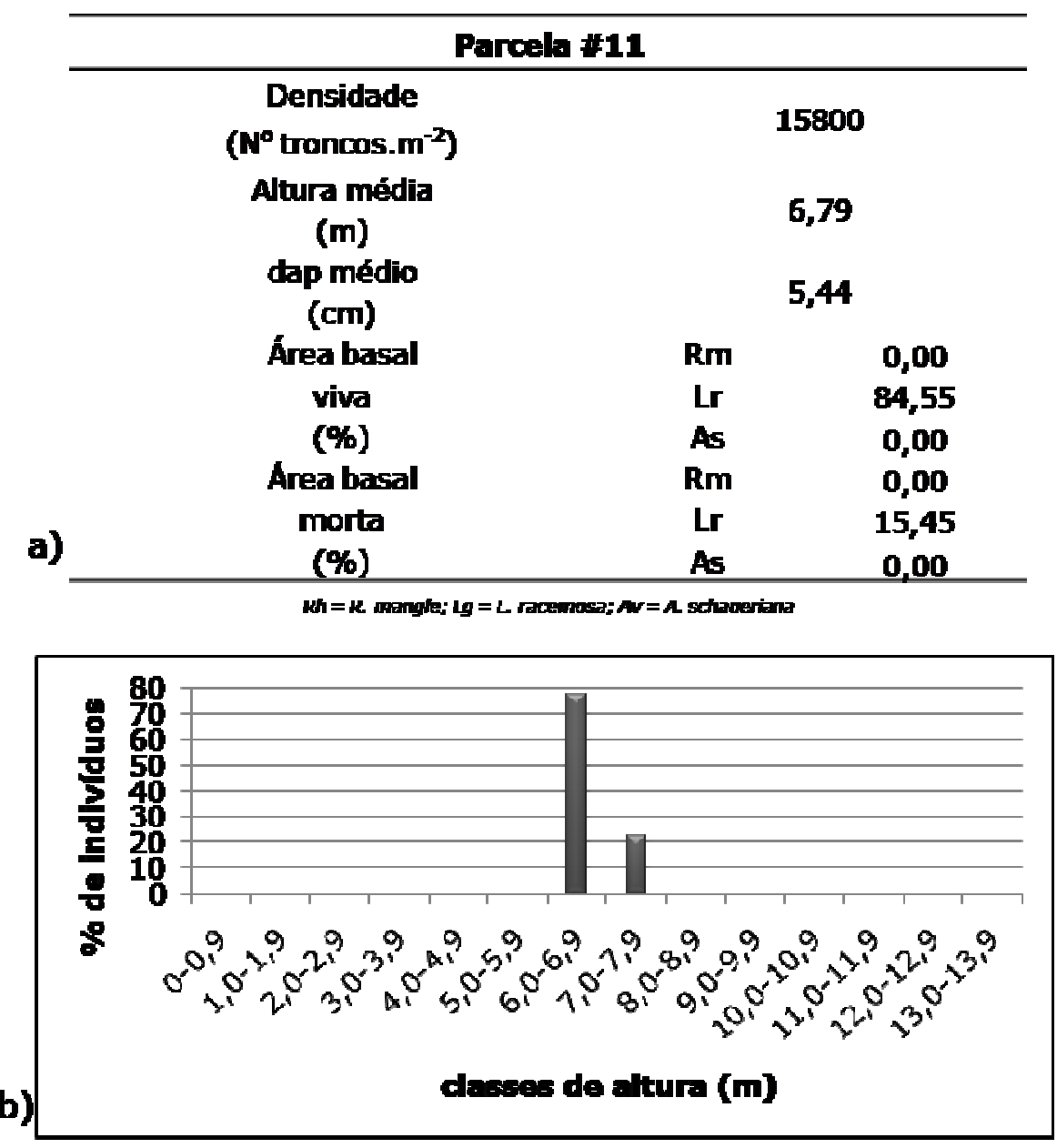

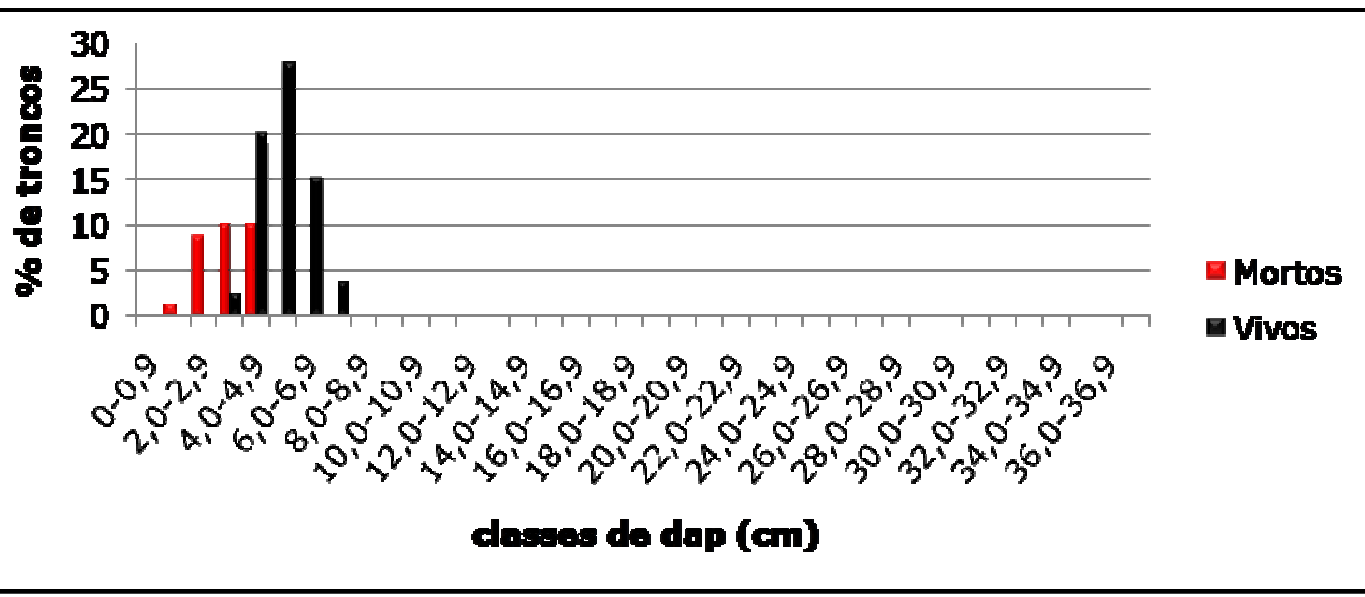


As parcelas \#10 e \#11 foram estabelecidas em campo de forma justapostas, isto se reflete nos dados semelhantes observados em ambas as parcelas. As parcelas \#10 e \#11 apresentaram 3,07 e 2,82 troncos por indivíduo, respectivamente. A densidade foi 5600 indivíduos por hectare em ambas as parcelas e de 17200 troncos por hectare na parcela \#10 e de 15800 na parcela \#11.

As alturas médias dos indivíduos das parcelas \#10 e \#11 também foram similares, 7,25 e 6,79m, respectivamente. A altura média inferior foi a mesma $(6,0 \mathrm{~m})$ e a superior também foi similar, 8,00 e 7,60m, respectivamente. Todos os indivíduos de ambas as parcelas apresentaram altura entre 6,0 e $8,0 \mathrm{~m}$.

Em ambas as parcelas o bosque apresentou dominância de indivíduos vivos bem ramificados. Os valores de dap dos troncos vivos variaram entre 4,0 e $6,0 \mathrm{~cm}$ e dos troncos mortos entre 2,0 e $4,0 \mathrm{~cm}$. 0 dap médio das parcelas foi de $5,58 \mathrm{~cm}$, para a parcela \#10 e de $5,44 \mathrm{~cm}$ para a parcela\# 11 .

L. racemosa foi a única espécie encontrada em ambas as parcelas, apresentando dominância em área basal viva e morta.

O dossel deste bosque também se mostrou bem fechado e o sedimento não apresentou cobertura de raízes respiratórias (pneumatóforos). 
Prancha XXII- Fotografias das parcelas \#12 e \#13: a) visão interna do bosque; b) sedimento; c) dossel.
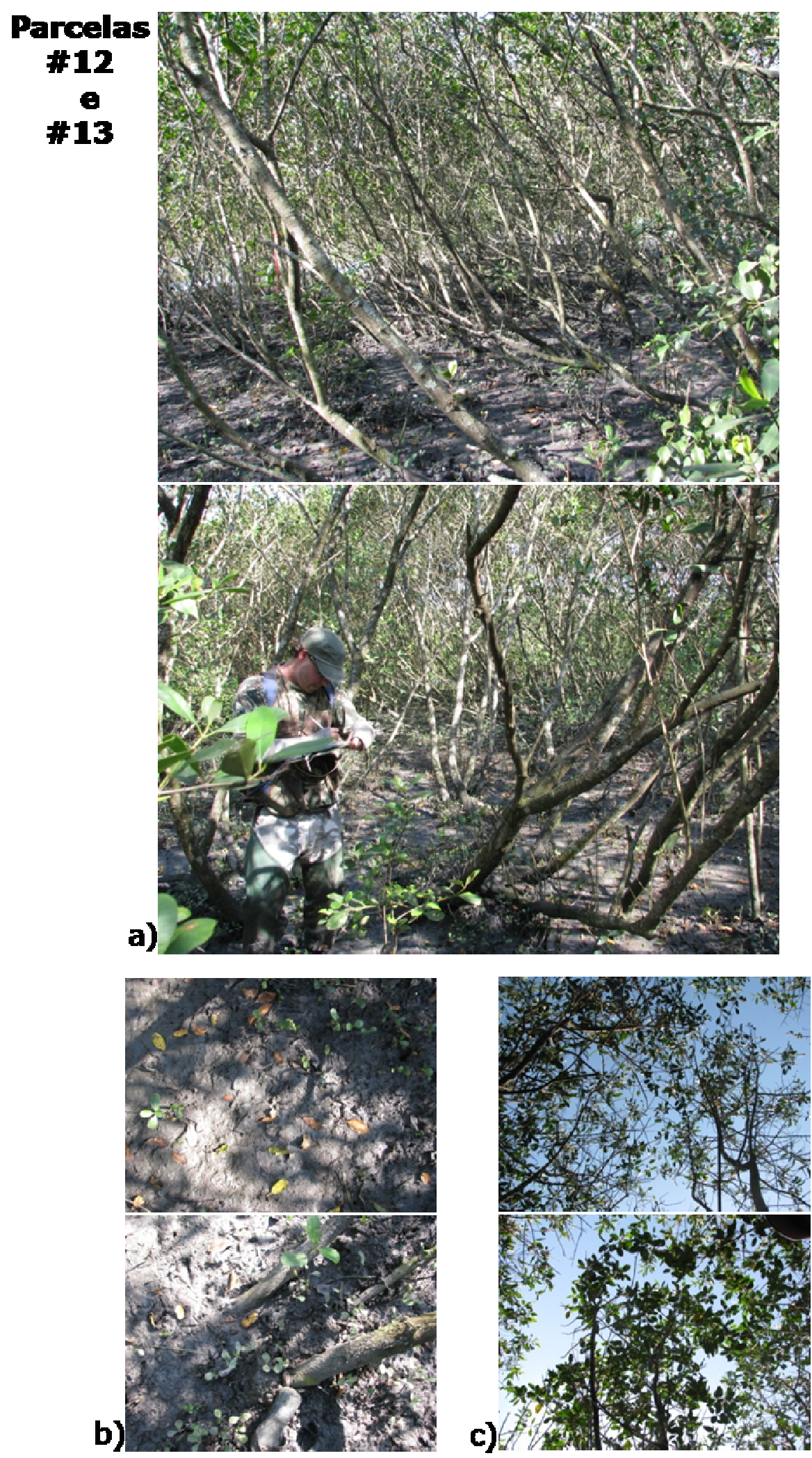
Prancha XXIII - Características estruturais da parcela \#12: a) tabela com características estruturais; b) figura com a dominância (\%) dos indivíduos por classes de altura; c) figura com a dominância (\%) de troncos vivos e mortos por classes de dap.

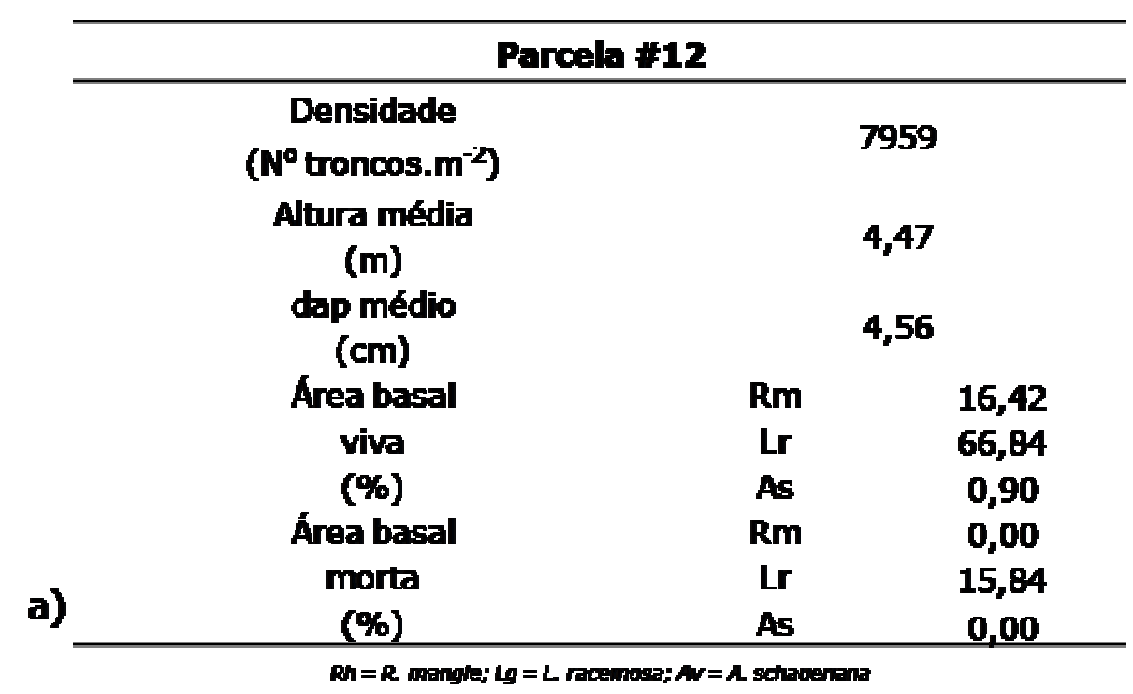

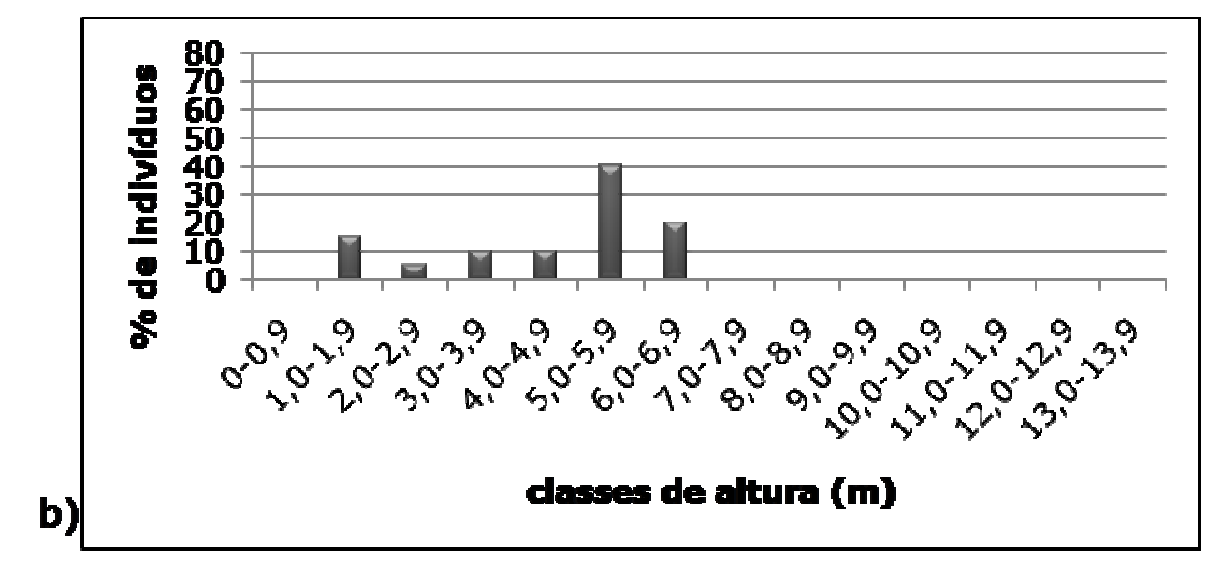

c)

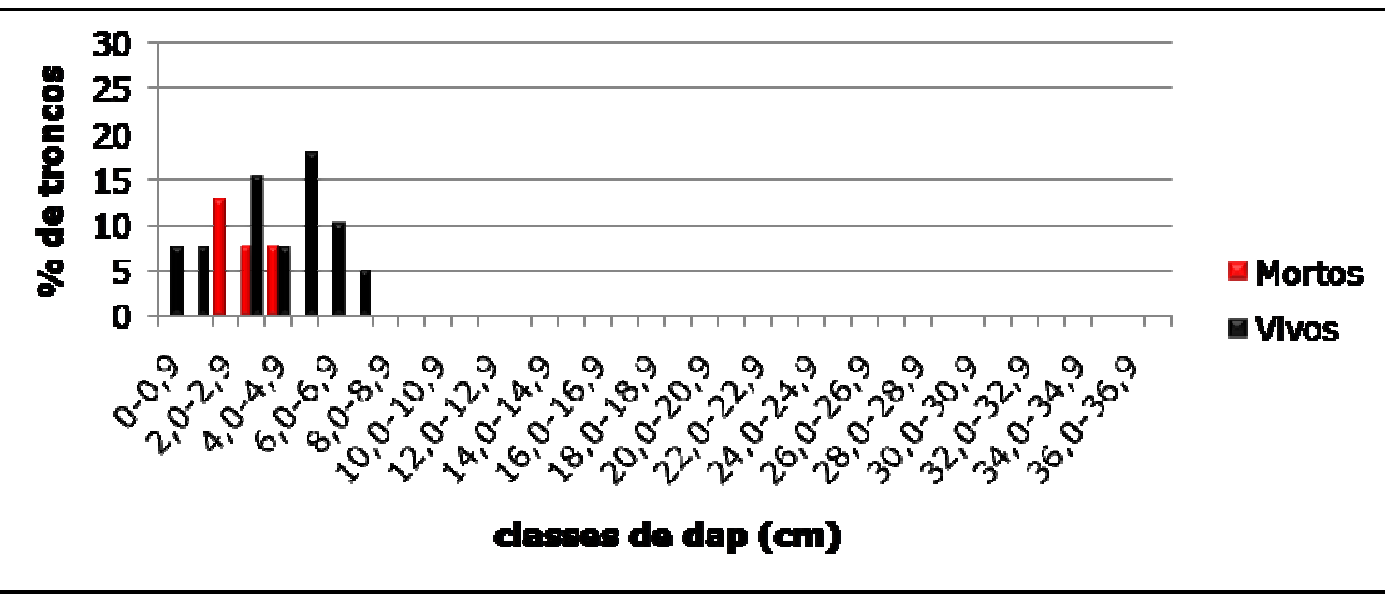


Prancha XXIV - Características estruturais da parcela \#12: a) tabela com características estruturais; b) figura com a dominância (\%) dos indivíduos por classes de altura; c) figura com a dominância (\%) de troncos vivos e mortos por classes de dap.

\begin{tabular}{|c|c|c|c|}
\hline & \multicolumn{3}{|c|}{ Parcela \#13 } \\
\hline & $\begin{array}{c}\text { Densidade } \\
\text { (N口) troncos.m } \mathrm{m}^{-2} \text { ) }\end{array}$ & \multicolumn{2}{|c|}{12653} \\
\hline & $\begin{array}{l}\text { Altura média } \\
\text { (m) } \\
\text { dap médio } \\
\text { (cm) }\end{array}$ & \multicolumn{2}{|c|}{4,36} \\
\hline & Área basal & $\mathbf{R m}$ & 0,00 \\
\hline & viva & $\mathbf{L r}$ & 88,78 \\
\hline & $(\%)$ & As & 0,74 \\
\hline & Area basal & Rm & 0,00 \\
\hline & morta & $\mathbf{L r}$ & 0,00 \\
\hline & $(\%)$ & As & 10,48 \\
\hline
\end{tabular}
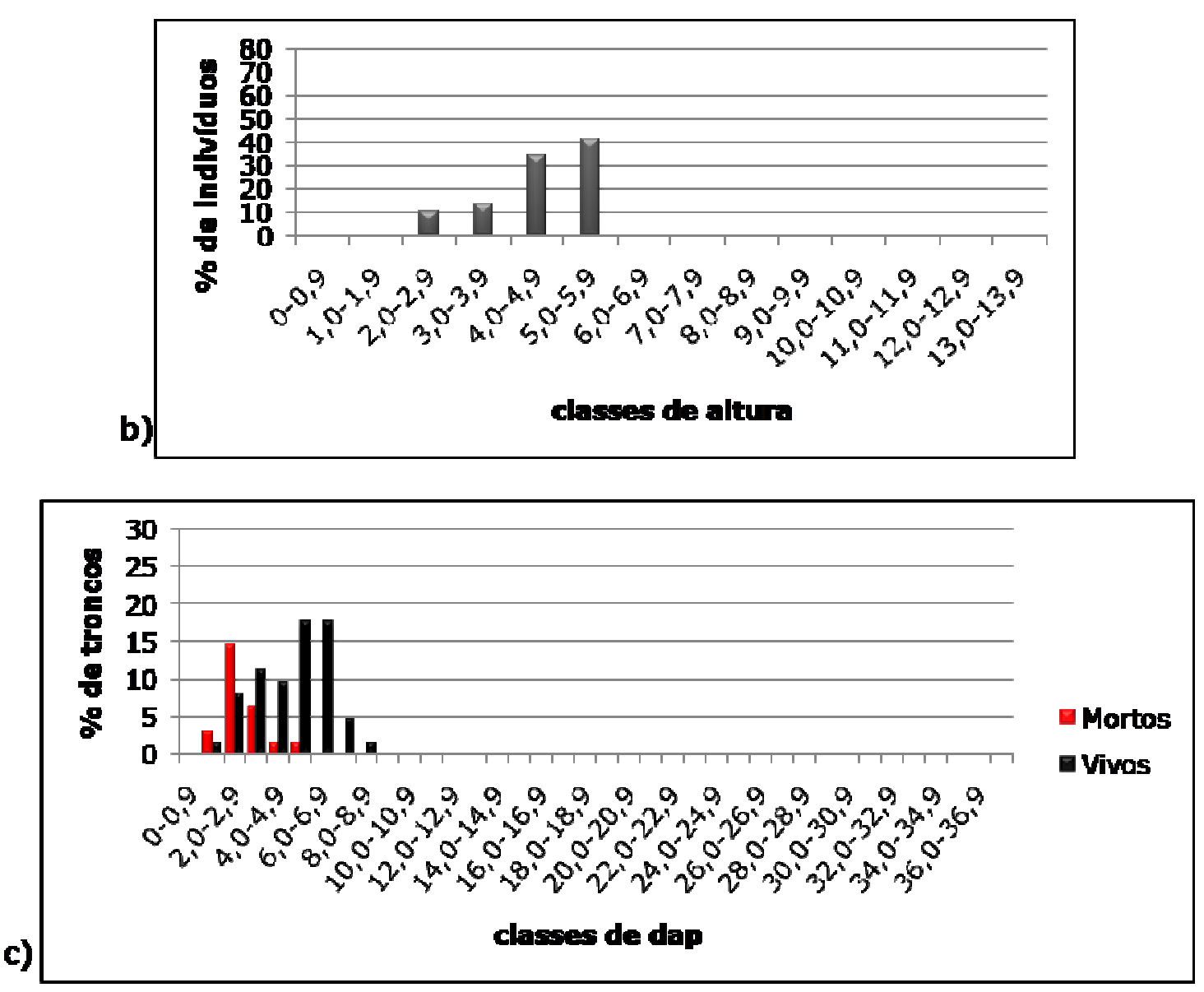
As parcelas \#12 e \#13 também foram estabelecidas em campo de forma justapostas, isto se reflete nos dados semelhantes observados em ambas as parcelas. As parcelas \#12 e \#13 apresentaram 1,44 e 1,88 troncos por indivíduo, respectivamente. As densidades foram de 5510 e 6735 indivíduos por hectare e de 7959 e 12653 troncos por hectare, respectivamente.

As alturas médias dos indivíduos das parcelas \#12 e \#13 também foram similares, 4,47 e 4,36m, respectivamente. A altura média inferior foi de 1,70 e $2,10 \mathrm{~m}$ e a superior de 6,40 e $5,20 \mathrm{~m}$, respectivamente. Os indivíduos da parcela \#12 apresentaram altura variando principalmente entre 5,0 e 7,0m e os indivíduos da parcela \#13 entre 4,0 e 6,0m.

Em ambas as parcelas o bosque apresentou dominância de indivíduos vivos, com alguns apresentando ramificações. Os valores de dap dos troncos vivos variaram entre 3,0 e 6,0 cm em ambas as parcelas e dos troncos mortos entre 2,0 e $4,0 \mathrm{~cm}$. O dap médio das parcelas foi de $4,56 \mathrm{~cm}$, para a parcela \#12 e de $5,14 \mathrm{~cm}$ para a parcela\#13.

L. racemosa foi a espécie dominante em ambas as parcelas, apresentando dominância em área basal viva e morta. Porém a espécie $A$. schaueriana foi encontrada em pequena quantidade em ambas as parcelas e $R$. mangle foi encontrada, também com pequena contribuição somente na parcela \#12.

O dossel deste bosque também se mostrou bem fechado e o sedimento não apresentou nenhuma característica que mereça receber destaque. 


\section{7 - DISCUSSÃO}

\section{1 - MONITORAMENTO DA ÁREA IMPACTADA PELO EVENTO DE 1998}

\subsection{1 - RECOMPOSIÇÃO NATURAL DA COBERTURA VEGETAL}

Assim como muitas florestas, os manguezais são dinâmicos, possuem crescimento contínuo e constantemente se restabelecem e se renovam. Diferem das florestas terrestres, principalmente, pelas adaptações requerentes a sobrevivência no ambiente do entremarés. Tais adaptações fazem com que o ecossistema manguezal seja apto a ocupar, dominar e se estabilizar nestes ambientes com severas condições hidrológicas e físico-químicas, sendo essencial desta forma a presença de processos regenerativos adaptáveis, progressivos e principalmente eficientes neste ecossistema (Duke, 2001).

O mesmo autor afirma que os manguezais possuem uma combinação de atributos e estratégias de crescimento que promovem sua sobrevivência, estabelecimento e regeneração em clareiras dentro do bosque, incluindo:

- Abundância de propágulos com capacidade de flutuar.

- Estratégias de "autoplantio" devido ao formato e ao peso dos propágulos.

- Propágulos possuem grandes reservas nutritivas auxiliando a sua dispersão e estabelecimento.

- Rápido crescimento de raízes e folhas pelo propágulo fixado (plântula).

- Habilidade de sustentar crescimento por cerca de 2 ou 3 anos sobre dossel fechado em um "banco de plântulas". 
- Intolerância à sombra, reduzindo os recursos exigidos por competidores de crescimento lento.

- Forte ligação trófica com a fauna bentônica local, promovendo taxas de crescimento em altura elevadas e ganho de biomassa.

A dinâmica de todos estes fatores pode diferir em resposta, dependendo de fatores internos (espécies envolvidas) e externos (exposição a ventos e ondas).

Os dados obtidos durante os seis anos de monitoramento demonstram que o bosque de mangue estudado apresentou uma capacidade de recomposição natural mesmo após o severo impacto causado pelo evento de 1998 na região.

Cintrón-Molero \& Schaeffer-Novelli (1992), apontaram a grande capacidade dos manguezais se manterem em locais com grande incidência de tensores, porém estes autores concluem que nestes locais os manguezais não conseguem alcançar o seu máximo desenvolvimento estrutural.

Avaliando todo o processo de recomposição natural, a queda observada nas taxas de mortalidade dos indivíduos em ambas as parcelas (R2 e R3), demonstra que o período de maior competição por espaço (desbaste natural) ocorreu nos primeiros anos de monitoramento, acarretando uma maior mortandade de indivíduos, fato este muitas vezes encontrado em bosques em estágios iniciais de crescimento e/ou recomposição natural (Cintrón \& Schaeffer- Novelli, 1984).

Os dados obtidos também apontam para uma maior taxa de crescimento médio dos indivíduos na parcela $R 2$, dominada pela espécie $L$. racemosa, quando comparada à parcela R3, onde $A$. schaueriana representa a espécie dominante. 
O fato das espécies estudadas apresentarem diferenças nas características inerentes ao crescimento é esperado. Segundo Tomlinson (1986), as espécies típicas de mangue representam diversos grupos taxonômicos, podendo desta forma se diferenciar quanto a sua morfologia, fenologia, fisiologia e grau de adaptação ao ambiente.

Fatores como salinidade (Ball, 1988; Krauss \& Allen, 2003a), baixos teores de oxigênio e freqüência de inundação (Smith, 1987; McKee \& Mendessohn, 1987; Jimenez \& Sauter, 1991; McKee, 1993; Ellison \& Farnsworth, 1993; Kitaya et al., 2002); competição interespecífica (Jimenez \& Sauter, op cit.; Clark \& Myerscough, 1993; Patterson et al., 1993); condições físico-químicas do sedimento (McKee, op cit.); luminosidade (Smith, op cit.; Ellison \& Farnsworth, 1996; Krauss \& Allen, op cit. e 2003b), e distúrbios (Ellison \& Farnsworth, op cit.; Duke et al., 1999) tem sido demonstrados que influenciam o crescimento e a dinâmica das plantas típicas de mangue.

Krauss et al. (2008), revisando os trabalhos sobre a ecofisiologia e o crescimento de plântulas em manguezais apontaram a salinidade, luz, nutrientes e freqüência de inundação como sendo os principais fatores que interferem na estabilização e crescimento das espécies típicas de mangue, porém apontaram a importância de se estudar mais a fundo a grande influência da biota local nestes processos.

Comparando plântulas de R. mangle, Avicennia germinans e $L$. racemosa crescendo na ausência dos seus tensores naturais (inundação, salinidade e herbívoros), McKee (1995) demostrou que estas espécies não apenas diferem em termos de crescimento potencial, mas também exibem diferentes padrões de compartimentação de biomassa, diferindo de acordo com a disponibilidade dos recursos (nutrientes e luz) no ambiente.

Outro fator que pode estar influenciando a menor taxa de crescimento dos indivíduos da parcela R3 deve-se ao fato que nesta parcela existem indivíduos emergentes de $A$. schaueriana que causam um 
grande sombreamento nos demais, limitando desta forma o crescimento médio dos indivíduos. Isto pode ser observado analisando a taxa de crescimento dos indivíduos emergentes desta parcela, que é maior que a média de todos os indivíduos.

Observando a localização das parcelas, podemos também perceber que a parcela R3 está mais próxima da franja do bosque. Embora não tenha sido observado nenhuma mortalidade massiva nos indivíduos desta parcela, o monitoramento da microtopografia demonstrou um intenso processo erosivo nesta região o que também pode estar interferindo na taxa de crescimento dos indivíduos. Esta colocação se torna mais clara, com a observação de campo de que todos os indivíduos emergentes desta parcela estão localizados na extremidade interna da parcela, portanto em região mais abrigada e um pouco mais distante do processo erosivo observado na franja.

Segundo a proposta de Jimenez et al. (1985) (Figura 1, p.3), concluímos que o bosque em recomposição natural começou a ser monitorado em 2002 quando possuía cerca de 2 anos de idade e terminou o monitoramento em 2007 com cerca de 7 anos de idade, portanto ainda está no processo de desenvolvimento inicial. Estes autores indicam que o final deste estágio é alcançado quando o crescimento em altura torna-se mais lento e o dossel alcança a sua altura máxima.

Como indicativo da altura máxima que provavelmente este bosque pode alcançar, temos os dados da caracterização estrutural realizada por Menghini (2004), no bosque de mangue remanescente ao evento de 1998. Segundo estes dados, a altura média do bosque é de cerca de 5-6 metros, com indivíduos emergentes de 7-8 metros de altura.

Considerando que as parcelas R2 e R3 apresentaram em 2007 (final do monitoramento) alturas médias de 3,94 e 2,85m e altura média das emergentes de 5,38 e 5,62m, respectivamente, e considerando que estes bosques mantenham as atuais taxas de crescimento, podemos concluir 
que os indivíduos da parcela R2 alcançarão uma altura média de 5-6 metros e a altura dos indivíduos emergentes 7-8 metros, quando tiverem cerca de 11 anos, portanto em 2011 (Figura 53).

Na parcela R3 os indivíduos emergentes alcançarão a altura de 7-8 metros com 12 anos (2012), porém a altura média de 5-6 metros apenas será atingida quando o bosque tiver com 23 anos, portanto apenas em 2023 (Figura 54). Este fato demonstra que a taxa de crescimento médio dos indivíduos da parcela R3 está muito abaixo do esperado.

Fromard et al. (1998), estudando bosques de mangue na Guiana Francesa, em diferentes estágios sucessionais, sugeriram que o final do estágio de desenvolvimento inicial se dá quando o bosque atinge cerca de 15 anos de idade, portanto muito parecido com o previsto no presente estudo. Porém esta comparação deve ser feita com cautela, pois os manguezais da Guiana Francesa estão localizados em uma região muito mais favorável ao seu desenvolvimento.

Outra ressalva que cabe ser colocada é que a continuidade do monitoramento realizado em agosto de 2008, portanto quase um ano após o término do monitoramento que foi analisado no presente estudo, foi observado uma expressiva queda na taxa de crescimento em ambas as parcelas.

Este fato corrobora a idéia de que embora no presente estudo tenha se monitorado a recomposição natural deste bosque durante 6 anos consecutivos, é necessário realizar monitoramentos contínuos em manguezais em recomposição natural, para se avaliar todo o processo de recomposição natural e não apenas uma fase deste processo. 


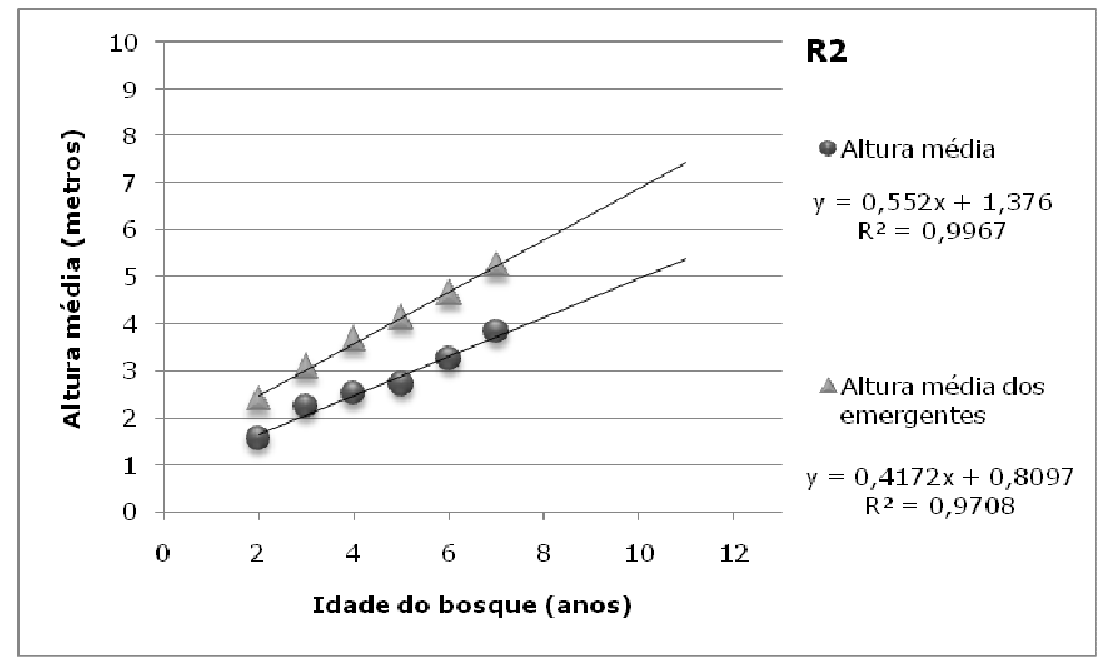

Figura 53 - Relação entre a idade do bosque e a altura média dos indivíduos na parcela R2 e projeção da idade que os indivíduos terão quando alcançarem o dossel (caso ocorra).

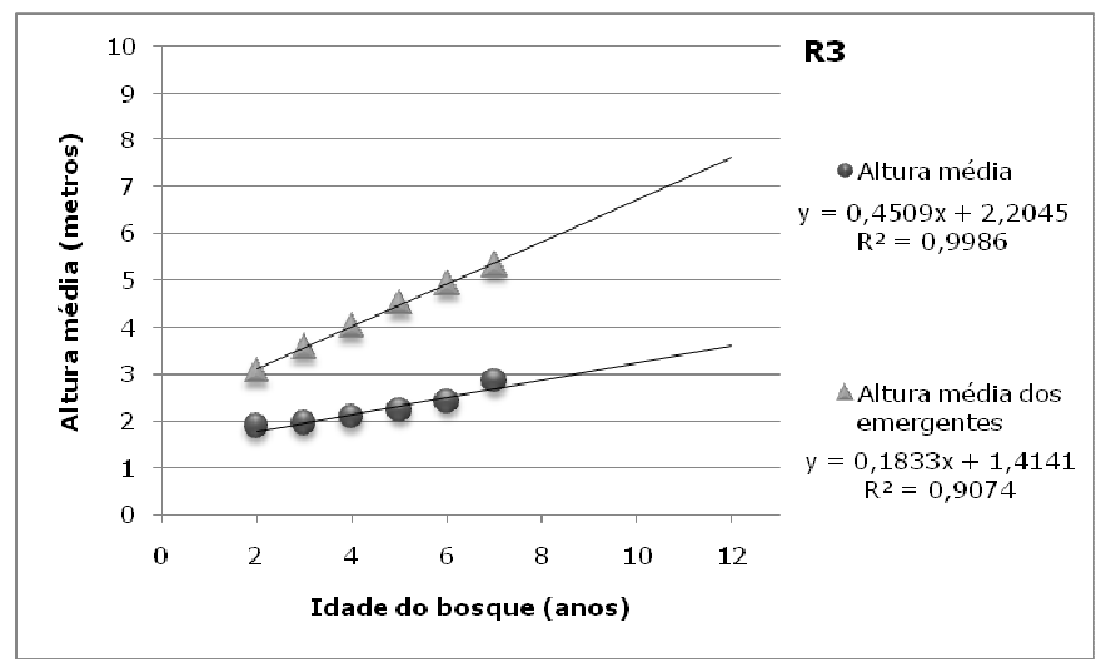

Figura 54 - Relação entre a idade do bosque e a altura média dos indivíduos na parcela $\mathrm{R} 3$ e projeção da idade que os indivíduos terão quando alcançarem o dossel (caso ocorra). 


\subsection{2 - PRODUÇÃO DE SERAPILHEIRA}

As características estruturais dos bosques de mangue exercem grande influência sobre as taxas de crescimento e na produção primária do bosque. Dentre os atributos estruturais, podemos destacar a densidade de troncos, área basal, índice de área foliar, além da distribuição e orientação das folhas no dossel (Clough, 1992).

O fato do bosque de mangue estudado estar sujeito a diversos tensores antrópicos, deve ser avaliado, pois estes causaram grandes impactos nas características estruturais do bosque (Menghini, 2004), influenciando concomitantemente seu funcionamento.

Uma das principais características a serem consideradas é que o bosque de mangue estudado apresenta um mosaico de árvores remanescentes ao evento de 1998 e árvores que colonizaram as clareiras abertas, portanto indivíduos de idades diferentes. Isto deve ser considerado, pois a produção de serapilheira pode apresentar características distintas de acordo com a idade das árvores do bosque.

Poucos trabalhos sobre a produção de serapilheira foram realizados em bosques com diferentes idades, destacando apenas o trabalho realizado por Clough et al. (2000), que avaliaram, entre outros parâmetros, a produção de serapilheira em bosques de mangue dominados por Rhizophora apiculata com diferentes idades (6, 9, 10, 12, 21 e 35 anos). As principais observações feitas foram que a produção de serapilheira foi maior no bosque de 12 anos de idade $\left(18,79\right.$ ton. ha ${ }^{-1}$. ano ${ }^{1}$ ) e a produção de propágulos foi maior nos bosques mais maduros (21 e 35 anos). 


\subsubsection{1 -VARIABILIDADE INTERANUAL}

Na maioria dos estudos de produtividade de manguezais, a produção primária (principalmente a queda de serapilheira) tem sido estudada apenas por curtos períodos de tempo, geralmente apenas um ou dois anos, porém trabalhos que monitoraram a queda de serapilheira por períodos maiores mostram que existe uma grande variação interanual nos valores encontrados. No entanto não se sabe ao certo se esta variabilidade é devida a características específicas do local ou a mudanças interanuais de fatores como precipitação, descarga de rios, temperatura ou salinidade (Pool et al., 1975; Lugo et al., 1988; Day Jr. et al., 1996).

No presente estudo a grande variabilidade interanual encontrada pode ser reflexo da dinâmica da recomposição natural que está ocorrendo no bosque em estudo, onde gradativamente a biomassa que foi perdida no evento de 1998, está sendo reincorporada ao sistema através da atividade fotossintética das espécies vegetais, portanto os valores de serapilheira estão apresentando valores crescentes ao longo dos anos estudados.

Brown \& Lugo (1990) realizaram uma extensa revisão bibliográfica das principais características ecológicas de diferentes tipos de florestas tropicais secundárias, e concluíram que os dados de queda de serapilheira nestas florestas podem ser um ótimo indicador do seu estágio sucessional. Os autores encontraram três tendências que podem ser visualizadas através da serapilheira: (1) contínuo incremento nas taxas por cerca de 12-15 anos; (2) um limite de cerca de 12-13 t.ha ${ }^{-1}$.ano ${ }^{-1}$ e (3) período que pode variar, com forte influência das condições climáticas ou não, dependendo da localização geográfica da floresta. Também concluíram que a produção de serapilheira em florestas secundárias jovens $(<20$ anos) é maior que a produção de biomassa (fitomassa), sendo a decomposição de folhas (serapilheira) mais rápida, a matéria orgânica é 
mais rapidamente reciclada pelo sistema do que se ficasse armazenada em biomassa.

O rápido aumento da produção de serapilheira durante os primeiros 15 anos do bosque demonstra a magnitude do desenvolvimento estrutural que ocorre durante as duas primeiras décadas em uma floresta secundária (Brown \& Lugo, 1990).

O bosque de mangue em estudo sofreu grande impacto causado pelo derramamento de produto químico (diciclopentadieno - DCPD) seguido de incêndio em setembro de 1998 (Menghini, 2004), portanto podemos considerá-lo como um bosque secundário de mangue com idade aproximada entre oito e nove anos.

A produção de serapilheira está apresentando um contínuo acréscimo nas suas taxas, principalmente da fração folhas, confirmando proposta de Brown \& Lugo (op. cit.), como um padrão encontrado nos primeiros anos em florestas tropicais secundárias.

\subsubsection{2 - SAZONALIDADE}

A produção de serapilheira do bosque de mangue da Ilha Barnabé mostrou marcada sazonalidade nas frações folhas, flores e frutos, ocorrendo os maiores valores nos meses de verão (meses quentes e úmidos). Diversos autores encontraram este padrão sazonal, destacandose os trabalhos clássicos feitos por Gill \& Tomlinson (1971), que apontaram inicialmente como fatores determinantes os maiores valores de temperatura do ar e luz incidente.

Pool et al. (1975) acrescentaram a importância da maior disponibilidade de água doce nos meses de verão, propondo desta forma que os manguezais tenham desenvolvido uma estratégia de queda de serapilheira, onde as folhas caem continuamente ao longo do ano, com 
maiores taxas durante a estação úmida, e as menores taxas durante a estação seca, que normalmente coincide com as menores temperaturas.

Esta marcada sazonalidade na produção total de serapilheira no manguezal da Ilha Barnabé também foi observada por outros pesquisadores em diversas partes do Brasil e do mundo (Pool et al., 1975; Adaime, 1985; Twilley et al., 1986; Flores-Verdugo et al., 1987; Menezes, 1994; Lamparelli, 1995; Clought et al., 2000; Almeida, 2004; Menghini, 2004; Chaves, 2007).

A Figura 55 mostra a variação mensal da temperatura média juntamente com os valores mensais de produção de serapilheira durante os cinco anos de monitoramento. Embora não tenha sido feito uma análise estatística, o gráfico mostra claramente a estreita relação entre o pico de queda de serapilheira com os meses mais quentes de verão.

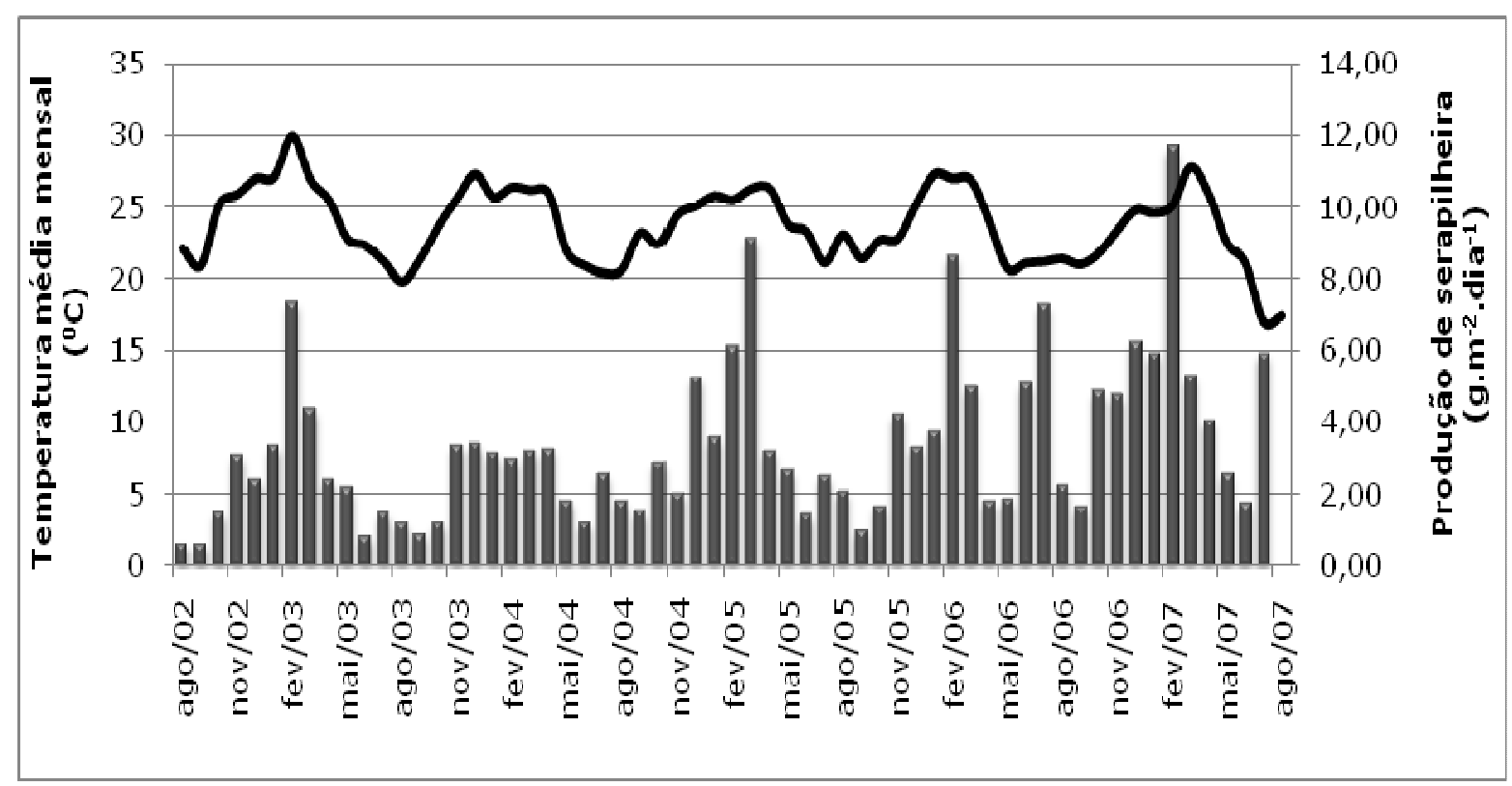

Figura 55 - Relação da temperatura média mensal com os valores de produção de serapilheira do bosque de mangue da Ilha Barnabé. 


\subsubsection{3 - SERAPILHEIRA: FERRAMENTA DE ANÁLISE DE MANGUEZAIS IMPACTADOS EM PROCESSO DE RECOMPOSIÇÃO NATURAL}

No aspecto quantitativo, as taxas totais de produção de serapilheira no bosque da Ilha Barnabé $\left(8,56\right.$ a 17,10 ton.ha ${ }^{-1}$.ano $\left.{ }^{-1}\right)$, e a produção média anual de 2,37 a $4,74 \mathrm{~g} \cdot \mathrm{m}^{-2} \cdot \mathrm{dia}^{-1}$, foram altas quando comparadas com outros bosques estudados na Baixada Santista.

Lamparelli (1995) estudou a produção de serapilheira em duas áreas do Canal de Bertioga (Rios Iriri e Itapanhaú), encontrando valores menores que os do presente estudo, variando de 4,17 a 6,55 ton. ha- ${ }^{-1}$. ano 1 , enquanto que Ponte et al. $(1984 ; 1990)$ analisando os efeitos de derramamento de óleo na serapilheira também no Canal de Bertioga (Rio Iriri) encontraram valores que variaram de 1,06 a 1,26 g.m $\mathrm{m}^{-2} \cdot \mathrm{dia}^{-1}$. Ambos trabalhos fazem menção a reduzida contribuição de propágulos.

A dominância de $L$. racemosa no compartimento foliar, com pouca contribuição das demais espécies, reflete os dados estruturais da cobertura vegetal do bosque, onde esta espécie é dominante, tanto em área basal, como em número de troncos vivos (Menghini, 2004).

Cabe ressaltar a baixa contribuição de folhas na serapilheira, que variou entre 43,1 a $58,7 \%$, com uma média de $52,54 \%$ durante os cinco anos de monitoramento, sendo que em condições normais, a queda de folhas representa de 70 a $80 \%$ dos componentes da serapilheira (Cintrón \& Schaeffer-Novelli, 1983).

A grande representatividade de propágulos foi responsável pela baixa representatividade de folhas. A porcentagem de propágulos variou entre $21,2 \%$ a $42,58 \%$ ao longo dos cinco anos de monitoramento, com uma média de $30,56 \%$. Este fato pode estar evidenciando uma resposta de estresse da cobertura vegetal, visto a grande quantidade de tensores presentes na Baixada Santista, principalmente na área de estudo. 
Chaves (2007), estudando a produção de serapilheira em manguezais da Baía de Guanabara (RJ), região que assim como a Baixada Santista, apresenta sérios problemas ambientais, encontrou uma representatividade de propágulos na produção total de serapilheira que variou de $6,5 \%$ a $34,4 \%$, com uma média de $18,7 \%$. Portanto, valores um pouco abaixo dos encontrados no presente estudo.

Não existem estudos específicos a cerca dos possíveis efeitos do estresse na reprodução das espécies típicas de mangue, quanto ao fato das espécies responderem com um aumento ou uma diminuição do aporte energético para fins reprodutivos (formação de flores e conseqüentemente de frutos e propágulos).

Embora exista uma relação entre o crescimento vegetativo e o reprodutivo, segundo Chiarello \& Gulmon (1991), este último é mais sensível aos efeitos de tensores. Os mesmos autores apontam que a maioria dos trabalhos realizados com este foco de pesquisa chegou à resposta de que é mais comum uma diminuição da produção de partes reprodutivas como efeito do estresse, porém apontam que podem ocorrer algumas exceções em situações onde a probabilidade de sobrevivência é baixa e as opções para reprodução são "now or never". Nestes casos onde a espécie vegetal estaria deslocando energia para fins reprodutivos, para compensar, estaria mantendo o crescimento vegetativo em níveis abaixo do necessário.

Poucos estudos sobre os impactos negativos no sistema reprodutor causados pelo estresse chegaram a esta conclusão. Boot (1986) concluiu que o estresse hídrico causou um aumento na produção de partes reprodutivas de Urtica dioica e Urtica urens (herbácea cosmopolita de regiões temperadas). 
Van Zandt et al. (2003) observaram uma diminuição no crescimento vegetativo e um incremento no reprodutivo em testes realizados com Iris hexagona (uma espécie de lírio encontrada em zonas úmidas norteamericanas) sobre influência de estresse salino.

Porém alguns estudos de serapilheira realizados em manguezais localizados em áreas mais preservadas encontraram valores variados, o que mostra que a representatividade dos propágulos depende de vários fatores locais, sendo provavelmente o mais importante as espécies presentes no bosque, já que existe uma grande diferença entre o peso dos propágulos das espécies típicas de mangue.

Fernandes (1997) estudando os manguezais da Ilha de Maracá (AP) encontrou uma variação na contribuição de propágulos entre 7,1 a 33\% do total de serapilheira.

Estudo realizado durante dois anos acerca da dinâmica da serapilheira ao longo de uma transversal em manguezal da Ilha do Cardoso (Cananéia-SP), dominado pela espécie $R$. mangle, Almeida (2005) encontrou a maior contribuição de propágulos nos bosques de franja $(5-35 \%)$ e os menores valores nos bosques de bacia (13-21\%).

O tamanho dos propágulos também interferiu na representatividade dos mesmos na produção de serapilheira no presente estudo, já que os anos que tiveram a maior representatividade de propágulos foram os anos de maior produção e queda de propágulos de $R$. mangle (ANOS I, III e V).

Portanto, embora ainda seja necessário aprofundar os estudos quanto aos efeitos do estresse na reprodução de espécies típicas de mangue, o presente estudo encontrou valores acima da média na produção de partes reprodutivas. Estes resultados podem estar indicando uma possível estratégia das espécies típicas de mangue sujeitas ao estresse. 
Porém, a presença constante de propágulos de $R$. mangle abortados no início do desenvolvimento (Figura 56) e/ou apresentando diversos padrões de deformações (Figura 57), é forte indício do estado de estresse na vegetação, principalmente por terem sido coletados em grande número nas cestas coletoras de serapilheira e constantemente observados em campo.

Lugo (1978) comenta que a vegetação quando em estado de estresse pode apresentar deformações e/ou aberrações.

Quando as partes reprodutivas são abortadas no começo do seu desenvolvimento, o custo energético para a planta pode ser relativamente menor comparado ao benefício potencial de ter um maior estoque de energia para usar em condições mais favoráveis (Chiarello \& Gulmon, 1991).

Porém, os possíveis motivos acima descritos para o aborto de partes reprodutivas, parecem não responderem aos dados observados no presente estudo, pois consta de um ambiente com incidência crônica de tensores. Portanto, é necessário um aprofundamento maior na possibilidade dos abortos serem em decorrência do estresse causado por algum tensor crônico do local.

A contribuição de madeira (necromassa) está relacionada a eventos episódicos, onde grande quantidade de troncos mortos encontrados no bosque (Menghini, 2004) contribuiu como fonte de galhos e ramos mortos durante eventos de frentes frias, tempestades ou mesmo quando árvores mortas tombaram como o ocorrido em agosto (inverno) dos ANOS IV e V, época de maior incidência desses fenômenos metereológicos. 


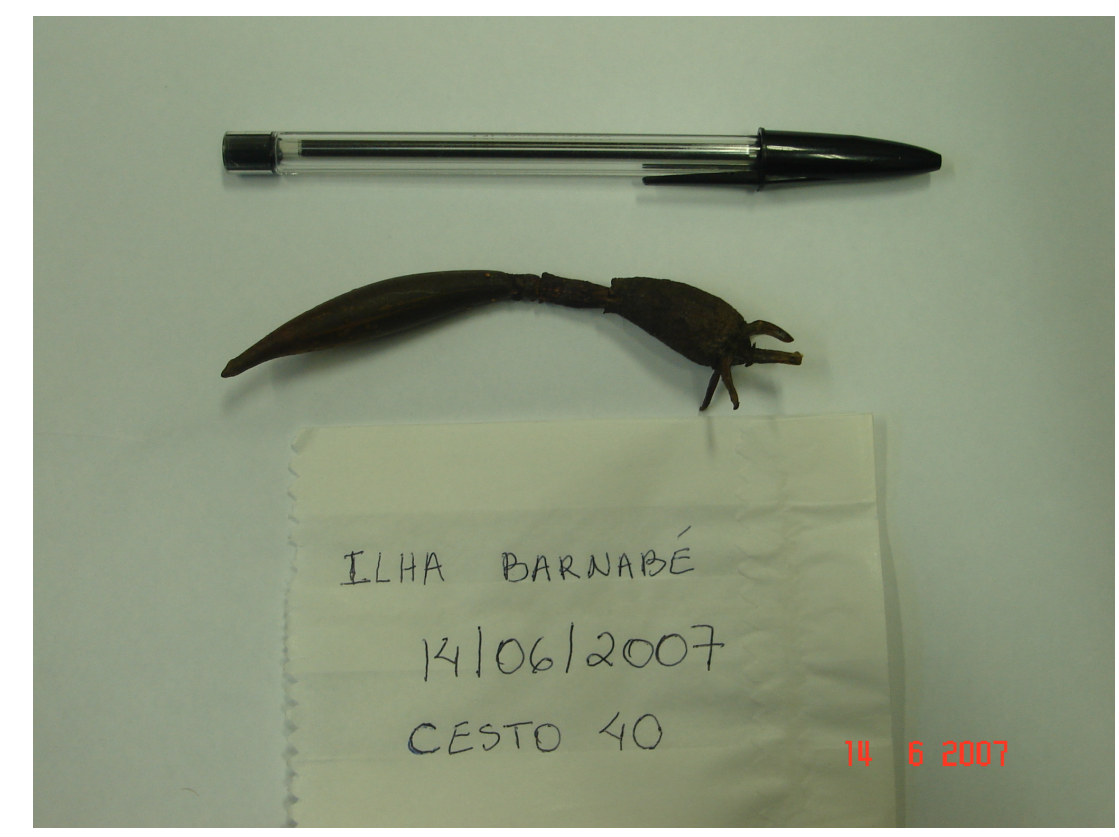

Figura 56 - Propágulo de Rhizophora mangle abortado no início do seu desenvolvimento, coletado em cesta de serapilheira no bosque de mangue da Ilha Barnabé.

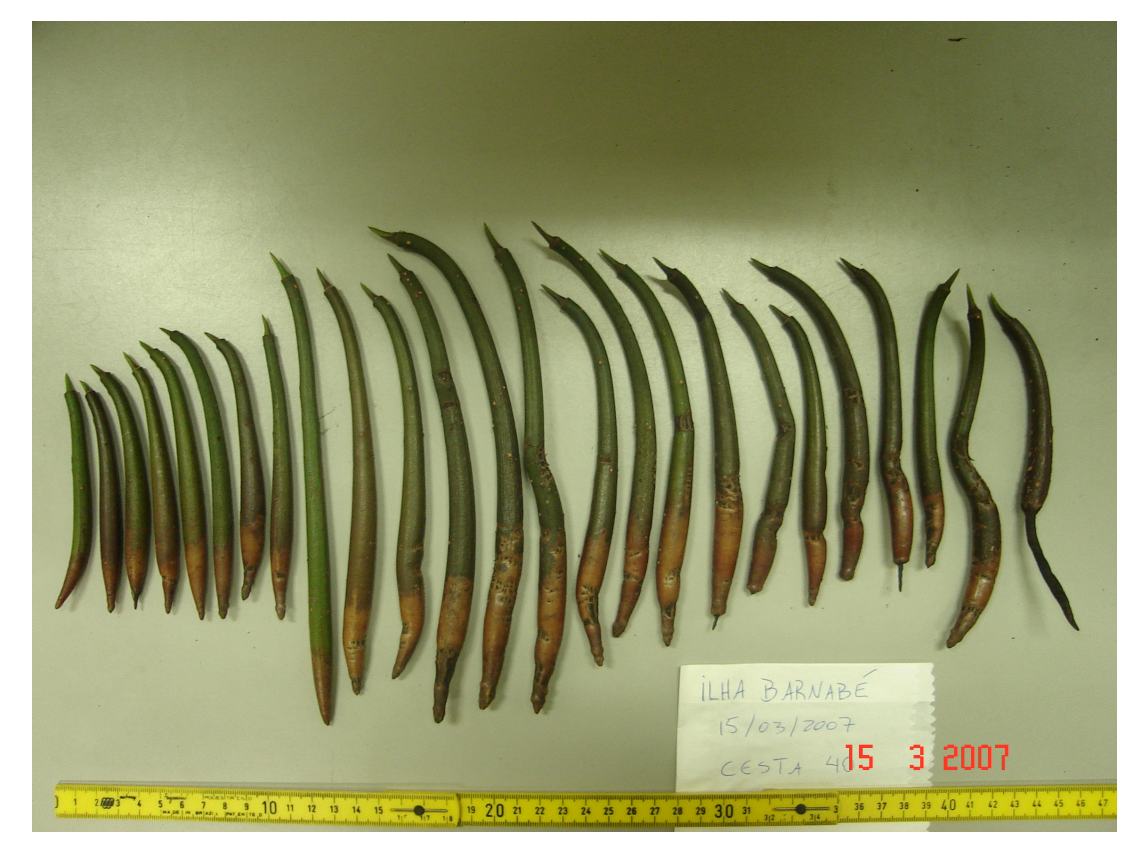

Figura 57 - Propágulos de Rhizophora mangle coletados em cesta de serapilheira no bosque de mangue da Ilha Barnabé apresentando deformações diversas (quantidade total coletada em uma cesta coletora). 
Poucos trabalhos utilizaram a produção de serapilheira como ferramenta para analisar possíveis respostas funcionais frente a perturbações em bosques de mangue, cabendo fazer referência aos trabalhos de Lugo et al. (1981), Ponte et al. (1984 e 1990) e Carmo et al. (1998).

Lugo et al. (1981), analisaram a queda de serapilheira em bosques de mangue atingidos por óleo em Porto Rico, sendo que concluíram como possível diferença no padrão da queda de serapilheira, apenas uma maior contribuição de folhas do bosque impactado na estação seca, quando comparado com o bosque controle, que manteve padrão sazonal com as maiores quedas na estação chuvosa. Cabe ressaltar que o trabalho foi realizado quatro anos após o evento (derramamento de óleo), não avaliando o efeito agudo inicial, que segundo os autores teria sido de desfolhamento total ou parcial do dossel.

No Canal de Bertioga (Baixada Santista) ocorreu em 1983, vazamento de óleo decorrente do rompimento de oleoduto. Estudos de serapilheira realizados na área antes e após o evento, não encontraram padrão atípico, relatando baixa produção anual que variou de 1,06 a 1,26 $\mathrm{g} \cdot \mathrm{m}^{-2} \cdot \mathrm{dia}^{-1}$. Também houve referência a presença de propágulos deformados e abortados após o derramamento de óleo (Ponte et al., $1984 ; 1990)$.

A extração da casca de $R$. mangle para obtenção de tanino para confecção de panelas de barro, pode ser considerado um dos impactos mais freqüentes sobre os manguezais da Baía de Vitória, Espírito Santo. Carmo et al. (1998) investigaram a influência desta extração sobre a produção de serapilheira, registrando inicialmente murchamento das folhas, seguido de senescência e intenso desfolhamento, ocasionando posteriormente, redução na produção de serapilheira, sendo que a parcela controle (sem extração da casca) apresentou produção em torno de 10 ton.ha ${ }^{-1} \cdot$ ano $^{-1}$, enquanto os valores da parcela teste (com extração da 
casca) foram de 7,53 ton.ha ${ }^{-1}$.ano ${ }^{1}$ em 1995 e 5,83 ton.ha ${ }^{-1}$.ano ${ }^{-1}$ em 1996.

A produção de serapilheira do bosque de mangue da Ilha Barnabé está mostrando alguns padrões que podem estar sugerindo certa desordem funcional no sistema, tal como a pequena contribuição de folhas e a grande contribuição de partes reprodutivas (flores e propágulos), além de propágulos abortados e deformados.

\subsection{3 - MICROTOPOGRAFIA}

A proteção desempenhada pelo ecossistema manguezal contra a erosão das linhas de costa é considerada importante função exercida por este ecossistema. Isto se deve ao emaranhado sistema radicial das espécies típicas de mangue, que amortece a energia do fluxo d'água e das ondas causando turbulência ao adentrarem ao bosque. Quando o fluxo da maré perde força (estofo da preamar) ocorre a deposição do material sedimentar em suspensão. As ramificações radiciais, principalmente as mais finas, contribuem para a retenção das partículas de sedimento devido à força eletrostática relacionada com a interação das trocas de cátions entre a superfície das raízes de absorção e os colóides orgânicos e grãos finos do sedimento, estabilizando desta forma o substrato (Spenceley, 1977; Cintrón et al., 1980; Semeniuk, 1980; Hamilton \& Snedaker, 1984; Othman, 1994; Furukawa \& Wolanski, 1996; Mazda et al., 1997 a e b).

Analisando os mapas gerados para o ano de 2004 e 2008 nota-se um grande "desnível" entre o bosque de mangue e a área localizada a sua frente, preteritamente ocupada pela franja do bosque queimada durante 0 incêndio no evento ocorrido em 1998.

A queima desta vegetação acarretou e/ou intensificou um processo de diminuição na cota do terreno na área. Após a supressão da cobertura 
vegetal, a vulnerabilidade destes sedimentos serem carreados devido ao intenso embate de ondas provocado principalmente pelo tráfego de grandes embarcações e pelos ventos do quadrante sul que atingem frontalmente o bosque intensificou-se, provocando desta forma nítida erosão do sedimento.

Outro fator relevante a ser considerado é que com a morte da vegetação, mesmo sem ocorrer à erosão do sedimento, a biomassa subterrânea (sistema radicial) morta sofre processo de decomposição, acarretando também desta forma uma diminuição na cota do terreno, pois o volume antes ocupado pela biomassa subterrânea foi perdido com a morte da vegetação.

Este processo de erosão/diminuição da cota do terreno está agindo como um tensor no bosque uma vez que começou a expor o sistema radicial das árvores do bosque remanescente, em contato com o embate constante de ondas. Ellison (1993), concluiu que a erosão pode debilitar o suporte das árvores de mangue frente a tempestades, ventos fortes, ressacas, acarretando a morte dos indivíduos ainda em pé.

Menghini (2004) através do modelo de terreno gerado pelo autor na época aventou a hipótese de que esta erosão poderia comprometer o bosque remanescente podendo causar a mortalidade de árvores da franja do bosque, pois na época podia se observar que algumas árvores já apresentavam uma exposição do seu sistema radicial (Figura 58). No presente estudo, com a reformulação dos modelos microtopográficos do ano de 2004 e a realização de novos modelos referente ao ano de 2008 podemos comprovar esta hipótese.

Atualmente as conseqüências desta erosão podem ser observadas em quase toda a extensão da franja do bosque, onde se observa uma mortalidade massiva de indivíduos (Figura 59). 


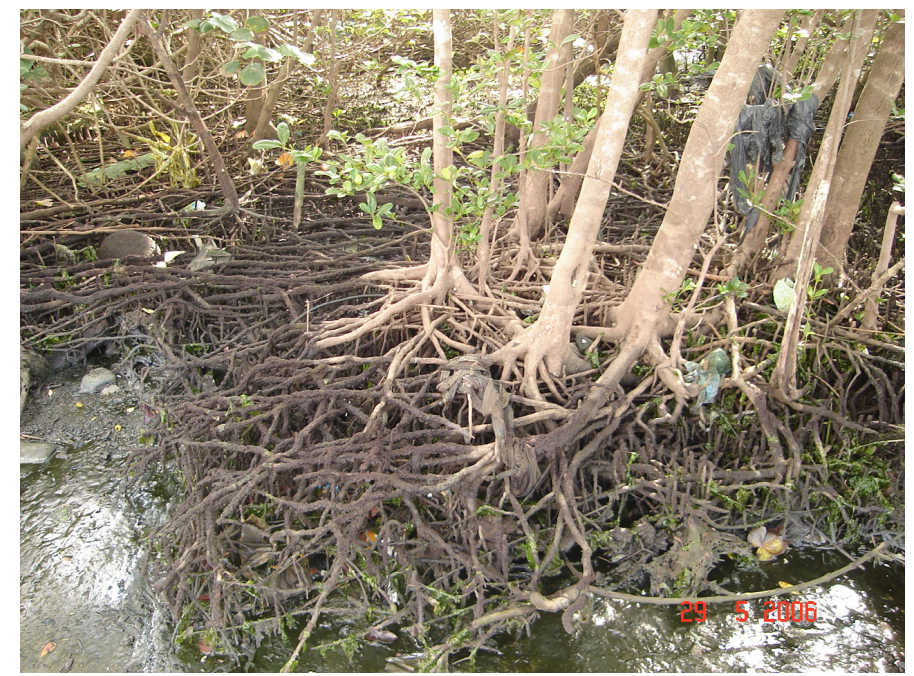

Figura 58 - Detalhe do sistema radicial exposto de alguns indivíduos presentes na franja do bosque.

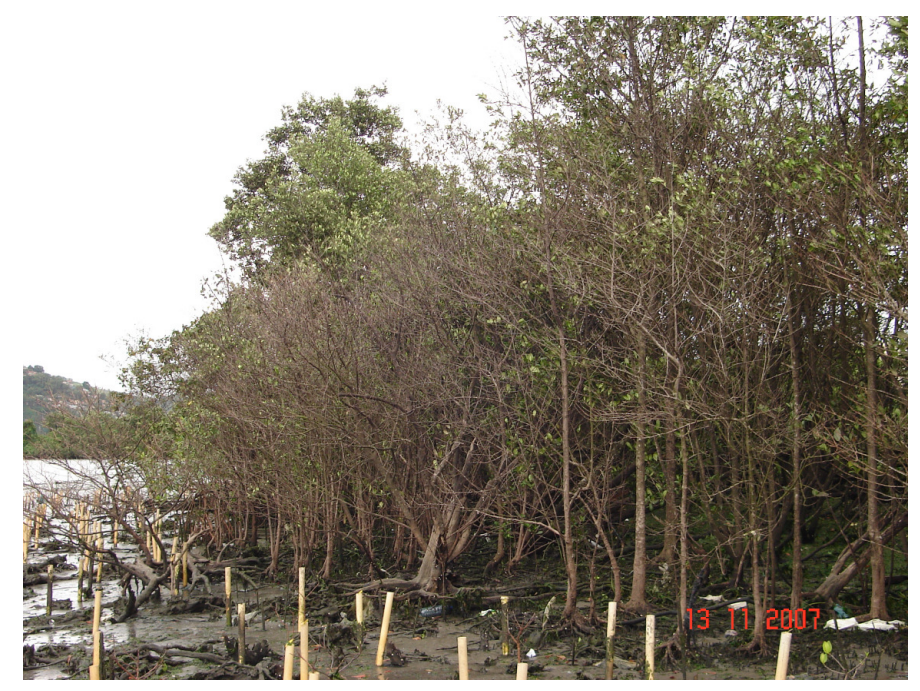

Figura 59 - Mortalidade de indivíduos localizados na franja do bosque. 
Cintrón et al. (1980), estudando a ecologia de manguezais em Porto Rico, frente a diferentes regimes de exposição a ondas, concluíram que o embate constante de ondas nas áreas menos abrigadas limita desenvolvimento e crescimento dos bosques.

Estudo feito por Semeniuk (1980) nos manguezais ao longo da costa noroeste da Austrália em processo erosivo, concluiu que a sucessão das comunidades é induzida pela rápida erosão da região, fazendo com que esses específicos habitats estejam continuamente migrando. Essa dinâmica faz com que bosques maduros bem desenvolvidos não consigam se estabelecer devido às constantes reposições de comunidades que ocorrem em anos ou décadas.

Podemos afirmar que a supressão da vegetação devido à queima acarretou e/ou intensificou processo de erosão na antiga franja do bosque, tornando esta área incapaz de se recompor naturalmente devido às novas condições impostas. Cabe ressaltar que durante todo o período de monitoramento (2001-2008) não foi observado qualquer recrutamento de plântulas nesta área.

Este registro vai de acordo com o proposto por Duke (2001), quando ele afirma que os bosques de mangue mais expostos (franjas) são particularmente mais vulneráveis aos fatores que influenciam sua recomposição, pois com este ambiente desflorestado, a recomposição natural neste local torna-se insustentável e o ecossistema como um todo pode caminhar a um colapso.

Lugo (1997) cita que quando a estrutura vegetal do bosque de mangue é retirada, o sedimento pode sofrer erosão, e o aumento da profundidade do nível d'água no local impede o restabelecimento do bosque. A energia das ondas (naturais ou induzidas) pode ocasionar erosão do sedimento e um estresse no bosque de mangue, podendo este ser eliminado do local. 
Porém, analisando a extensão do bosque de mangue nos anos de 2004 e 2008, podemos observar que ocorreu uma colonização por novas plântulas, no caso de L. racemosa, nas áreas laterais ao bosque (mais protegidos do embate constante de ondas). Observando as cotas do terreno, podemos ver que estas novas colonizações ocorreram em áreas onde houve elevação na cota do terreno significativa. Esta constatação reforça ainda mais os apontamento acima propostos que o fato mais agravante para a antiga franja não ter apresentado processo de recomposição natural deve-se a erosão/diminuição da cota do terreno na área.

As maiores elevações na cota do terreno foram observadas na porção leste do bosque de mangue. Nesta região, existe uma tubulação de liberação de efluentes de uma das empresas que operam na Ilha Barnabé. Esta tubulação pode estar agindo como uma barreira ao fluxo das águas da maré que adentram ao bosque, causando desta forma uma intensa sedimentação local.

As mudanças na cota do terreno também podem ter influência da vegetação que colonizou a área posteriormente.

Segundo Rogers et al. (2005), durante a fase de recolonização por plântulas a elevação da cota do terreno pode ser inicialmente controlada pelo acúmulo de matéria orgânica, numa taxa superior que a deposição de sedimentos. Portanto, é provável que tanto a sedimentação como a posterior colonização por indivíduos tenham controlado a elevação na cota do terreno.

Um fato relevante a ser considerado quanto à dinâmica sedimentar local é a provável conseqüência da construção do empreendimento Embraport (Figura 10; pg. 36) que teve suas obras iniciadas em março de 2008. Este empreendimento causará sérias modificações na dinâmica sedimentar desta região, pois está sendo construído aproximadamente à 500 metros a leste, e está aterrando uma extensa faixa de banco de lama. 
Os dados levantados no presente estudo mostram que embora grande parte dos manguezais da Baixada Santista estejam altamente alterados, eles continuam desempenhando a importante função de retenção de sedimentos.

A supressão desta vegetação nas margens do Porto de Santos com propósitos diversos e duvidosos acabam acarretando a necessidade de constantes dragagens do sedimento no canal de navegação, sendo que este assunto é de extrema importância econômica pelos altos custos com dragagem e ecológicos, devido aos altos níveis de contaminação destes sedimentos. 


\section{2 - ESTUDO DOS MANGUEZAIS DA ILHA BARNABÉ}

\subsection{1 - ANÁLISE MULTITEMPORAL DE FOTOGRAFIAS AÉREAS}

Técnicas de sensoriamento remoto, Sistema de Informação Geográfica (SIG) e uso de GPS fornecem informações de comparação do estado atual de áreas naturais com o passado, possibilitando projeções antecipadas de impactos ou alterações de uma dada região, auxiliando desta forma medidas mitigadoras com vistas ao gerenciamento costeiro de uma região (Dahdouh-Guebas, 2002).

O processamento de dados gerados através de sensoriamento remoto (fotografias aéreas e imagens de satélite) em ambiente computacional utilizando um SIG tem demonstrado ao longo dos últimos anos que é uma ótima ferramenta em estudos em áreas de manguezal visando avaliação/prevenção de impactos ambientais, avaliação de perda e/ou incremento de áreas de manguezais e conseqüentemente auxiliando o gerenciamento costeiro de diversas regiões ao longo do planeta.

No Brasil, podemos destacar alguns trabalhos, embora ainda exista a necessidade de ampliação do uso desta ferramenta, principalmente em regiões costeiras onde existem conflitos de interesse quanto ao uso da paisagem.

Cunha-Lignon $(2001 ; 2005)$ estudou a dinâmica da vegetação em manguezais do Complexo Estuarino-Lagunar de Cananéia-Iguape utilizando uma abordagem de escalas hierárquicas, que demonstrou a grande eficácia e necessidade de trabalhar em mais de uma escala de trabalho para se ter um resultado fidedigno da realidade em ambientes onde a dinâmica sedimentar é intensa.

Na região nordeste, Kampel et al. (2005), utilizando imagens de satélite CCD/CBERS e TM/LandSat, avaliaram a extensão da área de manguezais no litoral do Ceará e as mudanças ocorridas numa escala 
multi-temporal, confirmando os baixos custos e a eficácia desta metodologia.

Estudo realizado por Costa et al. (2006) buscou avaliar as potencialidades e fragilidades das áreas de manguezal inseridas no Pólo Ecoturístico dos Guarás, na Área de Proteção Ambiental (APA) das Reentrâncias Maranhenses e na Reserva Extrativista (RESEX) Marinha de Cururupu, na região costeira do Maranhão. Este estudo definiu algumas áreas com baixo potencial turístico devido constituírem sítios de reprodução do Guará (Eudocimos ruber) e apontou uma grande pressão nos recursos naturais da região em decorrência do crescimento de obras de infra-estrutura, concluindo que o grande desafio para o turismo no local será ordenar as suas atividades a fim de garantir sua sustentabilidade.

Na Baixada Santista, o trabalho realizado por Bonetti-Filho (1996) fez uma análise das principais feições encontradas na paisagem, destacando as extensas áreas de manguezal alteradas pela ação antrópica.

Santos (2007) e Santos et al. (2007) avaliaram as mudanças ocorridas em bosques de mangue do Canal de Bertioga (Baixada SantistaSP) após derramamento de petróleo e devido as diversas ocupações humanas para construção de marinas e conglomerados populacionais.

A construção de um extenso banco de dados georeferenciados com dados geomorfológicos, ecológicos, sociais e econômicos foi proposto por Sartor et al. (2007), como importante subsídio ao gerenciamento costeiro da Baixada Santista.

De grande utilidade tem sido a análise dos impactos negativos da carcinocultura na região costeira utilizando imagens de satélite. Cavalcanti et al. (2007), realizaram uma detecção dos viveiros de carcinocultura e de salinas localizados na APA Delta do Parnaíba e encaminharam os 
resultados as unidades do IBAMA responsáveis pela fiscalização da respectiva unidade de conservação.

Thu \& Populus (2006), realizaram um estudo temporal nos manguezais do Delta do Rio Mekong (Vietnan) utilizando imagens de satélite de 1965, 1995 e 2001 e concluíram que atualmente as maiores perdas nas décadas passadas foram devido a guerras, extração de madeira e conversão de áreas para a agricultura, porém recentemente as maiores perdas estão ocorrendo em decorrência da carcinocultura.

Manguezais do Sri Lanka também foram estudados utilizando imagens de satélite (Dahdouh-Guebas et al., 2000) e constatou-se a grande conversão de áreas de manguezal para a prática da carcinocultura neste país.

Recentemente, a utilização de estudos de sensoriamento remoto tem sido muito empregada em estudos ecológicos em áreas de manguezais ao longo do planeta, onde podemos destacar (HernádezCornejo et al., 2005) com enfoque etnobotânico nos manguezais de Sinaloa no México; (Dahdouh-Guebas, 2002) avaliando a dinâmica da vegetação em escala temporal utilizando fotografias aéreas; (DahdouhGuebas et al., 2002; Dahdouh-Guebas et al., 2004) ou imagens de satélite (Giri et al., 2007); a utilização de imagens de satélite de alta resolução (i.e. IKONOS) para deteç̧ão da composição florística em manguezais (Dahdouh-Guebas et al., 2005) ou avaliando a biomassa da vegetação (Proisy et al., 2007); analisando a intensa dinâmica sedimentar na região costeira da Guiana Francesa e as suas conseqüências ao manguezais da região (Fromard et al. 2004); gerando mapas de áreas de manguezal mais fidedignos da realidade (Vaiphasa et al., 2006; Verheyden et al., 2002) ou avaliando as mudanças na paisagem (Obade et al., 2004; Ramasubramanian et al., 2006). 
De forma mais ampla, o geoprocessamento também visa contribuir com o gerenciamento sustentável das regiões costeiras tropicais (Dahdouh-Guebas et al., 2000); em trabalhos de Avaliação Ecológica Rápida (Rapid Ecological Assessment) (Sayre \& Sheppard, 2000), no estabelecimento e monitoramento de Unidades de Conservação (Pires, 1997; Rodrigues, 1998; Sayre, 2000), no planejamento de zonas costeiras (Argento, 1989; Frischeisen et al., 1989; Clark, 1996; Zharicov et al., 2005) e no mapeamento de manguezais (Aschbacher et al., 1995; Gao, 1999; Herz, 1999)

O uso de técnicas de sensoriamento remoto no presente trabalho mostrou-se eficaz, gerando cartas que mostram claramente os diversos impactos ocorridos na Ilha Barnabé desde a década de 60 causados por atividades antrópicas. Embora o presente trabalho tenha sido realizado numa pequena área da Baixada Santista, a problemática ambiental encontrada na Ilha Barnabé se reflete no restante da região, portanto os conhecimentos acerca dos impactos aos manguezais causados pelas atividades antrópicas observados no presente estudo servem de base para o gerenciamento costeiro da Baixada Santista.

Blasco et al., (1998) afirmam que o tratamento de fotografias aéreas com técnicas de sensoriamento remoto é atualmente uma das melhores ferramentas para analisar impactos naturais e/ou antrópicos em bosques de mangue. $O$ uso de fotografias aéreas no presente estudo facilitou uma maior análise temporal (1962-2003) com resolução suficiente para a extensão da área estudada, fatos estes que tornam-se difíceis de serem alcançados com imagens de satélite, portanto a metodologia aplicada mostrou-se de extrema valia no presente estudo. 


\subsection{2 - CARACTERIZAÇÃO DOS BOSQUES DE MANGUE EM DIFERENTES ESTÁGIOS SUCESSIONAIS}

A caracterização estrutural da vegetação dos manguezais constitui valiosa ferramenta no que concerne à resposta desse ecossistema às condições ambientais existentes, bem como aos processos de alteração do meio ambiente, auxiliando assim, nos estudos e ações que objetivam a conservação desse ecossistema (Cintrón \& Schaeffer-Novelli, 1985).

Descrições a respeito da estrutura vegetal dos manguezais podem incluir medidas da composição das espécies, diversidade, altura do bosque, diâmetro dos troncos, área basal, densidade de árvores, distribuição por classe etária e padrões de distribuição espacial das espécies que compõe o bosque de mangue (Smith III, 1992). A estrutura dos bosques de mangue é resultado da combinação de diversas forças subsidiárias, tais como, energia solar, aporte de água doce e de nutrientes e energia das marés, como também por tensores naturais ou antrópicos (Lugo et al., 1981; Cintrón \& Schaeffer-Novelli, 1985).

Analisando os dados estruturais dos bosques de mangue estudados, podemos verificar que as idades estimadas para estes bosques (utilizando a análise multi-temporal das fotografias aéreas) corroboraram com dados observados na caracterização estrutural.

As parcelas onde a idade estimada dos bosques foi superior à 45 anos (\#1 à \#5), apresentaram os menores valores de densidade (1000 à 3900 indivíduos por hectare); os maiores valores de altura média (5,77 à $9,03 \mathrm{~m})$; dap médio elevado $(8,21$ à $13,64 \mathrm{~cm})$; grande dominância de área basal viva $(77,78$ à $99,54 \%)$ e dominâncias em todas as parcelas da espécie $A$. schaueriana. 
Como a análise multitemporal não observou nenhuma alteração brusca na vegetação nas áreas escolhidas para a caracterização estrutural destas cinco parcelas, parece bastante claro que estes bosques realmente possuam mais de 45 anos e já se encontram num estágio de maturidade.

A única observação a ser feita é que a parcela \#1 apresentou o menor desenvolvimento estrutural, possivelmente devido a sua maior proximidade com a estrada de ferro que corta a Ilha Barnabé. Portanto, possivelmente a construção desta estrada de ferro tenha interferido indiretamente no desenvolvimento deste bosque especificamente.

Nas parcelas de \#6 à \#9, a idade estimada foi de 15-17 anos, pois nas fotografias aéreas do ano de 1994, estas áreas já apresentavam claramente um início de recomposição natural da vegetação. Estes bosques apresentaram um desenvolvimento estrutural bem menor que as parcelas \#1 à \#5, evidenciando a menor idade dos bosques, porém apresentaram dois padrões distintos, um representado pelas parcelas \#6 e \#7 e outro padrão pelas parcelas \#8 e \#9.

As parcelas \#6 e \#7 foram bem similares: densidade elevada de indivíduos por hectare (14400 e 8800); altura média do bosque de 3,90 e 3,91m; dap médio bem reduzido (4,31 e 3,55cm); grande dominância de área basal viva 92,81 e $99,58 \%$ e dominância total da espécie $L$. racemosa.

Uma característica marcante destas duas parcelas foi a grande quantidade de árvores inclinadas e/ou tombadas, com grande quantidade de raízes expostas.

Já as parcelas \#8 e \#9 apresentaram: densidade de 5306 a 6122 indivíduos por hectare; altura média total de 1,71 e 5,62m devido a grande quantidade de indivíduos mortos ou com morte apical; dap médio de 5,76 e 6,90cm; dominância total de $L$. racemosa e as maiores porcentagens de área basal morta $(85,21$ e $61,43 \%)$, respectivamente. 
Portanto, podemos concluir que estas quatro parcelas (\#6 à \#9) representam bosques de mangue com idade estimada entre 15-17 anos, porém com características estruturais que nos levam a crer que estes bosques estão sobre a ação de tensores ou estão tentando se desenvolver em áreas que foram consideravelmente alteradas.

As parcelas \#10, \#11, \#12 e \#13 que tiveram suas idades estimadas sendo menores que 13 anos (nas fotografias aéreas do ano de 1994 ainda eram clareiras), também apresentaram características estruturais parecidas, porém com algumas peculiaridades.

Observamos que as parcelas \#10 e \#11 apresentaram densidade de 5600 indivíduos por hectare (ambas); altura média de 7,25 e 6,79m; dap médio de 5,58 e 5,44; dominância de área basal viva (82,71 e 84,55\%), respectivamente e dominância total da espécie $L$. racemosa. Uma característica marcante foi que ambas as parcelas apresentaram uma grande quantidade de troncos por indivíduo (3,07 na parcela \#10 e 2,82 na parcela \#11).

As parcelas \#12 e \#13 apresentaram: densidade de 5510 e 6735 indivíduos por hectare; altura média de 4,47 e 4,36m; dap médio de 4,56 e 5,14cm; domínio de área basal viva $(84,16$ e $89,52 \%)$ e grande domínio de $L$. racemosa com poucos indivíduos de $R$. mangle. Destaca-se nestas duas parcelas a presença de alguns indivíduos inclinados.

Portanto, as parcelas \#1 à \#5 apresentaram características estruturais de bosques maduros ( $>45$ anos), com um alto desenvolvimento estrutural.

As parcelas \#6 à \#9 apresentaram características de bosques em estágio inicial de maturidade (15-17 anos) com indícios de estresse, sendo que as parcelas \#6 e \#7 apresentaram baixo desenvolvimento estrutural, com árvores tombadas e caídas, e as parcelas \#8 e \#9 apresentaram uma mortalidade acentuada. 
As parcelas \#10 à \#13 apresentaram características de bosques em estágio final de desenvolvimento inicial, onde as parcelas \#10 e \#11 parecem estar em área mais propícia ao seu desenvolvimento, já que as parcelas \#12 e \#13 apresentaram um menor desenvolvimento e alguns sinais de estresse (árvores inclinadas).

Estes diferentes estágios sucessionais de cada grupo de parcelas ficam mais claros quando observamos a relação da idade estimada de cada bosque com o seu dap médio (Figura 60) e a sua densidade de indivíduos (Figura 61). Para a composição destes gráficos utilizou-se também os dados referentes às duas parcelas (R2 e R3) localizadas também na Ilha Barnabé, porém na área impactada pelo evento de 1998, onde a dinâmica da recomposição natural foi monitorada durante 6 anos.

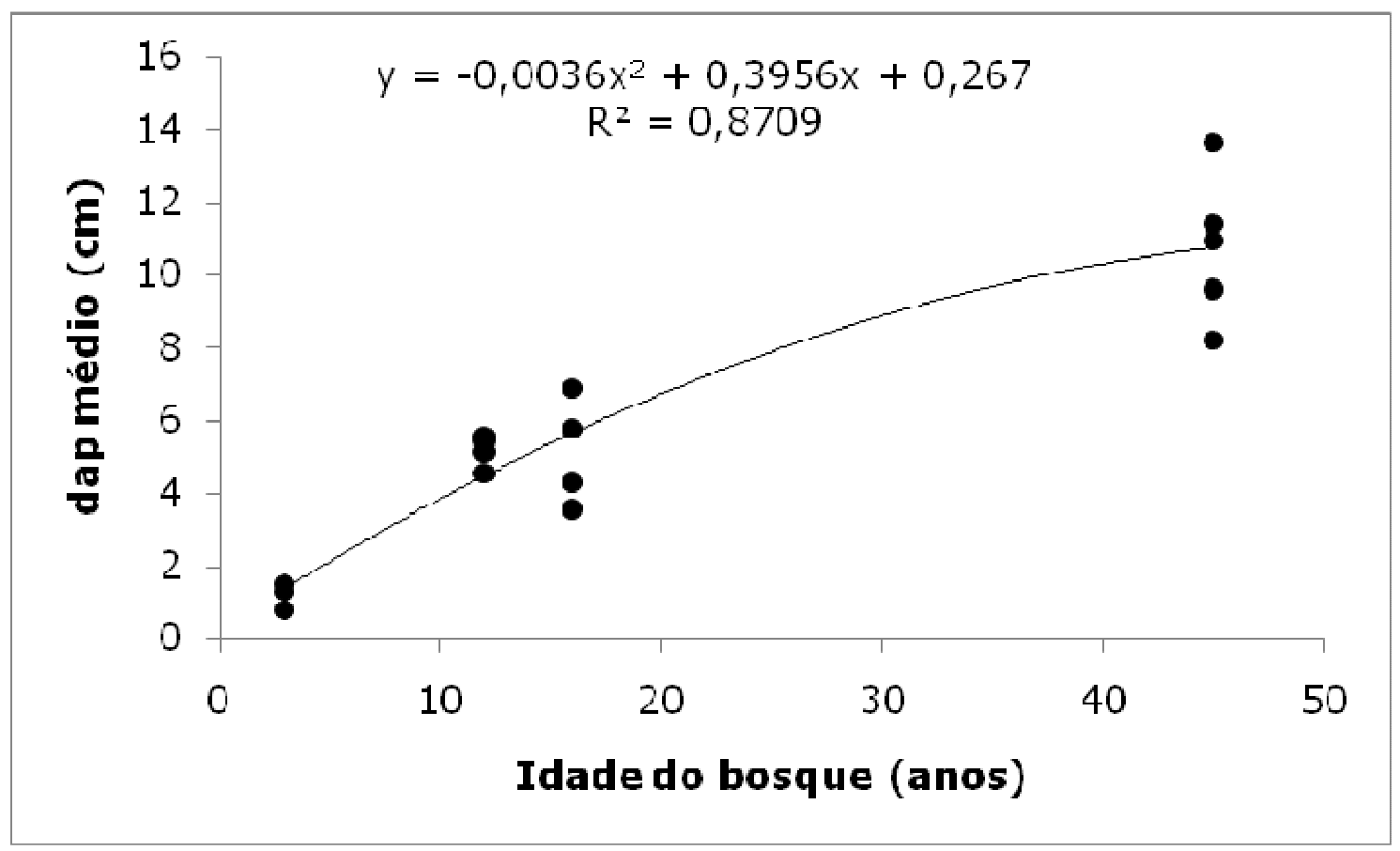

Figura 60 - Relação entre o dap médio e a idade dos bosques de mangue estudados na Ilha Barnabé. 


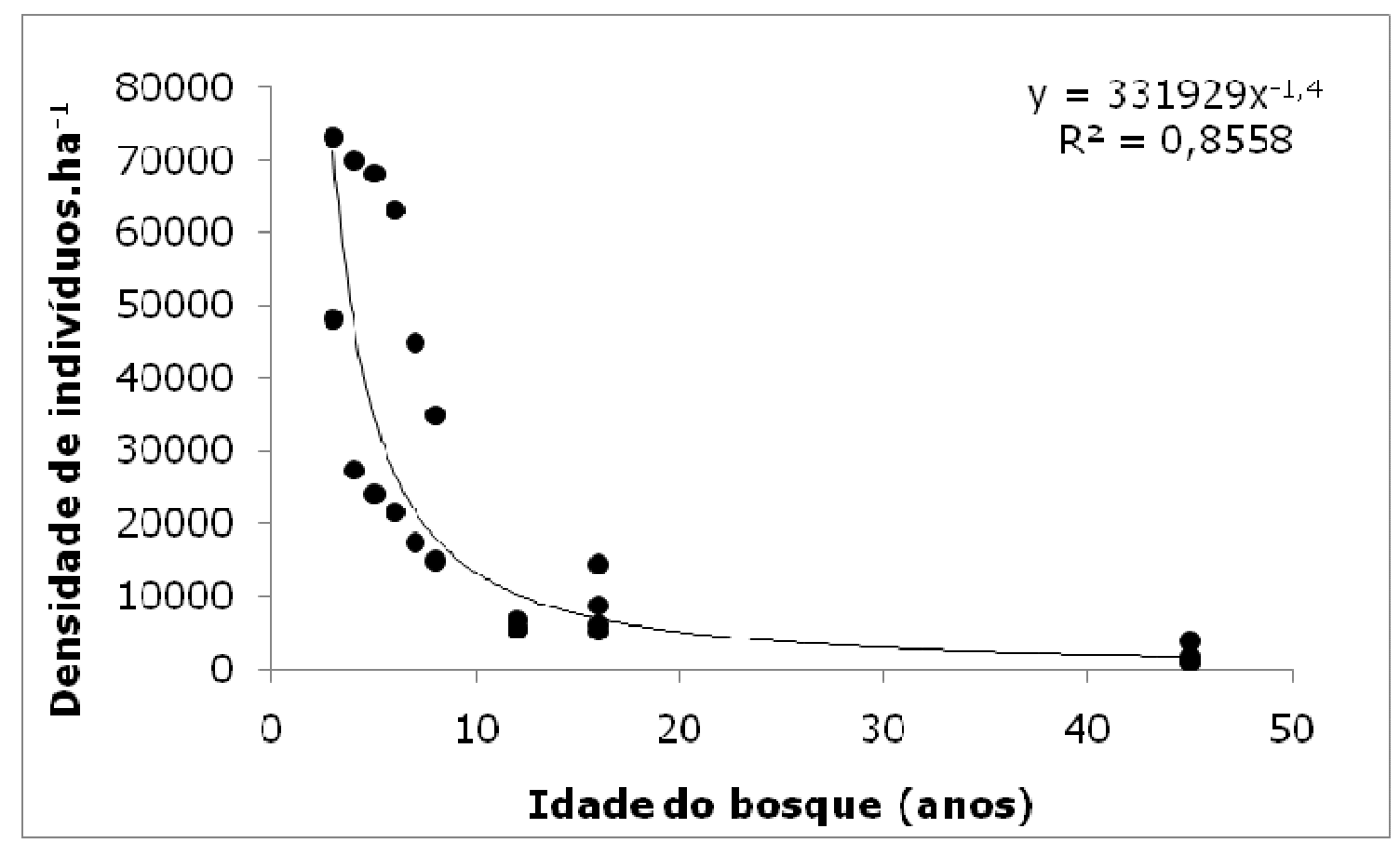

Figura 61 - Relação entre a densidade de indivíduos por hectare a idade dos bosques de mangue estudados na Ilha Barnabé.

Assim como em outras florestas o diâmetro do tronco das árvores aumenta e a densidade de indívíduos diminui conforme aumenta a idade do bosque. Este é um processo conhecido como desbaste natural, onde conforme os indivíduos que colonizaram o ambiente inicialmente vão crescendo, aumenta a competição por espaço e luz, acarretando a mortalidade dos menos aptos (Cintrón \& Schaeffer-Novelli, 1984).

Os resultados obtidos no presente estudo corroboram com o proposto inicialmente por Jimenez et al. (1985) e posteriormente corroborado por dados coletados na Guiana Francesa por Fromard et al. (1998).

Podemos considerar que os manguezais da Ilha Barnabé estão sujeitos a ação de tensores agudos (acidentes ocorridos, construção de estradas e ferrovias, abertura de canais) e crônicos (efluentes industriais, esgotos urbanos e atividades portuárias) e que o conjunto destes tensores 
compromete seriamente a qualidade dos recursos ambientais disponíveis, interferindo diretamente nas suas características estruturais e na sua capacidade de recomposição natural.

É notório que o ecossistema manguezal possui uma grande resiliência frente à ação de tensores naturais e/ou induzidos pelo homem (Lugo \& Snedaker, 1974; Lugo et al., 1981).

Podemos entender resiliência como a capacidade de se recompor após uma perturbação e esta resiliência é uma adaptação em resposta a ocupação de ambientes altamente dinâmicos (regiões costeiras) e uma seleção de espécies com características que favorecem a exploração de um rico habitat, porém efêmero (Cintrón \& Schaeffer-Novelli, 1992).

Segundo Tomlinson (1986), as espécies típicas de mangue apresentam pronunciadas características de espécies pioneiras em relação as suas estratégias reprodutivas e atributos de espécies clímax na estrutura da comunidade e no seu crescimento vegetativo. Portanto podemos considerar os manguezais como sistemas auto-sustentáveis (Lugo, 1980).

Alongi (2008) realizou uma extensa revisão dos trabalhos sobre a resiliência dos manguezais, e concluiu que este ecossistema possui certas características que contribuem para sua alta resiliência:

- Grande reserva de nutrientes no sedimento, que servem para repor eventuais perdas de biomassa.

- Rápida decomposição microbiana e ciclagem de nutrientes que facilitam a sua utilização pela biota.

- Controle biológico eficiente e complexo (altas taxas de uso de água e uso eficiente de nutrientes) que permitem uma ciclagem interna de recursos. 
- Arquitetura simples da vegetação, que permite uma rápida reconstrução e reabilitação após um distúrbio.

- Presença de espécies-chaves com funcionalidades redundantes, que permite a restauração de partes importantes do funcionamento e estrutura do ecossistema.

- Feedbacks positivos e negativos que providenciam maleabilidade, ajudando a amortecer oscilações durante a recomposição.

Essas características providenciam aos manguezais uma grande habilidade de se recomporem após distúrbios e persistirem em ambientes onde a incidência de tensores é crônica (Cintrón \& Schaeffer-Novelli, 1992).

Porém, mesmo o ecossistema estando adaptado a certos graus de perturbação, isto não significa que não ocorra perda de energia que seria empregada para a manutenção do próprio sistema (Lugo, 1978).

Esta perda de energia está interferindo diretamente na capacidade de recomposição natural dos bosques de mangue estudados em estágios de recomposição natural, pois podemos observar várias características deste dreno de energia no sistema, como mudanças na composição das espécies dominantes e baixo desenvolvimento estrutural (parcelas \#6, \#7, \#12 e \#13), e em casos mais extremos, observamos ainda a mortalidade de grande parte dos indivíduos que compõem o bosque (parcelas \#8 e \#9).

Também podemos considerar que as diferenças estruturais encontradas nos bosques em recomposição natural (parcelas \#6 à \#13), representam o mosaico de diferentes condições ambientais em que os manguezais da Ilha Barnabé estão inseridos, onde nos locais mais favoráveis a recomposição natural é facilitada (parcelas \# 10 e \#11) e nos locais onde ocorreram mudanças bruscas nas condições ambientais algum distúrbio (parcelas \#6, \#7, \#12 e \#13) a recomposição natural apresenta 
indícios de estresse, ou mesmo mortalidade massiva logo nos estágios intermediários de desenvolvimento (parcelas \#8 e \#9).

O fato da espécie $L$. racemosa ser dominante em todos os bosques de mangue em recomposição, sugere que esta é a espécie mais adaptada a iniciar uma sucessão secundária nos manguezais da Ilha Barnabé. Smith III (1992), afirma que em bosques sujeitos a maiores freqüências de distúrbios, ocorre menor representatividade de indivíduos do gênero Rhizophora, em comparação às espécies dos demais gêneros, por exemplo, Laguncularia e Avicennia.

Esta afirmação se confirma com observações de campo realizadas em outras clareiras da Ilha Barnabé, onde quando foi observada uma colonização recente, sempre foi por indivíduos de L. racemosa (Figura 62 e 63).

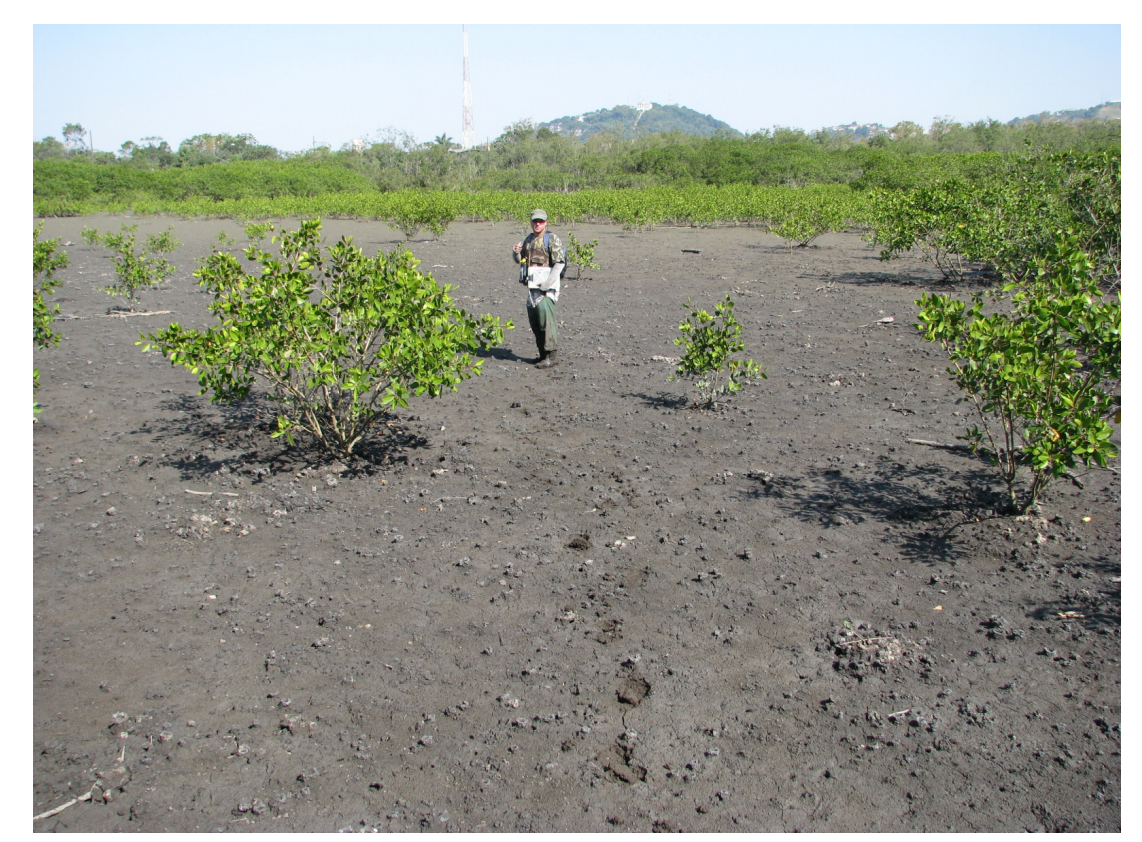

Figura 62 - Indivíduos de L. racemosa colonizando uma clareira de grandes proporções localizada na Ilha Barnabé (Fotografia tirada em 18.07.2008). 


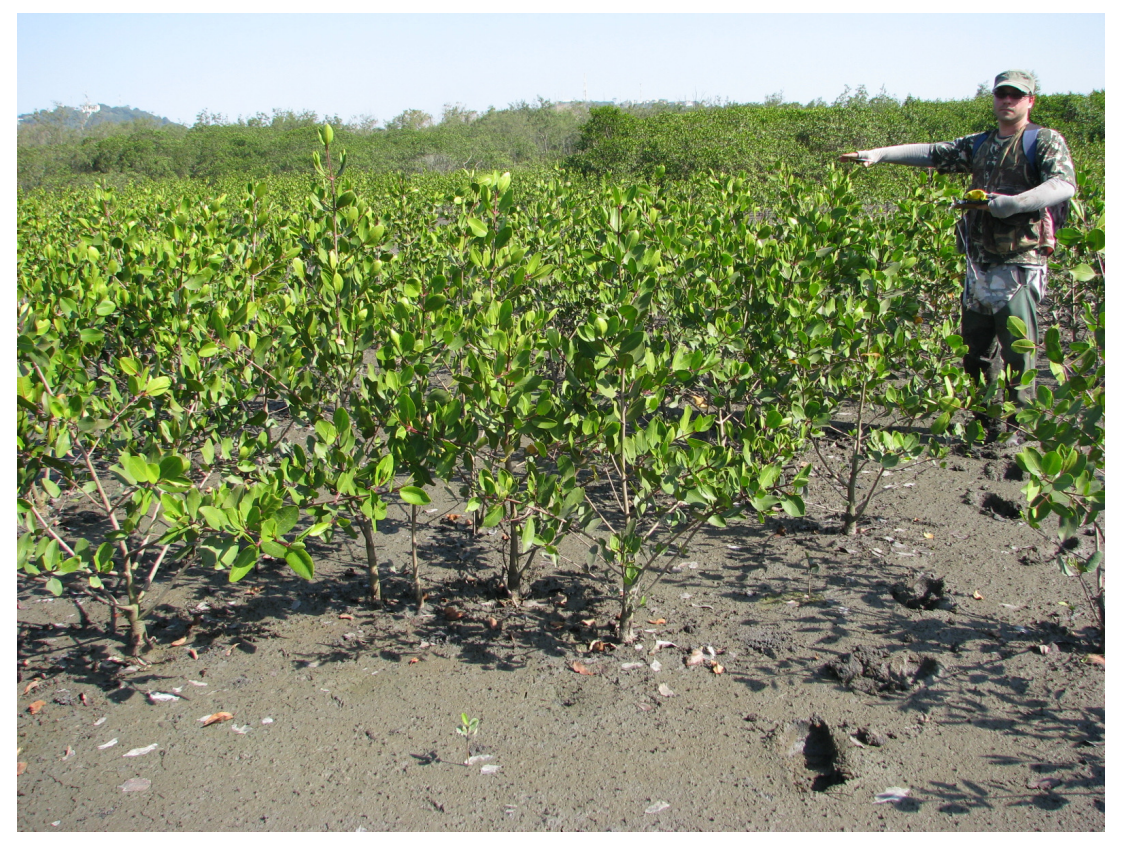

Figura 63 - Detalhe dos indivíduos de L. racemosa colonizando clareira na Ilha Barnabé (Fotografia tirada em 18.07.2008).

Uma característica que pode explicar a grande representatividade de L. racemosa nestes boques em recomposição, é que esta espécie requer consideravelmente menos tempo para germinação e estabelecimento de raízes que as demais espécies típicas de mangue, além do tamanho reduzido de seus propágulos serem dispersos pelas marés em áreas internas dos bosques com mais facilidade (Rabinowitz, 1975; 1978).

Porém, a permanência desta espécie, que é a pioneira até os estágios sucessionais observados nas parcelas de \#6 à \#13, como espécie dominante também pode ser considerado como um sinal de estresse, pois Lugo (1978) comenta que em locais onde a incidência de tensores é crônica, geralmente a espécie pioneira se mantém por mais tempo no local. 
A partir de todo o estudo realizado até o momento, propõem-se um modelo da sucessão secundária para os bosques de mangue da Ilha Barnabé estudados no presente trabalho (Figura 64).

O modelo se baseia no padrão de resposta de um ecossistema a um tensor intermitente proposto por Ewel (1971), onde, quando uma condição de estresse é repetida antes da completa recomposição, o sistema gradualmente perde sua capacidade de recomposição e pode se manter apenas num estado de menor desenvolvimento.

Para de avaliar o grau de desenvolvimento de cada bosque de mangue da Ilha Barnabé, utilizou-se os seguintes parâmetros estruturais da vegetação: dap médio, densidade de indivíduos, altura média, e porcentagem (\%) de área basal viva. Estes foram os parâmetros estruturais que melhor representaram as variações dos bosques observadas em campo.

Alguns parâmetros como o dap médio ou a área basal do bosque, utilizados separadamente não demonstraram claramente as diferenças estruturais observadas nos bosques.

As diferenças estruturais encontradas entre as parcelas \#1 a \#5 são devido às diferentes "assinaturas energéticas" locais, ou seja, a disponibilidade de energias subsidiárias (correntes de água fluvial ou marinha e os aportes de nutrientes trazidos pelos rios, marés, drenagem superficial e características do substrato), e no caso dos manguezais da Ilha Barnabé, as diferentes intensidades dos tensores locais, segundo proposta de Odum (1967). O fato de não terem sido observadas clareiras no dossel destes bosques dentro do período analisado (1962-2003) não descarta a possibilidade da dinâmica de "gaps" ter interferido nas características estruturais destes bosques. 
As diferenças estruturais encontradas nos bosques em diferentes estágios de desenvolvimento inicial (parcelas \#6 a \#13) também dependem da "assinatura energética" local, porém, a sua idade (Jimenez et al., 1985) também interfere, como pode ser observado na relação da idade do bosque com o dap médio e a densidade de indivíduos (Figuras 60 e 61).

Outra característica é que dentro de cada estágio sucessional, ou seja entre os bosques com idades semelhantes, o desenvolvimento estrutural depende principalmente do tipo e da intensidade do tensor local, pois eles apresentam uma zonação que reflete o gradiente de estresse local, não podendo ser confundido com estágios sucessionais (Lugo, 1978).

O monitoramento a longo prazo das parcelas \#6 a \#13 será de extrema importância para um melhor entendimento dos resultados obtidos até o momento, portanto este modelo proposto no presente trabalho será constantemente aprimorado com estudos futuros nos manguezais da Ilha Barnabé e de outras regiões que sofrem com a ação crônica e/ou aguda de tensores antrópicos. 


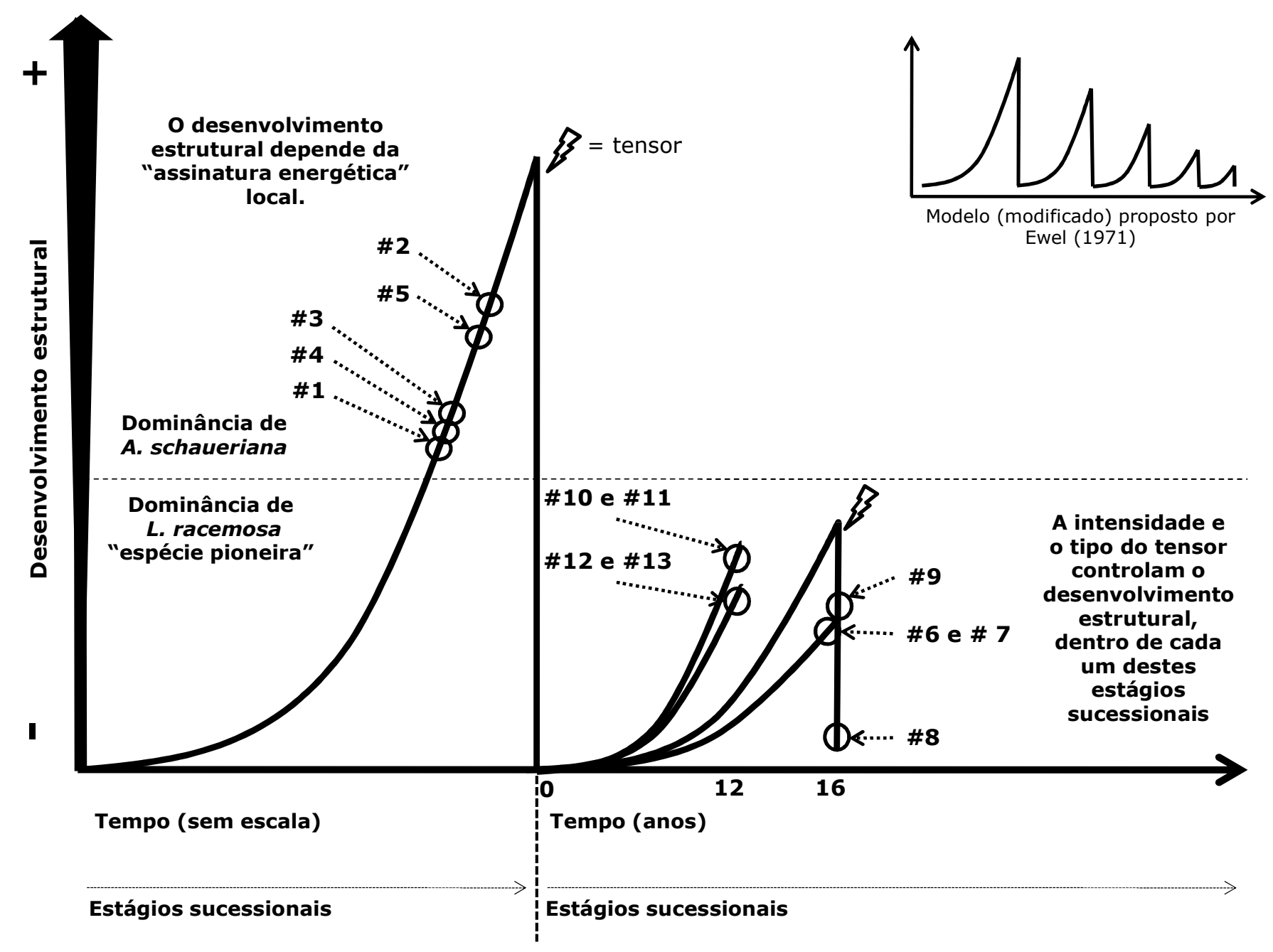

Figura 64 - Modelo proposto para o padrão de sucessão secundária encontrado nos manguezais estudados da Ilha Barnabé (para maiores informações vide texto). 


\section{8 - CONCLUSÕES}

A realização dos estudos em diferentes escalas hierárquicas facilitou o entendimento dos processos que regem (facilitam e/ou interferem) a recomposição natural dos bosques de mangue da Ilha Barnabé, onde a incidência de tensores antrópicos é recorrente.

O monitoramento do processo de recomposição natural da vegetação do bosque de mangue atingido pelo evento de 1998 demonstrou a capacidade de recomposição natural do bosque de mangue, porém em algumas áreas as espécies vegetais apresentaram uma lenta taxa de crescimento que demonstra o estado de estresse da vegetação.

A produção de serapilheira mostrou um contínuo acréscimo nas suas taxas, principalmente das frações folhas e propágulos, demonstrando que bosques de mangue em processo inicial de recomposição natural apresentam um acréscimo na produção de serapilheira, assim como outras florestas secundárias.

Estes dados contribuem para o entendimento da funcionalidade dos manguezais da Baixada Santista que mesmo apresentando sinais de estresse, desempenham suas funções ecológicas, como a alta disponibilização de detritos orgânicos para as águas do estuário.

O monitoramento da produção de serapilheira também sugere que o bosque de mangue estudado está apresentando certa desordem funcional, pela pequena contribuição de folhas e grande de partes reprodutivas (propágulos), e um estado nítido de estresse, demonstrado na grande quantidade de propágulos abortados e deformados. 
Embora haja a necessidade de mais estudos para comprovarem este comportamento, a grande produção de propágulos pode estar evidenciando uma resposta da vegetação típica de mangue ao estresse, o que não é muito comum em outras espécies vegetais, que geralmente diminuem o aporte energético para fins reprodutivos nestas situações.

O monitoramento da microtopografia demonstrou a estreita relação dos bosques de mangue com a dinâmica sedimentar do estuário, como a colonização de indivíduos jovens em áreas de deposição sedimentar e a perda de hábitat em decorrência da erosão de sedimentos em decorrência da perda de vegetação.

Podemos verificar a função dos manguezais da Baixada Santista na retenção de sedimentos, sendo que uma das conseqüências da perda das áreas ocupadas por manguezais é a erosão dos sedimentos das margens dos canais, aumentando os gastos públicos com dragagem do canal de navegação do Porto de Santos.

O uso de fotografias aéreas no presente estudo facilitou uma análise temporal extensa (1962-2003) com resolução suficiente para a observação detalhada da área estudada e com baixo custo de aquisição de materiais.

Esta análise multitemporal dos manguezais da Ilha Barnabé demonstrou os severos impactos na vegetação causados pelas diversas modificações que aconteceram desde a década de 70 (construção de rodovia, estrada de ferro, retilinização de canais e expansão portuária). O reflexo destes impactos pôde ser observado nas clareiras ("gaps") formadas no dossel da vegetação. 
Esta análise também demonstrou numa escala temporal maior que a estudada na recomposição da vegetação impactada pelo evento de 1998, a capacidade de recomposição natural da vegetação, pois diversas clareiras apresentaram sinais de recomposição natural total ou parcial. Porém, esta recomposição também se mostrou lenta, pois mesmo após um longo tempo ainda existem clareiras na vegetação, demonstrando a severidade dos impactos causados pelas modificações locais.

O uso e a análise correta das fotografias áreas também se mostraram como uma excelente ferramenta metodológica, permitindo a escolha dos pontos de coleta para a realização da caracterização estrutural dos bosques de mangue em diferentes estágios sucessionais.

A caracterização estrutural dos bosques de mangue em diferentes estágios sucessionais demonstrou aspectos importantes da sucessão secundária nestes bosques, tais como a mudança das espécies dominantes entre os bosques maduros e os bosques em recomposição natural e as diferenças estruturais dentro de cada estágio sucessional em decorrência da intensidade e tipo do tensor que está atuando localmente nas diferentes regiões da Ilha Barnabé, refletindo desta forma, nos diferentes graus de estresse em que a vegetação se encontra.

Finalizando, concluímos que todas as ferramentas utilizadas no presente estudo demonstraram a capacidade de recomposição natural dos bosques de mangue da Ilha Barnabé, demonstrando que mesmo estando sobre a influência de diversos impactos antrópicos é possível reverter a situação atual de degradação dos manguezais da Baixada Santista, retirando os tensores antrópicos da região e propiciando desta forma a recomposição natural deste ecossistema que apresenta uma alta resiliência. Tais informações geradas subsidiarão o gerenciamento costeiro da Baixada Santista, na busca de uma maior qualidade ambiental para a região. 


\section{9 - REFERÊNCIAS BIBLIOGRÁFICAS}

ACIESP, 1997. Glossário de Ecologia. Academia de Ciências do Estado de São Paulo-CNPq-FINEP. $2^{a}$ Ed. São Paulo. 352p.

ADAIME, R. R. 1985. Produção do bosque de mangue da Gamboa Nóbrega (Cananéia, $25^{\circ}$ Lat. S. - Brasil). Tese de Doutorado, Universidade de São Paulo, Instituto Oceanográfico, São Paulo, 305p.

ALMEIDA, R. 2004. Ecologia de manguezais: dinâmica da serapilheira e funcionamento do ecossistema, Ilha do Cardoso, Cananéia, São Paulo, Brasil. Tese de doutorado. Instituto Oceanográfico, Universidade de São Paulo. 183p.

ALONGI, D. M. 2002. Present state and future of the world's mangrove forests. Environmental Conservation, 29(3): 331-349.

ALONGI, D. M. 2008. Mangrove forests: resilience, protection from tsunamis, and responses to global climate change. Estuarine Coastal and Shelf Science, 76: 1-13.

ARGENTO, M. S. 1989. The geographical information system of the Brazilian coastal management program. 84-94. In: Neves, C. (ed.) Coastlines of Brazil, New York, American Society of Civil Engineers, O. T. Magoon, 296p.

ASCHBACHER, J.; OFREN, R.: DELSON, J. P.: SUSELO, T. B.: VIBULSRESTH, S. \& CHARRUPAT, T. 1995. An integrated comparative approach to mangrove vegetation mapping using advanced remote sensing and GIS technologies: preliminary results. Hydrobiologia, 295: 285-294.

AZEVEDO, A. (Ed.) 1965. A Baixada Santista: aspectos geográficos. Editora da Universidade de São Paulo, São Paulo, 4 vols.

BALL, M. C. 1988. Ecophysiology of mangroves. Trees, (2): 129-142.

BLASCO, F.; GAUQUELIN, T.; RASOLOFOHARINORO, M.; DENIS, J.; AIZPURU, M.; CALDAIROU, V. 1998. Recent advances in mangrove studies using remote sensing data. Marine and Freshwater Research, 49(4): 287-296. 
BONETTI FILHO, J. 1996. Sensoriamento remoto aplicado à análise de ambientes costeiros impactados: avaliação metodológica - Baixada Santista. São Paulo, Tese de Doutorado, Universidade de São Paulo, Departamento de Geografia, 260p + anexos.

BOOT, R.; RAYNAL, D. J. \& GRIME, J. P. 1986. A comparative study of the influence of drought stress on flowering in Urtica dioica and Urtica urens. Journal of Ecology, 74:485-495.

BROWN, S. \& LUGO, A. E. 1990. Tropical secondary forests. Journal of Tropical Ecology 6: 1-32.

CAMARA, G.; SOUZA, R. C. M.; Freitas, U. M.; GARRIDO, J. \& II, F. M. 1996. Spring: Integrating remote sensing and GIS by object-oriented data modelling. Computers \& Graphics, 20(3): 395-403, may-jun.

CARMO, T. M. S.; ALMEIDA, R. \& OLIVEIRA, A. R. 1998. Consequences of the peeling of Rhizophora mangle over the mangrove litterfall. In: ANAIS DEL $7^{\circ}$ CONGRESSO LATINO-AMERICANO Y DEL XIV CONGRESSO MEXICANO DE BOTÂNICA. Ciudad de Mexico, Mexico.

CAVALVANTI, D. R.; CARVALHO, E. V. T.; ZAGAGLIA, C. R.; BARRETO, R.; SANTOS, R. N. A. 2007. Anais do XIII Simpósio Brasileiro de Sensoriamento Remoto, Florianópolis, Brasil. INPE. p. 3813-3819.

CETESB. 1978. Poluição das águas no Estuário e Baía de Santos. Relatório Técnico, CETESB. Vols 1 e 2.

CETESB. 1988. Estudo dos manguezais da Baixada Santista - Relatório Final. São Paulo: CETESB. 70p.

CETESB. 1990. Ação da CETESB em Cubatão: situação em janeiro de 1990. CETESB, Relatório Técnico, São Paulo, São Paulo. 33 p.

CETESB. 1991. Avaliação do estado da degradação dos ecossistemas da Baixada Santista - SP. CETESB. Relatório Técnico. São Paulo, São Paulo. 45 p.

CETESB. 1998. Registro de Acidente Ambiental. Operação 259/98. CETESB. São Paulo. 
CETESB. 1999. Registro de Acidente Ambiental. Operação Brasterminais. Maio de 1999. CETESB. São Paulo.

CETESB. 2001. Sistema estuarino de Santos e São Vicente. Relatório Técnico. Procop: Programa de Controle de Poluição. (CD-ROM).

CHAVES, F. O. 2007. Caracterização e relações ambientais da produção de serapilheira em florestas de mangue da Baía de Guanabara, Rio de Janeiro - Brasil. Tese de doutorado. Instituto Oceanográfico, Universidade de São Paulo. 347p.

CHIARELLO, N. R. \& GULMON, S. L. 1991. Stress effects on plant reproduction. In: Mooney, H. A.; Winner, W. E. \& Pell, E. J. (Eds.) Responses of plants to multiples stresses. Academic Press. New York. 161-188.

CINTRON, G. \& Y, SCHAEFFER-NOVELLI. 1983. Mangrove forests: Ecology and response to natural and man induced stressors. In: Ogden, J.C. \& Gladfelter, E.H. (Eds.) Coral reefs, seagrass beds and mangroves: Their interaction in the coastal zones of the Caribbean. Unesco Reports in Marine Science, n.23, appendix 1, p.87-110.

CINTRÓN, G. \& SCHAEFFER-NOVELLI, 1984. Methods for studying mangrove structure, pp. 91-113. In: S. C. Snedaker \& J. G. Snedaker (eds.) The mangrove ecosystem: Research methods, UNESCO, Bungay, United Kingdom, $251 \mathrm{p}$.

CINTRÓN, G. \& SCHAEFFER-NOVELLI, Y. 1985. Caracteristicas y desarrolo estructural de los manglares de norte y sur America. Ciencia Interamericana, vol. 25(1-4): 4-15.

CINTRÓN-MOLERO, G. \& SCHAEFFER-NOVELLI, Y. 1992. Ecology and management of New World Mangroves: 233-258. In: Coastal Plant Communities of Latin America. Seelinger, U. (ed.). California, Academic Press. $392 \mathrm{p}$. 
CINTRÓN, G.; C. GOENAGA \& J, GONZALES-LIBOY. 1980. Ecologia del manglar en una zona arida: exposición al oleaje y estrutura del manglar. Boletim do Instituto Oceanográfico da Universidade de São Paulo. 29(2): 113-127.

CLARK, J. R. 1996. Coastal Zone Management Handbook. New York, Lewis Publish, 694p.

CLARKE, P. L.; P. J. MYERSCOUGH. 1993. The interdital distribuition of the grey mangrove (Avicennia marina) in southeastern Australia: The effects of physical conditions, interspecific competition, and predation on propagule establishment and survival. Australian Journal of Ecology. 18: 307-315.

CLARKE, P. J. \& KERRIGAN, R. A. 2000. Population structure and community composition of forest gaps in tropical mangroves. Biotropica 32: 642652.

CLOUGH, B. F. 1992. Primary Production and Growth of Mangrove Forests. In: Tropical Mangrove Ecosystems. A. I. Robertson \& D. M. Alongi (eds.). Coastal and Estuarine Studies. American Geophysical Union, Washington, D. C., 329p.

CLOUGH, B.; TAN, D. T.; PHUONG, D. X.; BUU, D. C. 2000. Canopy leaf area index and litterfall in stands of the mangrove Rhizophora apiculata of different age in the Mekong Delta, Vietnan. Aquatic Botany, 66: 311320.

CODESP, 2006. Plano de Desenvolvimento e Zoneamento do Porto de Santos - PDZPS. 179 p.

COELHO-JR, C. 2003. Ecologia de Manguezais: Zonação e dinâmica da cobertura vegetal em gradientes ambientais, Cananéia, São Paulo, Brasil. Tese de Doutorado. Instituto Oceanográfico da Universidade de São Paulo. 166p. 
COMELLI, F. A. M.; A. C. E. PONTE \& S. M. C. A. CLARO. 1996. Aspectos estruturais de um manguezal de Cubatão. In: Anais do III Simpósio de ecossistemas da costa brasileira, Serra Negra, São Paulo. ACIESP, Serra Negra. vol.I: pp. 97- 103.

COSTA, S. D. 2005. O uso da avaliação ambiental estratégica para definição de políticas portuárias: o caso do Porto de Santos/SP. Monografia de especialização. Centro de desenvolvimento sustentável. Universidade de Brasília. 83p.

COSTA, M. R. P.; ALCÂNTARA, E. H.; AMORIM, A. J. E.; MOCHEL, F. R. 2006. Avaliação das potencialidades e fragilidades das áreas de manguezal para a implementação do ecoturismo usando ferramentas de sensoriamento remoto em Cururupu - MA, Brasil. Caminhos da Geografia 22(17): 237-243.

COSTANZA, R. \& FARLEY, J. 2007. Ecological economics of coastal disasters: Introduction to the special issue. Ecological Economics. doi: 10.1016/j.ecolecon2007.03.002

COSTANZA, R., , A. RALPH; R. GROOT; S. FARBER; M. GRASSO; B. HANNON; K. LIMBURG; S. NAEEM; R. V. O'NEILL; J. PARUELO; R. G. RASKIN; P. SUTTON \& M. VAN DEN BELT. 1997. The value of the world's ecosystem services and natural capital. Nature. 387: 253-260.

CUNHA-LIGNON, M. 2001. Ecologia de Manguezais: Dinâmica do manguezal no sistema de Cananéia-Iguape, Estado de São Paulo - Brasil. Dissertação de mestrado. Instituto Oceanográfico, Universidade de São Paulo, $105 \mathrm{p}$.

CUNHA-LIGNON, M. 2005. Desenvolvimento espaço-temporal no sistema costeiro Cananéia-Iguape, São Paulo, Brasil. Tese de doutorado. Instituto Oceanográfico, Universidade de São Paulo. 
DAHDOUH-GUEBAS, F. 2002. The use of remote sensingh and GIS in the sustainable management of tropical coastal ecosystems. Environment, Development and Sustainability, 4: 93-112.

DAHDOUH-GUEBAS, F.; VERHEYDEN, A.; GENST, W.; HETTIARACHCHI, S.; KOEDAM, N. 2000. Four decade vegetation dynamics in Sri Lanka mangroves as detected from sequencial aerial photography: a case study in Galle. Bulletin of Marine Science, 67(2): 741-759.

DAY, J.W.; CORONADO-MOLINA, C.; VERA-HERRERA, F.R.; TWILLEY, R.R.; RIVERA-MONROY, V.H.; ALVAREZ-GUILLEN, H.; DAY, R. \& CONNER, W. 1996. Aquatic Botany, 55:39-60.

DUKE, C. N. 2001. Gap creation and regeneration processes driving diversity and structure of mangrove ecosystems. Wetlands and Ecology Management, (9): 257-269.

DUKE, N. C.; Z. S. PINZÓN \& M. C. PRADA. 1999. Recovery of tropical mangrove forests, following a major oil spill: a study of recruitment and growth, and the benefits of planting. In: YÁÑEZ-ARANCIBIA, A. AND LARA-DOINGUEZ, A. L. (Eds.), Ecosistemas de Manglar en América Tropical. México, Instituto de Ecología, UICN/ROMA, p. 231254.

DUKE, N. C.; MEYNECKE, J. O.; DITTMANN, S.; ELLISON, A. M.; ANGER, K.; BERGER, U.; CANNICCI, S.; DIELE, K.; EWEL, K. C.; FIELD, C. D.; KOEDAM, N.; LEE, S. Y.; MARCHAND, C.; NORDHAUS, I.; DAHDOUHGUEBAS, F. 2007. A World without Mangroves? Science, 317: 41-42.

ELLISON, J.C. 1993. Mangrove retreat with rising sea-level, Bermuda. Est., Coast. Shelf Sci. 37: 75-87.

ELLISON, A. M. \& E. J. FARNSWORTH. 1993. Seedling survivirship, growth, and response to disturbance in Belizean Mangal. American Journal of Botany, vol. 80(10): 1137-1145. 
ELLISON, A. M. \& E. J. FARNSWORTH. 1996. Antropogenic Disturbance of Caribbean Mangrove Ecosystem: Past Impacts, Present Trends and Future Predictions. Biotropica, vol. 28(4a): 549-565.

EQUISTAR. 2003. Equistar Chemical Company. Disponível: www.equistarchem.com [capturado em 16 de março de 2003].

EWEL, J. J. 1971. Biomass changes in early tropical sucession. Turrialba 21: 110-112.

EWEL, J. J. 1976. Litterfall and leaf decomposition in a tropical forest sucession in eastern Guatemala. Journal of Ecology, 64: 293-308.

EWEL, K. C.; BOURGEOIS, J. A.; COLE, T. G.; ZHENG, S. 1998. Variation in environmental characteristics and vegetation in high-rainfall mangrove forests, Kosrae, Micronesia. Global Ecology and Biogeography Letters 7(1): 49-56.

FURUKAWA, K. \& E. WOLANSKI. 1996. Sedimentation in mangrove forests. Mangroves and Salt Marshes. 1: 3-10.

FELLER, I. C. \& MATHIS, W. N. 1997. Primary herbivory by wood-boring insects along an archictutural gradient of Rhizophora mangle. Biotropica 29: 440-451.

FELLER, I. C. \& McKEE, K. L. 1999. Small gap creation in Belizean mangrove forests by a wood-boring insect. Biotropica 31(4): 607-617.

FLORES-VERDUGO, F. J.; DAY J. W. \& BRISENO-DUENAS, R. 1987. Structure, litterfall, decomposition and detritus dynamic of mangroves in a Mexican coastal lagoon with ephemeral inlet. Mar. Ecol. Prog. Ser. 35: 51-56.

FRISCHEISEN, E. R.; ARGENTO, M. S.: HERZ, R. \& CARNEIRO, R. P. 1989. The coastal management program in Brazil. Neves, C. (ed.) Coastlines of Brazil, New York, American Society of Civil Engineers, O. T. Magoon, 296p. 
FROMARD, F.; PUIG, H.; MOUGIN, E.; MARTY, G.; BETOULLE, J. L.; CADAMURO, L. 1998. Structure and above-ground biomass of mangrove ecosystems: new data from French Guiana. Oecologia 115: 39- 53.

FROMARD, F.; VEGA, C.; PROYSY, C. 2004. Half a century of dynamic coastal change affecting mangrove shorelines of French Guiana. A case study based on remote sensing data analyses and field surveys. Marine Geology, 208: 265-280.

GAO, J. 1999. A comparative study on spatial and spectra resolution of sdatellite data in mapping mangrove forests. Int. Journal of Remote Sensing, 20 (14): 2823-2833.

GEFE, W.; AMORIM, L. F.; AMORIN, A. C. 2004. Aspectos socioeconômicos da pesca artesanal na Baixada Santista. Anais do IV Congresso Brasileiro de Pesquisas Ambientais e Saúde - CBPAS. Santos, SP. p:1321.

GILL, A.M. \& P. B. TOMLINSON. 1971. Studies on the growth of red mangrove (Rhizophora mangle L.). 3. Phenology of the shoot. Biotropica 3:109-124.

GIRI, C.; PENGRA, B.; ZHU, Z.; SINGH, A.; TIESZEN. 2007. Monitoring mangroves Forest dynamics of the Sundarbans in Bangladesh and India using multi-temporal satellite data from 1973 to 2000. Estuarine, Coastal and Shelf Science, 73: 91-100.

GOLDENTEIN, L. 1972. A industrialização da Baixada Santista. Coleção de teses e monografias, no 7. Universidade de São Paulo, Instituto de Geografia. São Paulo, SP. 342p.

HAMILTON, L.S. \& S. C. SNEDAKER. 1984. Handbook for mangrove area management. UNEP, Gland. 
HARARI, J; MESQUITA, A. R.; MARONE, E.; FRANÇA, C. A. S.; CAMARGO, R.; PEREIRAJ. E. R.; ADÃO, C. J. G. P. \& SÁ JUNIOR, I. L. 1990. Technical report of the project "Flow measurements in the Bay of Santos". FUNDESPA. São Paulo, SP. 56p.

HERNADEZ-CORNEJO， R.; KOEDAM， N.; RUIZ-LUNA， A; TROELL, M.; DAHDOUH-GUEBAS, F. 2005. Remote sensing and ethnobotanical assessment of the mangrove forest changes in the Navachiste-San Ignacio-Macapule Lagoon Complex, Sinaloa, Mexico. Ecology and Society 10(1):16-25.

HERZ, R. 1987. A regional program on coastal monitoring and management of mangrove in Brazil. In: SYMPOSIUM ON COASTAL AND OCEAN MANAGEMENT, 5., 1987, New York. Proceedings. Seattle, ASMCE., (2): 2262-2268.

HERZ, R. 1999. Procesamiento digital de imagines de satellite para el reconocimiento de patrones en los manglares. In: YANEZ-ARANCIBIA, A. \& A.L. LARA-DOMINGUEZ (Eds.). Ecosistemas de manglar en America Tropical. México: UICN/ORMA, p.83-108.

JIMENEZ, J. A. \& K. SAUTER. 1991. Structure and dynamics of mangrove forests along a flooding gradient. Estuaries, 14 (1): 49-56.

JIMÉNEZ, J. A.; A. E. LUGO \& G. CINTRÓN. 1985. Tree motalility in mangrove forests. Biotropica, 17(3): 177-185.

JORNAL A TRIBUNA. 1998. Fogo na Ilha Barnabé põe a Cidade em perigo. Jornal A Tribuna. Caderno: Região. pp: A9-A14.

KAMPEL, M.; AMARAL, S.; SOARES, M. L. G. 2005. Imagens CCD/CBERS e TM/Landsat para análise multi-temporal de manguezais no Nordeste brasileiro. Um estudo de caso do Estado do Ceará. Anais do XII Simpósio Brasileiro de Sensoriamento Remoto, Goiânia, Brasil. INPE. p. 979-986. 
KITAYA, Y.; V. JINTANA; S. PIRIYAYOYHA; D. JAIJING; K. YABUKI; S. IZUTANI; A. NISHIMIYA \& M. IWASAKI. 2002. Early growth of seven mangrove species planted at different elevations in a Thai estuary. Trees. 16: 150-154.

KRAUSS, K. W. \& J A ALLEN. 2003a. Influence of salinity and shade on seedling photosynthesis and growth of two mangrove species, Rhizophora mangle and Bruguiera sexangula, introduced to Hawaii. Aquatic Botany. 77: 311-324.

KRAUSS, K. W. \& J. A. ALLEN 2003b. Factors influencing the regeneration of the mangrove Bruguiera gymnorrhiza (L.) Lamk. on a tropical Pacific island. Forest Ecology and Management, vol. 176: 49-60.

KRAUSS, K. W.; LOVELOCK, C. E.; MCKEE, K. L.; LÓPEZ-HOFFMAN, L.; EWE, S. M. L.; SOUSA, W. P. 2008. Environmental drivers in mangrove establishment and early development: a review. Aquatic Botany 89: 105-127.

KUTNER, A. S. 1976. Levantamentos sedimentológicos de apoio na pesquisa e reconhecimento da áreas portuárias. Anais do $1^{\circ}$ Congresso Bras. de Geol. de Engenharia. Vol. 2: Rio de Janeiro.

LAMPARELLI, C. C. 1995. Dinâmica da serapilheira em manguezais de Bertioga, região sudeste do Brasil. Tese de Doutorado. Faculdade de Saúde Pública da Universidade de São Paulo.

LONGHURST, A. 1998. Ecological geography of the sea. Academic Press, California, USA, 398p.

LUEDERWALDT, H. 1919. Os Manguesaes de Santos. Revista do Museu Paulista, 11: 309-408.

LUGO, A. E. 1978. Stress and Ecosystems. pp. 62-98. In: J. H. Thorp \& J. W. Gibbons (eds.), Energy and Environmental Stress in Aquatic Systems. DOE. Symposium Series. National Technical Information Service, Springfield, USA. 
LUGO, A. E. 1980. Mangrove ecosystem: Sucessional or steady-state? Biotropica. 12:65-72.

LUGO, A.E. 1997. Old-Growth mangrove forests in the United States. Conservation Biology, 11(1): 11-20.

LUGO, A. E. 1999. Mangrove ecosystem research with emphasis on nutrient cycling. In: YANEZ-ARANCIBIA, A. \& A.L. LARA-DOMINGUEZ (Eds.). Ecosistemas de manglar en America Tropical. México: UICN/ORMA, p.17-38.

LUGO, A. E. \& SNEDAKER, S. C. 1974. The ecology of mangroves. A Rev. Ecol. Syst., (5): 39-64.

LUGO, A. E. \& PATTERSON-ZUCCA, C. 1977. The impact of low temperature stress on mangrove structure and growth. Tropical Ecology 18:149161.

LUGO, A. E.; G. CINTRÓN \& C. GOENAGA. 1981. Mangrove ecosystem under stress. Pp. 129-153. In: G. W. Barret \& R. Rosemberg (eds.). Stress Effects on Natural Ecosystems. Jonh Wiley \& Sons Ltd.

LUGO, A. E.; BROWN, S. \& BRINSON, M. 1988. Forested wetlands in freshwater and salt-water environments. Limnol. Oceanogr., $33(4,2)$ 894-909.

MARTNEZ, M. L.; INTRALAWAN, A.; VÁZQUEZ, G.; PÉREZ-MAQUEO, O.; SUTTON, P.; LANDGRAVE, R. 2007. The coasts of our world: ecological, economic and social importance. Ecological Economics. doi:10.1016/j.ecolecon.2006.10.022.

MAZDA, A. Y.; M. MAGI; M. KOGO \& P. N. HONG. 1997a. Mangroves as a coastal protection from waves in the Tong King delta, Vietnam. Mangroves and Salt Marshes. 1: 127-135.

MAZDA, A. Y.; E. WOLANSKI; B. KING; A. SASE; D. OHTSUKA \& M. MAGI. 1997b. Drag force due to vegetation in mangrove swamps. Mangroves and Salt Marshes. 1: 193-199. 
MCKEE, L.K., 1993. Soil physicochemical patterns and mangroves species distribuition: reciprocal effects? Journal of Ecology. 81: 477-487.

MCKEE, L.K., 1995. Interspecific variation in growth, biomass partitioning, and defensive characteristics of neotropical mangrove seedlings: response to light and nutrient availability. Am. J. Bot. 82, 299-307.

MCKEE, L.K \& I. A. MENDELSSOHN. 1987. Root metabolism in the black mangrove, Avicennia germinans (L.) L.: response to hypoxia. Environmental and Experimental Botany. 27: 147-156.

MENEZES, G. V. 1994. Produção e decomposição de bosque de mangue da Ilha do Cardoso, Cananéia, SP. Dissertação de mestrado. Universidade de São Paulo, Instituto Oceanográfico, 116 p.

MENEZES, G. V. 2000. Recuperação de manguezais: um estudo de caso na Baixada Santista, Estado de São Paulo, Brasil. Tese de Doutorado, Instituto Oceanográfico, Universidade de São Paulo, 164 p. + Anexos com figuras e tabelas.

MENGHINI, R. P. 2004. Ecologia de Manguezais: Grau de Perturbação e processos regenerativos em bosque de mangue da Ilha Barnabé, São Paulo, Brasil. Dissertação de Mestrado, Instituto Oceanográfico, Universidade de São Paulo, 96 p.

MIRANDA, E. E. de. (Coord.). 2005. Brasil em Relevo. Campinas: Embrapa Monitoramento por Satélite, 2005. Disponível em: <http://www.relevobr.cnpm.embrapa.br>. Acesso em: 19 set. 2008 OBADE, P. T.; DAHDOUH-GUEBAS, F.; KOEDAM, N.; DE WULL, R.; TACK, J. 2004. GIS-based integration of interdisciplinary ecological data to detect land-cover changes in creek mangroves at Grazi Bay, Kenya. Western Indian Ocean J. Mar. Sci., 3(1): 11-27.

ODUM, H. T. 1967. Work circuits and system stress. In: E. E. Young (eds.). Symposium on Primary Productivity and Mineral Cycling in Natural Ecosystems. Univ. of Marine Press. Orono. Maine. Pp. 81-138. 
ODUM, E. P. 1981. The effects of stress on the trajectory of ecological succession. pp. 43-47. In: G. W. Barret \& R. Rosemberg (eds.). Stress Effects on Natural Ecosystems. Jonh Wiley \& Sons Ltd.

OTHMAN, A. M. 1994. Value of mangroves in coastal protection. Hydrobiologia. 285: 277-282.

PATTERSON, C. S.; I. A. MENDELSSOHN \& E. M. SWENSON. 1993. Growth and survival of Avicennia germinans seedlings in a mangal/saltmarsh community in Lousiana, U. S. A. Journal of Coastal Research. 9(3): 801-810.

PELLEGRINI, J. A. C. 2000. Caracterização da planície hipersalina (apicum) associado a um bosque de mangue em Guaratiba - Baía de Sepetiba RJ. Dissertação de mestrado. Instituto Oceanográfico, Universidade de São Paulo, 101 p.

PENTEADO. A. R. 1965. As bases geológicas. In: Azevedo, A. (Ed.) A Baixada Santista: aspectos geográficos. Editora da Universidade de São Paulo, SP. $v 1$.

PERIA, L. C. S.; P. P. C. P. FERnANDES; G. V. MENEZES; M. GRASSO \& M. M. P. TOGNELLA. 1990. Estudos estruturais comparativos entre bosques de mangue impactados (Canal de Bertioga) e não-impactados (Ilha do Cardoso), Estado de São Paulo, pp. 183-193. In: Anais do II Simpósio de Ecossistemas da Costa Sul e Sudeste Brasileira: estrutura, função e manejo, Águas de Lindóia, São Paulo, Academia de Ciências e do Estado de São Paulo, v 2.

PIRES, I. O. 1997. Monitoramento de manguezais através de correlação de dados da fitomassa e d e radiancia TM/Lnadsat. Exemplo: APAGuapimirim (RJ). Tese de Doutorado, Universidade de São Paulo, Departamento de Geografia, 143p. 
PONTE, A. C. E.; I. A. Z. FONSECA; M. MARQUES; M. L. FREITAS \& S. M. C. A. CLARO. 1984. Produção de serapilheira e decomposição do material foliar em ecossistema de mangue. In: Anais do IV Congr. SBSP. 103107.

PONTE, A. C. E.; I. A. Z. FONSECA \& S. M. C. A. CLARO. 1987. Impacto causado por petróleo no manguezal do Canal de Bertioga - Estrutura de vegetação. In: Simpósio Sobre Ecossistemas da Costa Sul e Sudeste Brasileira. Síntese dos Conhecimentos, Cananéia, São Paulo: ACIESP, v.2, p.138-47.

PONTE, A. C. E.; I. A. Z. FONSECA \& S. M. C. A. CLARO. 1990. Produção de serapilheira em bosque impacto por petróleo. In: Simpósio de Ecossistemas da Costa Sul e Sudeste Brasileira. Estrutura, função e manejo. Águas de Lindóia, São Paulo: ACIESP, v.2, p.241-253.

POOL, D. J.; A. E. LUGO \& S. C. SNEDAKER. 1975. Litter production in mangrove forests of Southern Florida and Puerto Rico. In: WALSH, G., SNEDAKER, S. C., TEAS, H. (Eds). Proceedings of international symposium on biology and Management of Mangroves, Gainesville, IFAS, University of Florida, v.1, p. 213-237.

POZZI-NETO, D. 2001. Baixada Santista, manguezal e vazamento de óleo: uma valoração econômica-ecológica. Dissertação de Mestrado. Programa de Pós-Graduação em Ciência Ambiental. Universidade de São Paulo. 114 p.

PROISY, C.; COUTERON, P.; FORMARD, F. 2007. Predicting and mapping mangrove biomass from canopy grain analysis using Fourier-based textural ordination of IKONOS images. Remote Sensing and Environment, doi:10.1016/j.rse.2007.01.009. 
RABINOWITZ, D. 1975. Planting experiments in mangroves swamps of Panama. In: Walsh, G. E.; Snedaker, S. C. \& Teas, H. J. (eds.) Proceeding of International Symposium on Biology and Management of Mangroves. Institute of Food and Agriculture Science, Univ. of Florida, Gainesville, p. 385-393.

RABINOWITZ, D. 1978. Early growth of mangrove seedlings in Panama, and Hypothesis concerning the relationship of dispersal and zonation. J. Biogeogr. 5: 113-133.

RAMASUBRAMANIAN, R.; GNANAPPAZHAM, L.; RAVISHANKAR, T.; NAVAMUNIYAMMAL, M. 2006. Mangroves of Godavari - analysis through remote sensing approach. Wetlands Ecology and Management, 14: 2937.

RODRIGUES, J. C. 1965. As bases geológicas. In: Azevedo, A. (Ed.). A Baixada Santista: aspectos geográficos. Editora da Universidade de São Paulo, SP. v 1.

RODRIGUES, J. 2004. PPP vai viabilizar novo terminal em Santos. Valor Econômico, 03 maio 2004, p. 39.

RODRIGUES, F. O. ; D. O. MOURA \& C. C. LAMPARELLI. 1990. Evolução das alterações estruturais e funcionais provocadas por óleo no manguezal do Rio Iriri. In: Simpósio de Ecossistemas da Costa Sul e Sudeste Brasileira. Estrutura, função e manejo. Águas de Lindóia, 1990. São Paulo: ACIESP, v.2, p.194-208.

RODRIGUES, M. G. 1998. Análise do status de conservação das unidades de paisagem no complexo estuarino-lagunar de Iguape-CananéiaGuaraqueçaba, Dissertação de Mestrado, Universidade de São Paulo, Instituto de Biociências, 183p. + anexos.

ROGER, K.; SAINTILAN, N.; CAHOON, D. 2005. Surface elevation dynamics in a regeneration mangrove forest at Homebush Bay, Australia. Wetlands Ecology and Management, 13: 587-598. 
SANTOS, E. 1965. Características climáticas. Baixada Santista: aspectos geográficos. In: Departamento de Geografia da Faculdade de Filosofia e Letras da Universidade de São Paulo. V. 1.

SARTOR, S. M.; HANS M. F. P.; PALM, L.; SARTOR, L. M.; LEÃO A. L. 2007. Coastal marine mapping as an ecosystem based management - the case study of the Baixada Santista Region - São Paulo, Brazil. Journal of Coastal Research, SI50: 1178-1182.

SAYRE , R. 2000. Mapping Technologies: new tools for conservation. In: Sayre, R.; Roca, E.; Sedaghatksh, G.; Young, B. Keel, S. Roca, R. L. \& Sheppard, S. Nature in Focus: Rapid Ecological Assesment. Washington, D.C., Island Press, The Nature Conservancy. P. 47-61.

SAYRE , R. \& SHEPPARD, S. 2000. The REA mapping process. In: Sayre, R.; Roca, E.; Sedaghatksh, G.; Young, B. Keel, S. Roca, R. L. \& Sheppard, S. Nature in Focus: Rapid Ecological Assesment. Washington, D.C., Island Press, The Nature Conservancy. P. 63-75.

SCHAEFFER-NOVELLI, Y. 1989. Perfil dos ecossistemas litorâneos brasileiros, com especial ênfase sobre o ecossistema manguezal. Publicação. Esp. Inst. Oceanogr. S. Paulo. (7): 16p.

SCHAEFFER-NOVELLI, Y. 1991. Manguezais brasileiros. Tese de Livre Docência. Universidade de São Paulo, Instituto Oceanográfico. 2 vols. SCHAEFFER-NOVELLI, Y. 2002. Manguezal: ecossistema que ultrapassa suas próprias fronteiras. In: Congresso Nacional de Botânica, 53., 2002, Recife, p. 34-37.

SCHAEFFER-NOVELLI, Y. \& CINTRÓN, G. 1986. Guia para o estudo de áreas de manguezal, estrutura, função e flora. Caribbean Ecological Research, 1986. São Paulo, 150 p. +3 apêndices.

SCHAEFFER-NOVELLI, Y.; CINTRÓN-MOLERO， G; ADAIME， R. R. \& CAMARGO, T. M. 1990. Variability of mangrove ecosystems along the Brazilian coast. Estuaries, (13) 2: 204-218. 
SCHAEFFER-NOVELLI， Y.; CINTRON-MOLERO， G.; CUNHA-LIGNON， M.; COELHO-JR, C. 2005. A conceptual Hierarquichal Framework for Marine Coastal Management and Conservation: A Janus-Like Approach. Jornal of Coastal Research, 42: 191-197.

SCHAEFFER-NOVELLI, Y.; MENGHINI, R. P.; TAMASATO, R. K.; ALMEIDA, R.; PAIXÃO, N. C.; CUNHA-LIGNON, M.; SUGUIU, K. \& PATU, G. N. S. 2003. Baixada Santista, Estado de São Paulo, Brasil: Instrumento Técnico Científico. BIOMA - Centro de Ensino e Informação sobre Zonas Úmidas Costeiras Tropicais com ênfase no ecossistema manguezal. Instituto Oceanográfico - USP, São Paulo, SP. SP. Ref. Rep. no 08123,030,384/98-05, ofício do Ministério Público Federal no município de Santos. 40p.

SEMENIUK, V. 1980. Mangrove zonation along an eroding coastline in King Sound North-Western Australia. Blackwell Scientific Publications, p. 789-812.

SHERMAN, R. E.; FAHEY, T. J. \& BARRLES, J. J. 2000. Small-scale disturbance and regeneration dynamics in a neotropical mangrove forest. Journal of Ecology, 88: 165-178.

SMITH, T. J. III 1992. Forest structure. In: Robertson, A. I. \& Alongi D. M. (Eds.) Tropical Mangrove Ecosystems, pp. 101-136. American Geophysical Union, Washington, DC.

SMITH, T. J. III; ROBBLEE, M. B.; WANLESS, H. R. \& DOYLE, T. W. 1994. Mangroves, hurricanes and lightning strikes. Bioscience, 44: 256-262.

SOARES, M. L. G. 1997. Estudo da biomassa aérea de manguezais do sudeste do Brasil - análise de modelos. Tese de doutorado, Universidade de São Paulo, Instituto Oceanográfico, 2 vols.

SUGUIU, K. \& MARTIN, L. 1978. Formações quaternárias marinhas do litoral paulista e sul fluminense. International Symposium on Coastal Evolution in The Quaternary. Special Publ. $n^{0}$ 1. IGCP-BRIG-USP/SBG, São Paulo, 56p. 
SPENCELEY, A. P. 1977. The role of pneumatophores in sedimentary processes. Marine Geology. 24: M31-M37.

TEXMARK, 2003. Texmark CXI. dicyclopentadiene (DCPD), resin intermediates, n-butanol and contract processing. Disponível: www.texmark.com. [capturado em 16 de março de 2003].

THOM, B. G. 1982. Mangrove ecology: a geomorfology perspective. In: Clough, B. F. (Ed.). Mangrove Ecosystems in Australia. Australian National University Press. Camberra. Pg. 3-16.

THOM, B. G. 1984. Costal landforms and geomorphic process. In: Snedaker, S. C. \& Snedaker, J. G. (Eds.). The Mangrove Ecosystem: research methods. UNESCO. Pg. 3-17.

THU, P. M. \& POPULUS, J. 2006. Status and changes of mangrove forest in Mekong Delta: Case study in Tra Vinh, Vietnan. Estuarine, Coastal and Shelf Science. Doi:10.1016/j.ecss.2006.08.007

TOMMASI. L. R. 1979. Considerações ecológicas sobre o Sistema Estuarino de Santos, São Paulo. Tese de Livre Docência. Universidade de São Paulo, Instituto Oceanográfico. São Paulo. 2 vols.

TOMLINSON, P. B.1986. The Botany of Mangroves. Ed. Cambridge, University Press. 413p.

TWILLEY, R. R.; LUGO, A. E. \& PATTERSON-ZUCCA, C. 1986. Litter production and turnover in basin mangrove forests in southwest Florida. Ecology. 67(3): 670-683.

TWILLEY, R. R., S. C. SNEDAKER, A. YÁÑES-ARANCIBIA \& E. MEDINA. 1996. Biodiversity and ecosystem processes on tropical estuaries: perspectives of mangrove ecosystems. In: MOONEY, H. A ; CUSHMAN, J. H. \& MEDINA, E. et. al. (eds): Functional Roles Biodiversity: A Global Perspective, p.327-370.

VAIPHASA, C.; SKIDMORE, A. K.; BOER, W. F. 2006. A post-classifier for mangrove mapping using ecological data. Journal of Photogrammetry \& Remote Sensing, 61: 1-10. 
VALIELA, I.; BOWEN, J. L.; YORK, J. K. 2001. Mangrove forests: one of the world's threatened major tropical environments. BioScience 51: 807815.

VAN ZANDT, P. A.; TOBLER, M. A.; MOUTON, E.; HASENSTEIN, K. H.; MOPPER, S. 2003. Positive and negative consequences of salinity stress for the growth and reproduction of the clonal plant, Iris hexagona. Journal of Ecology, 91:837-846.

VERHEYDEN, A.; DAHDOUH-GUEBAS, F.; THOMAES, K.; GENST, W.; HETTIARACHCHI, S.; KOEDAM, N. 2002. High-resolution vegetation data for mangrove research as obtained from aerial photography. Environment, Development and Sustainability, 4: 113-133.

ZHARIKOV, Y; SKILLETER, G. A. LONERAGAN, N. R.; TARANTO, T; CAMERON, B. E. 2005. Mapping and characterizing subtropical estuarine landscapes using aerial photography and GIS for potential application in wildlife conservation and management. Biological Conservation, 125: 87-100. 